Universidade de São Paulo

Instituto de Física

\title{
Gotas e pontes capilares na escala nanométrica
}

\author{
Alexandre Barros de Almeida
}

Tese de doutorado apresentada ao Instituto de Física para a obtenção do título de Doutor em Ciências

Banca Examinadora:

Prof. Dr. Adriano Mesquita Alencar (IFUSP)

Profa. Dra. Kaline Rabelo Coutinho (IFUSP)

Profa. Dra. Vera Bohomoletz Henriques (IFUSP)

Prof. Dr. Douglas Soares Galvão (UNICAMP)

Prof. Dr. Luis Paulo Barbour Scott (UFABC)

São Paulo 


\section{FICHA CATALOGRÁFICA \\ Preparada pelo Serviço de Biblioteca e Informação do Instituto de Física da Universidade de São Paulo}

Almeida, Alexandre Barros de

Gotas e pontes capilares na escala nanométrica. São Paulo, 2017.

Tese (Doutorado) - Universidade de São Paulo. Instituto de Física. Depto. de Física Geral.

Orientador: Prof. Dr. Adriano Mesquita Alencar

Área de Concentração: Física Geral

Unitermos: 1. Água; 2. Simulação (Estatística); 3. Molécula;

4. Física do estado líquido; 5 . Física computacional.

USP/IF/SBI-032/2017 
Dedico essa tese à minha família, professores $e$ amigos que contribuíram para minha formação. 



\section{Agradecimentos}

Primeiramente, agradeço à minha família, meu pai José Francisco, minha mãe Salete e minha irmã Ana Paula, polo apoio na profissão que escolhi, a qual os estudos não conseguiria concluir sem o suporte deles. Agradeço minha namorada Helyda, que conheci no final do meu doutorado, e que me deu todo o apoio para a conclusão deste trabalho.

Agradeço ao meu orientador, Prof. Adriano M. Alencar, que além do mestrado, me aceitou para continuar o doutorado, e foi com quem aprendi grande parte dos conhecimentos presentes nesta tese. Com ele, iniciei o aprendizado da escrita de artigos e projetos de pesquisa, pude publicar meus primeiros trabalhos e aprendi como me tornar independente academicamente. Além do trabalho, agradeço-o pela amizade e pelas boas conversas.

Ao Prof. Sergey Buldyrev, que me supervisionou durante um ano de estágio de doutorado sanduíche na Yeshiva University, e com quem também publiquei meus primeiros trabalhos, aprendi e pude discutir parte dos conteúdos desta tese e de outros trabalhos que planejamos desenvolver.

Ao Prof. Dr. Nicolas Giovambattista do City University of New York - Brooklyn College, que conheci durante o doutorado sanduíche e com quem pude também colaborar e discutir sobre o trabalho apresentado aqui.

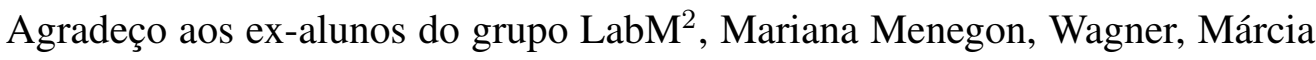
e Matheus pelos bons momentos que tivemos, pelas conversas sobre Física, Engenharia, Política, e pelos cafés.

Aos atuais alunos e outros membros do grupo, Adriana, Marcel, André, Ísis, Juan, Caio, Natália, Verônica, Lígia, Jennifer, Mariana Sacrini e Antônio, agradeçoos pelas conversas, críticas durante as correções de projetos de pesquisa e da tese, pelas conversas, momentos descontraídos e pelos cafés.

Aos funcionários do Departamento de Física Geral, Fátima, Elza, Dirce, Silvana, Marcelino e Valdir, e da Pós-graduação do Instituto de Física da USP, Cláudia, Andrea, Éber, Paula e Renata, por todo apoio necessário durante esses quatro anos de doutorado.

Agradeço a CAPES pela minha bolsa de doutorado e de doutorado sanduíche, e ao CNPQ e FAPESP pelo suporte à pesquisa que desenvolvi no LabM $^{2}$. 



\section{Abstract}

The capillarity phenomenon at macroscopic scale are described by the capillarity theory (CT), which uses continuous surfaces to model the interfaces formed between two media, wherever one medium is liquid and the other can be liquid, gas or solid. The CT is employed in several areas ranging from biology, microgravity environments and applications on the nanoscale, such as in the atomic force microscope. However, the continuous approach may not be adequate for systems at nanoscale, where anomalous behaviors have been reported, such as the filling of liquids in nanochannels and carbon nanotubes, oscillations in measurements of capillary adhesion force and large negative values of Laplace pressures. These facts motivate the study of capillarity phenomenon at the nanometric scale by computational simulations. Here, we use the molecular dynamics to study the droplets and capillary bridges interfaces composed of SPC/E water model and volumes in the order of $100 \mathrm{~nm}^{3}$, and attached to hydrophobic/hydrophilic $\beta$-cristobalite walls. We have compared the droplets and capillary bridges properties with the macroscopic CT predictions, which are based on profile fitting and analytic calculations. Specifically, we have compared the interface profiles, the contact angles $\theta_{c}$, the capillary adhesion forces, the Laplace pressures and the water surface tension. These analyzes were divided into three steps. In the first step, we have studied droplets and capillary bridges with axial and translational symmetries, where the capillary bridge height remained constant. In the second step, we have focused our studies on capillary bridges with axial symmetry (AS bridge), and we have studied the bridges rupture process. Finally, in the third step, we have studied the fluctuations, which are not predicted by the CT, in simpler systems, such as free droplets, which are not attached to walls, and droplets with axial symmetry. We have shown that the macroscopic CT is able to satisfactorily predict systems with volumes in the order of $100 \mathrm{~nm}^{3}$, in which we have been submitted our results to rigorous comparisons to the analytic CT solutions, which is able to predict the dependence of $\theta_{c}$ on the AS bridge rupture heights, and the volumes of droplets formed after rupture. 



\section{Resumo}

O fenômeno da capilaridade na escala macroscópica é descrito pela teoria capilar (TC) que se utiliza de superfícies contínuas para modelar as interfaces formadas entre dois meios, sendo um líquido e o outro líquido, gasoso, sólido. A TC é empregada em diversas áreas da biologia, ambientes de microgravidade e em aplicações na escala nanométrica, como no microscópio de força atômica. Essa aproximação por superfícies contínuas pode não ser adequada para sistemas na escala nanométrica, em que são reportados comportamentos anômalos como no preenchimento de líquidos em nanocanais e nanotubos de carbono, oscilações nas medidas de força de adesão capilar e grandes valores de pressões de Laplace negativas. Esses fatos motivam o estudo do fenômeno da capilaridade na escala nanométrica por meio de simulações computacionais. Aqui, utilizamos a dinâmica molecular para estudar a interface de gotas e pontes capilares constituídas de água do modelo SPC/E com volumes da ordem de $100 \mathrm{~nm}^{3}$ e aderidas a placas de $\beta$-cristobalita hidrofóbicas/hidrofílicas. Comparamos as propriedades dessas gotas e pontes capilares com as previsões da TC macroscópica, que são baseadas nos ajustes dos perfis e em cálculos analíticos. Especificamente, confrontamos os perfis das interfaces, os ângulos de contato $\theta_{c}$, as forças de adesão capilar, as pressões de Laplace e o valor da tensão superficial da água. Essas análises foram divididas em três etapas. Na primeira etapa, estudamos as gotas e pontes capilares com simetrias axial e translacional, em que a altura da ponte capilar permaneceu constante. Na segunda etapa, focamos nossos estudos nas pontes capilares com simetria axial (ponte SA) e estudamos o processo de ruptura dessa. Finalmente, na terceira etapa, estudamos as flutuações, que não são previstas pela TC, em sistemas mais simples, como no caso de gotas livres, que não estão aderidas a placas, e em gotas com simetria axial. Mostramos que a TC macroscópica é capaz de explicar satisfatoriamente sistemas com volumes da ordem de $100 \mathrm{~nm}^{3}$, em que submetemos nossos resultados a comparações rigorosas das soluções analíticas da TC, sendo essa capaz de prever a dependência de $\theta_{\mathrm{c}}$ nas alturas das rupturas das ponte $\mathrm{SA}$ e os volumes das gotas formadas após a ruptura. 



\section{Sumário}

Abstract vii

Resumo ix

Lista de Figuras $\quad$ xiii

$\begin{array}{lr}\text { Lista de Tabelas } & \text { xvii }\end{array}$

1 Introdução 1

2 Métodos $\quad 17$

2.1 Princípios da teoria capilar . . . . . . . . . . . . . . . . 17

2.1.1 Perfil de gotas com simetrias axial e translacional . . . . . . . . . . . . . . . . . . . . .

2.1.2 Cálculo do perfil das pontes capilares . . . . . . . . . . . . . 21

2.2 Dinâmica molecular para o estudo da capilaridade . . . . . . . . . . . . . 38

2.2.1 Campos de força e topologia das moléculas de água e das placas de $\beta$-cristobalita ........................ 39

2.2.2 Algoritmo de dinâmica molecular . . . . . . . . . . . . . . 43

2.2.3 Procedimento da execução das simulações . . . . . . . . . . . . . . . 47

2.3 Perfil de gotas e pontes capilares obtidas das simulações $\ldots \ldots$. . . . . . . 50

2.4 Cálculo do perfil teórico das gotas e pontes capilares . . . . . . . . . . . 52

2.5 Cálculo da tensão superficial utilizando o método Kirkwood-Buff (KB) . . . . 55

2.6 Modelo gás de rede para o estudo de interfaces . . . . . . . . . . . . 55

2.7 Cálculo do expoente de Hurst . . . . . . . . . . . . . . . . . . 58

3 Resultados e Discussões $\quad 60$

3.1 Estudo das gotas SA e ST, e pontes SA e ST com altura constante . . . . . . . 61

3.1.1 Comparação dos perfis gerados pela simulação de DM com os obtidos analiticamente pela TC macroscópica . . . . . . . . . . . . 61

3.1.2 Cálculo da Tensão superficial, força de adesão capilar e pressão de Laplace das pontes SA e ST . . . . . . . . . . . . . . 67

3.1.3 Cálculo da tensão superficial utilizando o método KB . . . . . . . . . . 72 
3.2 Estudo sobre o aumento da altura das pontes SA . . . . . . . . . . . . 72

3.2.1 Perfis das pontes capilares com simetria axial, força de adesão capilar e pressão de Laplace induzidas nas placas de $\beta$-cristobalita . . . . . . . . 74

3.2.2 Mecanismos de ruptura e limite da estabilidade da ponte capilar com simetria axial . . . . . . . . . . . . . . . . 85

3.3 Flutuação do centro de massa de gotas . . . . . . . . . . . . . . . . . . 97

3.3.1 Flutuação das gotas livres . . . . . . . . . . . . . . . . . . . . . 97

3.3 .2 Flutuação de gotas SA . . . . . . . . . . . . . . . . . . . . . . . . . . . . . . . . . . . . . .

3.4 Outros estudos realizados . . . . . . . . . . . . . . . . . . . . . . . . . 99

3.4 .1 Estudo da tensão de linha . . . . . . . . . . . . . . . . . 100

3.4.2 Pressão de Laplace no interior de gotas . . . . . . . . . . . . . . 101

3.4.3 Estudo da pontes SA no modelo gás de rede . . . . . . . . . . . . . . 103

4 Conclusões $\quad 112$

5 Referências Bibliográficas $\quad 116$

$\begin{array}{ll}\text { Apêndices } & 133\end{array}$

\begin{tabular}{l|l} 
A Arquivo de entrada do LAMMPS & 134
\end{tabular}

$\begin{array}{lll}B & \text { Arquivo de configuração do LAMMPS } & 137\end{array}$

C Atividades acadêmicas $\quad 142$

$\begin{array}{lll}\text { D Lista de Abreviaturas } & 200\end{array}$ 


\section{Lista de Figuras}

1.1 Ilustrações do preenchimento capilar para a água e para o mercúrio. . . . . . . . 1

1.2 Ilustrações das gotas e pontes capilares, aderidas em superfícies com formatos diferentes, estudadas nessa tese. . . . . . . . . . . . . . . 2

1.3 Imagens de algumas situações onde a capilaridade é encontrada: . . . . . . . . 4

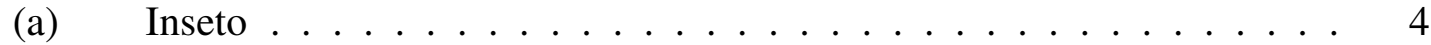

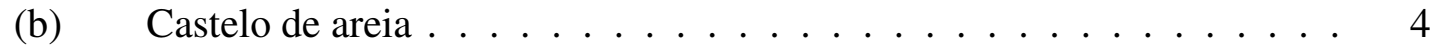

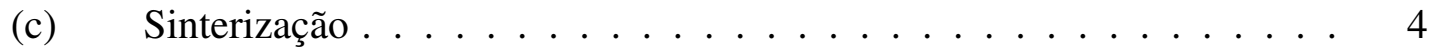

(d) Microgravidade . . . . . . . . . . . . . . . . 4

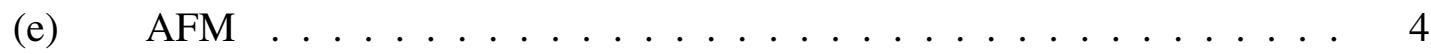

1.4 Ilustração mostrando o transporte de tinta na nanolitografia dip-pen. . . . . . . 5

1.5 Gráfico mostrando o grande potencial termodinâmico em função do raio da ponte capilar, e para várias alturas $h$ de separação da ponta do cantilever do AFM do substrato de Au. . . . . . . . . . . . . . . . . . . . . . . . 9

1.6 Ilustração mostrando a emissão dos ruídos de crepitação devido à ruptura das pontes capilares no interior das vias aéreas pulmonares . . . . . . . . . . 10

1.7 Ilustração de uma simulação de dinâmica molecular de uma ponte capilar, constituída de um líquido não volátil, formada entre a ponta do AFM e o substrato. .

1.8 Ilustração de uma simulação de dinâmica molecular de uma ponte capilar, constituída de um líquido não volátil, formada entre dois substratos planos. . . . . . .

2.1 Ilustrações mostrando o equilíbrio das forças na ordenada e na abscissa de uma gota SA, e uma exemplificação do cálculo da curvatura em um dado ponto $\mathrm{M}$ de uma superfície. . . . . . . . . . . . . . . . . . . . . . . . . . 18

2.2 Ilustrações das gotas com simetrias axial e translacional. . . . . . . . . . . . 20

2.3 Ilustrações das pontes capilares com simetrias axial e translacional. . . . . . . . 22

2.4 Ilustração do modelo de molécula de água SPC/E e imagens de uma placa de $\beta$-cristobalita hidrofílica. . . . . . . . . . . . . . . . . . . . . . 40

2.5 Gráficos do pontecial de Lennard-Jones e de Coulomb. . . . . . . . . . . . . . 41

2.6 Imagens mostrando a construção da configuração inicial de uma gota com simetria axial. . . . . . . . . . . . . . . . . . . . . . 48 
2.7 Ilustrações mostrando a contagem das moléculas de água de uma configuração obtida da dinâmica molecular para o cálculo do perfil das pontes capilares com simetrias axial e translacional. . . . . . . . . . . . . . 50

2.8 Ilustração do ajuste do perfil da ponte capilar com simetria axial utilizando a equação diferencial obtida da teoria capilar macroscópica. . . . . . . . . . . . 52

2.9 Ilustração mostrando o formato da caixa de simulação para o cálculo da tensão superficial com o método Kirkwood-Buff. . . . . . . . . . . . . . 55

2.10 Ilustração de uma seção transversal da ponte capilar com simetria axial e imagens das simulações com modelo gás de rede mostrando o rompimento das pontes capilares aderidas a duas placas planas ou hemisférios. . . . . . . . . 58

2.11 Ilustração mostrando o cálculo do expoente de Hurst de uma série temporal da posição do centro de massa na coordenada $z \ldots \ldots \ldots$. . . . . . .

3.1 Imagens mostrando as configurações das moléculas de água formando as gotas e pontes capilares com simetria axial e translacional aderidas às placas de $\beta$ cristobalita hidrofóbicas com polaridade nula. . . . . . . . . . . . . . .

3.2 Gráficos exemplificando as funções de densidade das gotas e pontes capilares com simetria axial.

3.3 Resultados dos ajustes dos perfis das interfaces das gotas com simetria axial e translacional aderidas às placas de $\beta$-cristobalita com diferentes polaridades. . .

3.4 Resultados dos ajustes dos perfis das interfaces das pontes capilares com simetria axial e translacional aderidas às placas de $\beta$-cristobalita com diferentes polaridades e separadas de $50 \AA$. . . . . . . . . . . . . . . . .

3.5 Resultados do cálculo dos ângulos de contato das gotas e pontes capilares com simetria axial e translacional obtidos com os ajustes das equações analíticas da teoria capilar macroscópica.

3.6 Resultados do cálculo da tensão superficial da água do modelo SPC/E utilizando as pontes capilares com simetria axial e translacional. . . . . . . . . . . . . .

3.7 Resultados das forças de adesão capilar das pontes com simetria axial e translacional medidas nas simulações de DM e com as previsões da teoria capilar macroscópica em função da polaridade e do ângulo de contato. . . . . . . . . . .

3.8 Resultados da medida da pressão de Laplace no interior de pontes capilares com simetria axial e translacional em função do ângulo de contato e da polaridade. .

3.9 Imagens da última configuração das moleculas de água da simulção para calcular com o método Kirkwood-Buff a tensão superficial da água do modelo SPC/E. 72

3.10 Gráfico mostrando o equilíbrio da ponte capilar logo depois da movimentação das placas de $\beta$-cristobalita com polaridade $k=0,4$. . . . . . . . . . . 74

3.11 Resultados dos ajustes dos perfis das pontes com simetria axial aderidas às placas de $\beta$-cristobalita com diferentes separações e polaridades. . . . . . . . . . . 76 
3.12 Resultados do cálculo com o ajuste das equações analíticas da teoria capilar macroscópica do ângulo de contato das pontes capilares com simetria axial aderidas a placas de $\beta$-cristobalita com diferentes polaridades e diferentes alturas. .

3.13 Resultados mostrando a variação das áreas das interfaces líquido-sólido e líquidogás, do volume e da energia livre das pontes capilares com simetria axial aderidas às placas com diferentes polaridades e alturas. . . . . . . . . . . . .

3.14 Comparação dos resultados da tensão superficial da água do modelo SPC/E calculados nessa tese com os valores encotrados na literatura. . . . . . . . . .

3.15 Comparação entre a soma das forças de Lennard-Jones e Coulombianas exercidas pelas moléculas de água sobre as placas de $\beta$-cristobalita com diferentes separações e polaridades, e entre as forças de adesão capilar e as componentes dessas calculadas a partir da teoria capilar macroscópica. . . . . . . . . . . .

3.16 Resultados das medidas da pressão de Laplace em pontes capilares com simetria axial em função da altura e para as placas de $\beta$-cristobalita com diferentes

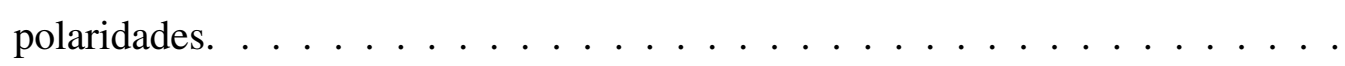

3.17 Resultados mostrando a evolução temporal dos perfis até o memento da ruptura das pontes capilares com simetria axial em contato com as placas de $\beta$ cristobalita com diferentes polaridades e com altura crítica $h_{\mathrm{C}^{\prime}} \ldots \ldots \ldots 8$

3.18 Imagens das configurações geradas das simulações de dinâmica molecular das pontes capilares com simetria axial no instante da ruptura na altura crítica $h_{\mathrm{C}^{\prime}}$.

3.19 Resultados mostrando a evolução temporal dos perfis até o memento da ruptura das pontes capilares com simetria axial em contato com as placas de $\beta$ cristobalita com diferentes polaridades e com altura crítica $h_{\mathrm{C}} \ldots \ldots \ldots$

3.20 Imagens das configurações geradas das simulações de dinâmica molecular das pontes capilares com simetria axial no instante da ruptura na altura crítica $h_{\mathrm{C}}$. .

3.21 Resultado mostrando a proporção no volume das gotas com simetria axial formadas logo após a ruptura da ponte capilar com simetria axial. . . . . . . . . 93

3.22 Restudado comparando a previsão teórica da ruptura das pontes capilares com simetria axial com as alturas críticas $h_{\mathrm{C}^{\prime}}$ e $h_{\mathrm{C}}$ obtidas das simulações. . . . . .

3.23 Resultados mostrando a flutuação do raio e altura do "pescoço", e raio da base das pontes capilares com simetria axial em função da altura e para as placas de $\beta$-cristobalita com diferentes polaridades. . . . . . . . . . . .

3.24 Imagens das simulações do modelo gás de rede implementado com Monte Carlo e do modelo atomístico com dinâmica molecular mostrando as gotas livres. . .

3.25 Resultado mostrando o cálculo do expoente de Hurst na série temporal do deslocamento do centro de massa na coordenada $z$ e no plano $x y$ da gota livre simuladas no modelo gás de rede implementado método de Monte Carlo. . . . 
3.26 Resultado mostrando o cálculo do expoente de Hurst na série temporal do deslocamento do centro de massa da gota com simetria axial na coordenada $z \mathrm{e}$ no plano $x y$ simuladas no modelo gás de rede implementado com método de Monte Carlo.

3.27 Resultado mostrando o cálculo do expoente de Hurst na série temporal do deslocamento do centro de massa da gota com simetria axial na coordenada $z$ para as simulações de gás de rede implementado com método de Monte Carlo e para o modelo atomístico com dinâmica molecular. . . . . . . . . . . . . . . . . . 101

3.28 Resultado mostrando o cálculo do expoente de Hurst na série temporal do deslocamento do centro de massa da gota com simetria axial no plano $x y$ para as simulações de gás de rede implementado com método de Monte Carlo e para o modelo atomístico com dinâmica molecular. . . . . . . . . . . . . . . . . . . . 102

3.29 Resultado do cálculo da tensão de linha $\kappa$ e do ângulo de contato na macroescala.103

3.30 Resultados da medida da pressão de Laplace no interior de gotas com simetria axial e translacional em função do ângulo de contato. . . . . . . . . . . . . . . 104

3.31 Resultados das medidas feitas no modelo gás de rede das pontes capilares com simetria axial e com diferentes ângulos de contato aderidas entre duas placas. . 106

3.32 Resultados dos ajsutes dos perfis das pontes capilares com simetria axial simuladas com o modelo gás de rede. . . . . . . . . . . . . . . . . . . . . 107

3.33 Resultados do ângulo de contato e da curvatura das pontes capilares simuladas com o modelo gás de rede obtidos a partir do ajuste da equação analítica da teoria capilar macroscópica. ． . . . . . . . . . . . . . . . . . . . . . 108

3.34 Resultados do cálculo da tensão superficial e da energia livre do bulk das pontes capilares com simetria axial estudadas com o modelo gás de rede implementado com método de Monte Carlo. . . . . . . . . . . . . . . . . . . . . . . . . . . . 110

3.35 Resultados mostrando os perfis das pontes capilares com simetria axial aderidas a dois hemisférios . . . . . . . . . . . . . . . . . . . . 111 


\section{Lista de Tabelas}

2.1 Tabela mostrando as distâncias e ângulos utilizados nas simulações das moléculas de água e das placas de $\beta$-cristobalita. . . . . . . . . . . . . . . . . . 41

2.2 Tabela com os parâmetros de Lennard-Jones e de Coulomb utilizados nas simulações de dinâmica molecular. . . . . . . . . . . . . . . . . . . 42

2.3 Constantes de acoplamento no modelo gás de rede entre as partículas na distância $1 \ldots \ldots \ldots \ldots \ldots \ldots$

2.4 Constantes de acoplamento no modelo gás de rede entre as partículas na distân-

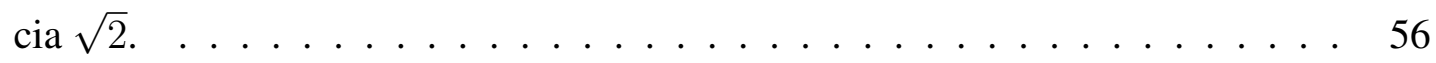

2.5 Constantes de acoplamento no modelo gás de rede entre as partículas na distân-

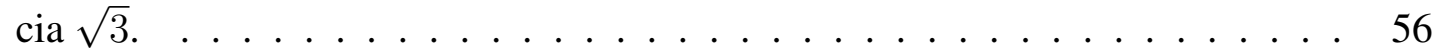

2.6 Constantes de acoplamento no modelo gás de rede para reproduzir diferentes ângulos de contato. . . . . . . . . . . . . . . . . . . 57

3.1 Parâmetros para gotas com simetrias axial e translacional obtidos a partir do ajuste das equações analíticas da teoria capilar macroscópica. . . . . . . . . . . 64

3.2 Parâmetros para pontes capilares com simetrias axial e translacional obtidos a partir do ajuste das equações analíticas da teoria capilar macroscópica. . . . . . . 66

3.3 Resultados da média temporal das forças exercidas pelas pontes capilares com simetria axial aderidas às placas de $\beta$-cristobalita superior e inferior. . . . . . . 68

3.4 Resultados da média temporal das forças exercidas pelas pontes capilares com simetria translacional aderidas às placas de $\beta$-cristobalita superior e inferior.

3.5 Resultado das médias dos tensores de pressão para calcular a tensão superficial utilizando com o método Kirkwood-Buff. . . . . . . . . . . . . . . . . . 73

3.6 Parâmetros para as pontes capilares com simetrias axial obtidos a partir do ajuste das equações analíticas da teoria capilar macroscópica para as alturas $50,0 \AA, 55,0 \AA, 60,0 \AA$ e $65,0 \AA$.

3.7 Parâmetros para as pontes capilares com simetrias axial obtidos a partir do ajuste das equações analíticas da teoria capilar macroscópica para as alturas $70,0 \AA, 75,0 \AA$ e na altura crítica $h_{\mathrm{C}} \ldots \ldots \ldots \ldots \ldots \ldots$

3.8 Resultados da média do ângulo de contato e do volume das pontes capilares com simetria axial aderidas às placas de $\beta$-cristobalita com polaridades diferentes. . 
Alexandre B. de Almeida

3.9 Parâmetros das pontes capilares com simetria axial obtidos no exato instante da ruptura. . . . . . . . . . . . . . . . . . . . 92

3.10 Resultado do cálculo da tensão de linha e do ângulo de contato na macroescala. 104 


\section{Capítulo 1}

\section{Introdução}

O fenômeno da capilaridade surge devido às forças de coesão e adesão ${ }^{1}$ de um líquido em uma condição de confinamento, ocasião em que a razão entre a soma das áreas das interfaces formadas e o volume desse líquido é grande [1]. A Figura 1.1(a) mostra o exemplo clássico do preenchimento capilar da água em tubos finos de vidro, e as interfaces envolvidas são: água-vidro, água-ar e vidro-ar. Nesse caso, a força de adesão da interface água-vidro é bastante forte, fazendo com que a água ocupe o espaço no interior dos tubos. Diferentemente, o mercúrio em uma condição de confinamento, como mostrado na Fig. 1.1(b), é repelido pelas paredes internas dos tubos de vidro devido à grande força de coesão. Dependendo do sistema, as interfaces podem ser formadas entre dois líquidos imiscíveis, ou entre um líquido e um gás, que podem ser constituídos de átomos/moléculas iguais
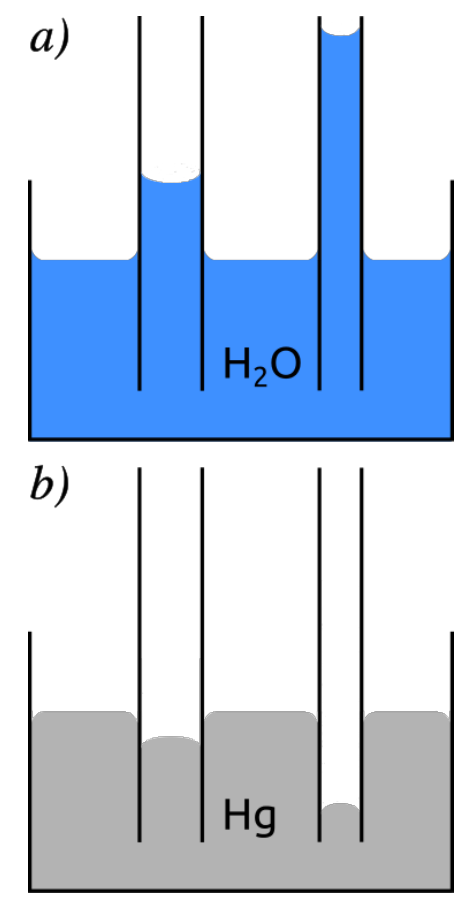

Figura 1.1: Diferença entre o preenchimento capilar de água (a) e mercúrio (b). ou diferentes, como água e vapor ou água e ar. Os formatos das interfaces formadas pela capilaridade, como exemplificado na Fig. 1.2, são descritos pela Teoria Capilar (TC), desenvolvida por Pierre Simon Laplace e Thomas Young no início do século XIX para estudar sistemas na escala macroscópica [2]. A TC macroscópica fundamenta-se no tratamento das interfaces como uma superfície contínua, já que o tamanho dos átomos/moléculas que as formam são muito

\footnotetext{
${ }^{1}$ As forças de coesão de adesão podem ter naturezas diferentes, como Coulombiana e van der Waals. A primeira e a segunda referem-se, respectivamente, à tendência de duas superfícies iguais e diferentes se aderirem.
} 


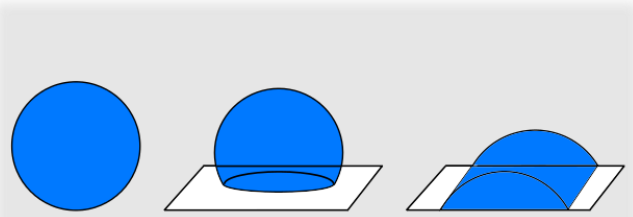

Gotas

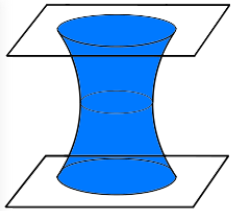

Pontes capilares
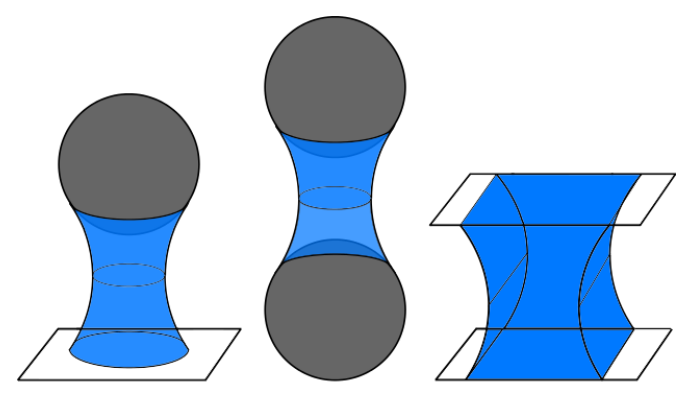

Figura 1.2: Ilustrações das gotas e pontes capilares aderidas em superfícies com formatos diferentes.

menores que os raios principais de curvatura dessas. Essa superfície também é modelada para possuir uma força de tração, denominada de tensão superficial, que se opõe às deformações que levariam a um aumento da área superficial. Quando o sistema é composto por mais de uma interface, o equilíbrio é descrito pela equação de Young, que relaciona a tensão superficial de cada interface com o ângulo de contato formado na linha de contato, ponto em que há a junção de todas as interfaces. Entretanto, todas essas fundamentações para o estudo de sistemas na escala macroscópica podem não funcionar se considerarmos um sistema na escala nanométrica, pois o tamanho dos átomos/moléculas é da mesma ordem de grandeza que da interface. Assim, nessa tese, estudamos essas fundamentações da TC macroscópica para a capilaridade na escala nanométrica, e mostraremos que a TC é capaz de descrever sistemas, como aqueles mostrados na Fig. 1.2, com volumes $\Omega$ da ordem de $100 \mathrm{~nm}^{3}$.

Aspectos gerais da capilaridade: A capilaridade possui um papel importante em diversas áreas da biologia, em ambientes de microgravidade, em ciências climáticas e do solo, em processo de impressão, no processo de sinterização de fase líquida, no dispositivo de armazenamento disco rígido, em aplicações na escala nanométrica, em auto-organização de estruturas milimétricas [3-5], dentre outros. Na biologia, a capilaridade permite que insetos possam caminhar sobre a água [6-10], como mostrado na Fig. 1.3(a), e se aderirem a uma superfície [11-14]; permite que pássaros da família scolopacidae possam se alimentar [15-20]; na fisiologia pulmonar está associada à obstrução das pequenas vias aéreas [21,22] e pela emissão de um ruído denominado de ruído de crepitação [23, 24]. A capilaridade é importante nas ciências climáticas para o processo de formação de nuvens e chuva [25]; nas ciências do solo é responsável pelo 
aumento da resistência da areia, permitindo a construção de um simples castelo de areia [26], como mostrado na Fig. 1.3(b), e até o transporte de grandes rochas durante o Egito antigo [27]; nos processos de impressão auxilia na transferência de tinta em impressoras de contato[2830]; no processo sinterização de fase líquida, utilizado para produção de cerâmicas e materiais metálicos, permite que materiais se tornem mais resistentes [31, 32]; nos discos rígidos é responsável pelo aumento do atrito estático do leitor em contato com disco [33, 34]; em ambiente de microgravidade [35] é importante para a compreensão do comportamento dos líquidos para futuras missões espaciais [36, 37]; na escala nanométrica é importante para a compreensão da molhabilidade, na formação de filmes de líquidos, no dispositivo electrospray e no microscópio de força atômica (AFM, do inglês Atomic Force Microscopy) [38]. O AFM mede a força de adesão entre da ponta do cantilever e um substrato, o que permite fazer imagens da superfície de um substrato [39] e a fabricação de nano-dispositivos com a técnica nanolitografia dip-pen (NDP) [40-42].

De modo geral, cada uma dessas situações que envolve o fenômeno da capilaridade está associado a um formato da superfície da interface [1]. Por exemplo, o formato esférico de uma gota de água, está associado à formação de gotas dentro de uma nuvem [25] e de gotículas no dispositivo electrospray geradas através da nebulização [43]. O formato semiesférico da interface está associado ao preenchimento capilar, fenômeno observado quando um líquido ocupa o espaço interno de um fino tubo capilar [44], ou, no contexto da molhabilidade, quando uma gota de água se espalha sobre uma superfície [45, 46]. O formato da superfície de uma catenoide é utilizado no cálculo da tensão superficial de filmes de surfactante com a balança de Wilhelmy [47]. A interface também pode assumir a forma de uma das superfícies de Delaunay, que se forma quando uma gota de um líquido fica confinada entre duas superfícies, que pode ser dois planos, duas esferas, ou até um plano e uma esfera. A gota nessa condição é também denominada de ponte capilar e está presente na maioria das situações citadas aqui.

Nas escalas macrométrica e micrométrica, a ponte capilar é a responsável pela força de adesão capilar que permite às formigas se aderirem em superfícies [11, 12], a construção do castelo de areia [26], a diminuição de atrito para a movimentação das grandes rochas [27], o transporte de líquidos [18-20], o aumento do atrito estático em discos rígidos [33, 34] e o aumento da 


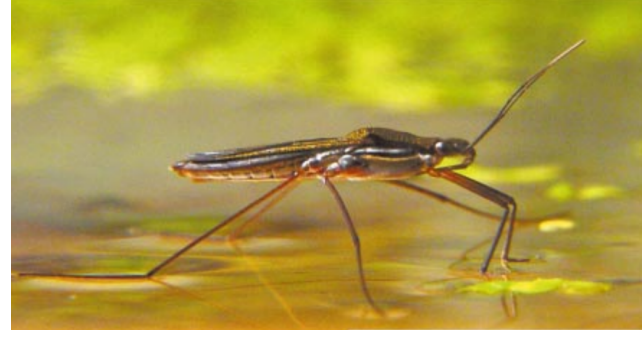

(a) Inseto

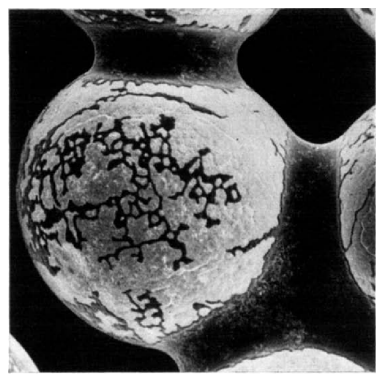

(c) Sinterização

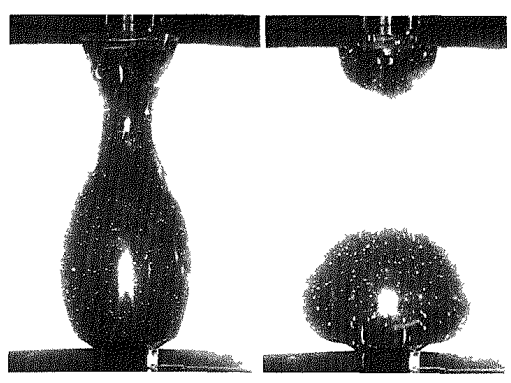

(d) Microgravidade

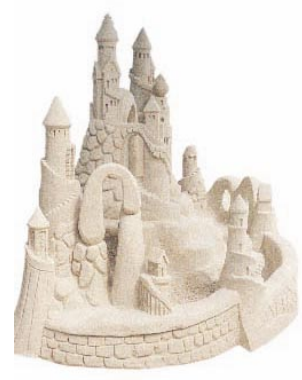

(b) Castelo de areia

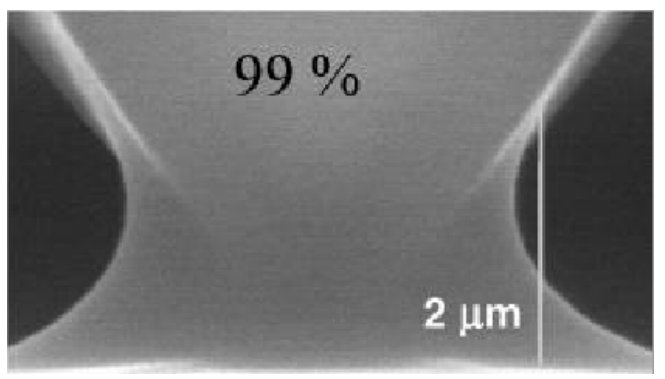

(e) AFM

Figura 1.3: (a) Imagem do inseto Gerris remigis sobre a superfície da água, por Hu et al.[6]. (b) Imagem de um castelo de areia, por Hornbaker et al.[26]. (c) Imagem do processo de sinterização do tungstênio em que a fase líquida é o cobre. O tamanho das esferas de tungstênio utilizadas foram de $214 \mp 7 \mu \mathrm{m}$ [32]. (d) Imagens mostrando a ruptura na altura $100 \mathrm{~mm}$ de uma ponte capilar aderida a dois discos de $35 \mathrm{~mm}$ de diâmetro e rotacionando a $10 \mathrm{rpm}$, durante um experimento de microgravidade na missão Spacelab D1 [48]. (e) Imagem feita por um microscópio eletrônico de varredura acoplado ao AFM de uma ponte capilar de $2 \mu \mathrm{m}$ formada na ponta do AFM em um ambiente com $99 \%$ de UR, por Weeks et al. [49].

resistência do material na sinterização de fase líquida. Nesse último caso, as pontes capilares surgem a partir do aquecimento da mistura de dois materiais com temperaturas de fusão diferentes, como cobre e tungstênio. O material com menor temperatura de fusão, no caso o cobre, se liquefaz primeiro dando origem a pontes capilares aderidas aos grãos do tungstênio [31, 32], como mostrado na Fig. 1.3(c).

No caso da fisiologia pulmonar, as pontes capilares podem se formar e obstruir as pequenas vias aéreas, gerando uma força de adesão capilar que dificulta a reabertura dessas [21]. Com a reabertura das vias aéreas durante a inspiração, e consequente ruptura das pontes capilares, devido às instabilidades mecânicas, ocorre a emissão dos ruídos de crepitação [23, 50, 51], ver as Figs. 1.6(a) e (b). Os ruídos de crepitação também podem ser auscultados na expiração e são originados pela formação da ponte capilar [52]. A ruptura de pontes capilares também é objeto 
de estudo em outros contextos, como em ambiente de microgravidade durante a missão espacial Spacelab D1, ver Fig. 1.3(d), e como mecanismo de transferência de tinta em impressoras de contato [28-30]. A ruptura e formação de pontes capilares na ponta do cantilever do AFM são bastante explorados, e entraremos em detalhes adiante.

Ponte capilar na escala nanométrica: $\mathrm{Na}$ escala nanométrica, as pontes capilares exercem um papel fundamental nos experimentos com AFM em ambiente com umidade. A presença de umidade no ambiente induz a condensação de moléculas de $\mathrm{H}_{2} \mathrm{O}$ na ponta do cantilever do AFM e no

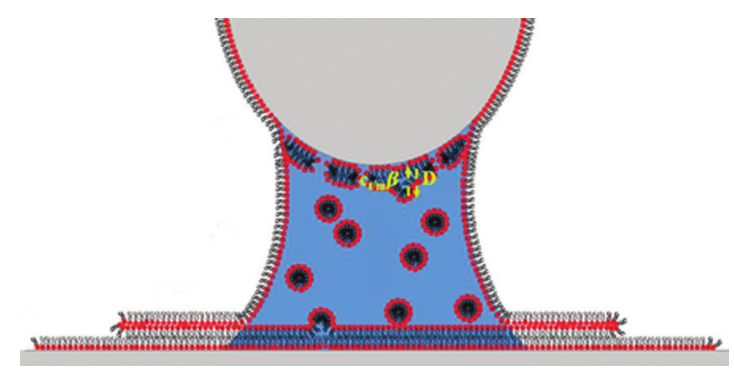

Figura 1.4: Transporte de tinta na NDP. Figura adaptada de Urtizberea et al. [53]. substrato $[49,54]$ dando origem a uma ponte capilar, como mostrado na Fig. 1.3(e), e o volume dessa ponte capilar é controlado pelo valor de umidade relativa (UR). Quando o AFM é utilizado na NDP, essa ponte capilar permite a difusão das moléculas de tinta $[53,55]$ até o substrato possibilitando o processo de escrita, como ilustrado na Fig. 1.4. Esse processo pode ser influenciado pela ruptura da ponte capilar [56]. Quando o AFM é utilizado para fazer imagens do substrato, é verificado que a UR [39, 57-60] e as rupturas [57] das pontes capilares exercem grande influência na qualidade das imagens. Além disso, dependendo dos valores da UR, as pontes capilares podem danificar o substrato [61, 62]. Por conta de todos esses fatores, existe um grande interesse da comunidade científica em compreender as pontes capilares na escala nanométrica.

A condensação da ponte capilar no AFM ocorre de acordo com a teoria de nucleação clássica em um ambiente confinado, e experimentos mostram que esse [63] é um processo termo ativado e obedece a lei de Arrhenius, ou seja, existe uma barreira de energia livre [64] que deve ser rompida para que haja a condensação em um certo intervalo de tempo característico, que é descrito pela estatística de Poisson $[65,66]$. Recentemente, foi observado que a ruptura de pontes capilares obedece a esse mesmo processo [67]. Em um problema similar, Restagno et al. [68, 69], a partir de teoria, simulação e experimento, observou que a lei de Arrhenius também se aplica para a nucleação entre duas superfícies planas. Como consequência da condensação e 
da ruptura das pontes capilares, e da força de adesão capilar, é observada uma curva de histerese na medida da força de adesão na ponta do AFM [70].

A força de adesão medida pelo AFM possui quatro componentes [71, 72]: força devido à interação de Van der Waals entre os átomos na ponta do cantilever do AFM e os átomos do substrato [71, 73-75], forças eletrostáticas, forças de adesão química e força de adesão capilar [76]. A intensidade da força de adesão capilar depende da UR [39, 74, 77-80], da geometria da ponta do cantilever do AFM [75, 78, 81], se o substrato é hidrofóbico ou hidrofílico [39, 74, 82], e da rugosidade $[74,78,80]$. Xiao et al. [82], utilizando uma ponta de nitreto de silício $\left(\mathrm{Si}_{3} \mathrm{~N}_{4}\right)$, estudou a condensação capilar em função da UR para superfícies hidrofílica de dióxido de silício $\left(\mathrm{SiO}_{2}\right)$ e hidrofóbica de $\mathrm{SiO}_{2}$ coberto com uma monocamada de octadecyltrimethoxysilane OTE/ $\mathrm{SiO}_{2}$. Ele mostrou que para a superfície de $\mathrm{SiO}_{2}$ exite um máximo na medição da força de adesão que não era bem descrita pelo modelo contínuo da TC macroscópica; a força de adesão era praticamente independente da UR para a superfície $\mathrm{OTE} / \mathrm{SiO}_{2}$. Yang et al. [75] explicou esse problema utilizando uma melhor descrição para o potencial Van der Waals com integrais de superfícies considerando duas regiões de integração, uma para a parte molhada e outra para a parte seca.

A medida experimental da força de adesão capilar por meio da observação direta da ponte capilar aderida na ponta do cantilever do AFM é uma tarefa complicada, pois requer a utilização de um microscópio eletrônico de varredura [49, 54], ver Fig. 1.3(e). Em geral, a medida experimental da força de adesão capilar é realizada indiretamente utilizando a TC macroscópica, na qual se despreza os detalhes moleculares pela aproximação da interface da ponte capilar por uma superfície contínua utilizando a estimativa da curvatura média, que é calculada pela equação de Kelvin através da medida da UR [83]. Além da força de adesão capilar, com esse método é possível medir todas as demais propriedades da ponte capilar nessa escala, como a pressão no interior da interface, conhecida também como pressão de Laplace. Nessas medidas, a superfície que aproxima a ponte capilar pode ser um toroide [74, 75, 78, 79, 81, 82, 84-89], ou podem ser utilizadas as superfícies de Delaunay [50, 52, 85] que são as soluções analíticas que descrevem as interfaces das pontes capilares. Na literatura existe uma discussão sobre a aplicabilidade da equação de Kelvin, já que na escala nanométrica o tamanho dos átomos/mo- 
léculas são da mesma ordem de grandeza dos raios médios da curvatura da superfície da ponte capilar $[62,79,82]$. Utilizando espalhamento de raio-X para baixos ângulos, Mitropoulos et al. [90] mostrou que a equação de Kelvin é válida para raios de curvaturas médios da ordem de $4.0 \mathrm{~nm}$, que é a escala utilizada nos estudos dessa tese.

A pressão no meio interior de uma interface, pressão de Laplace, também pode ser calculada utilizando o mesmo procedimento, e experimentos com AFM indicam, apesar de uma certa controvérsia [91-93], a existência de uma enorme pressão negativa [38] da ordem de -160 MPa [94]. Por conta disso, um diagrama de fase da água dependente da escala é proposto, uma vez que a pressão negativa no interior das pontes capilares poderia levar à ebulição a baixas temperaturas ou à formação de gelo a temperaturas superiores a $0^{\circ} \mathrm{C}$ [93]. Pressões negativas também podem ser encontradas em experimentos com nanocanais [95-97]. Recentemente, experimentos mostraram que a taxa de evaporação pode ser reduzida em pontes capilares com diferença da pressão interna e externa negativa [98].

A aproximação da interface por uma superfície contínua não leva em consideração os detalhes moleculares, os quais são uma característica intrínseca do problema. Por exemplo, esses detalhes podem fazer com que as moléculas de água se organizem em estruturas cristalinas em uma condição de confinamento na escala nanométrica [99], o que poderia causar anomalias na capilaridade. Os detalhes moleculares podem ser relevantes quando a distância entre duas superfícies às quais a ponte capilar está aderida se tornar menor que $2.0 \mathrm{~nm}$, e somente algumas moléculas de água separarão as duas superfícies [99-102]. Desse modo, aproximar a interface por uma superfície contínua para calcular a força de adesão capilar e a pressão de Laplace poderia levar a previsões errôneas, já que as moléculas se tornam da mesma ordem de grandeza que os raios principais de curvatura da superfície. Por conta disso, existe a necessidade de estudar estes sistemas na escala nanométrica com simulações computacionais.

Simulações das pontes capilares: Nos últimos 15 anos surgiram vários trabalhos sobre pontes capilares simuladas com o modelo gás de rede e com modelos atomísticos. Os modelos gás de rede foram utilizados para explorar a formação e ruptura das pontes capilares, e a força de adesão capilar para diferentes parâmetros das condições experimentais do AFM utilizado na 
técnica NDP. Em outro contexto, o modelo gás de rede foi utilizado para entender um problema da fisiologia pulmonar, que é a emissão dos ruídos de crepitação. Já os modelos atomísticos foram utilizados para entender o papel da capilaridade no aumento do atrito estático em discos rígidos, a deposição de tinta no AFM com a técnica NDP, o comportamento das pontes capilares no AFM em diferentes condições, a capilaridade em nanopartículas, as pontes capilares aderidas entre substratos planos, dentre outros estudos.

Com relação às simulações com modelo gás de rede das pontes capilares em experimentos com AFM na técnica NDP, Joonkyung Jang e colaboradores realizaram uma série de estudos com o método GCMC (do inglês Grand canonical Monte Carlo). Utilizando um modelo de duas dimensões (2D), eles estudaram a condensação da ponte capilar avaliando a influência da UR, da temperatura e da geometria da ponta do cantilever do AFM, com relação à molhabilidade e altura dessa. Eles observaram que a largura da ponte capilar diminui expressivamente com o aumento da curvatura e da altura, e com a diminuição da molhabilidade da ponta do cantilever [103]. Depois, implementando a técnica de integração termodinâmica (IT) alterando a temperatura ou o potencial químico, eles realizaram o primeiro estudo sobre a influência da UR e molhabilidade na força de adesão capilar, considerando os termos energéticos e entrópicos. Eles observaram que a força de adesão capilar é praticamente energética, e na altura em que a ponte capilar evapora o termo entrópico é relevante somente para grandes saturações [104]. Em seguida, eles implementaram a mesma metodologia para uma rede em três dimensões (3D) na qual a ponta do cantilever do AFM foi simulada como $1 / 8$ de uma esfera. Desta maneira, fizeram um estudo mais realístico da largura da ponte capilar, e observaram que essa largura é determinada pela altura e UR, sendo que um aumento da UR não implica necessariamente em um aumento da largura da ponte capilar [105]. Esse estudo com o modelo 3D foi aprimorado pela implementação da aproximação por DFT (do inglês Density Functional Theory) e IT. Eles mostraram que a força de adesão capilar, quando a UR era alterada continuamente, poderia atingir um plato máximo, crescer monotonicamente, ou ainda crescer e diminuir, a depender do valor da molhabilidade da ponta do cantilever do AFM [106]. Agora, utilizando um modelo mais realístico com uma ponta do cantilever do AFM constituída de $\mathrm{Si}_{3} \mathrm{~N}_{4}$ com diferentes rugosidades e um substrato de mica, simulados em um modelo 3D e implementando IT, eles 
observaram que a força de adesão capilar é bastante sensível à rugosidade [107]. Em outro trabalho com as mesmas condições do trabalho anterior, mas utilizando a aproximação DFT, eles mostraram novamente que a força de adesão capilar é bastante sensível às rugosidades [108]. Recentemente, Harrison et al. [109], seguindo os trabalhos de Jang et al. e utilizando a amostragem Wang-Landau Monte Carlo em uma rede 2D, estudaram a influência da UR, molhabilidade e da altura do cantilever do AFM. Eles mostraram que a força de adesão capilar pode ser significante para baixos valores de UR e com superfícies hidrofílicas; em superfícies com molhabilidade completa a força de adesão capilar apresenta um platô quando há um aumento da UR.
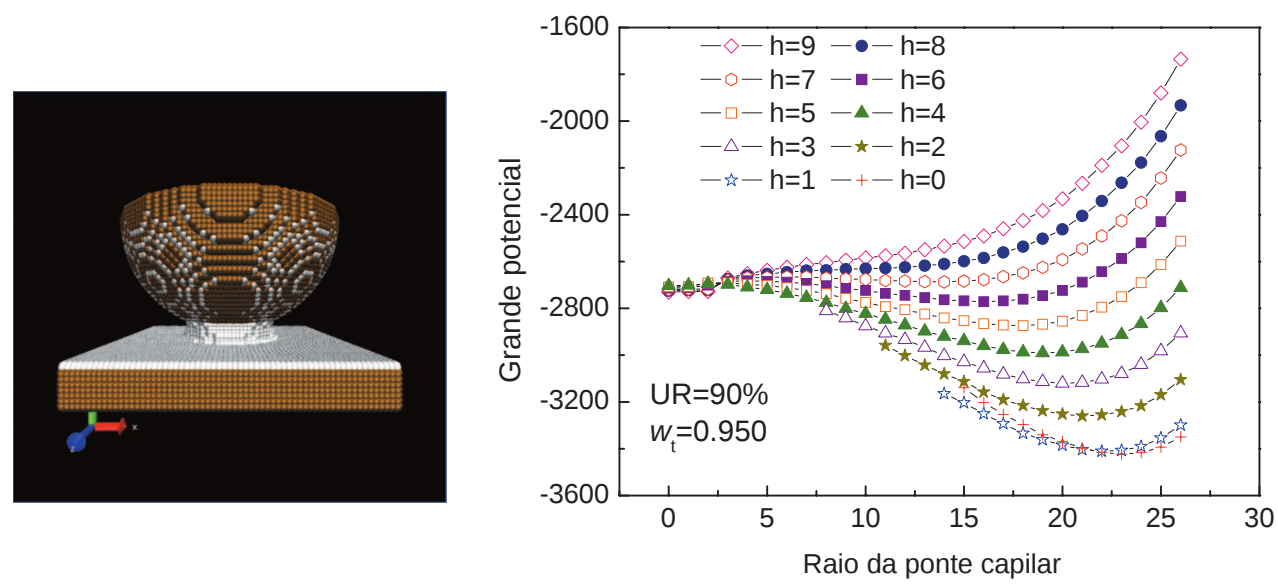

Figura 1.5: Grande potencial termodinâmico em função do raio da ponte capilar, e para várias alturas $h$ de separação da ponta do cantilever do AFM do substrato de Au. Nesse estudo foi utilizado UR=90\% e interação da ponta do cantilever com a água $w_{\mathrm{t}}=0.950$. Essas figuras foram adaptadas do trabalho de Men et al. [110].

Em outro trabalho importante da literatura, Men et al. [110], utilizando um substrato de ouro $(\mathrm{Au})$ e diferentes valores de UR, calcularam as forças de adesão capilar e o grande potencial termodinâmico do sistema com os métodos GCMC e DFT, em que foi adicionado um vínculo [111] que permitiu calcular os estados metaestáveis e instáveis durante a condensação e ruptura das pontes capilares aderidas à ponta do cantilever do AFM com diferentes molhabilidades e alturas $h$. Então, eles verificaram uma curva de histerese na medida da força de adesão capilar e calcularam as barreiras de energia livre para a condensação e evaporação da ponte capilar. A Figura 1.5 mostra o resultado obtido por Men et al. para UR=90\%. Podemos observar que para valores de $h$ pequenos a ponte capilar se forma espontaneamente, e com o aumento de $h$ surge uma barreira de energia livre que deve ser sobreposta para que haja a ruptura dessa. Para 
grandes valores de $h$ não ocorre a condensação, pois o mínimo do grande potencial termodinâmico esta localizado no raio com valor igual a zero. Em outro trabalho realizado empregando as mesmas condições do anterior, Men et al. [112] estudaram o processo de ruptura da ponte capilar alterando a distância entre a ponta do AFM e o substrato com diferentes velocidades. Foi verificado que, dependendo das condições termodinâmicas e das velocidades, múltiplas pontes capilares podem ser formadas.

No contexto da fisiologia pulmonar, Alencar et al. [50], utilizando um modelo gás de rede implementado com método de Monte Carlo (MC) e amostragem de Metropolis com interações de primeiros, segundos e terceiros vizinhos, cujas interações eram ajustadas para obter o ângulo de contato de interesse, estudaram pontes capilares aderidas a duas superfícies planas hidrofílicas com o intuito de entender o mecanismo de emissão do ruído de crepitação, como ilustrado nas Figs. 1.6(a) e (b). Eles observaram que na ruptura das pontes capilares há dissipação de energia, cuja magnitude depende do valor do ângulo de contato. Então, os perfis das pontes capilares e os valores

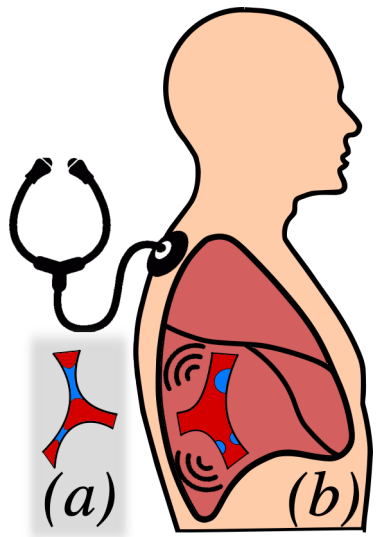

Figura 1.6: (a) Ponte capilar obstruindo a via aérea. (b) Emissão do ruído de crepitação. das energias dissipadas foram comparados com as previsões da TC macroscópica, mostrando concordância. Almeida et al. [52] estudaram o mesmo problema, mas para a formação da ponte capilar. Eles observaram dissipação de energia na formação da ponte capilar, bem como verificaram uma curva de histerese na energia livre da superfície e também calcularam a força de adesão capilar.

Com relação aos estudos da capilaridade com modelos atomísticos, o primeiro trabalho com essa modelagem foi realizado por Chen et al. [113] para entender o aumento do atrito estático em discos rígidos. Para isso, eles utilizaram um modelo em 2D com átomos de Lennard-Jones (LJ) de argônio e simulação de dinâmica molecular (DM), e observaram que a formação da ponte capilar e a força de adesão são dependentes da molhabilidade. Em um estudo mais detalhado que seguiu o trabalho anterior, Ogata et al. [87] utilizando um modelo em 3D e superfícies planas e rugosas modeladas com átomos de LJ, observaram que os átomos nas pontes capilares se organizam em camadas ordenadas, e esta ordenação poderia ser afetada pela rugosidade das 
superfícies.

Com relação ao transporte de tinta na técnica NDP, Kim et al. [55] estudaram com DM o transporte da tinta octadecanethiol (ODT), tratada com um modelo coarse-grained de átomos de LJ, através de uma ponte capilar de água do modelo SPC [114] aderida a uma ponta de silício ( $\mathrm{Si}$ ) no cantilever do AFM e a um substrato de Au, ambos constituídos de átomos de LJ. Eles observaram que há flutuação na ponte capilar e que a difusão do ODT se dá pela superfície dessa. Wu et al. [115] estudaram com DM a ponte capilar, constituída de terminal linear alkanethiols $\left(\mathrm{CH}_{3}\left(\mathrm{CH}_{2}\right)_{15} \mathrm{SH}\right)$ e aderida a uma ponta de Si do cantilever do AFM e um substrato de Au de diversas rugosidades, como mecanismo de deposição de tinta, e observaram que superfícies lisas são melhores para a deposição.

Com relação a outros estudos com pontes capilares no AFM, Choi et al. [116], estudaram com DM a ponte capilar de água do modelo TIP3P [114] condensadas entre a ponta do AFM e um substrato feitos de carbono (C), ambos modelados como átomos de LJ. Eles observaram que o perfil da ponte capilar poderia flutuar e que as medidas da força em função da altura foram compatíveis com as medidas de experimentos com AFM. Ko et al. [117] estudaram com DM a força de adesão da ponte capilar de água do modelo TIP3P [114] formada entre a ponta do cantilever do AFM e substratos com diferentes rugosidades, ambos constituídos de átomos de LJ. Eles observaram que o ângulo de contato e a força de adesão capilar diminuem quando a distância entre a ponta do cantiliver e o substrato aumenta, independentemente da rugosidade da superfície. Kim et al. [118] implementaram o método GCMC para estudar pontes capilares de água do modelo SPC [114] aderidas entre a ponta do cantilever do AFM e um substrato, ambos constituídos de átomos de $\mathrm{LJ}$ de $\mathrm{Au}$, com diferentes alturas e valores de UR, e observaram que a força de adesão capilar oscila, o que foi atribuído à formação de camadas moleculares. Cheng et al. [101] estudaram com DM pontes capilares formadas por um líquido não volátil, como mostrado na Fig. 1.7, constituído de uma cadeia linear de quatro átomos de LJ, aderida a uma ponta do cantilever do AFM e um substrato, ambos constituídos de átomos de LJ.

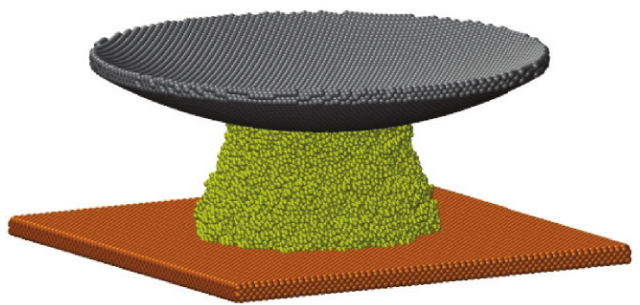

Figura 1.7: Ilustração do trabalho de Eles observaram que as medidas da forças de adesão Cheng et al. [101]. 
capilar são previstas pela TC macroscópica na escala $5-10 \mathrm{~nm}$, mas para distâncias inferiores 5 nm são observadas oscilações devido à formação de camadas moleculares.

Com relação ao estudo das pontes capilares aderidas a nanopartículas, Leroch et al. [119] estudaram com GCMC pontes capilares de água do modelo SPC [114] aderidas a duas nanopartículas de $\mathrm{SiO}_{2}$ com diâmetro de $4 \mathrm{~nm}$. Eles observaram que a força de adesão capilar aumenta e depois decai para altos valores de UR, e para distâncias menores do que $0.8 \mathrm{~nm}$, surgem oscilações na força de adesão devido ao ordenamento das moléculas de água. Salameh et al. [120] estudaram as forças de adesão capilar em agregados de nanopartículas de dióxido de titânio $\left(\mathrm{TiO}_{2}\right)$ de $10 \mathrm{~nm}$ de diâmetro em um ambiente com diferentes valores de UR por meio de espectroscopia de força com AFM e com simulações de DM de uma ponte capilar de água do modelo TIP3P [114] aderida a duas nanopartículas de $\mathrm{TiO}_{2}$. Eles observaram que camadas de moléculas de água absorvidas na superfície das nanopartículas exercem um papel fundamental nas forças de adesão causando um comportamento não monotônico. Em um trabalho mais recente, utilizando as mesmas condições do trabalho anterior, Laube et al. [121] estudaram mais detalhadamente a força de adesão entre duas nanopartículas de $\mathrm{TiO}_{2}$ por meio de DM, alterando a quantidade de moléculas de água absorvidas na superfície da nanopartícula, a UR e a rugosidade da superfície, e observaram que as forças de adesão capilar são bastante sensíveis à UR para nanopartículas rugosas, bem como constataram oscilações na medida da força para distâncias menores do que $0.5 \mathrm{~nm}$. Sepehrinia et al. [122] estudaram com DM o efeito de nanopartículas de $\mathrm{SiO}_{2}$ fluorada em pontes capilares de água do modelo TIP3P [114] e de decano aderidas a uma superfície de $\alpha$-quartzo hidroxilizado, que representa o poro de um meio rochoso, e observaram que as nanopartículas absorvem preferivelmente a superfície do mineral. Em outro contexto, as nanopartículas são estudadas na interface de fluidos $[5,123]$.

Recentemente, surgiram estudos mais detalhados sobre a capilaridade na escala nanométrica com pontes capilares aderidas a duas superfícies planas e paralelas. Uma continuação do trabalho de Cheng et al. [101],

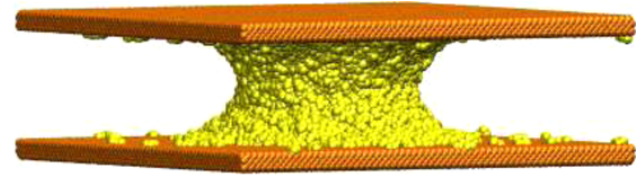

Figura 1.8: Ilustração do trabalho de Cheng et al. [102]. como mostrado na Fig. 1.8, mostrou que para alturas inferiores a $5 \mathrm{~nm}$ a medida da força de adesão capilar possui oscilações devido à formação de camadas moleculares nas pontes capila- 
res [102]. Outro estudo de DM sobre pontes capilares de água do modelo TIP4P/2005 [114] aderidas a dois substratos planos compostos por átomos de $\mathrm{LJ}$, sendo que um dos planos esta ligado a uma combinação paralela de molas, mostra que para distâncias menores do que $1 \mathrm{~nm}$, existe a formação de camadas moleculares e a força de adesão capilar possui oscilações, tornando-se descontínua e repulsiva [100].

Em um outro contexto, Wang et al. [20] estudaram com DM uma ponte capilar SPC/E [124] aderida a duas superfícies planas, lisas ou dentadas, e dispostas de tal forma que formavam um ângulo $\alpha$ entre si, para o transporte de líquidos [17], e observaram que com a variação de $\alpha$ a força resultante fazia com que a ponte capilar se deslocasse, e esse deslocamento era maior para superfícies hidrofóbicas. Além dos estudos com simulações de pontes capilares com modelos atomísticos, pode-se encontrar na literatura trabalhos da capilaridade com estudo de gotas na escala nanométrica. Por exemplo, encontram-se trabalhos realizados com DM para estudar gotas em superfícies super-hidrofílica [125], super-hidrofóbica [125-128], apolares [129], polares [130], o efeito de solvente na interface de gotas de água[131], e o efeito da tensão de linha [132, 133]. Estudos da capilaridade em nanotubos também podem ser encontrados, e recentemente foi observado preenchimento anômalo e molhabilidade reversa em simulações de DM de água [134]. Encontram-se também estudos sobre simulações de bolhas na escala nanométrica [135-137].

Trabalho desenvolvido na tese: Nessa tese, estudamos com DM os fundamentos da capilaridade na escala nanométrica utilizando pontes capilares com simetria axial (pontes SA), gotas com simetria axial (gotas SA), pontes capilares com simetria translacional (pontes ST) e gotas com simetria translacional (gotas ST), com volumes $\Omega$ da ordem de $100 \mathrm{~nm}^{3}$. Vale ressaltar que estudamos gotas com simetria axial grandes (gotas SAg) e gotas com simetria axial pequenas (gotas SAp). As gotas e pontes capilares são formadas por moléculas de água do modelo SPC/E [124] e são aderidas, respectivamente, a uma e duas placas planas e paralelas de $\beta$ cristobalita de polaridade $k$. Escolhemos estudar as pontes SA aderidas a duas placas planas e paralela, ao invés de um formato que representaria melhor a ponta do cantilever do AFM, porque essa já é bastante explorada analiticamente pela TC macroscópica [35, 50] e pouco ex- 
plorada na escala nanométrica.

O estudo dos fundamentos da capilaridade na escala nanométrica foi dividido em três etapas, e mostramos que nas condições analisadas as gotas e pontes capilares são bem descritas pela TC macroscópica.

Na primeira etapa, estudamos os ângulos de contato $\theta_{c}$ formados pelas interfaces de gotas e pontes capilares com as placas planas, e, de acordo com a TC, $\theta_{\mathrm{c}}$ é independente dos formatos das interfaces; nesse caso a distância entre as placas $h$, que é a altura das ponte SA e ST, foi mantida constante. $\mathrm{O}$ valor de $\theta_{\mathrm{c}}$ foi determinado ajustando as equações da TC que descrevem as interfaces de gotas e pontes capilares aos formatos dessas interfaces calculados com as simulações de DM. Depois, estudamos se a energia livre das pontes SA e ST podem ser expressas somente em termos das tensões das interfaces e da(s) área(s) da(s) interfaces dessas. A energia livre pode ser inferida a partir das forças exercidas sobre as placas, que é simplesmente a derivada dessa. Para isso, além de utilizar os resultados obtidos do ajuste, medimos durante as simulações as força exercidas pelas pontes SA e ST sobre as placas. Com isso, foi possível calcular o valor da tensão na interface líquido-gás $\gamma$ do modelo de água SPC/E [124], as forças de adesão capilar e as pressões de Laplace previstas pela TC.

Na segunda etapa, focamos no estudo das pontes SA aderidas às placas planas com polaridade $k$, mas agora aumentando o valor de $h$. Repetimos os procedimentos da primeira etapa, e, ademais, estudamos a maneira como a ponte SA se rompe. A TC macroscópica prevê que a ponte SA pode estar em uma condição de estabilidade ou instabilidade, dependendo de $h$ e de $\theta_{c}$. Essas duas condições são separadas pela altura máxima $h_{\max }\left(\theta_{c}\right)$ que pode ser calculada analiticamente, a partir do cálculo variacional baseado na minimização da energia livre da superfície e com restrições em $\Omega$ e em $\theta_{c}$. Quando a ponte SA possui uma atura crítica $h_{\mathrm{C}}$, tal que $h_{\mathrm{C}}>h_{\max }$, essa se encontra em uma condição instável e está prestes a romper; a ponte SA se encontra em condição estável quando possui uma atura $h_{\mathrm{S}}$, tal que $h_{\mathrm{S}}<h_{\max }$. Quando a ponte SA se encontra na altura $h_{\max }$ a TC macroscópica prevê que a ponte SA pode se romper e formar duas gotas com volumes $\Omega / 2$ aderidas a cada uma das placas se $\theta_{\mathrm{c}}<31^{\circ}$, ou então uma ou duas gotas, com volumes diferentes, se $\theta_{\mathrm{c}}>31^{\circ}$. Desse modo, é definido um diagrama de fase $\left(h, \theta_{c}\right)$ que define as regiões de estabilidade e instabilidade, e da formação de uma ou duas 
gotas. Alencar et al. [50] estudou esse problema com um modelo gás de rede implementado com método de Monte Carlo (MC) e mostrou concordância com a TC macroscópica.

$\mathrm{Na}$ terceira etapa, fizemos um estudo de um fato observado na segunda etapa. Constatamos que existe uma flutuação da ponte SA, como também verificado em outros trabalhos na literatura $[55,116]$. Para entender melhor essa flutuação na escala nanométrica, analisamos, através do cálculo do expoentes de Hurst, a série temporal gerada pela flutuação do centro de massa (CM) de dois simples sistema, uma gota livre, que não esta aderida a nenhuma placa, e gotas SA. Para efeito de comparação, esses dois sistemas foram comparados com simulações com gás de rede implementado com método de MC [50, 52].

Divisão da tese: Nessa tese, no Cap. 2 apresentaremos as metodologias utilizadas. Na Seção 2.1 mostraremos a aplicação da TC macroscópica às interfaces das gotas e pontes SA e ST, para determinarmos o perfil dessas, e outras propriedades, como a tensão superficial, a força de adesão capilar e a pressão de Laplace. Na Seção. 2.2, mostraremos a estrutura da molécula de água do modelo SPC/E [124] e também da placa de $\beta$-cristobalita hidrofílica e hidrofóbica; abordaremos brevemente os principais algoritmos empregados na DM e como foram executadas as simulações. Na Seção. 2.3 mostraremos o algorítimo empregado para determinar o perfil das gotas e pontes capilares a partir das configurações geradas na DM. Na Seção 2.4 mostramos como ajustar os perfis analíticos da TC aos perfis calculados com as médias das configurações de $\mathrm{H}_{2} \mathrm{O}$ geradas na DM. Na Seção 2.5, explicamos como determinar a tensão superficial utilizando o método Kirkwood-Buff. Na Seção 2.6 apresentaremos o modelo gás de rede e na Sec. 2.7 o cálculo do expoente de Hurst que serão utilizados na terceira etapa. Vale ressaltar que no final de cada seção enfatizaremos quais variáveis que serão importantes para a discussão dos resultados, e as que não estiverem explícitas poderão ser redefinidas.

No Capitulo 3 mostraremos os resultados obtidos juntamente com as respectivas discussões, e nas Secs. 3.1, 3.2 e 3.3 apresentaremos o trabalho da primeira, segunda e terceira etapas, respectivamente. Na Seção 3.4 apresentaremos outros resultados que complementam os estudos anteriores.

Finalmente, no Cap. 4 apresentaremos as principais conclusões dessa tese sobre gotas e 
Alexandre B. de Almeida

pontes capilares com volumes da ordem de $100 \mathrm{~nm}^{3}$ e as perspectivas do nosso trabalho futuro.

Nos Apêndices A e B apresentaremos exemplos dos arquivos de entrada para executar as simulações, e no Apêndice $\mathrm{C}$ apresentaremos a principais atividades acadêmicas desenvolvidas e trabalhos publicados. 


\section{Capítulo 2}

\section{Métodos}

O fenômeno da capilaridade na escala nanométrica será avaliado a partir das interfaces formadas por gotas e pontes capilares. Utilizaremos duas metodologias para estudar essas interfaces na escala nanométrica. A primeira delas, que será discutida na Sec. 2.1, será a teoria capilar que foi desenvolvida para descrever sistema na escala macroscópica. Mostraremos os principais conceitos dessa teoria, como determinar os perfis que descrevem as interfaces das gotas e pontes capilares e como determinar as principais propriedades desses sistemas. Na segunda metodologia, discutida na Sec. 2.2, mostraremos os modelos atomísticos para simular as gotas e pontes capilares assim como as superfícies de $\beta$-cristobalita a que estão aderidas. Além disso, apresentaremos os principais algoritmos empregados na simulação de DM para determinar as configurações das pontes capilares e gotas na escala nanométrica. Em seguida, compararemos as duas metodologias para interpretar o fenômeno da capilaridade na escala nanométrica. $\mathrm{Na}$ Sec. 2.3 mostraremos como determinar o perfil, tanto das gotas como das pontes capilares, a partir das configurações geradas pela DM, e na Sec. 2.4 mostraremos como comparar esses perfis com os perfis descritos pela TC para determinar as propriedades desses sistemas. Finalmente, na Sec. 2.5 apresentaremos o método Kirkwood-Buff (KB) que será utilizado para comparar os valores da tensão superficial, que também foram determinadas utilizando a TC.

\subsection{Princípios da teoria capilar}

Suponha um sistema constituído por uma gota com simetria axial (gota SA) sobre uma placa plana e rígida, como pode ser observado na Fig. 2.1(a). As interfaces formadas são líquido-gás, 
(a)

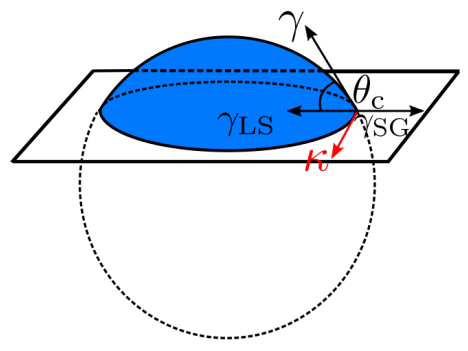

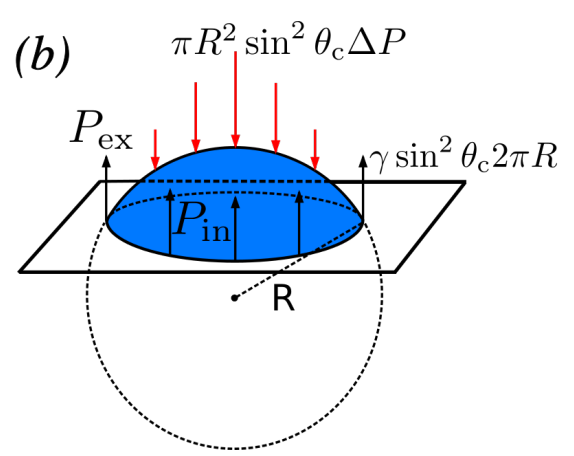

(c)

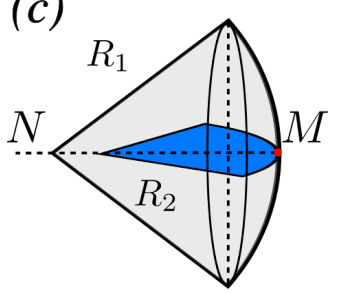

Figura 2.1: (a) Equilíbrio das forças (abscissa) das tensões superficiais $\gamma_{\mathrm{SG}}, \gamma_{\mathrm{LS}}$ e $\gamma$ das respectivas interfaces sólido-gás, líquido-sólido e líquido-gás, e também a tensão de linha $\kappa$ na região de contato das três interfaces em uma gota SA. Observa-se que $\gamma$ e $\gamma_{\mathrm{LS}}$ formam o ângulo de contato $\theta_{\mathrm{c}}$. (b) Equilíbrio das forças (ordenada) devido à tensão superficial $\left(\gamma \sin ^{2} \theta_{\mathrm{c}} 2 \pi R\right)$ e à diferença de pressão entre o meio interior e exterior da gota $\left(\pi R^{2} \sin ^{2} \theta_{\mathrm{c}}\left(P_{\mathrm{in}}-P_{\mathrm{ex}}\right)=\pi R^{2} \sin ^{2} \theta_{\mathrm{c}} \Delta P\right)$. (c) Raios principais de curvatura $R_{1}$ e $R_{2}$ no ponto hipotético $M$. Nota-se que $R_{1}$ e $R_{2}$ estão contidos em dois planos perpendiculares (cinza e azul) entre si, cuja interseção é a reta $N M$.

líquido-sólido e sólido-gás, e suas respectivas tensões superficiais são $\gamma_{\mathrm{LG}}{ }^{1}, \gamma_{\mathrm{LS}}$, e $\gamma_{\mathrm{SG}}$. Pode-se definir o parâmetro spreanding $S$, tal que $S=\gamma_{\mathrm{SG}}-\left(\gamma_{\mathrm{LS}}-\gamma\right)$, que explica o comportamento de um líquido sobre uma dada placa sólida $[1,138]$. Se $S>0$, significa que a interação entre o líquido e a placa é intensa, e o líquido se espalha por toda a placa formando um filme fino; para $S<0$, a interação entre o líquido e a placa é fraca, havendo então a formação de uma geometria, como a da gota SA.

As principais equações que descrevem a gota SA, assim como qualquer outro formato que possa ser adquirido pela interface, são as equações de Young e Young-Laplace, que estão relacionadas ao equilíbrio das forças em cada coordenada do sistema $[1,138]$. A equação de Young macroscópica, ver Fig. 2.1(a), relaciona o equilíbrio das forças devido às tensões superficiais no eixo da abscissa da linha de contato das três interfaces, e é dada por [138]:

$$
\cos \theta_{\mathrm{c}}=\frac{\gamma_{\mathrm{SG}}-\gamma_{\mathrm{LS}}}{\gamma}
$$

em que $\theta_{c}$ é o ângulo de contato formado entre as interfaces gás-líquido e líquido-sólido. Sobre a linha de contato existe uma tensão chamada de tensão de linha $\kappa$, que na escala macroscópica pode ser desprezada, uma vez que seu valor é da ordem de $10^{-10} \mathrm{~J} / \mathrm{m}[133,139]$. Entretanto, quando se trata de sistemas nanométricos, a tensão de linha deve ser considerada e um termo de

\footnotetext{
${ }^{1}$ Por simplicidade, trataremos no decorrer do texto $\gamma_{\mathrm{LG}}=\gamma$
} 
correção deve ser adicionado à Eq. 2.1:

$$
\cos \theta_{\mathrm{c}}=\cos \theta_{\infty}-\frac{\kappa}{\gamma} \frac{1}{r_{\mathrm{B}}},
$$

em que $\theta_{\infty}$ é o ângulo de contato na escala macroscópica dado pela Eq. 2.1 e $r_{\mathrm{B}}$ é o raio da base da interface formada.

Já a equação de Young-Laplace, ver Fig. 2.1(b), relaciona as forças na ordenana devido à diferença de pressão ( $\left.\Delta P=P_{\mathrm{in}}-P_{\mathrm{ex}}\right)$, que existe entre o meio interior da gota $\mathrm{SA}\left(P_{\mathrm{in}}\right)$ e o meio exterior $\left(P_{\mathrm{ex}}\right)$, e devido à tensão superficial $\gamma$, e é dada por:

$$
\Delta P=2 \gamma H, \quad H=\frac{1}{2}\left(\frac{1}{R_{1}}+\frac{1}{R_{2}}\right),
$$

em que $H$ é a curvatura média da interface formada pelo líquido, e $R_{1}$ e $R_{2}$ são os raios principais de curvatura. Esses raios estão ilustrados na Fig. 2.1(c), que exemplifica o conceito de curvatura média em um dado ponto $\mathrm{M}$ de uma superfície qualquer. No caso particular da gota SA, a equação de Young-Laplace é escrita como $\Delta P=2 \gamma / R$. Como consequência do equilíbrio do sistema, e de acordo com a Eq. 2.3, $\Delta P$ e $H$ serão constantes em qualquer ponto da interface da gota SA.

Utilizando as equações de Young e Young-Laplace, determinaremos os perfis $r(z)$ que descrevem o formato das interfaces estudadas: gotas SA e ST, e pontes SA e ST. Também mostraremos como determinar todas as propriedades das pontes SA, que foram estudadas com mais profundidade nessa tese.

Enfatizamos que as definições de $\gamma, \Delta P, r, z, r(z) P_{\text {in }}, P_{\mathrm{ex}}, H, R_{1}, R_{2}, \theta_{\infty}, \theta_{\mathrm{c}}, \kappa$ e $r_{\mathrm{B}}$ serão mantidas e serão utilizadas no restante da tese.

\subsubsection{Perfil de gotas com simetrias axial e translacional}

Suponha uma gota com simetria axial, em equilíbrio mecânico e termodinâmico, condensada em uma placa plana, como mostrado na Fig. 2.2(a). As forças que atuam em um ponto $(z, r)$ de uma seção transversal qualquer das gotas são devidas à tensão superficial $F_{\gamma}(z)$ e à diferença de pressão do meio interior e exterior $F_{\mathrm{P}}(z)$ à interface. Assim, como a resultante das 

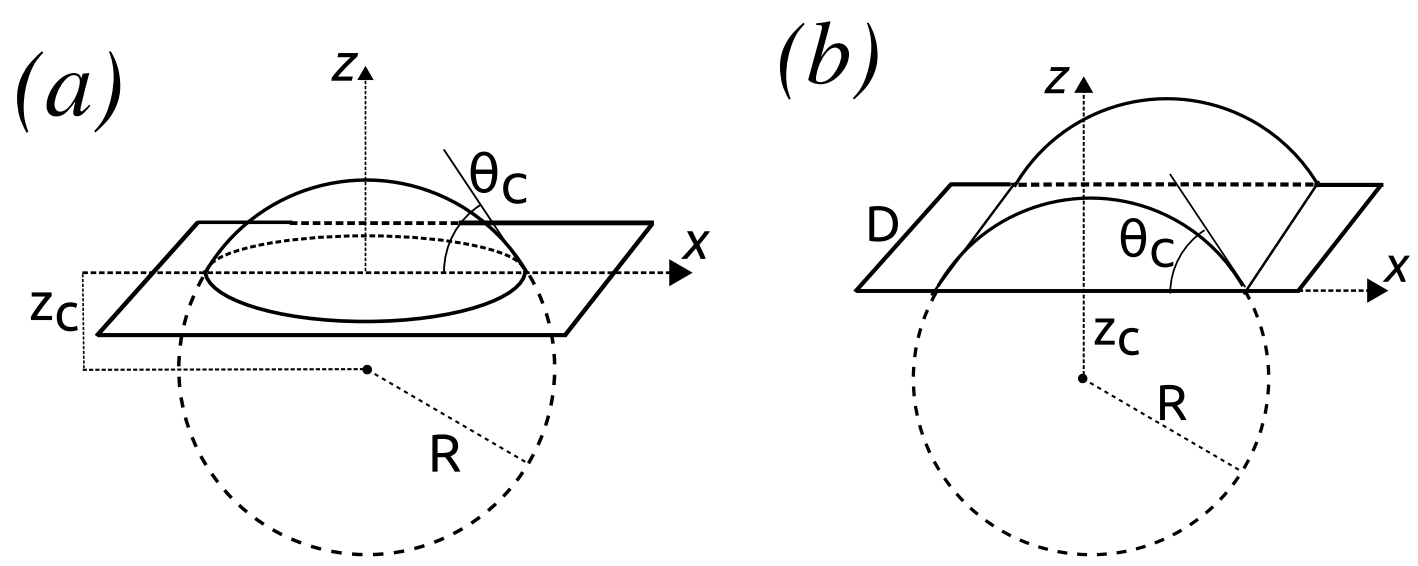

Figura 2.2: Ilustrações (a) da gota com simetria axial (gota SA) e (b) da gota com simetria translacional (gota ST) formadas sobre uma placa plana, cujas interfaces líquido-gás possuem um ângulo de contato $\theta_{\mathrm{c}}$. $R$ é o raio da circunferência que descreve as gotas, $z_{\mathrm{c}}$ é a distância do centro das gotas à origem do sistema e $D$ é o tamanho da lado da placa plana.

forças sobre essa seção transversal é nula, têm-se:

$$
\begin{gathered}
F_{\mathrm{z}}(z)=F_{\gamma}(z)+F_{\mathrm{P}}(z)=0, \\
2 \pi r \gamma \cos \xi-P_{\mathrm{ex}} r^{2} \pi+P_{\mathrm{in}} \pi r^{2}=0 .
\end{gathered}
$$

$\mathrm{O} \cos \xi$ na Eq. 2.5, em que $\xi$ é um ângulo formado entre a superfície da gota e um plano que tangencia a seção transversal, pode ser reescrito utilizando a derivada do perfil da gota $(\dot{r}=$ $\left.\frac{\mathrm{dr}}{\mathrm{dz}}=\tan \xi\right)$ e a identidade trigonométrica de Pitágoras:

$$
\cos \xi=\frac{1}{\sqrt{1+\frac{\mathrm{d} r^{2}}{\mathrm{~d} z}}} .
$$

Então, podemos reescrever a Eq. 2.5 como:

$$
\frac{\mathrm{dr}}{\mathrm{dz}}=\left(\frac{\frac{4 \gamma^{2}}{\Delta P^{2}}-r^{2}}{r}\right)^{1 / 2}
$$


A solução da Eq. 2.7 é obtida utilizando a Eq. 2.3 e considerando a constante de integração em $z=0$ como $r(0)=r_{\mathrm{B}}=R \sin \theta_{\mathrm{c}}$ :

$$
r(z)=\left(R^{2}-\left(z-z_{\mathrm{c}}\right)^{2}\right)^{1 / 2}
$$

em que $z_{\mathrm{c}}=R \cos \theta_{\mathrm{c}}$ é a distância do centro da circunferência à origem do sistema. Assim, podemos determinar $\theta_{\mathrm{c}}$ a partir dos parâmetros $R$ e $z_{\mathrm{c}}$ :

$$
\theta_{\mathrm{c}}=90^{\circ}+\frac{180^{\circ}}{\pi} \arcsin \left(\frac{z_{\mathrm{c}}}{R}\right)
$$

Com relação às gotas ST, a resultante das forças em uma seção transversal qualquer é dada por:

$$
2 D \gamma \cos \xi-P_{\text {ex }} D r \pi+P_{\text {in }} D r=0
$$

em que $D$ é o lado da placa plana. Logo, a solução do perfil das gotas ST é a mesma obtida para as gotas SA, Eq.2.8.

Enfatizamos que as definições de $R, z_{\mathrm{c}}, D, F_{\mathrm{z}}, F_{\gamma}$ e $F_{\mathrm{P}}$ serão mantidas e serão utilizadas no restante da tese.

\subsubsection{Cálculo do perfil das pontes capilares}

São denominadas pontes capilares um certo volume de líquido $(\Omega)$ que fica confinado entre duas placas que podem ter quaisquer formato. Trabalhamos com pontes capilares aderidas entre duas placas planas, paralelas e do mesmo material, o que implica que os ângulos de contato formados nas duas placas são iguais $\theta_{\mathrm{c} 1}=\theta_{\mathrm{c} 2}=\theta_{\mathrm{c}}$, ver Fig. 2.3(a) e (b). Primeiro descreveremos as pontes SA e depois as pontes ST.

\section{Pontes capilares simétricas com simetria axial}

A ponte SA é bastante explorada teoricamente [35, 50, 140-144], e por isso a escolhemos como modelo para explorar a capilaridade na escala nanométrica. Os perfis das pontes SA podem ser simétricos ou assimétricos. Primeiramente faremos uma abordagem mais simples da 

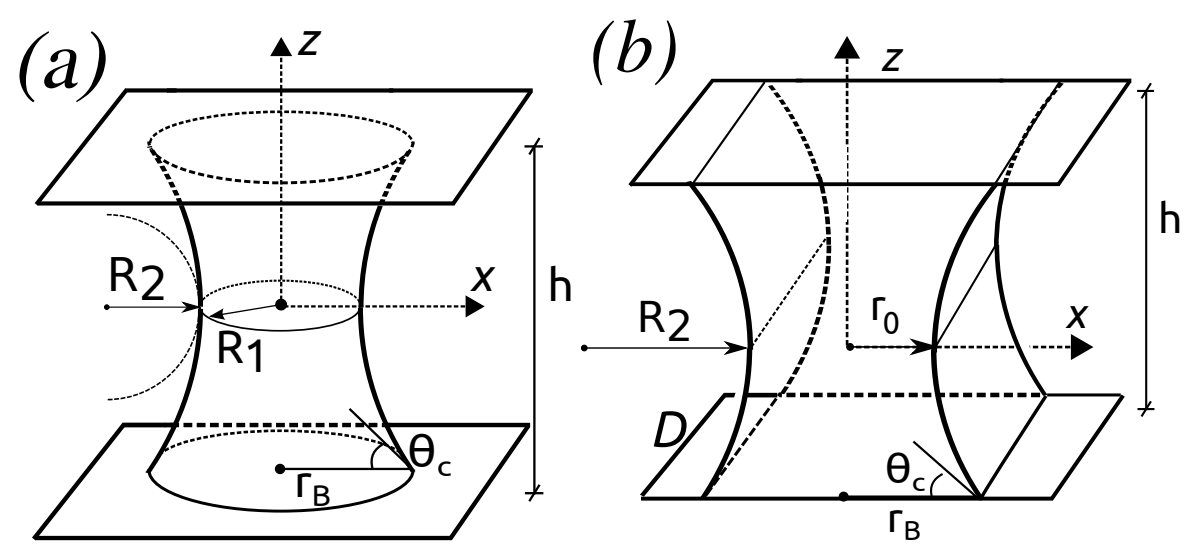

Figura 2.3: Ilustrações (a) da ponte capilar com simetria axial (ponte SA) e (b) da ponte capilar com simetria translacional (ponte $\mathrm{ST}$ ) aderidas a duas placas planas, paralelas e do mesmo material separadas de uma distância $h$. A curvatura da superfície é dada por $H=1 / 2\left(1 / R_{1}+1 / R_{2}\right)$, e para a ponte ST $R_{1}=\infty . r_{0}=R_{1}$ é o raio do "pescoço" das pontes, $\theta_{\mathrm{c}}$ é o ângulo de contato, $r_{\mathrm{B}}$ é o raio da base e $D$ é o tamanho do lado da placa plana. O perfil da ponte ST é descrito por $z^{2}+\left(r-r_{\mathrm{c}}\right)^{2}=R_{2}^{2}$, em que $r_{\mathrm{c}}=r_{0}-R_{2}$ é a distância do centro da circunferência à origem do sistema.

ponte SA com perfil simétrico e que é estável. Depois faremos uma discussão matemática mais rigorosa dos perfis simétricos e assimétricos da ponte SA que serão solucionados analiticamente por meio de método variacional e com integrais elípticas de Legendre, o que permitirá avaliar a estabilidade das pontes SA.

Na descrição matemática, a origem do sistema está no centro da ponte SA e são adotadas coordenadas cilíndricas. O perfil da superfície que descreve a interface das pontes SA é dado pela rotação de uma função $r(z)$ em torno do eixo $z$ e que é definido no intervalo $-h / 2 \leq z \leq$ $h / 2$, cujos extremos são as posições das duas placas planas às quais a ponte SA está aderida. O ponto $\mathrm{d} r / \mathrm{d} z=0$ é definido como o "pescoço" ${ }^{2}$ com raio $r(0)=r_{0}$, e os raios da base são definidos nos pontos $r(h / 2)=r(-h / 2)=r_{\mathrm{B}}$. A superfície da ponte SA simétrica e estável forma um ângulo de contato $\theta_{\mathrm{c}}$ com as placas planas e possui curvatura média $H\left(\Omega, h, \theta_{\mathrm{c}}\right)$ constante em qualquer ponto da superfície de revolução descrita por $r(z)$. Superfícies com essa característica são denominadas superfícies de Delaunay. A superfície formada pela revolução do perfil $r(z)$ possui três formas, que são distintas pelo valor de $H$. Se $H>0$ a superfície é conhecida como unduloid, e é obtida pela revolução da trajetória do foco de uma seção cônica arbitrária ao longo do eixo $z$; se $H<0$ a superfície é conhecida como nodoid e é obtida pela

\footnotetext{
${ }^{2} \mathrm{Na}$ literatura, o ponto em que $\frac{\mathrm{d} r}{\mathrm{~d} z}=0$ para as potes SA com $\theta_{\mathrm{c}}>\pi / 2$ é chamado de "barriga", e por simplicidade chamaremos de "pescoço" também.
} 
revolução da trajetória do foco de uma hipérbole; se $H=0$ a superfície é conhecida como catenoid e é obtida pela revolução da trajetória do foco de uma catenária [50].

A energia livre total do sistema em função da altura $h, \mathcal{E}_{\text {tot }}(h)$, pode ser definido como a soma das energias livre das interfaces $\mathcal{F}(h)$ mais a energia livre do bulk $\mathcal{E}_{\text {bulk }}(h)$,

$$
\mathcal{E}_{\text {tot }}(h)=\mathcal{F}(h)+\mathcal{E}_{\text {bulk }}(h),
$$

onde,

$$
\mathcal{F}(h)=\gamma A_{\mathrm{R}}(h)+\gamma_{\mathrm{LS}} A_{\mathrm{B}}(h)+\gamma_{\mathrm{GS}}\left(A_{\mathrm{T}}-A_{\mathrm{B}}(h)\right)-\gamma_{\mathrm{GS}} A_{\mathrm{T}},
$$

em que $A_{\mathrm{R}}(h)$ e $A_{\mathrm{B}}(h)$ são, respectivamente, as áreas das interfaces líquido-gás e líquidosólido na altura $h$; e $A_{\mathrm{T}}$ é a área total da placa plana à qual a ponte SA esta aderida. Utilizando a Eq. 2.1, a Eq. 2.12 pode ser escrita como:

$$
\mathcal{F}(h)=\gamma\left(A_{\mathrm{R}}(h)-\cos \theta_{\mathrm{c}} A_{\mathrm{B}}(h)\right) .
$$

A área da base $A_{\mathrm{B}}(h)$ pode ser escrita em termos do raio da ponte $\mathrm{SA} r(z)$ nos pontos $z=-h / 2$ $\mathrm{e} z=h / 2$,

$$
A_{\mathrm{B}}(h)=\pi\left(r(h / 2)^{2}+r(-h / 2)^{2}\right),
$$

e a área da interface líquido-gás $A_{\mathrm{R}}(h)$,

$$
A_{\mathrm{R}}(h)=\int_{-\mathrm{h} / 2}^{\mathrm{h} / 2} 2 \pi r(z) \sqrt{1+\left(\frac{\mathrm{d} r(z)}{\mathrm{d} z}\right)^{2}} \mathrm{~d} z,
$$

em que $2 \pi r(z)$ é o comprimento de uma seção transversal da ponte capilar na altura $z \mathrm{e}$ $\sqrt{1+\left(\frac{\mathrm{d} r(z)}{\mathrm{d} z}\right)^{2}} \mathrm{~d} z$ é um elemento infinitesimal do arco da função $r(z)$. Assim, podemos re- 
escrever $\mathcal{F}(h)$ como:

$$
\mathcal{F}(h)=\gamma \pi\left\{2 \int_{-\mathrm{h} / 2}^{\mathrm{h} / 2} r(z) \sqrt{1+\left(\frac{\mathrm{d} r(z)}{\mathrm{d} z}\right)^{2}} \mathrm{~d} z+\cos \theta_{\mathrm{c}}\left(r(h / 2)^{2}+r(-h / 2)^{2}\right)\right\} .
$$

A equação diferencial que descreve o perfil da ponte SA pode ser obtida de duas maneiras: a partir do equilíbrio de $F_{\gamma}(z)$ e $F_{\mathrm{P}}(z)$ em duas seções transversais da ponte SA, como feito anteriormente para as gotas SA, e a partir da minimização da Eq. 2.15 com o vínculo no volume, $\Omega=\pi \int_{\mathrm{h} / 2}^{-\mathrm{h} / 2} r(z)^{2} \mathrm{~d} z$. Trabalharemos com a primeira maneira nessa seção, uma vez que estamos estudando o particular caso da ponte SA estável e simétrica, e depois, para avaliar a estabilidade da ponte SA, aplicaremos o segundo método.

Seja $\left(0, r_{0}\right)$ e $(z, r)$ dois pontos do perfil $r(z)$ pertencentes a cada uma as seções transversais à superfície da ponte SA. Como a ponte SA está em equilíbrio, e aplicando a Eq. 2.4, temos que $F_{\mathrm{z}}(0)-F_{\mathrm{z}}(z)=0$,

$$
-\gamma 2 \pi r_{0}+\left(\pi r_{0}^{2}\right) P_{\text {in }}-\left(\pi r_{0}^{2}\right) P_{\text {ex }}+\gamma 2 \pi r \cos \xi-\left(\pi r^{2}\right) P_{\text {in }}+\left(\pi r^{2}\right) P_{\text {ex }}=0 .
$$

Utilizando a Eq.2.3 na Eq. 2.16:

$$
\gamma 2 \pi r \cos \xi-\gamma 2 \pi r_{0}-2 \pi \gamma H\left(r^{2}-r_{0}^{2}\right)=0
$$

Aplicando a Eq. 2.6 na Eq. 2.17,

$$
\pi \gamma \frac{r}{\sqrt{1+\left(\frac{\mathrm{d} r}{\mathrm{~d} z}\right)^{2}}}-2 \pi \gamma H r^{2}=2 \pi \gamma\left(r_{0}-r_{0}^{2} H\right)
$$

que pode ser reescrita como,

$$
\frac{\mathrm{d} z}{\mathrm{~d} r}= \pm \frac{\left|H\left(r^{2}-r_{0}^{2}\right)+r_{0}\right|}{\sqrt{r^{2}-\left[H\left(r^{2}-r_{0}^{2}\right)+r_{0}\right]^{2}}}
$$

que é a equação que descreve o perfil das pontes SA simétricas em equilíbrio e aderidas a dois 
planos paralelos do mesmo material, e cuja solução existe quando a condição

$$
r^{2}-\left[H\left(r^{2}-r_{0}^{2}\right)+r_{0}\right]^{2}>0
$$

é satisfeita. A Equação 2.19 pode ser resolvida a partir da integração numérica, e uma vez encontrada a solução, obtemos todas as propriedades das pontes SA, como $r_{\mathrm{B}}, r_{0}, \theta_{\mathrm{c}}, \Omega, H$ e as área das interfaces líquido-gás $A_{\mathrm{R}}$, líquido-sólido $A_{\mathrm{B}}$ e gás-sólido $\left(A_{\mathrm{T}}-A_{\mathrm{B}}\right)$, respectivamente.

$\mathrm{O}$ valor de $\theta_{\mathrm{c}}$ da ponte $\mathrm{SA}$ aderida às placas hidrofóbicas é encontrado a partir da inclinação $\mathrm{em} z\left(r_{\mathrm{B}}\right)$,

$$
\theta_{\mathrm{c}}=\frac{180^{\circ}}{\pi} \arctan \left(\left.\frac{\mathrm{d} z}{\mathrm{~d} r}\right|_{r_{\mathrm{B}}}\right)
$$

e para placas hidrofílicas,

$$
\theta_{\mathrm{c}}=180^{\circ}-\frac{180^{\circ}}{\pi} \arctan \left(\left.\frac{\mathrm{d} z}{\mathrm{~d} r}\right|_{r_{\mathrm{B}}}\right)
$$

Utilizando a Eq. 2.4, podemos calcular a força de adesão capilar $F_{z, \text { base }}=\left|F_{z}(h / 2)\right|=$ $\left|F_{\mathrm{z}}(-h / 2)\right|$ que a base da ponte SA exerce em cada placa plana,

$$
F_{\text {z, base }}=2 \pi \gamma r_{\mathrm{B}} \sin \theta_{\mathrm{c}}-P_{\mathrm{in}} A_{\mathrm{B}}
$$

em que $A_{\mathrm{B}}=\pi r_{\mathrm{B}}^{2}$, e $r_{\mathrm{B}}$ é o raio da base da ponte SA, como mostrado na Fig. 2.3(a). Utilizando a Eq. 2.3 e assumindo que na fase de vapor $P_{\mathrm{ex}} \approx 0$, podemos reescrever $P_{\mathrm{in}}=\Delta P=2 \gamma H$, e a $F_{z, \text { base }}$ pode ser reescrita,

$$
F_{\mathrm{z}, \text { base }}=2 \pi \gamma r_{\mathrm{B}} \sin \theta_{\mathrm{c}}-2 \pi \gamma H r_{\mathrm{B}}^{2},
$$

em que o primeiro termo é força devido à tensão superficial $F_{\gamma}$,

$$
F_{\gamma}=2 \pi \gamma r_{\mathrm{B}} \sin \theta_{\mathrm{c}}
$$


e o segundo termo é a componente devido à pressão de Laplace $F_{\mathrm{P}}$,

$$
F_{\mathrm{P}}=-\Delta P A_{\mathrm{B}}=-\Delta P\left(\pi r_{\mathrm{B}}^{2}\right)
$$

Similarmente, a força exercida no "pescoço" $F_{z, p c ̧ o}=\left|F_{z}(0)\right|$ da ponte SA pode calculada,

$$
F_{\mathrm{z}, \mathrm{pço}}=2 \pi \gamma \mathcal{C}=2 \pi \gamma\left(r_{0}-H r_{0}^{2}\right)
$$

em que $\mathcal{C}$ é um parâmetro que expressa a deformação no "pescoço". Como a ponte SA está em equilíbrio, temos que $F_{z, p c ̧ o}=F_{z, \text { base }}$, e conhecendo a força de adesão capilar $F_{\text {z,base }}$ e a deformação $\mathcal{C}$, podemos calcular a tensão superficial $\gamma$ a partir de um ajuste linear [145].

Finalmente, podemos calcular a pressão no interior das pontes SA, comumente denominada pressão de Laplace, utilizando a Eq. 2.4:

$$
P_{\mathrm{L}}=\frac{2 \pi \gamma r_{\mathrm{B}} \sin \theta_{\mathrm{c}}-F_{\mathrm{z}, \mathrm{base}}}{\pi r_{\mathrm{B}}^{2}}
$$

Enfatizamos que as definições de $\Omega, r_{0}, r_{\mathrm{c}}, h, \mathcal{E}_{\text {tot }}(h), \mathcal{F}(h), \mathcal{E}_{\text {bulk }}(h), A_{\mathrm{R}}(h), A_{\mathrm{B}}(h), F_{\text {z,base }}$, $F_{\mathrm{z}, \mathrm{pço}}, \mathcal{C}$ e $P_{\mathrm{L}}$ serão mantidas e serão utilizadas no restante da tese.

\section{Estabilidade das pontes capilares com simetria axial}

Agora, estudaremos as soluções completas das pontes SA simétricas e assimétricas para $\theta_{\mathrm{c}}<\pi / 2$ e $\theta_{\mathrm{c}}>\pi / 2$, e também a estabilidade dessas soluções. O material apresentado a seguir para $\theta_{c}<\pi / 2$ pode ser encontrado com maiores detalhes nas Refs. [35, 50]. Todavia, o material para $\theta_{\mathrm{c}}>\pi / 2$ é novo. Vale ressaltar também que todas as grandezas analíticas que deduziremos a seguir, e que serão comparadas com o resultado das simulações são marcadas com uma aspas simples $\left({ }^{\prime}\right)$.

A ponte SA com volume $\Omega$ pode estar em uma condição estável ou instável dependendo da região do espaço de fase $\left(\theta_{\mathrm{c}}, h\right)$ que se encontra, e os perfis $r(z)$ podem ser simétricos ou assimétricos. As pontes SA estáveis são aquelas cujas superfícies pertencem à classe de superfícies de Delaunay com curvatura média $H$ constante e o perfil $r(z)$ não possui nenhum ponto de inflexão $\left(\frac{\mathrm{d}^{2} r(z)}{\mathrm{d} z^{2}} \neq 0\right)$ no intervalo $[-h / 2, h / 2]$, o que implica que $r(z)$ é simétrico em relação à 
altura do pescoço com $z=z_{0}^{\prime}=0: r(-z)=r(z)$. Diferentemente, as pontes SA instáveis e assimétricas possuem $z_{0}^{\prime} \neq 0$ e a simetria dos perfis $r(-z)=r(z)$ deixa de valer. Outra condição, o perfil $r(z)$ deve pertencer a uma família de soluções contínuas para as quais $\partial \Omega^{*} / \partial H<0$, para qualquer $\Omega^{*} \geq \Omega$.

Quando aumentamos a altura $h$ da ponte SA, existe uma altura máxima $h_{\max }$ acima da qual a ponte SA se torna instável. Nas pontes SA com $\theta_{\mathrm{c}}<31^{\circ}$, a instabilidade surge no instante em que $\partial \Omega^{*} / \partial H=0$, e a ponte SA rompe simetricamente formando duas gotas com volumes iguais $\Omega / 2$ aderidas a cada uma das placas $\Omega / 2$. Para $\theta_{\mathrm{c}}>31^{\circ}$, as pontes SA tornam-se instáveis devido ao surgimento de pontos de inflexão na posição das placas planas $\frac{\mathrm{d}^{2} r(-h / 2)}{\mathrm{d} z^{2}}=\frac{\mathrm{d}^{2} r(h / 2)}{\mathrm{d} z^{2}}=$ 0, e a ruptura ocorre assimetricamente formando uma gota, ou gotas com volumes diferentes aderidas a cada uma das placas [50].

Para encontrar a solução das pontes SA devemos solucionar a Eq. 2.15 minimizando o funcional $\mathcal{F}-2 \gamma H \Omega$, em que $2 \gamma H$ é o multiplicador de Lagrange. Utilizando cálculo variacional, podemos determinar a Hamiltoniana da ponte SA,

$$
\mathcal{H}=2 \pi \gamma \frac{r(z)}{\sqrt{1+\left(\frac{\mathrm{d} r(z)}{\mathrm{d} z}\right)^{2}}}-2 \gamma H \pi r(z)^{2}=F_{\text {z,base }}^{\prime}
$$

A partir da solução da Eq. 2.27 obtemos a solução do perfil $r(z)$ para $\theta_{c}<\pi / 2$,

$$
z(r)= \pm s \int_{\mathrm{A}}^{\mathrm{r}} \frac{\mathrm{d} x\left(A B+x^{2}\right)}{\sqrt{\left(B^{2}-x^{2}\right)\left(x^{2}-A^{2}\right)}}+z_{0}^{\prime}
$$

e para $\theta_{\mathrm{c}}>\pi / 2$

$$
z(r)= \pm \int_{\mathrm{r}}^{\mathrm{B}} \frac{\mathrm{d} x\left(A B+x^{2}\right)}{\sqrt{\left(B^{2}-x^{2}\right)\left(x^{2}-A^{2}\right)}}+z_{0}^{\prime},
$$

e para $\theta_{\mathrm{c}}=\pi / 2$ a solução de $r(z)$ é a superfície de um cilindro. Nessas equações $|A|$ e $|B|$ estão relacionadas como:

$$
A B=\frac{C}{H}
$$


e

$$
A^{2}+B^{2}=\frac{1}{H^{2}}-2 \frac{C}{H}, \quad C=\frac{F_{\text {z,base }}^{\prime}}{2 \pi \gamma}
$$

em que $|A|$ e $|B|$ são, respectivamente, as distâncias mínima e máxima do perfil da ponte SA ao eixo $z$ de simetria, tal que $0<|A|<|B|$; $z_{0}^{\prime}$ é a altura do "pescoço" da ponte SA, e os sinais + $\mathrm{e}$ - correspondem, respectivamente, à porção do perfil $r(z)$ da ponte SA para $z>z_{0}^{\prime}$ e $z<z_{0}^{\prime}$. Na Equação 2.28, $s$ é o sinal da curvatura média $H$. Os valores $A$ e $B$ estão relacionados com o raio do pescoço da ponte SA. Assim, para $\theta_{c}<\pi / 2$ assumimos que o raio do "pescoço" é dado pela menor distância $r\left(z_{0}\right)=r_{0}=A$, tal que $A>0$, enquanto que $B$ pode ser positivo ou negativo. Os sinais de $B$ são determinados a partir da curvatura média $s \equiv \operatorname{sign}(B)=\operatorname{sign}(H)$. Assim, para as superfícies unduloids, nodoids e catenoids, têm-se, respectivamente, $B>0$, $B<0$ e $B=\infty$. No caso $\theta_{\mathrm{c}}>\pi / 2$, consideramos que o raio do "pescoço" é dado pela maior distância $r\left(z_{0}\right)=r_{0}=B$, enquanto que o sinal de $A$ pode ser positivo ou negativo, cujo valor é determinado a partir do sinal da $F_{\text {z,base }}^{\prime}$ : para a superfície unduloid $F_{z \text {,base }}^{\prime}<0$ e $A>0$, para a superfície nodoid $F_{\mathrm{z} \text {,base }}^{\prime}>0$ e $A<0$, e para uma esfera $F_{\mathrm{z} \text {,base }}^{\prime}=0$ e $A=0$. Observa-se que a Eq. 2.19 é um caso particular das Eqs. 2.28 e 2.29, em que para $\theta_{c}<\pi / 2$, e temos que $r_{0}=A$ e $r_{\mathrm{B}}=B$, e para $\theta_{\mathrm{c}}>\pi / 2$ temos que $r_{0}=B$ e $r_{\mathrm{B}}=A$, tal que $A<B$ e $A$ e $B$ são sempre positivos.

Solução simétrica $\left(z_{0}^{\prime}=0\right)$ para $\theta_{\mathrm{c}}<\pi / 2$ : A Equação 2.28 pode ser reescrita em termos de unidades adimensionais, tal que $a \equiv A / \chi, b \equiv B / \chi$ e $\zeta \equiv r / \chi$, em que $\zeta \in[a, 1]$; $\chi$ é o raio da base que satisfaz as condições de contorno $z(\chi)= \pm h / 2$ e $\frac{\mathrm{d} z(\chi)}{\mathrm{d} r}= \pm \tan \theta_{\mathrm{c}}$. Observa-se que nessas definições $A, B$ e $\chi$ definem uma família de soluções mais ampla quando comparada com aquelas da Eq. 2.19. A Equação 2.28 normalizada pode ser reescrita como:

$$
u(a, \zeta) \equiv s \frac{z(r)}{\chi} \equiv \pm s \int_{\mathrm{a}}^{\zeta} \frac{\left(a b+x^{2}\right) \mathrm{d} x}{\sqrt{\left(x^{2}-a^{2}\right)\left(b^{2}-x^{2}\right)}}
$$

A partir da integral por partes de $u(a, \zeta)$ [50], é possível determinar o volume $\Omega$ da ponte SA,

$$
\Omega=\frac{\pi h^{3}}{4} \omega(a)
$$


em que,

$$
\omega(a)=\frac{v(a, 1)}{u(a, 1)^{3}}
$$

onde,

$$
v(a, \zeta)=s \int_{\mathrm{a}}^{\zeta} \frac{x^{2}\left(a b+x^{2}\right) \mathrm{d} x}{\sqrt{\left(x^{2}-a^{2}\right)\left(b^{2}-x^{2}\right)}} .
$$

Mais adiante, as funções $u(a, \zeta)$ e $v(a, \zeta)$ serão redefinidas em termos de integrais elípticas de Legendre $F(\phi, k)$ e $E(\phi, k)$.

A Equação 2.33 depende dos parâmetros conhecidos $\Omega, h$ e $\theta_{\mathrm{c}}$, e $a$ é o único parâmetro desconhecido. Essa equação pode ser resolvida fazendo $\mathrm{d} \omega(a) / \mathrm{d} a=0$, que é uma equação transcendental complexa como mostrada na Ref. [50], Eq. A29, e possui uma única solução para cada $\theta_{\mathrm{c}}$. Assim, uma vez encontrada a raiz $a=a_{0}\left(\theta_{c}\right)$ é possível determinar todas as demais propriedades da ponte SA. Essa solução mostra que a altura máxima em que a ponte SA simétrica é estável $h_{\max , \mathrm{s}}$ é dada por

$$
h_{\max , \mathrm{s}}=2 u\left(a_{0}, 1\right)\left(\frac{\Omega}{2 \pi v\left(a_{0}, 1\right)}\right)^{\frac{1}{3}},
$$

e a análise numéria dessas soluções considerando $h>h_{\max , \mathrm{s}}$ mostra que não existe solução para $\mathrm{d} \omega(a) / \mathrm{d} a=0$, enquanto que para $h<h_{\max }$ existem duas soluções, tais que $a_{1}<a_{0}<a_{2}$ : uma refere-se a pontes SA com "pescoço" estreito e a outra para um "pescoço" mais largo. Essas soluções estão relacionadas à assimetria e instabilidade das pontes SA e serão exploradas adiante.

Assim, encontramos as equações analíticas, que dependem somente dos valores de $\Omega, h$ e $\theta_{\mathrm{c}}$ conhecidos a priori, que descrevem as demais grandezas da ponte SA como a energia livre da superfície $\mathcal{F}^{\prime}$, a força de adesão capilar $F_{z \text {,base }}^{\prime}$, a pressão de Laplace $P_{\mathrm{L}}^{\prime}$, o raio da base $r_{\mathrm{B}}^{\prime} \mathrm{e}$ o raio do "pescoço" $r_{0}^{\prime}$. A expressão da energia livre da superfície $\mathcal{F}^{\prime}$ é dada por:

$$
\mathcal{F}^{\prime}(a)=\frac{\gamma \pi h^{2}}{2} \frac{2 \sigma(a, 1)-\cos \theta_{\mathrm{c}}}{u(a, 1)^{2}}
$$


em que,

$$
\begin{aligned}
u(a, \zeta) & =a \tilde{F}\left(k, \phi_{\zeta}\right)+b \tilde{E}\left(k, \phi_{\zeta}\right) \\
v(a, \zeta) & =\left[-\mathcal{R}(a, \zeta)-a^{2} b \tilde{F}\left(k, \phi_{\zeta}\right)\right. \\
& \left.+b\left[3 a b+2\left(a^{2}+b^{2}\right)\right] \tilde{E}\left(k, \phi_{\zeta}\right)\right] / 3 .
\end{aligned}
$$

Nessas equações, tem-se:

$$
\begin{aligned}
b & =\left(\frac{1-a \sin \theta_{c}}{\sin \theta_{c}-a}\right) \\
k & =s \sqrt{b^{2}-a^{2}} / b \\
\mathcal{R}(a, \zeta) & =\zeta \sqrt{\left(\zeta^{2}-a^{2}\right)\left(b^{2}-\zeta^{2}\right)} \\
\phi_{\zeta} & =\arcsin \sqrt{\left(b^{2}-\zeta^{2}\right) /\left(b^{2}-a^{2}\right)}, \\
\tilde{F}(k, \phi) & =F(k, \pi / 2)-F(k, \phi), \\
\tilde{E}(k, \phi) & =E(k, \pi / 2)-E(k, \phi) .
\end{aligned}
$$

A força de adesão capilar $F_{z, b a s e}^{\prime}$ exercidas pela ponte SA sobre as placas planas pode ser escrita como:

$$
F_{\mathrm{z}, \mathrm{base}}^{\prime}=\pi \gamma a \frac{h\left(1-a \sin \theta_{\mathrm{c}}\right)}{\left(1-a^{2}\right) u(a, 1)},
$$

que é monotonicamente decrescente em função da altura $h$ [50]. As componentes de $F_{z \text {,base }}^{\prime}$, as forças devido à tensão superficial $F_{\gamma}^{\prime}$ (Eq. 2.23) e à pressão de Laplace $F_{\mathrm{P}}^{\prime}$ (Eq. 2.24) podem ser expressas em termos do raio da base $r_{\mathrm{B}}^{\prime}=\chi(a)$ calculado com integrais elípticas,

$$
r_{\mathrm{B}}^{\prime}(a)=\chi(a)=\left(\frac{4 \Omega}{\pi v(a, 1)}\right)^{1 / 3}
$$

Assim, temos que $F_{\gamma}^{\prime}$ equivale a

$$
F_{\gamma}^{\prime}(a)=2 \pi \gamma \sin \theta_{c}\left(\frac{4 \Omega}{\pi v(a, 1)}\right)^{1 / 3}
$$

Para determinar $F_{\mathrm{P}}^{\prime}$, precisamos da pressão de Laplace $P_{\mathrm{L}}^{\prime}$ no interior da ponte SA, que pode ser determinada a partir do calculo da curvatura média $H$ e utilizando a equação de Young-Laplace 
Eq. 2.3:

$$
P_{\mathrm{L}}^{\prime}=2 \gamma H=4 \gamma \frac{u(a, 1)\left(\sin \left(\theta_{\mathrm{c}}-a\right)\right)}{h\left(1-a^{2}\right)}
$$

Assim, temos que $F_{\mathrm{P}}^{\prime}$ equivale a

$$
F_{\mathrm{P}}^{\prime}(a)=4 \pi \gamma \frac{u(a, 1)\left(\sin \left(\theta_{\mathrm{c}}-a\right)\right)}{h\left(1-a^{2}\right)}\left(\frac{4 \Omega}{\pi v(a, 1)}\right)^{2 / 3}
$$

Solução assimétrica $\left(z_{0}^{\prime} \neq 0\right)$ para $\theta_{\mathrm{c}}<\pi / 2$ : Com relação à ruptura da ponte SA, a análise dos perfis $r(z)$ das pontes SA para $\theta_{\mathrm{c}}<\pi / 2$ e $\theta_{\mathrm{c}}>\pi / 2$, dados, respectivamente, pelas Eqs. 2.28 e 2.29, mostram que existem dois tipos de soluções para o perfil $r(z)$ da ponte SA: uma solução simétrica para $z_{0}^{\prime}=0$ e uma solução assimétrica para $z_{0}^{\prime} \neq 0$. De acordo com o teorema de Vogel [141, 146], somente os perfis simétricos são estáveis, e os perfis assimétricos possuem pontos de inflexão que tornam a ponte SA instável ocasionando a ruptura.

Como discutimos anteriormente, para $h<h_{\text {max,s }}$ (Eq. 2.36) existem duas soluções para $a$, tais que $a_{1}<a_{0}<a_{2}$. A análise com segunda variação [50] mostra que para $a_{1}<a_{0}$ os perfis $r(z)$ das pontes SA são sempre instáveis, e para $a_{2}=a_{\mathrm{c}}=\tan \theta_{\mathrm{c}} / 2$ existe uma bifurcação da solução de $r(z)$ gerando duas soluções assimétricas $r_{-}(z)$ e $r_{+}(z)$ em relação à altura do pescoço $\left(z_{0}^{\prime} \neq 0\right)$, tal que:

$$
r(z)= \begin{cases}r_{-}(z) & \text { para } z_{0}^{\prime}<0 \\ r_{+}(z) & \text { para } z_{0}^{\prime}>0\end{cases}
$$

Dessa forma é possível definir dois raios para as bases $R_{-}$e $R_{+}$de tal forma que $r(-h / 2)=$ $r_{-}(-h / 2)=R_{-}$e $r(h / 2)=r_{+}(h / 2)=R_{+}$, ou ainda $z\left(R_{ \pm}\right)= \pm h / 2$. Vale ressaltar que o caso $R_{-}=R_{+}=R$ corresponde ao caso anterior das soluções das pontes SA com perfis simétricos $\left(z_{0}^{\prime}=0\right)$. Assim, é possível definir as variáveis adimensionais $a=A / R_{+}$e $b=$ $B / R_{-}$, sendo que $R_{-}=A B / R_{+}$, que serão utilizadas na solução do problema das pontes assimétricas.

O parâmetro $a$ pode ser encontrando a partir de um sistema de duas equações que relacionam 
o volume $\Omega$ e a altura $h$ da ponte SA,

$$
\begin{aligned}
& u(a, 1)+u(a, a b)=\frac{2 h}{R_{+}}, \\
& v(a, 1)+v(a, a b)=\frac{\Omega}{R_{+}} .
\end{aligned}
$$

Assim, pode-se obter

$$
\tilde{\omega}(a) \equiv \frac{v(a, 1)+v(a, a b)}{[u(a, 1)+u(a, a b)]^{3}}=\frac{\Omega}{2 \pi h^{3}},
$$

que resolvida fornece as soluções da ponte SA assimétrica. A solução

$$
a=a_{\mathrm{c}}=\frac{1-\cos \theta_{\mathrm{c}}}{\sin \theta_{\mathrm{c}}}=\tan \frac{\theta_{\mathrm{c}}}{2}
$$

é o ponto que separa as soluções dos perfis $r(z)$ simétricos e assimétricos. Para $a>a_{\mathrm{c}}$ não existem pontos de inflexão no intervalo $[-h / 2, h / 2]$ de $r(z)$, e para $a<a_{\mathrm{c}}$ existem dois pontos de inflexão. Assim, é demonstrado [50] que $a_{\mathrm{c}}$ corresponde à largura do pescoço em que a ponte SA estável rompe assimetricamente, e $a_{0}$ é a largura do pescoço em que a ponte SA simétrica rompe simetricamente. Desse modo, a ponte SA é estável se $a>\max \left(a_{\mathrm{c}}, a_{0}\right)$, e a ponte SA é destruída por uma assimetria quando $a_{\mathrm{c}}>a_{0}$, e a ponte SA é destruída por uma simetria se $a_{\mathrm{c}}<a_{0}$. O ponto em que $a_{\mathrm{c}}\left(\theta_{\mathrm{c}}\right)=a_{0}\left(\theta_{\mathrm{c}}\right)$ possui uma única raiz que corresponde a $\theta_{\mathrm{c}} \approx 31^{\circ}$.

Assim, para $\theta_{\mathrm{c}}<31^{\circ}, a_{\mathrm{c}}<a_{0}$ e a ponte SA rompe devido a uma instabilidade simétrica e origina duas gotas com volumes aproximados $\Omega / 2$ aderidas às placas planas. Para $\theta_{\mathrm{c}}>31^{\circ}$, $a_{\mathrm{c}}>a_{0}$, e a ponte SA rompe devido a uma instabilidade simétrica e será originada uma única gota ou gotas com volumes diferentes aderidas a cada uma das placas. No exato ponto $\theta_{\mathrm{c}}=31^{\circ}$, $a_{\mathrm{c}}=a_{0}$, a ponte SA pode romper devido a uma instabilidade simétrica ou assimétrica. Assim, é definido um diagrama de fase $\left(h_{\max }, \theta_{c}\right)$ que define as regiões de estabilidade e instabilidade, e o mecanismo de ruptura, se será formado uma ou duas gotas aderidas às placas. Desse modo, podemos verificar também que a altura máxima acima da qual a ponte SA rompe simetricamente $h_{\text {max }, \mathrm{s}}$ para $\theta_{\mathrm{c}}<31^{\circ}$ é dada pela Eq. 2.36, e a altura máxima acima da qual a ponte SA rompe 
assimetricamente para $\theta_{\mathrm{c}}>31^{\circ}$ é dada por

$$
h_{\max , \mathrm{a}}=2 u\left(a_{\mathrm{c}}, 1\right)\left(\frac{\Omega}{2 \pi v\left(a_{\mathrm{c})}\right.}\right)^{\frac{1}{3}},
$$

e é interessante observar na Fig. 3.22 que para $\theta_{c}<31^{\circ}$ as Eqs. 2.36 e 2.46 são equivalentes.

Solução simétrica $\left(z_{0}^{\prime}=0\right)$ para $\theta_{\mathrm{c}}>\pi / 2: \quad \mathrm{O}$ mesmo formalismo apresentado para $\theta_{\mathrm{c}}<$ $\pi / 2$ é utilizado para solucionar a ponte $\mathrm{SA} \operatorname{com} \theta_{\mathrm{c}}>\pi / 2$. A Equação 2.29 pode ser reescrita de forma normalizada redefinindo as variáveis $A$ e $B$ como $a \equiv A / \chi, b \equiv B / \chi, \zeta \equiv r / \chi \in[1, b]$. Assim, obtemos

$$
u(b, \zeta) \equiv s \frac{z(r)}{\chi} \equiv \int_{\zeta}^{\mathrm{b}} \frac{\left(a b+x^{2}\right) \mathrm{d} x}{\sqrt{\left(x^{2}-a^{2}\right)\left(b^{2}-x^{2}\right)}},
$$

em que podemos definir a seguinte notação:

$$
\Lambda(b) \equiv u(b, 1)=h /(2 \chi)
$$

Desse modo, podemos obter o perfil $z(r)$ em termos de unidades normalizadas,

$$
z(r) \equiv \pm \frac{h u(b, 2 r \Lambda / h)}{\Lambda}
$$

tal que $z\left[(h /(2 \Lambda)]= \pm h / 2\right.$. Assim, podemos aplicar a condição de contorno para $\theta_{c}$ na solução da ponte SA

$$
\left.\frac{\mathrm{d} z}{\mathrm{~d} r}\right|_{ \pm h /(2 \Lambda)}= \pm \tan \theta_{\mathrm{c}}
$$

que permite expressar $a$ em termos do parâmetro adicional $b$,

$$
a(b)=\left(\frac{1-b \sin \theta_{c}}{\sin \theta_{c}-b}\right) .
$$

De maneira geral, a integral Eq. 2.47 é uma função elíptica. No caso especial $b \rightarrow 1 / \sin \theta_{c}$, $a \rightarrow 0$, a integral pode ser expressa em arcosenos, e a superfície se torna uma esfera [144]. Utilizando as Eqs. 2.30, 2.31, 2.50 e 2.48 podemos determinar a curvatura média $H$ da ponte 
SA,

$$
H=\frac{2 \Lambda\left(\sin \theta_{c}-b\right)}{h\left(1-b^{2}\right)}>0
$$

e a força de adesão capilar $F_{\text {base }, \mathrm{z}}^{\prime}=2 \pi \gamma C$,

$$
F_{\text {base }, \mathrm{z}}^{\prime}=\pi \gamma b \frac{h\left(1-b \sin \theta_{\mathrm{c}}\right)}{\Lambda\left(1-b^{2}\right)},
$$

cujo sinal pode mudar de atrativo (positivo), no caso $b>1 / \sin \theta_{\mathrm{c}}$, para repulsivo (negativo), no caso $b<1 / \sin \theta_{\text {c }}$.

A partir de uma integração por partes $\pi u^{2}(b, \zeta)-2 \pi \int_{0}^{\zeta} u(b, x) x \mathrm{~d} x=\pi \int_{0}^{\zeta} x^{2} \mathrm{~d} u$ podemos calcular o volume $\Omega$ formado pela superfície gerada pela revolução do perfil $z(r)$ da ponte SA aderida nas placas planas localizadas nas alturas $z= \pm h / 2$, e é dado por:

$$
\Omega=\frac{\pi h^{3}}{4} \omega(b)
$$

em que,

$$
\omega(b) \equiv \frac{v(b, 1)}{\Lambda^{3}}
$$

onde,

$$
v(b, \zeta) \equiv s \int_{\zeta}^{\mathrm{b}} \frac{x^{2}\left(a b+x^{2}\right) \mathrm{d} x}{\sqrt{\left(x^{2}-a^{2}\right)\left(b^{2}-x^{2}\right)}} .
$$

Portanto, o parâmetro $b$ pode ser encontrado a partir da Eq. 2.53, uma vez que $\Lambda(b), a(b)$ e $v(b, 1)$ são funções conhecidas de $b$ e são dadas, respectivamente, por Eq. 2.48, Eq. 2.50 e Eq. 2.55. Assim, a Eq. 2.53 contém somente a variável desconhecida $b$ que pode ser encontrada numericamente para os parâmetros de entrada da ponte SA $h, \Omega$ e $\theta_{c}$, e, assim, resolvemos completamente o problema de encontrar as propriedades da ponte SA. Consequentemente, podemos 
determinar o raio da base,

$$
r_{\mathrm{B}}^{\prime}=\chi(b)=h /(2 \Lambda(b))=\left(\frac{4 \Omega}{\pi v(b, 1)}\right)^{1 / 3} .
$$

A componente da tensão superficial $F_{\gamma}^{\prime}$ da $F_{\text {base,z }}^{\prime}$ pode ser obtida como,

$$
F_{\gamma}^{\prime}(b)=2 \pi \gamma \sin \theta_{c}\left(\frac{4 \Omega}{\pi v(b, 1)}\right)^{1 / 3}
$$

Para determinar $F_{\mathrm{P}}^{\prime}$, precisamos da pressão de Laplace $P_{\mathrm{L}}^{\prime}$ no interior da ponte SA, que pode ser determinada a partir do calculo da curvatura média $H$ e utilizando a equação de Young-Laplace Eq. 2.3:

$$
P_{\mathrm{L}}^{\prime}=2 \gamma H=4 \gamma \frac{u(b, 1)\left(\sin \left(\theta_{\mathrm{c}}-b\right)\right)}{h\left(1-b^{2}\right)}
$$

Assim, temos que $F_{\mathrm{P}}^{\prime}$ equivale a

$$
F_{\mathrm{P}}^{\prime}(b)=4 \pi \gamma \frac{u(b, 1)\left(\sin \left(\theta_{\mathrm{c}}-b\right)\right)}{h\left(1-b^{2}\right)}\left(\frac{4 \Omega}{\pi v(b, 1)}\right)^{2 / 3}
$$

Para determinar a energia livre da superfície $\mathcal{F}^{\prime}$, precisamos determinar a área da superfície de revolução de $z(r)$ que é dada por

$$
A_{\mathrm{R}}=2 \pi \sigma(b, 1) h^{2} / \Lambda^{2}
$$

em que,

$$
\sigma(b, \zeta) \equiv s \int_{\zeta}^{\mathrm{b}} \frac{(b+a) x^{2} \mathrm{~d} x}{\sqrt{\left(x^{2}-a^{2}\right)\left(b^{2}-x^{2}\right)}}
$$

pode ser encontrado utilizando fórmulas elementares para o cálculo de áreas de superfícies rotacionais. As expressões $u(b, \zeta) \sigma(b, \zeta) u(v, \zeta)$ podem ser expressas em termos das integrais elípticas de Legendre do primeiro tipo utilizando a mesma substituição de variáveis que fizemos 
para o caso em que $\theta_{\mathrm{c}}<\pi / 2, \phi_{\zeta}=\arcsin \sqrt{\left(b^{2}-\zeta^{2}\right) /\left(b^{2}-a^{2}\right)}$. Agora podemos obter

$$
\sigma(b, \zeta)=(b+a) b E\left(k, \phi_{\zeta}\right)
$$

onde,

$$
u(b, \zeta)=b F\left(k, \phi_{\zeta}\right)+b E\left(k, \phi_{\zeta}\right)
$$

em que $k=\sqrt{b^{2}-a^{2}} / b$. Finalmente, a partir da integração por partes podemos obter

$$
v(b, \zeta)=\left[\mathcal{R}(b, \zeta)-a^{2} b F\left(k, \phi_{\zeta}\right)+b\left[3 a b+2\left(a^{2}+b^{2}\right)\right] E\left(k, \phi_{\zeta}\right)\right] / 3
$$

em que

$$
\begin{aligned}
\mathcal{R}(b, \zeta) & =\zeta \sqrt{\left(\zeta^{2}-a^{2}\right)\left(b^{2}-\zeta^{2}\right)} \\
\mathcal{R}(b, 1) & =-\cos \theta_{\mathrm{c}}\left(1-b^{2}\right) /\left(\sin \theta_{\mathrm{c}}-b\right) \\
\mathcal{R}(b, a b) & =-a^{2} b^{2} \cos \theta_{\mathrm{c}}\left(1-b^{2}\right) /\left(\sin \theta_{\mathrm{c}}-b\right)
\end{aligned}
$$

A energia livre da superfície $\mathcal{F}^{\prime}$ pode ser obtida aplicando as Eqs. 2.60 e 2.56, sabendo que $A_{\mathrm{B}}=2 \pi \chi(b)^{2}$, na Eq. 2.12. Assim, obtemos:

$$
\mathcal{F}(b) \equiv \frac{\pi h^{2}}{2} \frac{2 \sigma(b, 1)-\cos \theta_{c}}{\Lambda^{2}}
$$

Como é realizado para as pontes $\mathrm{SA} \operatorname{com} \theta_{\mathrm{c}}<\pi / 2$, a solução da Eq. 2.53 com relação a $b$ nos permite obter todas as propriedades da ponte SA. Agora, $\omega(b)$ é uma função não monotônica de $b$ com um único mínimo no ponto $b=b_{0}\left(\theta_{c}\right)$, que pode ser encontrado como uma única raiz da equação

$$
\frac{\mathrm{d} \omega}{\mathrm{d} b}=\frac{\left(A_{0} F^{2}+2 B_{0} F E+C_{0} E^{2}+2 D_{0} F+2 E_{0} E+F_{0}\right)\left(b^{2}-1\right)}{\Lambda^{4}\left(b^{2}-2 b \sin \theta_{\mathrm{c}}+1\right)\left(b-\sin \theta_{\mathrm{c}}\right)}=0
$$


em que $A_{0}, B_{0}, C_{0}, D_{0}, E_{0}$, e $F_{0}$ são funções rotacionais de $b, \sin \theta_{\mathrm{c}}$, e $\cos \theta_{\mathrm{c}}$, e são dados por:

$$
\begin{aligned}
& A_{0}=-\frac{\sin \theta_{\mathrm{c}}\left(1-b \sin \theta_{\mathrm{c}}\right)^{2}\left[b-\cot \left(\theta_{\mathrm{c}} / 2\right)\right]\left[b-\tan \left(\theta_{\mathrm{c}} / 2\right)\right]}{\left(b-\sin \theta_{\mathrm{c}}\right)^{3}} \\
& B_{0}=\frac{\sin \theta_{\mathrm{c}}\left[1-2 b \sin \theta_{\mathrm{c}}+2 b^{2} \sin ^{2} \theta_{\mathrm{c}}-2 b^{3} \sin \theta_{\mathrm{c}}+b^{4}\right]\left[b-\cot \left(\theta_{\mathrm{c}} / 2\right)\right]\left[b-\tan \left(\theta_{\mathrm{c}} / 2\right)\right]}{\left(b-\sin \theta_{\mathrm{c}}\right)^{3}} \\
& C_{0}=-3 \frac{b^{2} \sin \theta_{\mathrm{c}}\left[b-\cot \left(\theta_{\mathrm{c}} / 2\right)\right]\left[b-\tan \left(\theta_{\mathrm{c}} / 2\right)\right]}{b-\sin \theta_{\mathrm{c}}} \\
& D_{0}=\frac{\cos \theta_{\mathrm{c}}\left(\sin \theta_{\mathrm{c}}-2 b\left(1+\sin ^{2} \theta_{\mathrm{c}}\right)+2 b^{2}\left(\sin \theta_{\mathrm{c}}+\sin ^{3} \theta_{\mathrm{c}}\right)+2 b^{3} \cos ^{2} \theta_{\mathrm{c}}-b^{4} \sin \theta_{\mathrm{c}}\right)}{2 b\left(b-\sin \theta_{\mathrm{c}}\right)^{2}} \\
& E_{0}=-\frac{\cos \theta_{\mathrm{c}} b\left(2-\sin ^{2} \theta_{\mathrm{c}}+b \sin \theta_{\mathrm{c}}-2 b^{2}\right)}{\left(b-\sin \theta_{\mathrm{c}}\right)} \\
& F_{0}=-2 \cos ^{2} \theta_{\mathrm{c}} .
\end{aligned}
$$

Realizando uma análise semelhante à feita para $\theta_{c}<\pi / 2$ [50], podemos obter a condição de estabilidade $b<b_{\mathrm{c}}=\tan \left(\theta_{\mathrm{c}}\right)$. Mas para $\theta_{\mathrm{c}}>\pi / 2, b_{0}>b_{\mathrm{c}}$, e portanto a ponte SA quebra assimetricamente para $\Omega / 2 \pi h^{3} \leq \omega\left(b_{c}\right)$. As soluções para $\Lambda\left(b_{c}\right), \sigma\left(b_{c}\right)$ e $v\left(b_{c}\right)$ coincidem com as soluções obtidas para $\theta_{c}<\pi / 2$. Assim, a altura máxima da ruptura $h_{\max , a}$ da ponte SA assimétrica $\operatorname{com} \theta_{\mathrm{c}}>\pi / 2$ é dada por,

$$
h_{\max , \mathrm{a}}=2 u\left(b_{\mathrm{c}}, 1\right)\left(\frac{\Omega}{2 \pi v\left(b_{\mathrm{c}}, 1\right)}\right)^{\frac{1}{3}}
$$

Enfatizamos que as definições de $\mathcal{H}, z_{0}^{\prime}, z_{\mathrm{B}}^{\prime}, F_{\mathrm{z} \text {,base }}^{\prime}, \mathcal{F}^{\prime}(h), P_{\mathrm{L}}^{\prime}, F_{\gamma}^{\prime}, F_{\mathrm{P}}^{\prime}, h_{\text {max }, \mathrm{s}}$ e $h_{\text {max,a }}$ serão mantidas e serão utilizadas no restante da tese.

\section{Pontes capilares com simetria translacional}

Agora, trataremos das pontes capilares com simetria translacional (pontes ST), como mostrado na Fig. 2.3(b). A curvatura média da superfície das pontes ST é dada por $H=1 /\left(2 R_{2}\right)$ já que $R_{1}=\infty$. Assim, analogamente ao caso da gota ST, a interface possui a forma de uma circunferência de raio $R_{2}$, cujo centro está localizando na posição $r_{\mathrm{c}}=r_{0}-R_{2}$, em que $r_{0}$ é a distância do "pescoço" da ponte ST ao plano de simetria que contém a origem do sistema: $r_{\mathrm{c}}=r_{0}-R_{2}$. Assim, a função que descreve o perfil $r(z)$ das pontes ST é dada por:

$$
z^{2}+\left(r-r_{\mathrm{c}}\right)^{2}=R_{2}^{2}
$$

A força de adesão capilar da ponte ST pode ser obtida, como feito para a ponte SA, a partir 
da Eq. 2.4:

$$
F_{\mathrm{z}, \mathrm{base}}=2 D \gamma \sin \theta_{\mathrm{c}}-4 \gamma H D r_{\mathrm{B}}
$$

e a força resultante no "pescoço" da ponte ST pode ser escrita como:

$$
F_{\text {z,p̧̧o }}=2 \gamma \mathcal{C}=2 \gamma D-4 \gamma H D r_{0}
$$

Como a ponte ST está em equilíbrio mecânico $F_{\mathrm{z} \text {,pço }}=F_{\mathrm{z} \text {,base }}$ é possível calcular a tensão superficial $\gamma$ a partir de um ajuste linear, de maneira similar à aquela descrita na Sec. 2.1.2.

A pressão de Laplace no interior da ponte ST pode ser determinada, como feito para a ponte SA:

$$
P_{\mathrm{L}}=\frac{2 \gamma D \sin \theta_{\mathrm{c}}-F_{\mathrm{z}, \mathrm{base}}}{2 r_{\mathrm{B}} D}
$$

$\mathrm{O}$ valor de $\theta_{\mathrm{c}}$ da ponte ST aderida a placas hidrofílicas e hidrofóbicas pode ser obtido a partir de $H$ e de $h / 2$. Assim:

$$
\theta_{\mathrm{c}}=90^{\circ}+\frac{180^{\circ}}{\pi} \arcsin \left(\frac{h / 2}{R_{2}}\right)
$$

Enfatizamos que a definição de $r_{\mathrm{c}}$ será mantida e será utilizada no restante da tese.

\subsection{Dinâmica molecular para o estudo da capilaridade}

A DM é uma técnica utilizada no cálculo das propriedades de sistemas de muitos corpos em geral no equilíbrio, e é baseada na implementação das leis da mecânica clássica para determinar a trajetória de átomos e moléculas. Utilizaremos a DM para estudar a capilaridade na escala nanométrica avaliando o comportamento das interfaces da gotas e pontes SA e ST formadas por moléculas de água do modelo SPC/E, e aderidas a superfícies de $\beta$-cristobalita com polaridade $k$. Na Seção 2.2.1 descreveremos o campo de força e a topologia das moléculas de água do modelo SPC/E e da superfície de $\beta$-cristobalita. Depois, na Sec. 2.2.2 discutiremos brevemente a implementação da DM e os principais algoritmos utilizados como o método particle-particle 
particle-mesh (PPPM), o algoritmo velocity-Verlet, o termostato de Nosé-Hoover e o algoritmo SHAKE. Na Seção 2.2.3, mostraremos o procedimento utilizado para construir as gotas e pontes SA e ST e executar as simulações.

Para executar essas simulações utilizamos o pacote LAMMPS [147], e nos Apêndices A e B mostramos um exemplo do arquivo de entrada para iniciar uma simulação de DM e de uma configuração inicial utilizada, respectivamente.

\subsubsection{Campos de força e topologia das moléculas de água e das placas de $\beta$-cristobalita}

O sistemas moleculares são governados pela mecânica quantica, e as interações são devidas às cargas elétricas. Entretanto, nessa tese trabalhamos com a interpretação clássica em que esses sistemas possuem dois tipos de interações predominantes: as interações intermoleculares entre duas ou mais moléculas, que são devido às forças de van der Waals, Coulombianas e repulsão de Pauli; e as interações intramoleculares, que são associadas às ligações químicas, como iônicas e covalentes. As interações intramoleculares não são relevantes para o estudo das gotas e pontes capilares e por isso trabalharemos com modelos em que as ligações formadas são rígidas, ou seja, não pode haver alterações nos comprimentos das ligações, dos ângulos entre as ligações e dos ângulos de torções.

Nas simulações de DM, as moléculas de água SPC/E e as placas de $\beta$-cristobalita possuem sítios de interação que são localizados na posição dos átomos, e esses descrevem como é a interação entre as moléculas e placas. Nos modelos atomísticos que trabalhamos, as interações intermoleculares serão descritas pelo potencial de Lennard-Jones $\mathcal{U}_{\mathrm{LJ}}(r)$ e de Coulomb $\mathcal{U}_{\mathrm{C}}(r)$. Assim, a energia potencial total entre dois sítios $\mu$ e $\nu$ é dada por:

$$
\begin{gathered}
\mathcal{U}\left(r_{\mu \nu}\right)=\mathcal{U}_{\mathrm{LJ}}\left(r_{\mu \nu}\right)+\mathcal{U}_{\mathrm{C}}\left(r_{\mu \nu}\right) \\
\mathcal{U}\left(r_{\mu \nu}\right)=4 \varepsilon_{\nu \mu}\left[\left(\frac{\sigma_{\nu \mu}}{r_{\nu \mu}}\right)^{12}-\left(\frac{\sigma_{\nu \mu}}{r_{\nu \mu}}\right)^{6}\right]+\frac{1}{4 \pi \varepsilon_{0}} \frac{q_{\nu} q_{\mu}}{r_{\nu \mu}},
\end{gathered}
$$

em que o primeiro, segundo e terceiro termos representam, respectivamente, a repulsão de Pauli, a interação de van der Waals e a interação de Coulomb; $\varepsilon_{\nu \mu}=\sqrt{\varepsilon_{\nu} \varepsilon_{\mu}}$ e $\sigma_{\nu \mu}=\sqrt{\sigma_{\nu} \sigma_{\mu}}$ são as 
combinações geométricas entre os parâmetros de $\mathrm{LJ}$ dos sítios, em que $\varepsilon=\varepsilon_{\nu \nu}$ é a profundidade do poço de potencial, $\sigma=\sigma_{\mu \mu}$ é a distância na qual o potencial é igual a zero, $r_{\nu \mu}=\left|\boldsymbol{r}_{\nu}-\boldsymbol{r}_{\mu}\right|$ é a distância entre dois sítios, $q_{\nu}$ e $q_{\mu}$ são as cargas de cada sítio. Desse modo, cada sítio $\mu$ pode ser caracterizado pelos parâmetros $\varepsilon_{\mu}, \sigma_{\mu}$ e $q_{\mu}$. A Figura 2.5(a) e (b) exemplifica, respectivamente, os potenciais de LJ e Coulomb entre dois sítios.

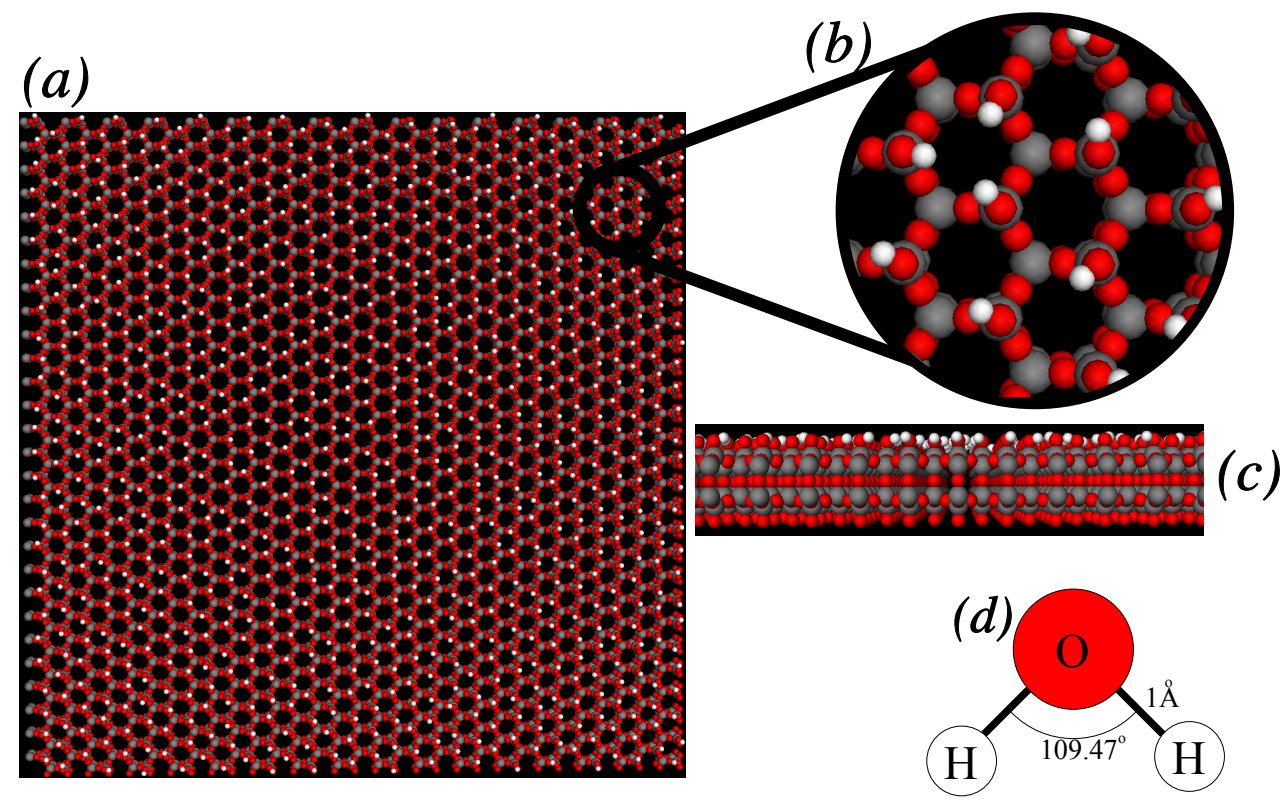

Figura 2.4: (a) Imagem superior da placa de $\beta$-cristobalita hidrofílica com lado $D=138,6 \AA$, e em (b) observa-se uma amplificação de uma pequena região dessa placa. (c) Imagem de perfil da placa de $\beta$-cristobalita hidrofílica. (d) Ilustração do modelo de molécula de água SPC/E mostrando os três sítios de interação, o ângulo H-O-H e a distância O-H que são rígidos. Pode-se observar os átomos de $\mathrm{O}$ (vermelho), Si (cinza) e H (branco).

A molécula de água SPC/E [124] consiste de uma molécula triatômica com sítios centrados em cada átomo e com ligações rígidas, como pode ser observado na Fig. 2.4(d). O tamanho das ligações O-H e o ângulo H-O-H formado entre as duas ligações são mostrados na Tab. 2.1, e cada sítio é descrito pelos parâmetros dos potenciais de $\mathrm{LJ}(\sigma, \varepsilon)$ e de Coulomb $(q)$, cujos valores são mostrados na Tab. 2.2. As Figuras 2.5 (a) e (b) mostram esses potenciais de interação entre os sítios $\mathrm{OO}, \mathrm{OH}$ e $\mathrm{HH}$ na molécula de $\mathrm{H}_{2} \mathrm{O}$ do modelo SPC/E.

As placas às quais as gotas e as pontes capilares ficam aderidas foram modeladas para serem de $\beta$-cristobalita, e podem ter sua polaridade alterada, podendo ser hidrofílicas ou hidrofóbicas. As Figuras 2.4(a)-(c) mostram ilustrações da $\beta$-cristobalita hidrofílica. Basicamente, a placa hidrofóbica é constituída de átomos de $\mathrm{O}$ e $\mathrm{Si}$, e a estrutura dessa é composta por quatro camadas 

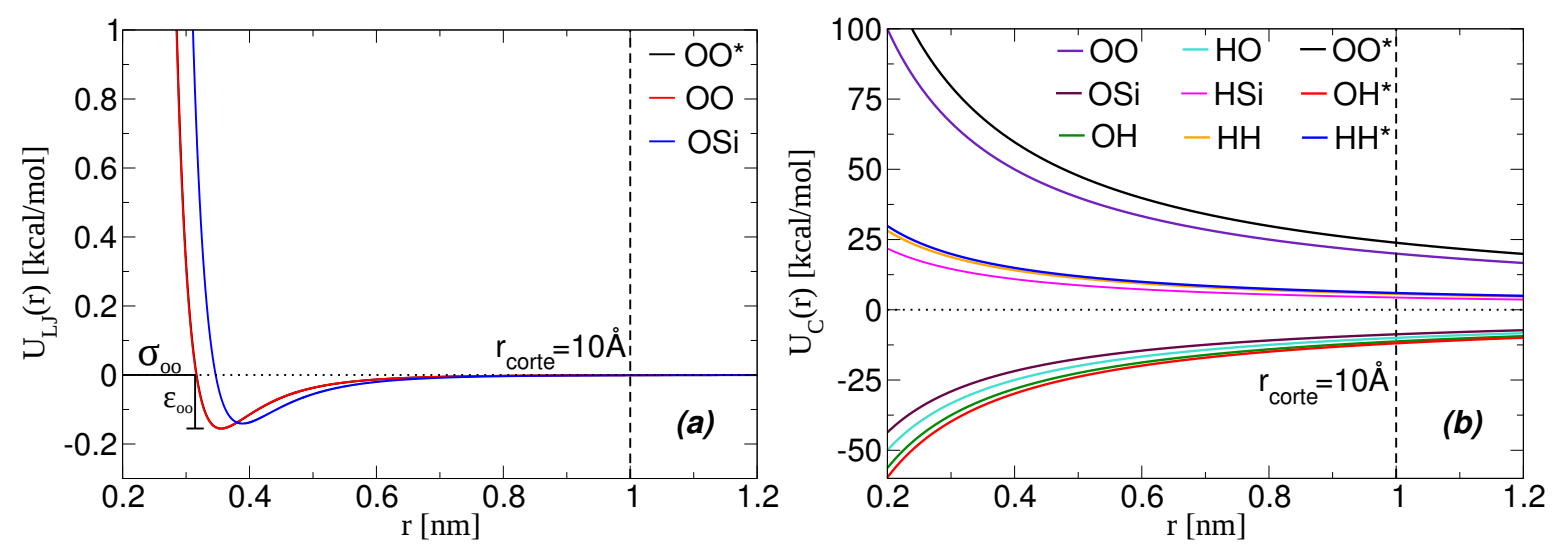

Figura 2.5: Potenciais de (a) Lennard-Jones e (b) de Coulomb entre dois sítios $\mu \nu$, em que $\mu$ e $\nu$ indicam, respectivamente, um tipo de sítio da molécula de água do modelo SPC/E $(\mathrm{O}$ e H) e da placa de $\beta$-cristobalita hidrofílica com polaridade $k=1,0(\mathrm{O}, \mathrm{Si}, \mathrm{H}) . \mathrm{O}$ simbolo * indica que a interação se dá entre dois sítios da molécula de $\mathrm{H}_{2} \mathrm{O} ; r_{\text {corte }}$ é o raio de corte do potencial de LJ e de Coulomb. Em (a), vale ressaltar que a interação entre os sítios $\mathrm{OO}^{*}$ (preto) é praticamente idêntica à interação de $\mathrm{OO}$ (vermelho), e as curvas dos potenciais estão sobrepostas

Tabela 2.1: Distâncias e ângulos formados entre os átomos $\mathrm{O}$ e $\mathrm{H}$ da molécula de água SPC/E, e dos átomos $\mathrm{O}, \mathrm{Si}$, e $\mathrm{H}$ das placas de $\beta$-cristobalita hidrofílica com polaridade $k=1,0$; para a placa hidrofóbica com polaridade $k=0$ não existe o átomo de $\mathrm{H}$ na superfície dessa. ${ }^{\dagger} \mathrm{Os}$ átomos $\mathrm{O}$ e Si pertencem à primeira camada em contato com as pontes capilares ou gotas.

\begin{tabular}{ccccc}
\hline \hline \multirow{3}{*}{ SPC/E } & \multicolumn{2}{c}{ Ligação (nm) } & \multicolumn{2}{c}{ Ângulo $\left(^{\circ}\right)$} \\
& O-H & 0,1 & H-O-H & 109,47 \\
& & & & \\
\multirow{5}{*}{$\beta$-cristobalita } & Si-O & 0,151 & & \\
& O-O & 0,247 & Si-O-H & 109,27 \\
& ${\mathrm{O}-H^{\dagger}}^{\dagger}$ & 0,1 & & \\
& $\mathrm{Si}^{\dagger} \mathrm{H}^{\dagger}$ & 0,296 & & \\
\hline \hline
\end{tabular}

de $\mathrm{SiO}_{2}$, reproduzindo a face octaédrica $(1,1,1)$ da $\beta$-cristobalita. A célula unitária $\mathrm{SiO}_{2}$ é um tetraedro, cujas distâncias interatômicas O-O e Si-O, são mostradas na Tab.2.1. A placa é ortogonal ao eixo $z$ e cobre totalmente o plano $x y$ da caixa de simulação tornando-se infinita. A placa possui lado $D=138,6 \AA$ e é composta por um total de $N_{\mathrm{O}}$ átomos de $\mathrm{O}$ e $N_{\mathrm{Si}}$ átomos de Si, como mostrados na Tab. 2.2.

As placas de $\beta$-cristobalita hidrofílicas são construídas a partir da placa hidrofóbica. Isso é feito criando-se grupos silanois na superfície da placa que ficará em contato com as gotas e pontes capilares, pela adesão de $N_{\mathrm{H}}$ átomos de hidrogênio, ver Tab.2.2. Cada átomo de H é aderido ao átomo de $\mathrm{O}$ através de uma ligação rígida, e pode rotacionar livremente em torno de 
Tabela 2.2: Parâmetros do potencial de Lennard-Jones e de Coulomb do modelo de molécula água SPC/E e das placas de $\beta$-cristobalita hidrofílica com polaridade $k=1,0$; para a placa hidrofóbica com polaridade $k=0$ não existe o átomo de $\mathrm{H}$ na superfície dessa. $q, \sigma$ e $\varepsilon$ representam, respectivamente, a carga elétrica, a distância em que o potencial é nulo e a profundidade do poço. $N_{\mathrm{i}}, \operatorname{com} i=\mathrm{O}, \mathrm{H}, \mathrm{Si}$ representa o número de átomos de cada espécie. ${ }^{\ddagger}$ Para o estudo das gotas SA grandes, as placas possuíam um número de átomos maior.

\begin{tabular}{cccccc}
\hline \hline & Átomo & $q_{0}(\mathrm{e})$ & $\sigma(\mathrm{nm})$ & $\varepsilon(\mathrm{Kcal} / \mathrm{mol})$ & $N_{\mathrm{i}}$ \\
SPC/E & $\mathrm{O}$ & $-0,8476$ & 0,3166 & 0,1553 & 1 \\
& $\mathrm{H}$ & 0,4238 & 0,0000 & 0,0000 & 2 \\
& & & & & \\
$\beta$-cristobalita & $\mathrm{O}$ & $-0,7100$ & 0,3154 & 0,1550 & $8064 / 32256^{\ddagger}$ \\
& $\mathrm{Si}$ & 0,3100 & 0,3795 & 0,1275 & $3584 / 14336^{\ddagger}$ \\
& $\mathrm{H}$ & 0,4000 & 0,0000 & 0,0000 & $896 / 3584^{\ddagger}$ \\
\hline \hline
\end{tabular}

um eixo $z$ perpendicular a esse. Para isso, as distâncias Si-H e O-H do grupo silanol são fixadas simultaneamente, e os valores dessas distâncias e o ângulo Si-O-H formado são mostrados na Tab.2.1. Os átomos $\mathrm{H}$ e $\mathrm{O}$ do grupo silanol ficam localizados em planos separados pela distância $\Delta z_{\mathrm{OH}} \approx 0,33 \AA ̊$. O grupo silanol possui cargas parciais cujos valores são $q_{0, \mathrm{Si}}, q_{0, \mathrm{O}}$, e $q_{0, \mathrm{H}}$, como mostrado na Tab. 2.2, formando um momento de dipolo $\vec{p}=\vec{p}_{\mathrm{SiO}}+\vec{p}_{\mathrm{OH}}$. Para alterar a hidrofilicidade/hidrofobicidade da placa, as cargas do grupo silanol são reescaladas por um fator $0 \leq k \leq 1$, tal que $q_{\mathrm{k}, \mathrm{i}} \rightarrow k \times q_{0, \mathrm{i}}$, onde $i=\mathrm{O}$, Si e H. Para $k>0,35(k<0,35)$ as placas são hidrofílicas (hidrofóbicas). Para $k=1(k=0)$, é obtido a placa hidrofílica (hidrofóbica) original utilizada na Ref. [99]; para $k=0$ não existe átomos de $\mathrm{H}$ na primeira camada. Todos os átomos da placa, com exceção dos átomos de $\mathrm{H}$ da primeira camada, interagem com a água por meio da interação de Lennard-Jones, e somente o grupo silanol pode interagir com a água SPC/E por meio de interação Coulombiana. Os parâmetros dessas interações são mostrados na Tab. 2.2, e as Figs. 2.5(a) e (b) mostram, respectivamente, os potenciais de LJ e Coulomb entre os sítios $\mathrm{O}$ e $\mathrm{H}$ da água com os sítios $\mathrm{O}, \mathrm{Si}$, e $\mathrm{H}$ da placa. Mais detalhes sobre a estrutura das placas podem ser encontrados nas Refs. [99, 130].

Vale ressaltar que no estudo das gotas é utilizado somente uma placa na simulação, e para as pontes capilares são utilizadas duas placas. No caso das pontes capilares, a distância entre duas placas hidrofóbicas com polaridade $k=0$ é definida como a distância entre os dois planos que possuem os átomos de $\mathrm{O}$, e no caso das demais placas com polaridade $k>0$, que possuem o grupo silanol, a distância entre essas é definida como a distância entre os dois planos que 
contém os átomos de H. Outro ponto importante, os átomos de O e Si são mantidos fixos durante a simulação para acelerar o cálculo computacional, e um trabalho da literatura mostrou que a vibração de placas de grafite causa pouca influência nas medidas do ângulo de contato de uma gota [133]. Estudamos também gotas SA com um volume maior, e para isso foi necessário utilizar uma placa maior. Essa possuía a mesma estrutura da placa descrita anteriormente, mas com lado $D=277,2 \AA$, e o total de átomos utilizados $4 \times N_{\mathrm{O}}, 4 \times N_{\mathrm{Si}}$ e $4 \times N_{\mathrm{H}}$.

\subsubsection{Algoritmo de dinâmica molecular}

Nossa simulação de DM se inicia com a criação de uma caixa cúbica de tamanho $L \times$ $L \times L$ que é ocupada pelas moléculas de $\mathrm{H}_{2} \mathrm{O}$ e por uma placa de $\beta$-cristobalita, no estudo das gotas, e duas placas no estudo das pontes capilares. Assim $\vec{r}_{\mathrm{H}_{2} \mathrm{O}}=\left\{\vec{r}_{\mathrm{O}_{\mu}}, \ldots, \vec{r}_{\mathrm{H}_{\nu}}, \ldots\right\}$ é o vetor de coordenadas de todos sítios que constituem as moléculas de $\mathrm{H}_{2} \mathrm{O}$, contendo $N$ átomos de $\mathrm{O}$ e $2 N$ átomos de $\mathrm{H}$, em que $N$ é o número de moléculas de água; $\vec{r}_{\text {placa, } 1}=$ $\left\{\vec{r}_{\mathrm{O}_{\mu}}, \ldots, \vec{r}_{\mathrm{Si}_{\nu}}, \ldots, \vec{r}_{\mathrm{H}_{\eta}}, \ldots\right\}$, é o vetor de coordenadas de todos os sítios da placa superior $(i=1)$ contendo $N_{\mathrm{O}}$ átomos de $\mathrm{O}, N_{\mathrm{Si}}$ átomos de $\mathrm{Si}, N_{\mathrm{H}}$ átomos de $\mathrm{H} ; \vec{r}_{\mathrm{placa}, 2}$ são as coordenadas dos sítios da placa inferior $(i=2)$, que esta localizada a uma distância $h$ da placa superior. Além disso, no inicio da simulação também são atribuídas velocidades aleatórias a cada um dos sítios das moléculas de água $\dot{\vec{r}}_{\mathrm{H}_{2} \mathrm{O}}$ de modo que o momento total do sistema seja nulo. Aos sítios das placas são atribuídas velocidades $\dot{\vec{r}}_{\text {placa, } 1}$ e $\dot{\vec{r}}_{\text {placa, } 2}$ de tal forma que $\dot{\vec{r}}_{\mathrm{O}_{\mu}}=\dot{\vec{r}}_{\mathrm{Si}_{\nu}}=\overrightarrow{0}$, e $\dot{\vec{r}}_{\mathrm{H}_{\eta}} \cdot \hat{k}=0$, e assim somente os átomos de $\mathrm{H}$ podem se mover. Vale ressaltar que para as placas de $\beta$-cristobalita hidrofóbica com polaridade $k=0$ não possui átomos de $\mathrm{H}$ aderidos.

O passo seguinte na simulação de DM é determinar a força resultante em cada sítio devido a todos os sítios vizinhos, dadas posições iniciais $\vec{r}_{\mathrm{H}_{2} \mathrm{O}}, \vec{r}_{\text {placa, } 1}$ e $\vec{r}_{\text {placa, } 2 \text {. Para isso, devemos }}$ calcular inicialmente a energia potencial total do sistema $\mathcal{U}_{\text {tot }}$. Para o caso de uma gota sobre uma placa temos:

$$
\mathcal{U}_{\text {tot }}\left(\vec{r}_{\mathrm{H}_{2} \mathrm{O}}, \vec{r}_{\text {placa }, 2}\right)=\sum_{\mu=1}^{3 \mathrm{~N}} \sum_{\nu>\mu}^{3 \mathrm{~N}} \mathcal{U}\left(r_{\mu \nu}\right)+\sum_{\mu=1}^{3 \mathrm{~N}} \sum_{\nu=1}^{\mathrm{N}_{\mathrm{O}}+\mathrm{N}_{\mathrm{Si}}+\mathrm{N}_{\mathrm{H}}} \mathcal{U}\left(r_{\mu \nu}\right) .
$$

Analogamente, a energia potencial total de uma ponte capilar aderida a duas placas pode ser 
escrita como:

$$
\mathcal{U}_{\text {tot }}\left(\vec{r}_{\mathrm{H}_{2} \mathrm{O}}, \vec{r}_{\text {placa }, 1}, \vec{r}_{\text {placa }, 2}\right)=\sum_{\mu=1}^{3 \mathrm{~N}} \sum_{\nu>\mu}^{3 \mathrm{~N}} \mathcal{U}\left(r_{\mu \nu}\right)+\sum_{\mu=1}^{3 \mathrm{~N}} \sum_{\nu=1}^{2 \mathrm{~N}_{\mathrm{O}}+2 \mathrm{~N}_{\mathrm{Si}}+2 \mathrm{~N}_{\mathrm{H}}} \mathcal{U}\left(r_{\mu \nu}\right)
$$

Nota-se que a interação entre as placas superior e inferior não foram consideradas uma vez que essas permanecem imoveis durante as simulações. Desse modo, podemos escrever a força resultante sobre um dado sítio $\mu$ pertencente a uma gota como:

$$
\vec{f}_{\mu}=\frac{\partial}{\partial \vec{r}_{\mu}} \mathcal{U}_{\text {tot }}\left(\vec{r}_{\mathrm{H}_{2} \mathrm{O}}, \vec{r}_{\text {placa }, 2}\right)
$$

e para uma ponte capilar,

$$
\vec{f}_{\mu}=\frac{\partial}{\partial \vec{r}_{\mu}} \mathcal{U}_{\text {tot }}\left(\vec{r}_{\mathrm{H}_{2} \mathrm{O}}, \vec{r}_{\text {placa }, 1}, \vec{r}_{\text {placa }, 2}\right)
$$

em que $\vec{r}_{\mu}$ é o vetor de posição de cada sítio associado aos átomos $\mathrm{O}, \mathrm{H}$ e Si pertencentes às moléculas de água ou à placa de $\beta$-cristobalita. O cálculo da força entre todos os pares de sítios $\nu$ e $\mu$ é a parte mais custosa computacionalmente. Para lidar com esse problema, a

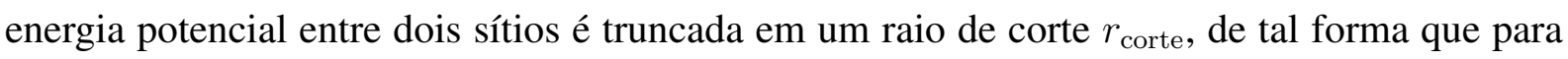
$r_{\nu \mu}>r_{\text {corte }} \rightarrow \mathcal{U}\left(r_{\mu \nu}\right)=0$. A Figura 2.5 (a) e (b) mostra que o termo $r_{\mu \nu}^{-6}$ do potencial de LJ decai rapidamente para próximo de zero, enquanto que o potencial de Coulomb não. Esse truncamento causa um erro numérico no cálculo das propriedades do sistema, e por isso o potencial de longo alcance deve ser corrigidos por outros métodos.

Método PPPM: Existe uma série de métodos desenvolvidos para corrigir esse erro de truncamento, e escolhemos utilizar o método particle-particle particle-mesh (PPPM) [148] para corrigir a interação Coulombiana. Esse é um método hibrido baseado nos métodos particleparticle (PP) e particle-mesh (PM). O método PP se baseia no cálculo da força de curto alcance $\vec{f}_{\mathrm{pp}}\left(r_{\mu \nu}\right)$ entre todos pares de sítios $\mu$ e $\nu$ que estão localizados até a distância de $r_{\text {corte. No }}$ método PM a força é calculada para os sítios que estão distantes a mais de $r_{\text {corte. Então, para }}$ calcular essas forças de longo alcance $\vec{f}_{\mathrm{pm}}\left(r_{\mu \nu}\right)$ é realizada uma aproximação em que cria-se 
uma malha em 3D à qual são atribuídas as cargas elétricas de cada molécula de $\mathrm{H}_{2} \mathrm{O}$ e dos grupos $\mathrm{SiOH}$ das placas de $\beta$-cristobalita. Então, a equação de Poisson é resolvida por meio da transformada rápida de Fourier, determinando-se assim o potencial Coulombiano e as forças na malha. Em seguida, as forças $\vec{f}_{\mathrm{pm}}\left(r_{\mu \nu}\right)$ no sítio $\mu$ são determinadas por uma interpolação das forças na malha. Assim, no método PPPM a força total $\vec{f}_{\mu}$ no sítio $\mu$ pode ser aproximada como $\vec{f}_{\mu} \approx \sum \vec{f}_{\mathrm{pp}}\left(r_{\mu \nu}\right)+\sum \vec{f}_{\mathrm{pm}}\left(r_{\mu \nu}\right)$. No programa LAMMPS [147], o parâmetro de acurácia do método PPPM determina o erro relativo da raiz quadrada da média dos quadrados das forças calculadas para cada átomo [149], e é definido como um número adimensional, relativo à força exercida entre duas cargas pontuais separadas pela distância de $1 \AA$.

Algoritmo de velocity-Verlet: Após determinada as forças $\vec{f}_{\mu}$, a trajetória de cada sítio é determinada utilizando o algoritmo de velocity-Verlet, que é uma variante do alrgorítmo de Verlet explicado a seguir.

Seja $\vec{r}_{\mu}(t+\delta t)$ a posição do sítio $\mu$ no instante $t+\delta t$, e $\vec{r}_{\mu}(t-\delta t)$ a posição do sítio $\mu$ no instante $t-\delta t$, em que $\delta t$ é o tamanho do passo de integração. A expansão em Taylor da trajetória de um sítio no instante $t+\delta t$ é dada por,

$$
\vec{r}_{\mu}(t+\delta t)=\vec{r}_{\mu}(t)+\dot{\vec{r}}_{\mu}(t) \delta t+\frac{\vec{f}_{\mu}(t)}{2 m} \delta t^{2}+\frac{\delta t^{3}}{3 !} \dddot{\vec{r}}_{\mu}+\mathcal{O}\left(\delta t^{4}\right)
$$

e no instante anterior $t-\delta t$ é dada por,

$$
\vec{r}_{\mu}(t-\delta t)=\vec{r}_{\mu}(t)-\dot{\vec{r}}_{\mu}(t) \delta t+\frac{\vec{f}_{\mu}(t)}{2 m} \delta t^{2}-\frac{\delta t^{3}}{3 !} \dddot{\vec{r}}_{\mu}+\mathcal{O}\left(\delta t^{4}\right)
$$

Somando as Eqs. 2.80 e 2.81, obtém-se:

$$
\vec{r}_{\mu}(t+\delta t) \approx 2 \vec{r}_{\mu}(t)-\vec{r}_{\mu}(t-\delta t)+\frac{\vec{f}_{\mu}(t)}{2 m} \delta t^{2}
$$

em que os erros da integração são estimados da ordem de $\mathcal{O}\left(\delta t^{4}\right)$. Observa-se que na Eq. 2.82 a velocidade do sítio $\mu$ no instante $t$ não é utilizada na integração da equação de movimento, e 
essa pode ser determinada simplesmente por:

$$
\dot{\vec{r}}_{\mu}(t)=\frac{\vec{r}_{\mu}(t+\delta t)-\vec{r}_{\mu}(t-\delta t)}{2 \delta t}+\mathcal{O}\left(\delta t^{2}\right)
$$

em que os erros da integração são estimados da ordem de $\mathcal{O}\left(\delta t^{2}\right)$.

No algoritmo velocity-Verlet, as velocidades são atualizadas de acordo com:

$$
\dot{\vec{r}}_{\mu}(t+\delta t)=\dot{\vec{r}}_{\mu}(t)+\frac{\vec{f}_{\mu}(t+\delta t)+\vec{f}_{\mu}(t)}{2 m} \delta t
$$

Neste método, as novas velocidades são calculadas após a determinação das forças em cada sítio $\mu$ no novo tempo $t+\delta t$. Pode-se observar também que as velocidades e as posições dos sítios são determinados ao mesmo tempo.

Termostato de Nosé-Hoover: Os algoritmos para executar as simulações de DM mostrados até então produzem configurações no ensemble microcanônico em quem a energia, o volume e o número de moléculas permanecem constantes. Entretanto, nosso problema é melhor representado pelo ensemble canônico, em que a temperatura, volume e o número de moléculas são constantes. Para que nosso espectro de configurações pertença ao ensemble canônico, devemos utilizar um algoritmo que controle a velocidade das moléculas, a assim manter a temperatura constante. Para isso, utilizamos o termostato de Nosé-Hoover [150]. Esse método se baseia no uso de uma Lagrangiana estendida, em que é introduzida artificialmente uma coordenada $s$ que faz com que o banho térmico seja uma parte integrante do sistema. Assim, a Lagrangiana estendida pode pode ser escrita como:

$$
\begin{array}{r}
\mathcal{L}\left(\vec{r}_{\mathrm{H}_{2} \mathrm{O}}, \dot{\vec{r}}_{\mathrm{H}_{2} \mathrm{O}}, \vec{r}_{\text {placa }, 1}, \dot{\vec{r}}_{\text {placa }, 1}, \vec{r}_{\text {placa }, 2}, \dot{\vec{r}}_{\text {placa }, 2}, s, \dot{s}\right)= \\
\sum_{\mathrm{i}=1}^{3 \mathrm{~N}+\mathrm{N}_{\mathrm{H}}} \frac{m_{\mathrm{i}}}{2} s^{2} \dot{\vec{r}}_{\mu}^{2}-\mathcal{U}_{\text {tot }}\left(\vec{r}_{\mathrm{H}_{2} \mathrm{O}}, \vec{r}_{\text {placa }, 1}, \vec{r}_{\text {placa }, 2}\right)+\frac{Q}{2} \dot{s}^{2}-k_{\mathrm{B}} T G \ln s
\end{array}
$$

em que os dois primeiros termos representam a energia cinética e potencial dos sítios das moléculas de $\mathrm{H}_{2} \mathrm{O}$ e dos átomos de $\mathrm{H}$ do grupo silanol das placas, os dois últimos são a energia cinética e potencial do banho térmico; $Q$ está associado à massa fictícia do banho térmico, 
com o acoplamento do banho com o sistema e com a flutuação da temperatura no sistema; $G$ é o número de graus de liberdade. De modo simplificado, a coordenada $s$ reescala as demais variáveis do sistema de modo a manter constante a temperatura. No pacote LAMMPS, o termostato de Nosé-Hoover é implementado com as equações de movimento de Newton descritas na abordagem de Shinoda et al. [151].

Algoritmo SHAKE: Uma vez determinadas as forças em cada sítio $\mu$, essas devem ser corrigidas antes da determinação da posição no instante $t+\delta t$ para que sejam mantidos constantes o comprimento das ligações e os ângulos. Esse procedimento é realizado por meio do algoritmo SHAKE. Em nosso caso, devem ser inseridos vínculos aos átomos de $\mathrm{O}$ e $\mathrm{H}$ das moléculas de água e do grupo silanol das placas para que o comprimento da ligação seja constante. Mais especificamente, os vínculos são implementados nas posições dos sítios $\vec{r}_{\mathrm{O}}$ e $\vec{r}_{\mathrm{H}}$ de uma mesma molécula de $\mathrm{H}_{2} \mathrm{O}$, tal que $\left(\vec{r}_{\mathrm{O}}(t+\delta t)-\vec{r}_{\mathrm{H}}(t+\delta t)\right) \cdot\left(\vec{r}_{\mathrm{O}}(t+\delta t)-\vec{r}_{\mathrm{H}}(t+\delta t)\right)=\left(\vec{r}_{\mathrm{O}}(t)-\vec{r}_{\mathrm{H}}(t)\right)$. $\left(\vec{r}_{\mathrm{O}}(t)-\vec{r}_{\mathrm{H}}(t)\right)=1 \AA$ e na velocidade $\left(\dot{\vec{r}}_{\mathrm{O}}(t+\delta t)-\dot{\vec{r}}_{\mathrm{H}}(t+\delta t)\right) \cdot\left(\vec{r}_{\mathrm{O}}(t+\delta t)-\vec{r}_{\mathrm{H}}(t+\delta t)\right)=0$. Essa correção é feita através de um processo iterativo, e assim as forças são corrigidas para manter o tamanho das ligações e os ângulos constantes. Mais detalhes sobre esse e os demais métodos discutidos anteriormente podem ser encontrados nas Refs. [148, 152-154].

Enfatizamos que as definições de $k, L, \vec{r}_{\text {placa, }, 1}, \vec{r}_{\text {placa, }, 2}, \vec{r}_{\mathrm{H}_{2} \mathrm{O}}, \vec{r}_{O_{\mu}}, N, \delta t, t, r_{\text {corte }}$ e $\vec{f}_{\mu}$ serão mantidas e serão utilizadas no restante da tese.

\subsubsection{Procedimento da execução das simulações}

Como descrito anteriormente, nossas simulações das gotas e pontes capilares foram realizadas em uma caixa de simulação cúbica de lado $L=140 \AA$ e com condição periódica em todas as direções. A temperatura adotada para todas simulações foi de $T=300 \mathrm{~K}$ e o passo de integração utilizado foi $\delta t=1,0$ fs. O raio de corte adotado foi de $r_{\text {corte }}=10 \AA$ e a acurácia utilizada no método PPPM foi de $1 \times 10^{-5}$. Nós utilizamos dois termostatos, um para as moléculas de água e outro para os átomos de $\mathrm{H}$ aderidos às placas de $\beta$-cristobalita.

Para estudar as gotas SA pequenas e pontes SA foram utilizadas $N=3375$ moléculas de $\mathrm{H}_{2} \mathrm{O}$ e no estudo das gotas ST e pontes ST $N=9897$; no estudo das gotas SA grandes utilizamos $N=6750$. As gotas SAp e SAg, e pontes SA são simétricas com relação a uma 
rotação no eixo $z$, que é perpendicular às placas; as gotas e pontes ST são simétricas com relação ao plano $z x$. As gotas e pontes ST foram utilizadas para remover qualquer efeito da tensão de linha, que pode ter um papel relevante para gotas e pontes SA na escala nanométrica [133, 155].
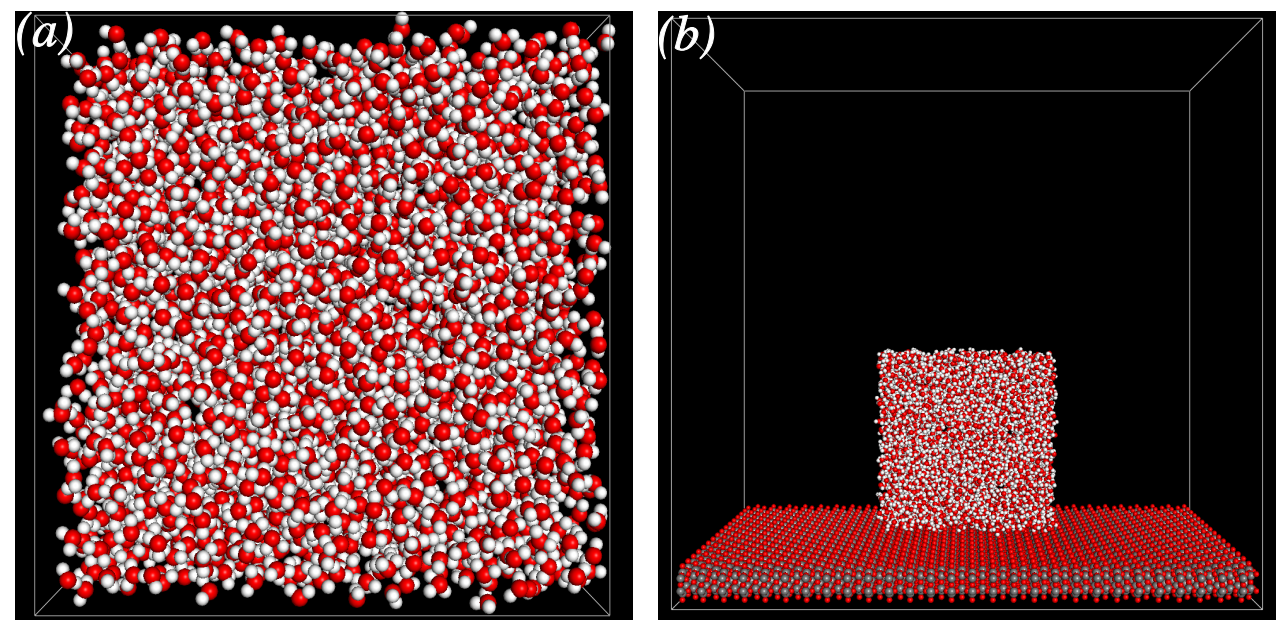

Figura 2.6: (a) Configuração em equilíbrio da simulação de bulk de água com densidade $\rho=1 \mathrm{~g} / \mathrm{cm}^{3}$ e $T=300 \mathrm{~K}$. (b) Imagem da configuração mostrada em (a) colocada sobre a placa de $\beta$-cristobalita hidrofóbica com polaridade $k=0$ para criar uma configuração inicial da simulação da gota SA.

As configurações iniciais das gotas SAp, SAg e ST, e das pontes SA e ST foram construídas a partir de simulações independentes de bulk de água com densidade $\rho=1 \mathrm{~g} / \mathrm{cm}^{3}$ e $T=$ $300 \mathrm{~K}$, como mostrado na Fig. 2.6(a), cuja configuração inicial as moléculas de água foram dispostas em uma rede cristalina ortorrômbica. Então, uma configuração do bulk de água em equilíbrio foi colocada sobre a superfície da placa de $\beta$-cristobalita para criar as configurações iniciais das gotas SAp, SAg e ST, como mostrado na Fig. 2.6(b) para a criação de uma gota SA. Analogamente, a configuração em equilíbrio do bulk foi colocada entre duas placas de $\beta$-cristobalita, separadas por uma distância de $h=50 \AA$, para gerar as configurações iniciais das pontes SA e ST. Em todos os casos, foi empregada uma segunda termalização para que as moléculas de água entrassem em equilíbrio com as placas formando o ângulo de contato $\theta_{\mathrm{c}}$ desejado. Observamos que a configuração inicial não é relevante, pois são necessários somente alguns picossegundos para as moléculas de água adquirirem o formato das gotas SA e ST, e pontes SA e ST. Então, foram executados um tempo de simulação $\Delta t_{\text {sim }}$ no qual foi possível gerar as configurações das moléculas de água para estudarmos as propriedades desses sistemas.

Com relação ao estudo da primeira etapa, na qual estudamos as gotas SA e ST, e as pontes 
SA e ST, em que a altura dessas permaneceu constante, foram executados $\Delta t_{\text {sim }}=5 \mathrm{~ns}$ para cada uma das placas e somente os últimos 2 ns foram utilizados para a análise de dados, sendo que a cada 1 ps era impressa uma configuração. Nos estudos com as pontes SA e ST, a força exercida sobre as placas foi medida durante a simulação no final de cada 1 ps. A força na placa $\vec{F}_{\text {placa,i }}$, em que $i=1,2$ designam a placa superior e inferior pode ser escrita como:

$$
\vec{F}_{\text {placa }, \mathrm{i}}=\sum_{\mu \in \text { placa }, \mathrm{i}} \vec{f}_{\mu}
$$

que é basicamente a soma das forças de Coulomb e LJ, entre os sítios das moléculas de água e os sítios das placas de $\beta$-cristobalita, calculadas pelo método PPPM aplicadas em cada um dos sítios $\mu$ pertencentes às placas superior $(i=1)$ e inferior $(i=2)$. Vale ressaltar que para $k=0$, $N_{\mathrm{H}}=0$.

Na segunda etapa focamos nas pontes SA e exploramos o comportamento dessa quando a altura $h$ era aumentada progressivamente por um deslocamento induzido nas placas na direção $\hat{k}$. Cada deslocamento corresponde a alterar $h$ para $h^{\prime}=h+5 \AA$, em que $h^{\prime}$ é a nova altura da ponte SA. Para isso, durante a integração das equações de movimento do sistema, as placas são movidas lentamente a cada $1 \mathrm{fs}$, por $250 \mathrm{fs}: \vec{r}_{\text {placa }, 1} \rightarrow \vec{r}_{\text {placa }, 1}+0,01 \hat{k} \AA$ e $\vec{r}_{\text {placa }, 2} \rightarrow \vec{r}_{\text {placa }, 2}-$ $0,01 \hat{k} \AA$. Isso é feito para evitar a ruptura prematura da ponte SA durante a movimentação $h \rightarrow$ $h^{\prime}=h+5 \AA$. Para o primeiro deslocamento $h=55 \AA$ executamos $\Delta t_{\text {sim }}=5 \mathrm{~ns}$ e utilizamos somente os 2 ns finais para a análise. Durante a simulação, as configurações das moléculas de água $\vec{r}_{\mathrm{H}_{2} \mathrm{O}}$ e as forças exercidas sobre as placas $\vec{F}_{\text {placa,i }}$ eram salvas a cada 1 ps, como feito na primeira etapa. Para os demais deslocamentos das placas $h=60,65, \ldots \AA$ executamos $\Delta t_{\text {sim }}=3 \mathrm{~ns}$, e as placas foram movidas até ocorrer a ruptura da ponte SA. Vale resaltar que para $h=50 \AA$ utilizamos os dados da primeira etapa. A taxa $\Delta h / \Delta t_{\text {sim }}$ com que a altura da ponte SA era alterada foi lenta o suficiente para que esse processo possa ser considerado quaseestático. Utilizando esse procedimento, identificamos todas as alturas $h_{\mathrm{S}}$ em que a ponte SA é estável e a altura crítica $h_{\mathrm{C}^{\prime}} \equiv h_{\mathrm{S}}+5 \AA$ em que a ruptura da ponte SA acontece. Se a distância entre as placas for aumentada mais lentamente, é de se esperar que a ruptura ocorra em uma altura menor que $h_{\mathrm{C}^{\prime}}$. Assim, executamos uma simulação adicional para obter uma segunda 
estimativa da altura crítica de ruptura $h_{\mathrm{C}}$. Especificamente, para obter $h_{\mathrm{C}}$ executamos uma nova simulação de tal forma que $h=h_{S}+2,5 \AA$. Se a ponte SA não romper em $\Delta t_{\text {sim }}=20 \mathrm{ns,}$ as placas são movidas novamente para $h=\left(h_{S}+2,5\right)+1,25 \AA$ e a simulação é executada até a ponte SA se romper.

$\mathrm{Na}$ terceira etapa estudamos as flutuações que existem na escala nanométrica, como observamos na segunda etapa. Para isso, estudamos gotas livres, que não estão aderidas a placas, e gotas SA, ambas constituídas de $N=2575$ moléculas de água. A gota SA estava aderida a uma placa hidrofóbica com polaridade $k=0$. Para os dois casos, executamos $\Delta t_{\text {sim }}=20 \mathrm{~ns}$ e com as configurações geradas $\vec{r}_{\mathrm{H}_{2} \mathrm{O}}$ calculamos os expoentes de Hurst da série temporal do movimento do CM. Para efeito de comparação, estudamos esses sistemas com modelo gás de rede, utilizando $N$ partículas de líquido. As gotas SA foram aderidas a superfícies planas que reproduzem o mesmo ângulo de contato das placas de $\beta$-cristobalita com polaridade $k=0$.

Enfatizamos que as definições de $T, \rho, \Delta t_{\text {sim }}, \vec{F}_{\text {placa, },}, h_{\mathrm{C}^{\prime}}, h_{\mathrm{C}}$ e $h_{\mathrm{S}}$ serão mantidas e serão utilizadas no restante da tese.

\subsection{Perfil de gotas e pontes capilares obtidas das simulações}
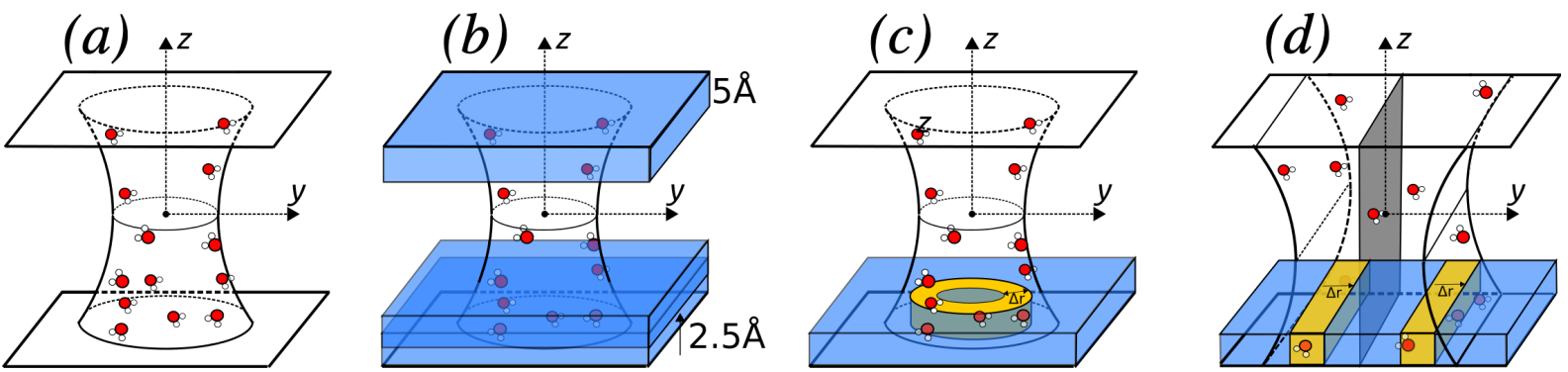

Figura 2.7: Ilustrações mostrando a contagem das moléculas de água de uma configuração obtida da dinâmica molecular para o cálculo do perfil das pontes SA e ST. (a) Sistema de coordenadas, cuja origem está localizada no CM da ponte SA. (b) Caixas de dimensão $L \times L \times 5 \AA^{3}$ e separadas de $2,5 \AA$ preenchendo o espaço entre as placas de $\beta$-cristobalita. Divisão das caixas (c) em anéis de raios internos $r$ e externos $r+\Delta r$, com $\Delta r=0,5 \AA$ para a ponte SA; e (d) em paralelepípedos com tamanho $\Delta r \times \Delta r \times L \AA^{3}$ com os lados separados de $r$ e $r+\Delta r$ em relação ao plano de simetria $z x$, para a ponte ST.

Para cada configuração de moléculas de $\mathrm{H}_{2} \mathrm{O}$ gerada pela simulação de DM das gotas SAp, SAg e ST, e pontes SA e ST define-se um eixo $z$ que é perpendicular às placas e passa através do centro de massa CM do sistema, como ilustrado na Fig. 2.7(a) para a ponte SA. Tivemos que tomar um cuidado com o cálculo do CM para tempos de simulação muito longos das gotas 
e pontes SA. Para as configurações $\vec{r}_{\mathrm{H}_{2} \mathrm{O}}$ geradas, calculamos as projeções do $\mathrm{CM} \overrightarrow{C M}=$ $\frac{1}{N} \sum_{\mathrm{i}}^{\mathrm{N}} \vec{r}_{\mathrm{i}}$ na coordenada $z$ e no plano $x y$, em que $\vec{r}_{\mathrm{O}_{\mu}}$ é a posição do sítio, e $N$ é o número total de moléculas. A condição periódica de contorno é um problema para o cálculo do CM, pois para tempos longos, as gotas e pontes SA podem estar localizadas nas bordas e a posição dos átomos/moléculas dessas devem ser corrigidas. Para corrigir esse problema, seguimos o procedimento descrito a seguir. Primeiro, calculamos $\overrightarrow{C M^{\prime}}$ das gotas e pontes SA, e deslocamos cada molécula de $-\overrightarrow{C M^{\prime}}$ para colocar as gotas no centro da caixa de simulação. Durante esse processo, a seguinte condição é aplicada às coordenadas $x, y \mathrm{e} z$ da molécula $i$ :

$$
x_{\mathrm{i}}=\left\{\begin{array}{ccc}
x_{\mathrm{i}}-C M_{\mathrm{i}}^{\prime} & \text { if } & 0<\left(x_{\mathrm{i}}-C M_{\mathrm{i}}{ }^{\prime}\right)<L \\
x_{\mathrm{i}}-C M_{\mathrm{i}}^{\prime}+L & \text { if } & \left(x_{\mathrm{i}}-C M_{\mathrm{i}}{ }^{\prime}\right)<L \\
x_{\mathrm{i}}-C M_{\mathrm{i}}^{\prime}-L & \text { if } & \left(x_{\mathrm{i}}-C M_{\mathrm{i}}{ }^{\prime}\right)>L
\end{array}\right.
$$

Então, todas as moléculas são movidas para sua posição original, agora desconsiderando a condição periódica de contorno, somando $\overrightarrow{C M^{\prime}}$ à posição dessas. Finalmente, calculamos novamente o CM, e obtemos o valor correto de $\overrightarrow{C M}$. Deve-se enfatizar que esse método á valido se somente algumas moléculas atravessam a borda da caixa de simulação.

Uma vez determinado o $\mathrm{CM}$, ao longo do eixo $z$, são criadas caixas no formato de paralelepípedos, paralelas às placas hidrofílicas/hidrofóbicas, de dimensões $L \times L \times 5 \AA^{3}$. O centro dessas caixas são separados de $2,5 \AA$ de tal forma que as caixas possam se sobrepor, como ilustrado na Fig. 2.7(b) para a ponte SA.

Para as gotas e pontes SA, cada caixa foi dividida em anéis de raios internos $r$ e externos $r+\Delta r$, com $\Delta r=0,5 \AA$, e o número de átomos de $\mathrm{O}$ da molécula de $\mathrm{H}_{2} \mathrm{O}$ foi contabilizado dentro de cada anel, ver Fig. 2.7(c) para o caso da ponte SA. Para as gotas e pontes ST foi definido um plano de simetria $z x$ passando pelo centro de massa desses, e cada uma das caixas foi dividida em outros paralelepípedos com tamanho $\Delta r \times \Delta r \times L \AA^{3}$, sendo o comprimento $L$ e com lados separados de $r$ e $r+\Delta r$ do plano $z x$, ver Fig. 2.7(d) para o caso da ponte ST. Então, contabilizando todas as posições do átomo de $\mathrm{O}$ das configurações geradas no tempo de simulação $\Delta t_{\text {sim }}$, a densidade média para cada caixa $\rho_{\mathrm{c}}(r)$ foi calculada como uma função da distância radial $r$ do eixo $z$. Desse modo, foi possível obter os perfis das gotas e pontes 
capilares das simulações $r_{\mathrm{p}}(z)$ a partir de $\rho_{\mathrm{c}}(r)$, utilizando uma densidade de corte $\rho_{\mathrm{c}}(r)=$ $\rho_{0}=0,2 \mathrm{~g} / \mathrm{cm}^{3}$ separando a fase líquida da fase de vapor [130].

As pontes SA e ST são simétricas com relação ao "pescoço", $z_{0}=0$. Por isso, o perfil foi calculado como a média do perfil entre $r_{\mathrm{p}}(z)$ para $z>0$ e $z<0$ e reportado somente o valor para $0 \leq z \leq h / 2$.

Enfatizamos que as definições de $\rho_{\mathrm{c}}(r), \rho_{0}$ e $r_{\mathrm{p}}(z)$ serão mantidas e serão utilizadas no restante da tese.

\subsection{Cálculo do perfil teórico das gotas e pontes capilares}

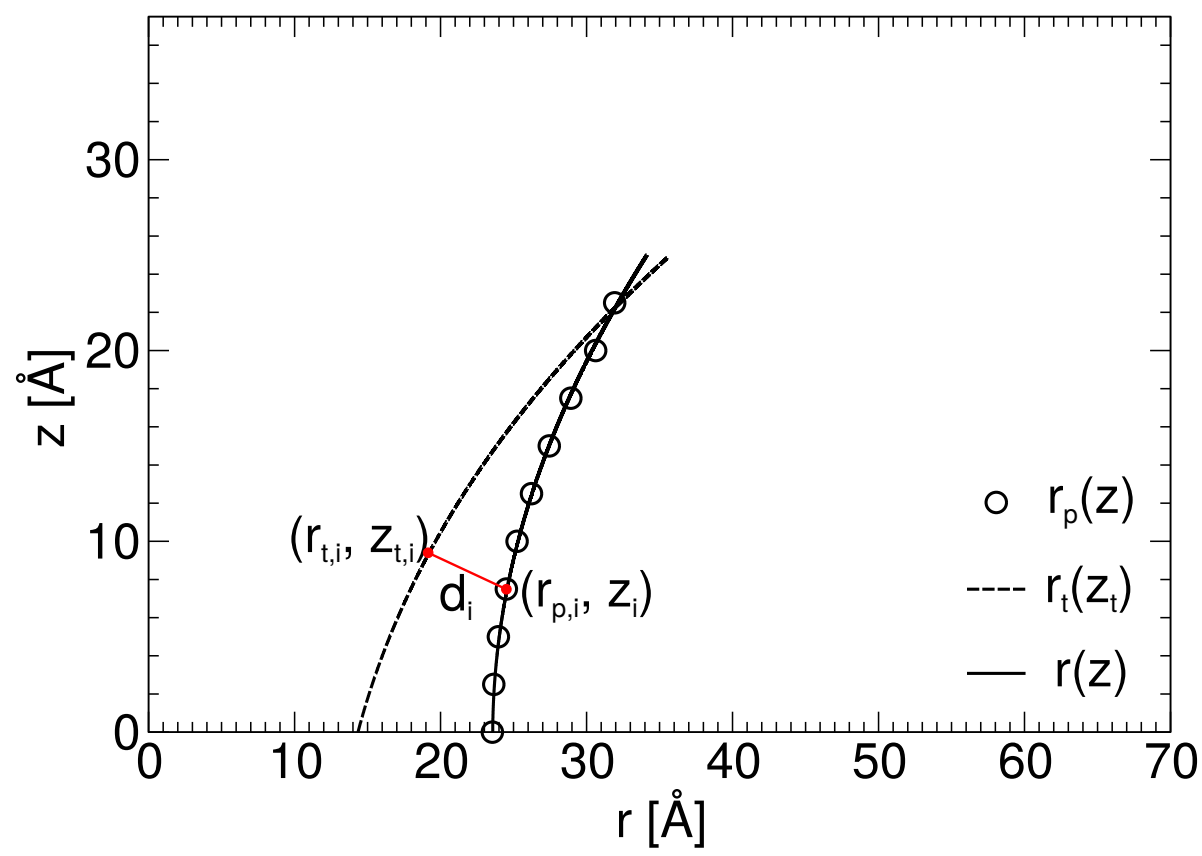

Figura 2.8: Ajuste do perfil teórico $r(z)$ da ponte SA (linha contínua) obtido da teoria capilar macroscópica ao perfil $r_{\mathrm{p}}(z)$ (círculos) obtido da simulação de DM; $r_{\mathrm{t}}\left(z_{\mathrm{t}}\right)$ (linha tracejada) é o perfil teste de ajuste obtido com os parâmetros de teste $r_{0, \mathrm{t}}$ e $R_{2, \mathrm{t}} ; d_{\mathrm{i}}$ é a distância entre dois pontos $\left(r_{\mathrm{t}, \mathrm{i}}, z_{\mathrm{t}, \mathrm{i}}\right)$ e $\left(r_{\mathrm{p}, \mathrm{i}}\right.$, $\left.z_{\mathrm{i}}\right): d_{\mathrm{i}}=\sqrt{\left(r_{\mathrm{i}, \mathrm{t}}-r_{\mathrm{p}, \mathrm{i}}\right)^{2}+\left(z_{\mathrm{t}, \mathrm{i}}-z_{\mathrm{i}}\right)^{2}}$.

As equações analíticas da TC $r(z)$ que descrevem os perfis das gotas SA e ST, Eq. 2.8, das pontes SA, Eq. 2.19, e das pontes ST, Eq.2.70, foram utilizadas para descrever os perfis $r_{\mathrm{p}}(z)$ obtidos a partir das simulações de DM. Para isso, foi necessário encontrar os parâmetros $\left(R, z_{\mathrm{c}}\right)$ para as gotas SA e ST, $\left(H\left(r_{0}, R_{2}\right), r_{0}\right)$ para as pontes SA e $\left(R, r_{\mathrm{c}}\right)$ para as pontes ST que melhor descrevem $r_{\mathrm{p}}(z)$. Assim, empregamos o seguinte procedimento do ajuste, que é ilustrado na Fig. 2.8 para a ponte SA: 
(i) A partir dos perfis $r_{\mathrm{p}}(z)$ foram determinados intervalos numéricos referentes a cada conjunto de parâmetros de ajuste $\left(R, z_{\mathrm{c}}\right),\left(H\left(r_{0}, R_{2}\right), r_{0}\right)$ e $\left(R, r_{\mathrm{c}}\right)$ para criar um perfil teste $r_{\mathrm{t}}\left(z_{\mathrm{t}}\right): R_{\min }<R_{\mathrm{t}}<R_{\max }, r_{0, \min }<r_{0, \mathrm{t}}<r_{0, \max }, R_{2, \min }<R_{2, \mathrm{t}}<R_{2, \max }$, $z_{c, \min }<z_{\mathrm{c}, \mathrm{t}}<z_{\mathrm{c}, \max }$ e $r_{\mathrm{c}, \min }<r_{\mathrm{c}, \mathrm{t}}<r_{\mathrm{c}, \max }$;

(ii) Para cada ponto $\left(r_{\mathrm{p}, \mathrm{i}}, z_{\mathrm{i}}\right)$ de $r_{\mathrm{p}}(z)$ foi calculada uma reta que intercepta $r_{\mathrm{t}}\left(z_{\mathrm{t}}\right)$ em um ponto $\left(r_{\mathrm{t}, \mathrm{i}}, z_{\mathrm{t}, \mathrm{i}}\right)$ formando um ângulo reto, e a distância entre esses dois pontos $d_{\mathrm{i}}$ foi determinada: $d_{\mathrm{i}}=\sqrt{\left(r_{\mathrm{t}, \mathrm{i}}-r_{\mathrm{p}, \mathrm{i}}\right)^{2}+\left(z_{\mathrm{t}, \mathrm{i}}-z_{\mathrm{i}}\right)^{2}}$;

(iii) Então é calculado o erro $\epsilon$ entre $r_{\mathrm{t}}\left(z_{\mathrm{t}}\right)$ e $r_{\mathrm{p}}(z)$ :

$$
\epsilon=\sqrt{\frac{1}{N_{\mathrm{p}}} \sum_{i=1}^{\mathrm{N}_{\mathrm{p}}} d_{\mathrm{i}}^{2}} ;
$$

em que $N_{\mathrm{p}}$ é o número de pontos de $r_{\mathrm{p}}(z)$.

(iv) Os parâmetros $R_{\mathrm{t}}, r_{0, \mathrm{t}}, R_{2, \mathrm{t}}, z_{\mathrm{c}, \mathrm{t}} \mathrm{e} r_{\mathrm{c}, \mathrm{t}}$ são alterados de $0,1 \AA$.

Então, os passos (ii), (iii) e (iv) são repetidos até varrer todos os intervalos estabelecidos em (i). De todas as funções $r_{\mathrm{t}}\left(z_{\mathrm{t}}\right)$ geradas, aquela que possuir o menor valor de $\epsilon$ será utilizada como a equação analítica da TC $r(z)$ que descreve $r_{\mathrm{p}}(z)$.

Posteriormente à determinação de $r(z)$, foi possível calcular as áreas das interfaces líquidosólido $A_{\mathrm{B}}$ e líquido-gás $A_{\mathrm{R}}$, e o volume $\Omega$ das pontes $\mathrm{SA}$. A área $A_{\mathrm{B}}$ é calculada simplesmente como:

$$
A_{\mathrm{B}}=2 \pi r_{\mathrm{N}_{\mathrm{p}}-1}^{2},
$$

em que $N_{\mathrm{p}}$ é o número de pontos $\left(r_{\mathrm{i}}, z_{\mathrm{i}}\right)$ que constituem o perfil $r(z)$, e o fator 2 advém da ponte SA estar aderida a duas placas planas. A área $A_{\mathrm{R}}$ e o volume $\Omega$ foram calculados implementando-se o método do trapézio para a integração numérica. A área de uma superfície de revolução $A_{\mathrm{i}}$ e o volume $\Omega_{\mathrm{i}}$ entre dois pontos consecutivos $\left(r_{\mathrm{i}}, z_{\mathrm{i}}\right)$ e $\left(r_{\mathrm{i}+1}, z_{\mathrm{i}+1}\right)$ de $r(z)$ pode ser calculada aproximando-se a função $r(z)$ entre esses dois pontos por uma reta $u(z)=g z+l$, 
em que $g$ e $l$ são, respectivamente, os coeficientes angular e linear dessa. Assim, utilizando a Eq. 2.14 podemos escrever $A_{\mathrm{R}}$ como:

$$
\begin{gathered}
A_{\mathrm{i}}=\int_{\mathrm{z}_{\mathrm{i}}}^{\mathrm{z}_{\mathrm{i}+1}} 2 \pi r(z) \sqrt{r^{\prime}(z)^{2}+1} \mathrm{~d} z \\
A_{\mathrm{i}} \approx \pi \sqrt{g^{2}+1}\left[g\left(z_{\mathrm{i}+1}^{2}-z_{\mathrm{i}}^{2}\right)+2 l\left(z_{\mathrm{i}+1}-z_{\mathrm{i}}\right)\right] . \\
A_{\mathrm{R}}=\sum_{\mathrm{i}=0}^{\mathrm{i}=\mathrm{N}_{\mathrm{p}}-1} A_{\mathrm{i}}
\end{gathered}
$$

Analogamente, podemos calcular o volume $\Omega$ como:

$$
\begin{gathered}
\Omega_{\mathrm{i}}=\int_{\mathrm{z}_{\mathrm{i}}}^{\mathrm{z}_{\mathrm{i}+1}} \pi r(z)^{2} \mathrm{~d} z \approx \int_{\mathrm{z}_{\mathrm{i}}}^{\mathrm{z}_{\mathrm{i}+1}} \pi(g z+l)^{2} \mathrm{~d} z \\
\Omega_{\mathrm{i}} \approx \pi\left(\frac{g^{2}}{3}\left[z_{\mathrm{i}+1}^{3}-z_{\mathrm{i}}^{3}\right]+g l\left[z_{\mathrm{i}+1}^{2}-z_{\mathrm{i}}^{2}\right]+l^{2}\left[z_{\mathrm{i}+1}-z_{\mathrm{i}}\right]\right), \\
\Omega=\sum_{\mathrm{i}=0}^{\mathrm{i}=\mathrm{N}_{\mathrm{p}}-1} \Omega_{\mathrm{i}}
\end{gathered}
$$

em que os coeficientes $g$ e $l$ de cada interpolação podem ser calculados como:

$$
g=\frac{\left(r_{\mathrm{i}+1}-r_{\mathrm{i}}\right)}{\left(z_{\mathrm{i}+1}-z_{\mathrm{i}}\right)}, \quad l=\frac{\left(r_{\mathrm{i}} z_{\mathrm{i}+1}-r_{\mathrm{i}+1} z_{\mathrm{i}}\right)}{\left(z_{\mathrm{i}+1}-z_{\mathrm{i}}\right)}
$$

Enfatizamos que as definições de $R_{\mathrm{t}}, r_{0, \mathrm{t}}, R_{2, \mathrm{t}}, z_{\mathrm{c}, \mathrm{t}}$ e $r_{\mathrm{c}, \mathrm{t}}$ serão mantidas e serão utilizadas no restante da tese. 


\subsection{Cálculo da tensão superficial utilizando o método Kirkwood-Buff (KB)}

Para checar a consistência das medidas que foram realizadas da tensão superficial por meio das Eq. 2.22 e Eq. 2.72, foi utilizado o método Kirkwood-Buff (KB) [156]. Nesse método, é utilizada uma caixa de simulação de dimensões $L_{\mathrm{x}} \times L_{\mathrm{y}} \times L_{\mathrm{z}}$ tal que $L_{\mathrm{y}}<L_{\mathrm{z}}$ e $L_{\mathrm{x}}=L_{\mathrm{y}}$, como ilustrado na Fig. 2.9. No centro dessa caixa é colocada uma configuração de moléculas de $\mathrm{H}_{2} \mathrm{O}$, que foi a mesma configuração

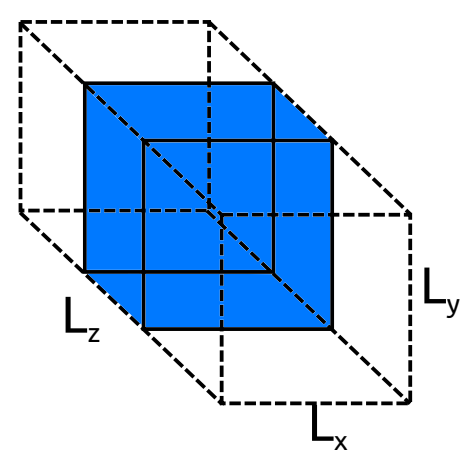

Figura 2.9: Caixa de simulação com dimensões $L_{\mathrm{x}} \times L_{\mathrm{y}} \times L_{\mathrm{z}}$. ortorrômbica inicial utilizada para formar as gotas SA, como descrito anteriormente. Nessas simulações foram formadas duas interfaces líquido-vapor, e por meio da medida das componentes perpendiculares $P_{\perp}$ e paralelas $P_{\|}$do tensor de estresse será possível medir a tensão superficial $\gamma$, dada por:

$$
\gamma=L_{\mathrm{z}}\left\langle 2 P_{\mathrm{zz}}-P_{\mathrm{xx}}-P_{\mathrm{yy}}\right\rangle / 4
$$

onde $P_{\mathrm{xx}}$ e $P_{\mathrm{yy}}$ são as componentes paralelas e $P_{\mathrm{zz}}$ é a componente perpendicular do tensor de estresse.

Enfatizamos que as definições de $L_{\mathrm{x}}, L_{\mathrm{y}}, L_{\mathrm{z}}, P_{\mathrm{xx}}, P_{\mathrm{yy}}$ e $P_{\mathrm{zz}}$ serão mantidas e serão utilizadas no restante da tese.

\subsection{Modelo gás de rede para o estudo de interfaces}

Nosso modelo gás de rede foi desenvolvido para o estudo de interfaces formadas por pontes capilares e gotas é baseado no modelo clássico de gás de rede, com a diferença de que as partículas dos sítios da rede possuem interações de primeiro, segundo e terceiros vizinhos [50, 52, 157]. Cada uma dessas partículas do modelo representa uma porção do meio líquido, ou do meio sólido, ou do meio gasoso que formam a interface. A energia desse modelo é dada pelo hamiltoniano:

$$
\mathcal{H}_{\mathrm{GR}}=\frac{J}{2} \sum_{1}^{V} E_{\mu}
$$


sendo:

$$
E_{\mu}=\sum_{\nu=1}^{26} J_{\mathrm{i}(\mu) \mathrm{j}(\nu)}
$$

em que $J$ é a unidade de energia, $E_{\mu}$ é o hamiltoniano do sítio $\mu$ da rede, $J_{\mathrm{ij}}$ é a constante de acoplamento entre as partículas $(i, j)=s, l, g$, em que $s, l$ e $g$ representam, respectivamente, partículas de sólido, líquido e gás, que ocupam os sítios $\nu$ e $\mu$. Os valores das contantes de acoplamento utilizadas podem ser encontrados nas Tabs.2.3, 2.4 e 2.5 mostradas a seguir.

Tabela 2.3: Constantes de acoplamento $J_{\mathrm{i}(\mu) \mathrm{j}(\nu)}$ entre as partículas na distância 1 .

\begin{tabular}{|c|c|c|c|}
\hline & gás & líquido & sólido \\
\hline gás & $J_{g g}=0$ & $J_{g l}=-0,02$ & $J_{g s}=-0,032$ \\
\hline líquido & $J_{g l}=J_{l g}$ & $J_{l l}=-1,00$ & $J_{l s}=-1,45$ \\
\hline sólido & $J_{g s}=J_{s g}$ & $J_{l s}=J_{s l}$ & \\
\hline
\end{tabular}

Tabela 2.4: Constantes de acoplamento $J_{\mathrm{i}(\mu) \mathrm{j}(\nu)}$ entre as partículas na distância $\sqrt{2}$.

\begin{tabular}{|c|c|c|c|}
\hline & gás & líquido & sólido \\
\hline gás & $J_{g g}=0$ & $J_{g l}=0$ & $J_{g s}=0$ \\
\hline líquido & $J_{g l}=J_{l g}$ & $J_{l l}=-0,7$ & $J_{l s}=-0,7$ \\
\hline sólido & $J_{g s}=J_{s g}$ & $J_{l s}=J_{s l}$ & \\
\hline
\end{tabular}

Tabela 2.5: Constantes de acoplamento $J_{\mathrm{i}(\mu) \mathrm{j}(\nu)}$ entre as partículas na distância $\sqrt{3}$.

\begin{tabular}{|c|c|c|c|}
\hline & gás & líquido & sólido \\
\hline gás & $J_{g g}=0$ & $J_{g l}=0$ & $J_{g s}=0$ \\
\hline líquido & $J_{g l}=J_{l g}$ & $J_{l l}=-0,4$ & $J_{l s}=0$ \\
\hline sólido & $J_{g s}=J_{s g}$ & $J_{l s}=J_{s l}$ & \\
\hline
\end{tabular}

As pontes capilares e as gotas são caracterizadas pelos ângulos de contato $\theta_{c}$, que são determinados pelos ajustes das constantes de acoplamento $J_{\mathrm{ls}}$. Foram utilizados quatro ângulos de contato, cujos valores de $J_{\text {ls }}$ são mostrados na Tab. 2.6. Observa-se, portanto, que as constantes $J_{\mathrm{ij}}$ não possuem outro significado a não ser criar uma força de coesão para manter as partículas agrupadas e alterar os valores de $\theta_{\mathrm{c}}$. 
Tabela 2.6: Constantes de acoplamento $J_{\text {ls }}$ para reproduzir os ângulos de contato $\theta_{\mathrm{c}}=39^{\circ}, 51^{\circ}, 66^{\circ} \mathrm{e}$ $74^{\mathrm{o}}$.

\begin{tabular}{|c|c|c|c|}
\hline & 1 & $\sqrt{2}$ & $\sqrt{3}$ \\
\hline$\theta_{c}=39^{\circ}$ & $J_{l s}=-1,55$ & $J_{l s}=-0,775$ & $J_{l s}=0$ \\
\hline$\theta_{c}=51^{\circ}$ & $J_{l s}=-1,4$ & $J_{l s}=-0,7$ & $J_{l s}=0$ \\
\hline$\theta_{c}=66^{\circ}$ & $J_{l s}=-1,2$ & $J_{l s}=-0,6$ & $J_{l s}=0$ \\
\hline$\theta_{c}=74^{\circ}$ & $J_{l s}=-0,9$ & $J_{l s}=-0,6$ & $J_{l s}=0$ \\
\hline
\end{tabular}

Nosso modelo é implementado com o método MC com algoritmo de Metropolis [158, 159]. No programa são realizadas trocas de partículas de líquido por partículas de gás com a dinâmica de Kawasaki [160], que mantém a densidade constante durante a simulação, e as trocas são ponderadas pelo fator de Boltzmann. Vale ressaltar não existe troca entre partículas iguais para fins de desempenho computacional. Além disso, as partículas de sólido são mantidas fixas durante cada ciclo de MC para manter invariável a geometria à qual a ponte capilar ou gota fica aderida.

Para cada cada ciclo de MC que se conclui, calculamos o valor médio de $\mathcal{H}_{\mathrm{GR}}$ e também medimos as propriedades de todos os clusters. As propriedades dos clusters são medidas com um algoritmo forest-fire, que identifica todos os clusters formados. O maior cluster formado é aquele que constitui a gota ou a ponte capilar, e, então, determinamos todas as demais propriedades desse, como a área total da interface líquido-sólido, a área total da interface líquido-gás, o volume, a energia interna $\mathcal{H}_{\mathrm{c}}$, o perfil $r_{\mathrm{MC}}(z)$ e o CM. Calculamos o perfil aproximado $r_{\mathrm{MC}}(z)$ da ponte capilar a partir da área $A_{\mathrm{sec}}(z)$ na altura $z$ de uma seção transversal formadas de líquidos: $r_{\mathrm{MC}}(z)=\sqrt{A_{\mathrm{sec}}(z)} / \pi$. A Figura 2.10(a) exemplifica esse cálculo. Podemos também determinar a força de adesão capilar na altura $h / 2$ do modelo gás de rede $F_{\text {base,gr }}$, assumindo que a energia interna do maior cluster é igual à energia livre. Assim:

$$
F_{\text {base }, \mathrm{gr}}(h / 2)=\frac{\Delta \mathcal{H}_{\mathrm{c}}}{\Delta h}=\frac{\left\langle\mathcal{H}_{\mathrm{c}, \mathrm{h}+1}\right\rangle-\left\langle\mathcal{H}_{\mathrm{c}, \mathrm{h}}\right\rangle}{1}
$$

em que $\left\langle\mathcal{H}_{\mathrm{c}, \mathrm{h}+1}\right\rangle$ e $\left\langle\mathcal{H}_{\mathrm{c}, \mathrm{h}}\right\rangle$ são as médias das energias do maior cluster nas alturas $h+1 \mathrm{e} h$, respectivamente.

Estudamos duas situações com o modelo gás de rede que exemplificam as aplicações dis- 

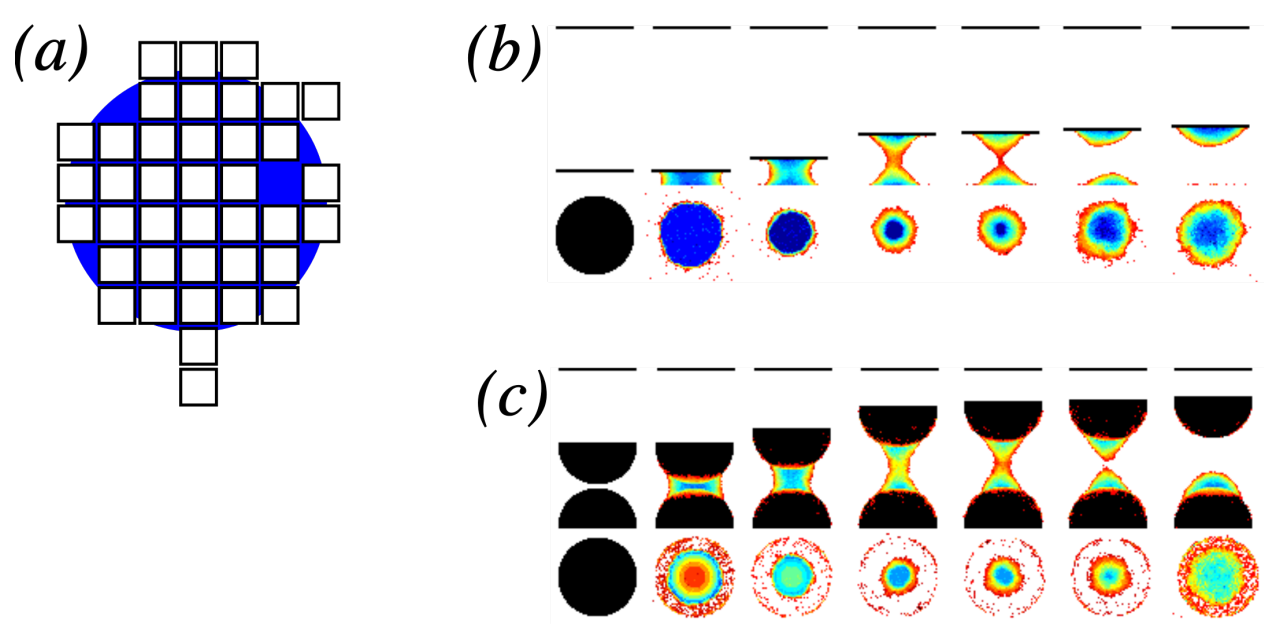

Figura 2.10: (a) Ilustração de como é realizado o cálculo do perfil $r_{\mathrm{MC}}(z)$ a partir da área da seção transversal $A_{\mathrm{sec}}(z)$ na altura $z$ da ponte capilar: $r_{\mathrm{MC}}(z)=\sqrt{A_{\mathrm{sec}}(z)} / \pi$. Processo de rompimento da ponte capilar aderida a duas geometrias diferentes: (b) duas placas planas como realizado no trabalho inicial [50,52]; e (c) dois hemisférios, simulando o que ocorre no processo de sinterização. Em (b) e (c) as pontes capilares são esticadas até romperem nas proximidades da altura $h_{\max }$. $\mathrm{O}$ gradiente de cor do azul para o vermelho indica densidade de partículas de líquido: azul representa muitas partículas e vermelho poucas.

cutidas no Cap. 1. No primeiro caso, ver Fig. 2.10(b), estudamos uma ponte SA aderida a duas placas planas, como será realizado para as simulações com DM, e no segundo caso, a ponte SA foi aderida a dois hemisférios que simulam um material granular, como pode ser verificado na Fig. 2.10(c). Observa-se nas Figs. 2.10(b) e (c) que à medida que a distância $h$ entre as geometrias é alterada, a ponte capilar é esticada até ocorrer a ruptura da ponte SA.

Para estudar a ponte SA em diferentes alturas $h$ podemos utilizar dois procedimentos: no primeiro, a ponte SA já pode estar no inicio da simulação na altura desejada, e então é efetuada uma etapa de termalização para depois poder medir as propriedades do sistema; no segundo, a altura pode ser alterada gradualmente, em que a ponte SA é cortada na região de menor raio a configuração é copiada de um sítio no sentido de deslocamento das geometrias, e depois o excesso de partículas de líquido é removido do sistema.

Enfatizamos que as definições de $J_{\mathrm{ls}}, \mathcal{H}_{\mathrm{gr}}, \mathcal{H}_{\mathrm{c}}, r_{\mathrm{MC}}(z)$ e $F_{\text {base,GR }}$ serão mantidas e serão utilizadas no restante da tese.

\subsection{Cálculo do expoente de Hurst}

$\mathrm{Na}$ terceira etapa estudamos a série temporal gerada pelas posições do CM das configurações $\vec{r}_{\mathrm{H}_{2} \mathrm{O}}$ das gotas para longos tempos de simulação, e para analisar essas séries fizemos o 


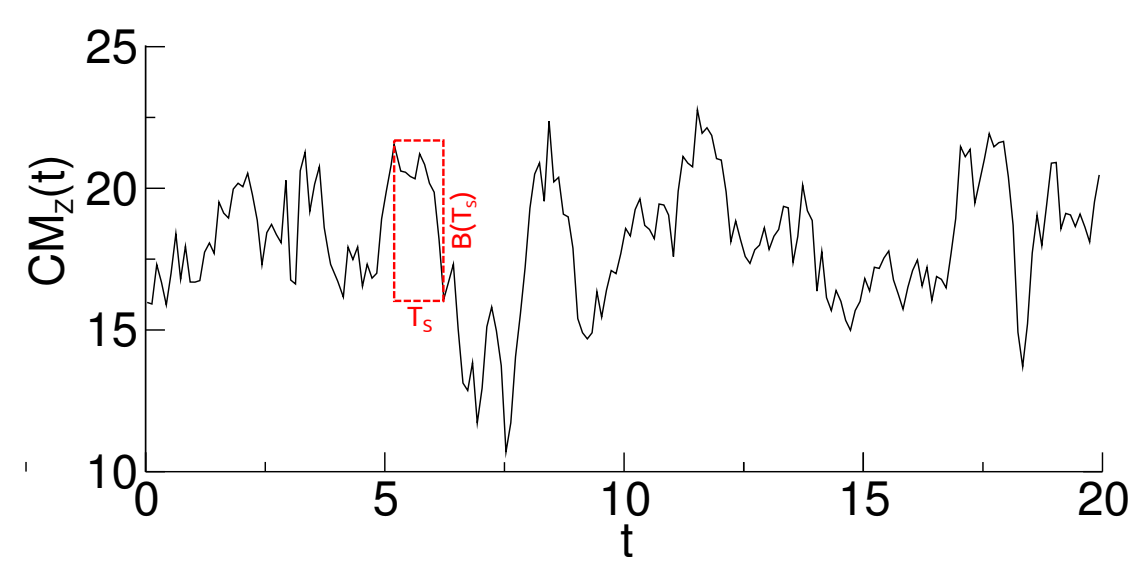

Figura 2.11: Ilustração mostrando o cálculo do expoente de Hurst de uma série temporal da posição do CM na coordenada $z$. Pode-se observar a janela temporal $T_{\mathrm{S}}$ e a diferença entre dois pontos $B\left(T_{\mathrm{S}}\right)$.

cálculo do expoente de Hurst. O expoente de Hurst é calculado a partir dos deslocamentos do $\mathrm{CM}$ das gotas na coordenada $z$ e no plano $x y$. Para uma janela temporal de tamanho $T_{\mathrm{S}}$, medimos a média do quadrado da distância absoluta entre dois pontos $B\left(T_{\mathrm{S}}\right)$, considerando toda a série temporal. Como exemplo, a Fig. 2.11 mostra a flutuação do centro de massa na coordenada $z$ e as grandezas $T_{\mathrm{S}}$ e $B\left(T_{\mathrm{S}}\right)$. A partir da relação de escala entre $\left\langle B\left(T_{\mathrm{S}}\right)^{2}\right\rangle$ e $T_{\mathrm{S}}$, podemos calcular o expoente de Hurst como:

$$
\left\langle B\left(T_{\mathrm{S}}\right)^{2}\right\rangle \propto T_{\mathrm{S}}^{2 \lambda}
$$

em que $\lambda$ é o expoente de Hurst $[161,162]$. O valor de $\lambda$ é obtido a partir da regressão linear da Eq. 2.96 em um gráfico com escalas logarítmicas. No caso de $\lambda=1 / 2$, o movimento é aleatório, também conhecido como Browniano; para $\lambda<1 / 2$ o movimento é anti-persistente, e nesse caso o trassado da flutuação possui a tendência de repetir valores anteriores; para $\lambda>1 / 2$ o movimento é persistente, e nesse caso o trassado da flutuação possui a tendencia de prosseguir no trajeto de seu comportamento anterior; para $\lambda=0$, o movimento é confinado não possuindo nenhuma tendência ao longo do tempo. Os movimentos persistentes e anti-persistentes possuem memória, que caracteriza o comportamento não aleatório.

Enfatizamos que as definições de $\lambda, B$ e $T_{\mathrm{S}}$ serão mantidas e serão utilizadas no restante da tese. 


\section{Capítulo 3}

\section{Resultados e Discussões}

Apresentaremos nesse capitulo os resultados e paralelamente as discussões sobre a capilaridade na escala nanométrica, em que gotas e pontes capilares, aderidas a placas de $\beta$-cristobalita com diferentes polaridade $k$, foram simuladas com DM e as propriedades dessas foram comparadas com as previsões da TC macroscópica.

Na Seção 3.1, apresentaremos os resultados da primeira etapa sobre o estudo das gotas SAp, SAg e ST, e as pontes SA e ST com altura constante. Os perfis dessas interfaces foram obtidos pelas configurações geradas nas simulações de DM, e então foram comparados com os perfis analíticos determinados pela TC, o que permitiu calcular todas as propriedades desses sistemas. As forças que as pontes SA e ST exercem sobre as placas também foram medidas, e essa possibilitou calcular a tensão superficial da água do modelo SPC/E, a força de adesão capilar e a pressão de Laplace no interior dessas interfaces. O trabalho concluído nessa etapa resultou na publicação de um artigo na revista The Journal of Physical Chemistry C [163].

Na Seção 3.2, passaremos para os resultados da segunda etapa, em que focamos no estudo da ponte SA com diferentes alturas. O diagrama de fase $\left(h_{\max }, \theta_{\mathrm{c}}\right)$ foi explorado até altura superiores a $h_{\max }\left(\theta_{\mathrm{c}}\right)$, que separa a região de estabilidade e instabilidade das pontes SA. Para a região de estabilidade, efetuamos os mesmos procedimentos descritos na primeira etapa. Depois, exploramos a região de instabilidade, e analisamos o mecanismo de ruptura da ponte SA para os diferentes valores de $\theta_{c}$. $O$ trabalho apresentado nessa etapa esta em processo de revisão e submissão para a revista The Journal of Physical Chemistry $C$.

Na Seção 3.3 mostraremos os resultados da terceira etapa, em que a série temporal gerada 
pela flutuação do centro de massa $(\mathrm{CM})$ de gotas livres, que não estão aderidas a placas, e gotas SA foram analisadas calculando-se o expoente de Hurst. Esse trabalho foi apresentado como resumo expandido na conferência 6th International Conference on Nonlinear Science and Complexity.

Finalmente, na Sec. 3.4 serão mostrados outros estudos que complementam os trabalhos discutidos anteriormente.

As discussões serão realizadas à medida que os resultados forem apresentados.

\subsection{Estudo das gotas SA e ST, e pontes SA e ST com altura constante}

Nesse primeira etapa apresentaremos os resultados e discussões sobre os fundamentos da TC na escala nanométrica com o estudo das gotas SAp, SAg e ST, e pontes SA e ST com $h=50,0 \AA$ aderidas às placas de $\beta$-cristobalita com polaridades $0 \leq k \leq 0,65$. Na Seção 3.1.1, mostraremos um exemplo do cálculo do perfil $r_{\mathrm{p}}(z)$ de uma gota SA a partir das funções de densidade $\rho_{\mathrm{c}}(r)$, que foram geradas com as médias das configurações $\vec{r}_{\mathrm{H}_{2} \mathrm{O}}$. Em seguida, mostraremos os perfis $r_{\mathrm{p}}(z)$ das gotas e pontes capilares com os respectivos perfis analíticos $r(z)$ obtidos da TC. O cálculo de $r(z)$ permitiu calcular o ângulo de contato $\theta_{\mathrm{c}}$ de todas as interfaces líquido-gás, assim como determinar as demais propriedades geométricas como o raio da gota $R$ e a distância do centro da gota à origem do sistema de coordenadas $z_{\mathrm{c}}$, e o raio do "pescoço" $r_{0}$, raios de curvatura $R_{1}$ e $R_{2}$, e a curvatura média $H$ das pontes capilares.

Na Seção 3.1.2, analisaremos as forças $\vec{F}_{\text {placa,i }}$ que as pontes SA e ST exercem sobre as placas superior e inferior de $\beta$-cristobalita com polaridade $k$. Assumindo que $\vec{F}_{\text {placa,i }}$ possuam o mesmo significado que a força de adesão capilar $F_{z, \text { base }}$, e utilizando os resultados obtidos dos ajustes $r(z)$ foi possível calcular a tensão superficial $\gamma$ da água do modelo SPC/E, a força de adesão capilar $F_{z \text {,base }}$ e a pressão de Laplace $P_{\mathrm{L}}$ no interior dessas interfaces. Depois, a consistência desse cálculo de $\gamma$ foi testada utilizando o método KB.

\subsubsection{Comparação dos perfis gerados pela simulação de DM com os obtidos analitica- mente pela TC macroscópica}

Primeiramente mostramos as configurações geradas pela simulação de DM do último instante de tempo 5 ns para cada uma das interfaces estudadas, como mostrado na Fig. 3.1(a) para 
a gota SA, Fig. 3.1(b) para a gota ST, Fig. 3.1(c) para a ponte SA e Fig. 3.1(d) para a ponte ST. Podemos observar as gotas e pontes capilares aderidas às placas de $\beta$-cristobalita hidrofóbicas com polaridade $k=0$, e as cores branco, vermelho e cinza representam os átomos de $\mathrm{H}, \mathrm{O}$ e $\mathrm{Si}$ que formam as moléculas de $\mathrm{H}_{2} \mathrm{O}$ e as placas. Observa-se ainda que não existem átomos de $\mathrm{H}$ aderidos à superfície dessas placas, como discutimos na Sec. 2.2.1.
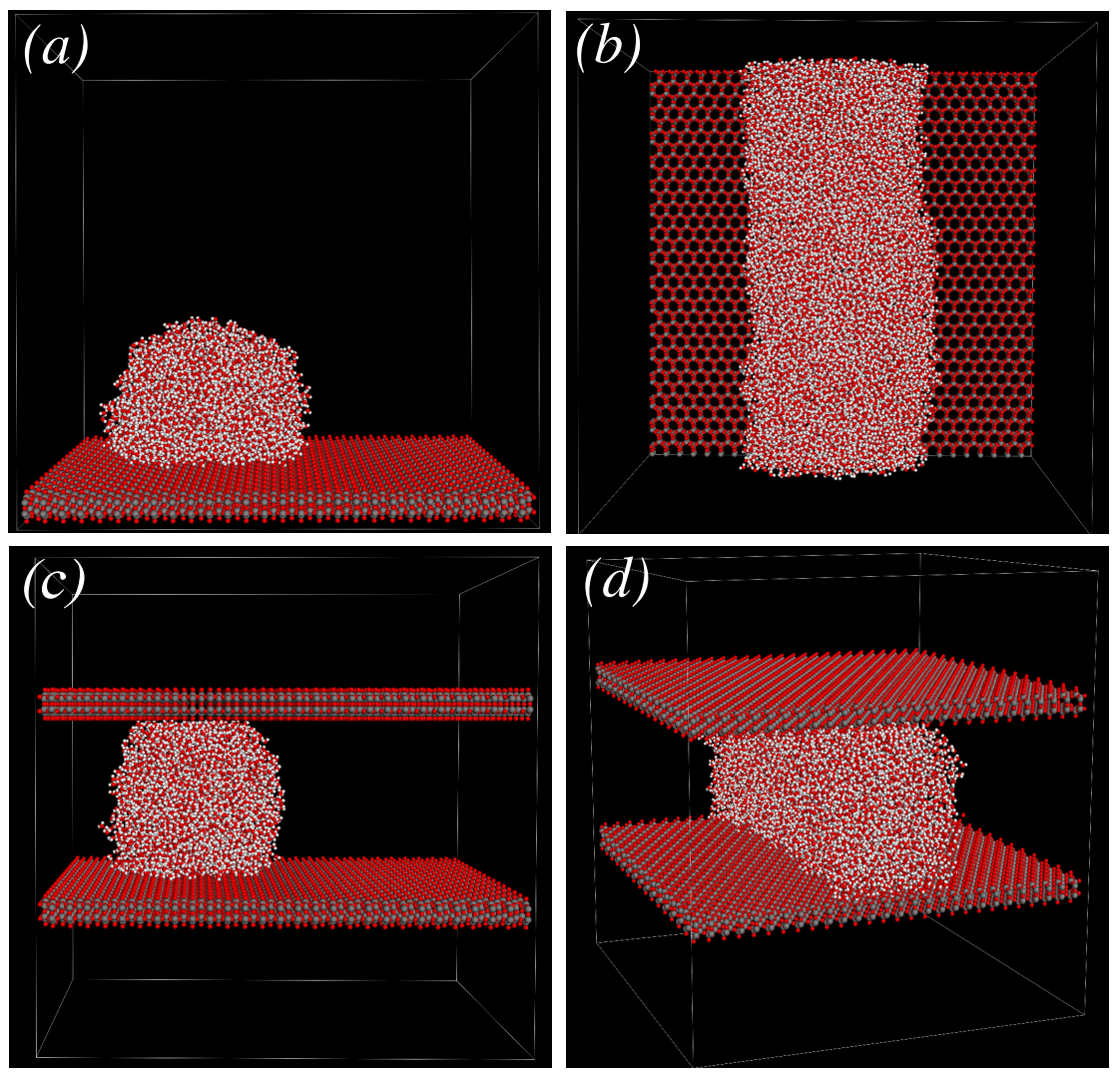

Figura 3.1: Imagens mostrando as configurações das moléculas de $\mathrm{H}_{2} \mathrm{O}$ formando a (a) gota $\mathrm{SA}$, (b) gotas ST, (c) ponte SA e (d) ponte ST aderidas as placas hidrofóbicas com polaridade $k=0$, no último instante de tempo $5 \mathrm{~ns}$ da simulação de DM. As cores branco, vermelho e cinza representam, respectivamente, átomos de $\mathrm{H}, \mathrm{O}$ e Si.

Para analisar os dados, do total de $\Delta t_{\text {sim }}=5 \mathrm{~ns}$ utilizamos apenas os últimos $2 \mathrm{~ns}$, que correspondem a 2000 configurações de moléculas de $\mathrm{H}_{2} \mathrm{O}$. Então, como discutido na Sec. 2.3, calculamos as densidades médias $\rho_{\mathrm{c}}(r)$ dentro de cada caixa, para em seguida calcular os perfis das interfaces das gotas e pontes capilares $r_{\mathrm{p}}(z)$ geradas pelas simulações de DM. As Figuras 3.2(a)-(b) mostram dois casos do cálculo de $\rho_{\mathrm{c}}(r)$ para (a) gota SA e (b) ponte SA aderidas às placas de $\beta$-cristobalita com superfície hidrofílica de polaridade $k=0,6$. Como é esperado, observamos que $\rho_{\mathrm{c}}(r) \approx 1 \mathrm{~g} / \mathrm{cm}^{3}$ no interior da gota e ponte SA, e decai abruptamente para zero 
na fase de vapor. Posteriormente, utilizando uma densidade de corte $\rho_{\mathrm{c}}(r)=\rho_{0}=0,2 \mathrm{~g} / \mathrm{cm}^{3}$ para todas as funções $\rho_{\mathrm{c}}(r)$, calculamos o perfil $r_{\mathrm{p}}(z)$ dessas gotas e ponte SA. Esse procedimento foi aplicado para todas gotas e pontes SA e ST aderidas às placas com polaridades $0 \leq k \leq 0,65$, e os perfis $r_{\mathrm{p}}(z)$ obtidos, representados por círculos, podem ser observados na Fig. 3.3(a) para a gota SAp, na Fig. 3.3(b) para a gota ST, na Fig. 3.4(a) para a ponte SA, e na Fig. 3.4(b) para a ponte ST.
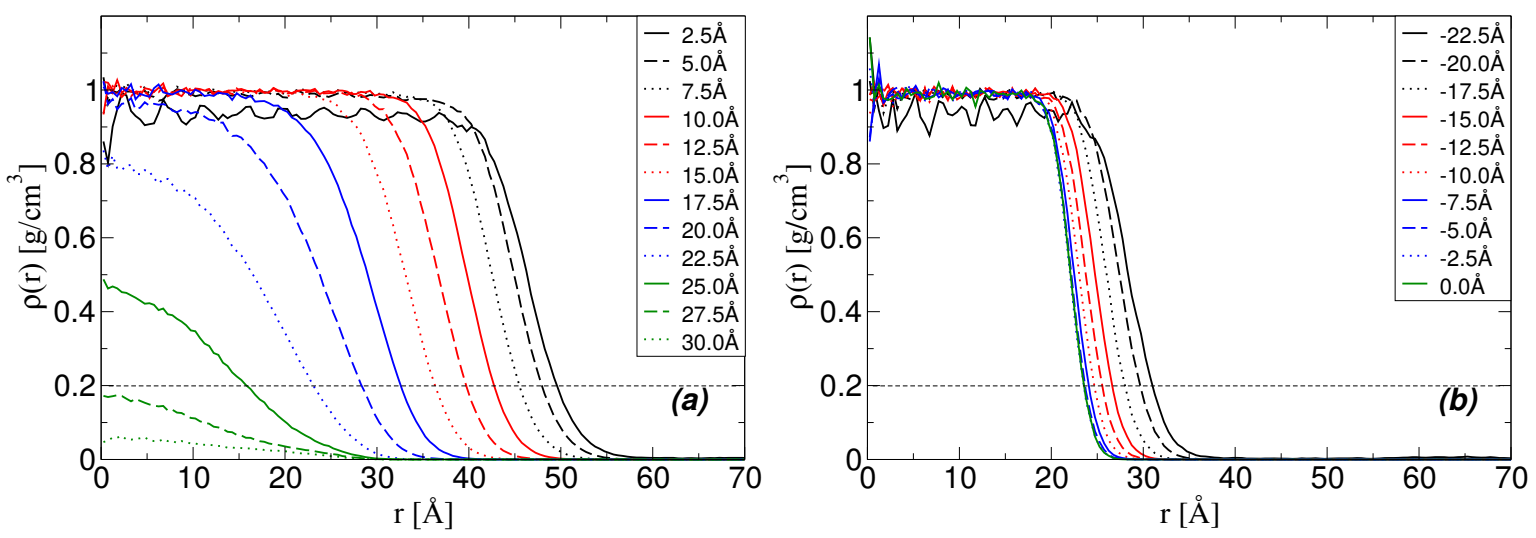

Figura 3.2: Gráficos das funções de densidade $\rho_{\mathrm{c}}(r)$ (a) da gota SA e (b) da ponte SA aderidas às placas de $\beta$-cristobalitas com superfície hidrofílica de polaridade $k=0,6$. Cada linha representa função $\rho_{\mathrm{c}}(r)$ de cada uma das caixas de dimensões $L \times L \times 5 \AA^{3}$ que estão dispostas em diferentes alturas e distantes entre si de $2,5 \AA$, ver Sec. 2.3. Observa-se que $\rho_{\mathrm{c}}(r) \approx 1 \mathrm{~g} / \mathrm{cm}^{3}$ no interior da gota e ponte SA, e decai abruptamente para zero na fase de vapor. O perfil $r_{\mathrm{p}}(z)$ da gota e ponte SA foi definido como a distância $r$ em que $\rho_{\mathrm{c}}(r)=\rho_{0}=0,2 \mathrm{~g} / \mathrm{cm}^{3}$. No caso da (a) gota SA a origem do sistema está localizado na placa de $\beta$-cristobalita, e para (b) ponte SA a origem do sistema esta localizado no CM dessa. Vale enfatizar ainda que a (b) ponte SA possui altura de $50 \AA$.

Uma vez determinados os perfis $r_{\mathrm{p}}(z)$, obtivemos os perfis teóricos $r(z)$ das gotas e pontes SA e ST calculando conjunto de parâmetros de ajuste $\left(R, z_{\mathrm{c}}\right),\left(H\left(r_{0}, R_{2}\right), r_{0}\right)$ e $\left(R, r_{\mathrm{c}}\right)$ das respectivas Eqs. 2.8, 2.19 e 2.70, e utilizando o procedimento descrito na Sec. 2.4. Esses parâmetros podem ser visualizados na Fig. 2.2(a) para a gota SA, na Fig. 2.2(b) para a gota ST, na Fig. 2.3(a) para a ponte SA, e na Fig. 2.3(b) para a ponte ST. Os intervalos que utilizamos para determinar esses parâmetros foram ajustados de acordo com a hidrofobicidade/hidrofilicidade das placas: para placas hidrofóbicas $0,0<R_{\mathrm{t}}<40 \AA$, $23<r_{0, \mathrm{t}}<35 \AA$, $50<R_{2, \mathrm{t}}<800 \AA$, $0<z_{\mathrm{c}, \mathrm{t}}<40 \AA$ e $18<r_{\mathrm{c}, \mathrm{t}}<29 \AA$; para placas hidrofílicas $0<R_{\mathrm{t}}<80 \AA, 20<r_{0, \mathrm{t}}<40 \AA$, $-300<R_{2, \mathrm{t}}<-1 \AA, 0<z_{\mathrm{c}, \mathrm{t}}<150 \AA$ e $18<r_{\mathrm{c}, \mathrm{t}}<29 \AA$. Os valores de $R_{\mathrm{t}}, r_{0, \mathrm{t}}, R_{2, \mathrm{t}}, z_{\mathrm{c}, \mathrm{t}} \mathrm{e}$ $r_{\mathrm{c}, \mathrm{t}}$ foram alterados de $0,1 \AA$ até encontrar os parâmetros $R, r_{0}, R_{2}, z_{\mathrm{c}}$ e $r_{\mathrm{c}}$ que minimizam o erro $\epsilon$ da Eq. 2.88. Esses valores podem ser encontrados nas Tab. 3.1 para as gotas, e na Tab. 3.2 
para as pontes capilares. Assim, os perfis $r(z)$ foram determinados e podem ser observados, representados por uma linha contínua, na Fig. 3.3(a) para a gota SAp, Fig. 3.3(b) para a gota ST, Fig. 3.4(a) para a ponte SA, Fig. 3.4(b) para a ponte ST. Verifica-se que todos os perfis $r_{\mathrm{p}}(z)$ das gotas e pontes capilares são bem descritos pelos perfis teóricos $r(z)$.
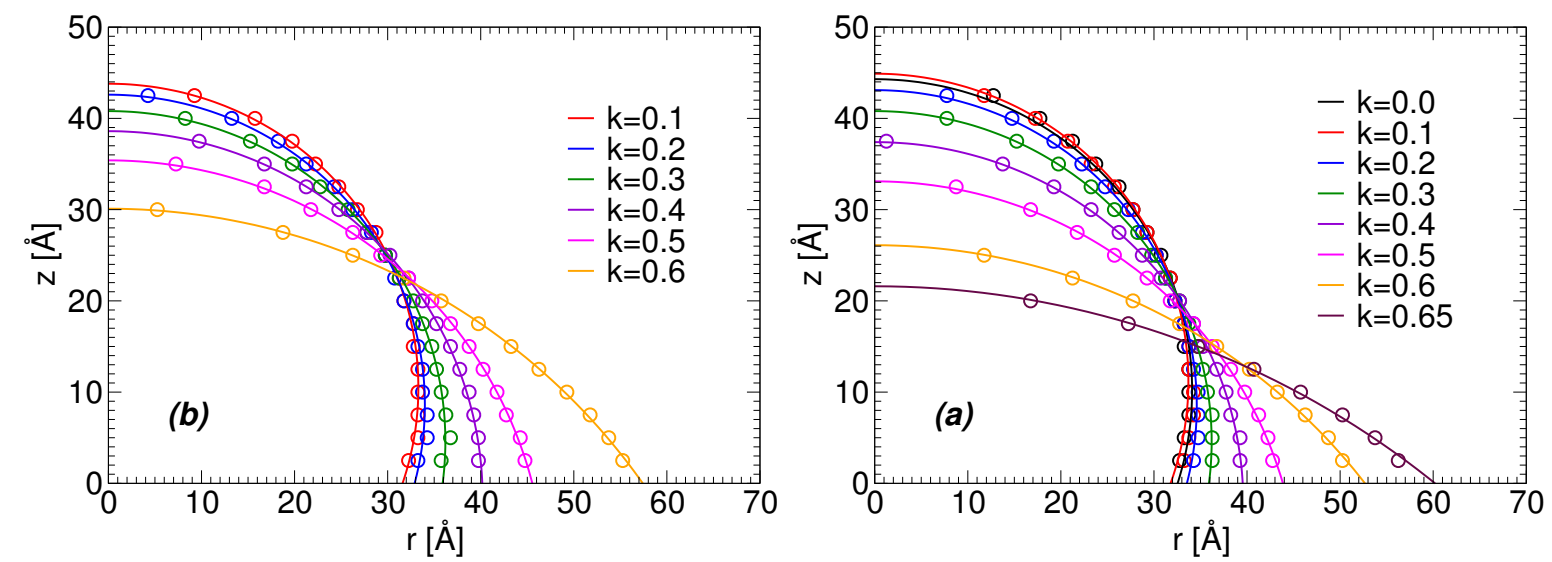

Figura 3.3: Perfis (a) das gotas SA e (b) das gotas ST aderidas à superfície de $\beta$-cristobalita com diferentes polaridades, $0,0<k<0,65$. Os círculos representam os perfis $r_{\mathrm{p}}(z)$ das gotas calculados na DM, como descrito na Sec. 2.3, e as linhas são os ajustes $r(z)$ da TC utilizando a Eq. 2.8 e o procedimento descrito na Sec. 2.4. Nota-se que a Eq. 2.8 descreve bem os perfis das gotas na escala nanométrica. Nas figuras é mostrada somente a metade do perfil total das gotas, e $r$ e $z$ são, respectivamente, o raio e altura das gotas. As gotas SA e ST são formadas, respectivamente, por 3375 e 9897 moléculas de $\mathrm{H}_{2} \mathrm{O}$ do modelo SPC/E.

Tabela 3.1: Parâmetros obtidos a partir do ajuste da Eq. 2.8 da TC para gotas SA e ST. Foram estudadas duas gotas SA: uma pequena com 3375 (SAp) e outra grande com 6750 (SAg) moléculas de $\mathrm{H}_{2} \mathrm{O}$; a gota ST possui 9897 moléculas de $\mathrm{H}_{2} \mathrm{O} . k$ é a polaridade da superfície de $\beta$-cristobalita; $z_{\mathrm{c}}$ é a distância do centro de massa das gotas à origem do sistema; $\theta_{\mathrm{c}}$ é o ângulo de contato; $R$ é o raio da circunferência; $\epsilon$ é o erro obtido a partir do ajuste da Eq. 2.88; o erro em $z_{\mathrm{c}}$ e $R$ são de $\pm 0,05 \AA$.

\begin{tabular}{ccccccccccccc}
\hline \hline & \multicolumn{4}{c}{ gota SAp } & \multicolumn{1}{c}{ gota SAg } & \multicolumn{4}{c}{ gota ST } \\
$\mathrm{k}$ & $\mathrm{R}(\AA)$ & $z_{\mathrm{c}}(\AA)$ & $\theta_{\mathrm{c}}\left({ }^{\circ}\right)$ & $\epsilon(\AA)$ & $\mathrm{R}(\AA)$ & $z_{\mathrm{c}}(\AA)$ & $\theta_{\mathrm{c}}\left(^{\circ}\right)$ & $\epsilon(\AA)$ & $\mathrm{R}(\AA)$ & $z_{\mathrm{c}}(\AA)$ & $\theta_{\mathrm{c}}\left({ }^{\circ}\right)$ & $\epsilon(\AA)$ \\
\hline 0 & 33,7 & 11,2 & 109,4 & 0,15 & 42,0 & 14,0 & 109,5 & 0,18 & 32,7 & 11,3 & 110,2 & 0,15 \\
0,1 & 34,1 & 10,2 & 107,4 & 0,21 & 42,6 & 12,5 & 107,0 & 0,15 & 33,3 & 10,5 & 108,4 & 0,18 \\
0,2 & 34,6 & 8,5 & 104,2 & 0,21 & 43,4 & 10,4 & 103,9 & 0,21 & 34,0 & 8,6 & 104,7 & 0,19 \\
0,3 & 36,2 & 4,6 & 97,3 & 0,10 & 45,0 & 6,2 & 97,9 & 0,18 & 36,2 & 4,6 & 97,3 & 0,20 \\
0,4 & 39,6 & $-2,2$ & 86,8 & 0,15 & 48,8 & $-1,7$ & 88,0 & 0,19 & 40,2 & $-1,6$ & 87,7 & 0,12 \\
0,5 & 45,6 & $-12,5$ & 74,1 & 0,15 & 57,4 & $-16,2$ & 77,6 & 0,18 & 47,0 & $-11,6$ & 75,7 & 0,13 \\
0,6 & 66,2 & $-40,1$ & 52,7 & 0,14 & 78,8 & $-45,4$ & 54,8 & 0,16 & 69,8 & $-39,7$ & 55,3 & 0,15 \\
0,65 & 94,7 & $-73,1$ & 39,5 & 0,21 & 121,9 & $-95,7$ & 38,3 & 0,12 & -- & -- & -- & -- \\
\hline \hline
\end{tabular}

Como já foi discutido, a TC macroscópica prevê que o ângulo de contato $\theta_{c}$ é independente do formato da interface e do substrato, e depende somente do equilíbrio energético das tensões superficiais, como descrito pela Eq. 2.1. Nossos resultados de $\theta_{c}$ mostraram que essa 

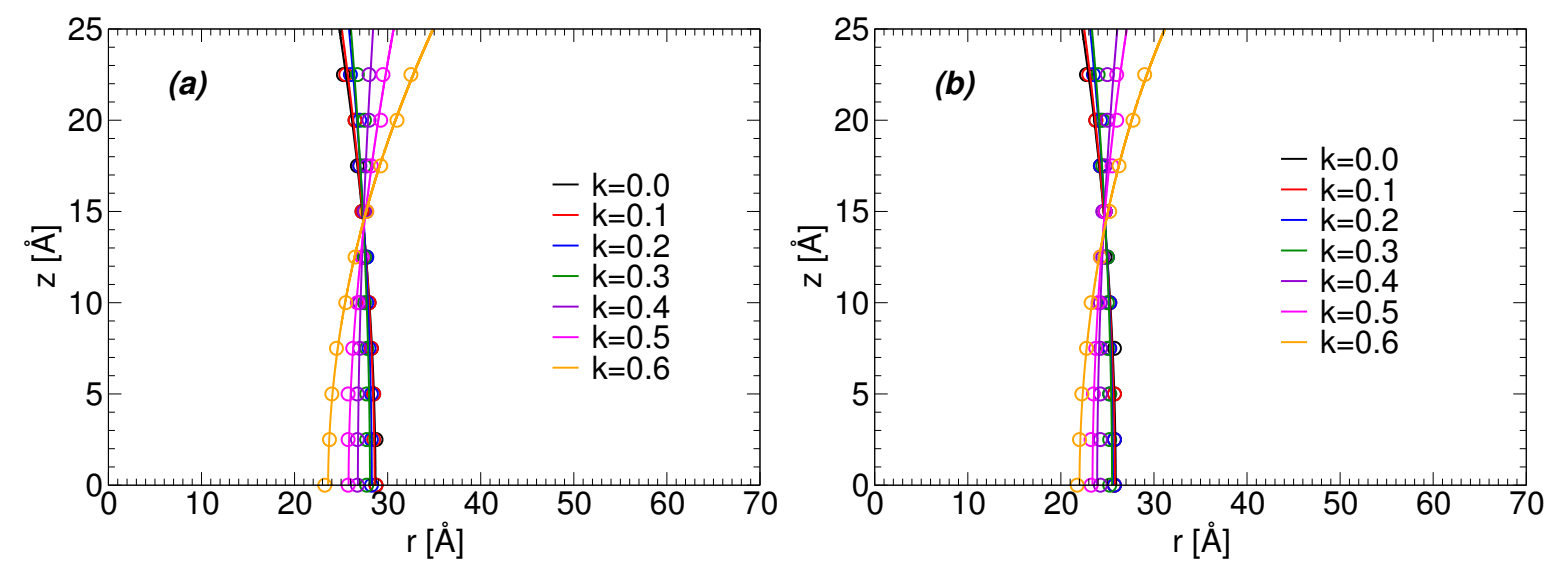

Figura 3.4: Perfis (a) das pontes SA e (b) das pontes ST aderidas à superfície de $\beta$-cristobalita com diferentes polaridades, $0,0<k<0,65$. Os círculos representam os perfis das pontes $r_{\mathrm{p}}(z)$ calculados na DM, como descrito na Sec. 2.3, e as linhas são os ajustes $r(z)$ da TC utilizando a TC, Eq. 2.19 para as pontes SA e Eq. 2.70 para as pontes ST e o procedimento descrito na Sec. 2.4. Nota-se que as Eqs. 2.8 e 2.70 descrevem bem os perfis das pontes capilares na escala nanométrica. Nas figuras é mostrado somente $1 / 4$ do perfil total das pontes capilares, $r$ e $z$ são, respectivamente, o raio e altura das pontes capilares. As pontes SA e ST são formadas, respectivamente, por 3375 e 9897 moléculas de $\mathrm{H}_{2} \mathrm{O}$ do modelo SPC/E.

previsão ainda é válida para as condições estudadas na escala nanométrica, e os valores desses para as gotas SAp, SAg e ST podem ser encontrados na Tab. 3.1, e para as pontes SA e ST são encontrados na Tab. 3.2. A Figura 3.5(a) mostra $\theta_{c}$ em função de $k$, sendo $0<k<0,65$, e verifica-se que $\theta_{c}$ é praticamente uma função de $k$ independente do formato da interface, ou seja $\theta_{\mathrm{c}}=\theta_{\mathrm{c}}(k)$. Essa observação ainda sugere que, como $\theta_{\mathrm{c}}$ depende somente de $\gamma, \gamma_{\mathrm{LS}}$ e $\gamma_{\mathrm{SG}}$, na escala $2-10 \mathrm{~nm}$ a tensão superficial $\gamma$ pode ser considerada como independente de $H\left(r_{0}, R_{2}\right)$, um resultado não trivial [138, 164]. Portanto, o conceito de ângulo de contato e de tensão superficial são mantidos até na escala $2-10 \mathrm{~nm}$ para as pontes capilares e gotas estudadas. Cheng et al. [101] encontraram que gotas SA e ST também possuem o mesmo valor de $\theta_{c}$. É interessante observar que a menor gota estudada está em contato com a superfície de $\beta$-cristobalita com polaridade $k=0,65$ e possui somente $2 \mathrm{~nm}$ de altura, enquanto que as interfaces líquido-vapor e sólido-líquido possuem, respectivamente, dimensões da ordem de 0,8-1 nm e 1-1, 4 nm [165]. Nesse caso, existe um pequeno espaço sobrando dentro da gota para conter um bulk com a mesma densidade da água.

Devemos enfatizar que no cálculo de $r(z)$ não foi incluído o conceito de tensão de linha $\kappa$, e os resultados de $\theta_{\mathrm{c}}$ indicam que, para gotas e pontes capilares maiores que $2 \mathrm{~nm}$ a tensão 
Tabela 3.2: Parâmetros obtidos a partir dos ajustes da Eq. 2.19 para as pontes SA, e da Eq. 2.70 para as pontes ST. Foram estudadas pontes SA com 3375 moléculas de $\mathrm{H}_{2} \mathrm{O}$ e pontes ST com 9897 moléculas de $\mathrm{H}_{2} \mathrm{O}$. $k$ é a polaridade da superfície $\beta$-cristobalita; $r_{0}=R_{1}$ e $R_{2}$ são os raios principais de curvatura; $H$ é aproximadamente a curvatura média; $\theta_{\mathrm{c}}$ é o ângulo de contato; $\epsilon$ é o erro obtido a partir do ajuste da Eq. 2.88; os erros em $R_{2}$ e $r_{0}$ são de $\pm 0,05 \AA$. Para as pontes ST tem-se que $R_{1}=\infty$ e $r_{0}$ se torna a espessura do "pescoço" da ponte capilar.

\begin{tabular}{ccccccccccc}
\hline \hline & \multicolumn{3}{c}{ pontes SA } & \multicolumn{1}{c}{ pontes ST } \\
\hline $\mathrm{k}$ & $r_{0}(\AA)$ & $R_{2}(\AA)$ & $\mathrm{H}\left(\AA^{-1}\right)$ & $\theta_{\mathrm{c}}\left(^{\circ}\right)$ & $\epsilon(\AA)$ & $r_{0}(\AA)$ & $R_{2}(\AA)$ & $\mathrm{H}\left(\AA^{-1}\right)$ & $\theta_{\mathrm{c}}\left({ }^{\circ}\right)$ & $\epsilon(\AA)$ \\
0 & 28,8 & 80,4 & 0,0236 & 106,6 & 0,18 & 25,9 & 90,1 & 0,00555 & 106,3 & 0,15 \\
0,1 & 28,7 & 84,4 & 0,0233 & 105,7 & 0,14 & 25,8 & 98,9 & 0,00506 & 104,8 & 0,11 \\
0,2 & 28,2 & 126,6 & 0,0217 & 100,3 & 0,12 & 25,6 & 132,2 & 0,00378 & 101,1 & 0,15 \\
0,3 & 27,8 & 225,9 & 0,0202 & 95,7 & 0,09 & 25,5 & 150,0 & 0,00333 & 99,7 & 0,21 \\
0,4 & 26,8 & $-229,0$ & 0,0165 & 84,6 & 0,18 & 23,9 & $-150,0$ & $-0,00333$ & 80,3 & 0,30 \\
0,5 & 25,7 & $-60,0$ & 0,0111 & 70,0 & 0,15 & 23,4 & $-88,9$ & $-0,00562$ & 73,5 & 0,19 \\
0,6 & 23,8 & $-29,8$ & 0,0042 & 50,11 & 0,12 & 22,0 & $-39,2$ & $-0,0127$ & 50,0 & 0,13 \\
0,65 & 22,2 & $-21,9$ & $-0,0003$ & 34,75 & 0,16 & -- & -- & -- & -- & -- \\
\hline \hline
\end{tabular}

$\kappa$ possui um efeito mínimo, como pode ser verificado na Tab. 3.1. A correção nos cálculos de $\theta_{\mathrm{c}}(k)$ devido à $\kappa(k) \neq 0$ podem ser obtidos a partir da Eq. 2.2. Para as gotas ST podemos considerar que $\theta_{c}=\theta_{\infty}$, pois devido à simetria translacional o conceito de $\kappa$ não é aplicado. $\mathrm{O}$ efeito de $\kappa$ implicaria em diferentes valores de $\theta_{\mathrm{c}}$ das gotas SAp, SAg e ST. Entretanto, comparando os dados de $\theta_{c}$ da Tab.3.1 conclui-se que as diferenças dos ângulos de contato encontrados são da ordem de $\left|\Delta \theta_{c}\right| \leq 3,5^{\circ}$. Os valores de $\left|\Delta \theta_{c}\right|$ são muito próximos para gotas SAp e SAg. Assim, o número de médias utilizados nas simulações não são suficientes para calcular com precisão os efeitos da tensão linear.

A Figura 3.5(b) mostra os valores de $\cos \theta_{c}$ em função de $k$ obtidos a partir da média dos dados reproduzidos na Figura 3.5(a). Esses dados podem ser ajustados por um polinômio de ordem dois: $\cos \theta_{\mathrm{c}}(k)=-0,29-0,29 k+2,98 k^{2}$. Podemos interpretar que o comportamento quadrático de $\cos \theta_{\mathrm{c}}(k)$ está relacionado com a equação de Young Eq. 2.1 assumindo que $\gamma$ é independente de $k$, e que $\gamma_{\mathrm{SG}} \approx 0$, uma vez que a densidade na fase vapor é pequena. Assim, a principal dependência de $\cos \theta_{\mathrm{c}}(k)$ é com $\gamma_{\mathrm{LS}}$, que é proporcional à polaridade $k$ e deve se comportar de modo $\gamma_{\mathrm{LS}}(k)=a-b k^{2}$, onde $a$ e $b$ são constantes. A maior contribuição para $\gamma_{\mathrm{LS}}(k)$ são as interações de dipolo-dipolo entre as moléculas de $\mathrm{H}_{2} \mathrm{O}$ e dos grupos $\mathrm{SiOH}$ na superfície. Uma vez que os momentos de dipolos das placas de $\beta$-cristobalita causam polaridade na camada formada por moléculas de $\mathrm{H}_{2} \mathrm{O}$ logo acima dessas, como verificado na Ref. [130], têm-se que $\gamma_{\mathrm{LS}}(k)$ deve ser proporcional a $-k^{2}$. Um argumento semelhante pode ser encontrado 

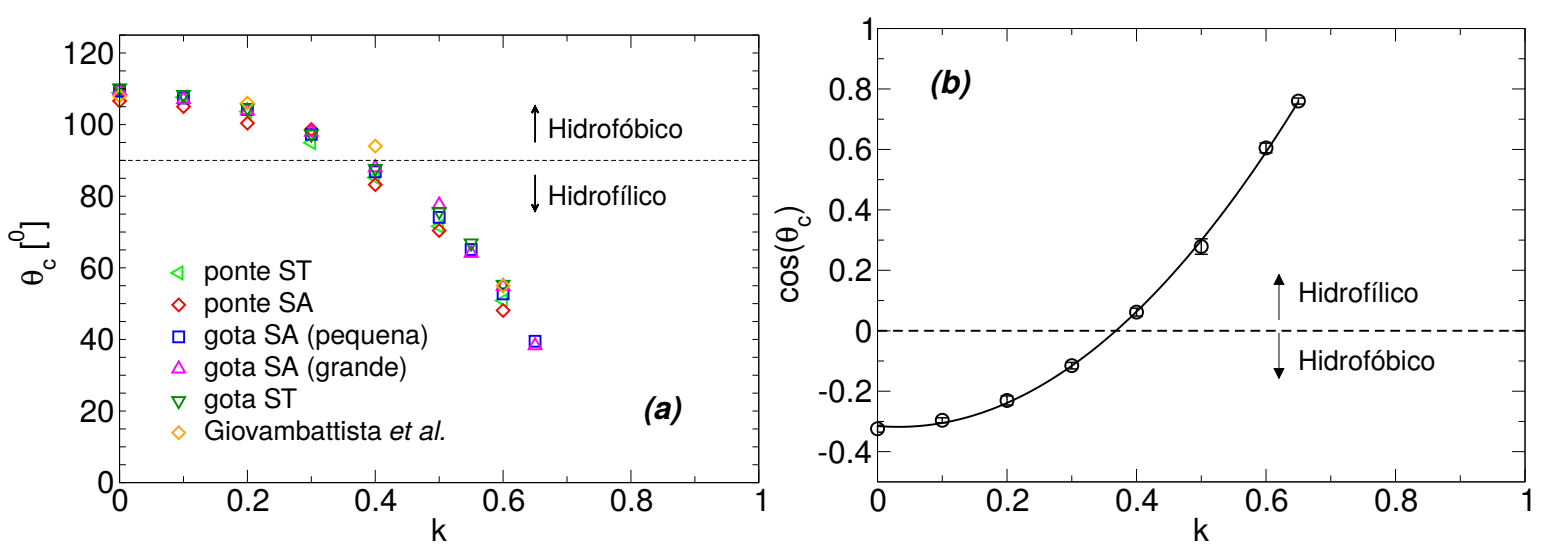

Figura 3.5: Gráficos (a) dos ângulos de contato $\theta_{c}$ e (b) dos cossenos das médias de $\theta_{c}$ em função da polaridade $k$, obtidos a partir dos ajustes des $r(z)$ aos perfis $r_{\mathrm{p}}(z)$ das gotas SA, mostrados na Fig. 3.3(a); gotas ST, mostrados na Fig. 3.3(b); pontes SA, mostrados na Fig. 3.4(a); pontes ST, mostrados na Fig. 3.4(b). Em (a), o ângulo de contato $\theta_{\text {c }}$ para a gota SAg (grande), formada por $N=6750$ moléculas de $\mathrm{H}_{2} \mathrm{O}$, foi adicionado para comparação. Vê-se que as gotas SAp, SAg e ST, e as pontes SA e ST possuem os mesmos $\theta_{\text {c }}$ para cada uma das placas com polaridades $k$ estudadas. Além disso, também foram adicionados para comparação os dados do trabalho de Giovambattista et al. [130]. Em (b), a linha sólida é o ajuste quadrático da função: $\cos \theta_{\mathrm{c}}(k)=-0,29-0,29 k+2,98 k^{2}$. A intersecção da reta $\cos \theta_{\mathrm{c}}=0, \theta_{\mathrm{c}}=90^{\circ}$, com o ajuste de $\cos \theta_{\mathrm{c}}(k)$ define a região em que a superfície de $\beta$-cristobalita deixa de ser hidrofílica, para $k>0,35$, e passa a ser hidrofóbica, para $k<0,35$.

na Ref. [1], que é baseado no conceito de polarizabilidades, que ocorre devido às interações de van der Waals. Entretanto, nas nossas simulações, as polarizabilidades são omitidas. Assim, a dependência de $\cos \left(\theta_{c}\right) \operatorname{com} k$ é diferente daquela apresentada em Ref. [1].

\subsubsection{Cálculo da Tensão superficial, força de adesão capilar e pressão de Laplace das pontes SA e ST}

Na seção anterior mostramos que a TC macroscópica descreve bem o perfil das interfaces das gotas e pontes capilares na escala $2-10 \mathrm{~nm}$, e agora estudaremos se a TC também é capaz de reproduzir a tensão superficial $\gamma$ do modelo de água SPC/E, e as forças de adesão capilar $F_{z \text { zbase }}$ e a pressão de Laplace $P_{\mathrm{L}}$ que as pontes SA e ST exercem sobre as placas hidrofílicas e hidrofóbicas.

As forças $\vec{F}_{\text {placa,i }}$ exercidas pelas pontes SA e ST sobre as placas de $\beta$-cristobalita superior, $i=1$, e inferior, $i=2$, foram calculadas diretamente nas simulações de DM a cada 1 ps. Como discutido na Sec. 2.2.2, $\vec{F}_{\text {placa,i }}$ é basicamente a soma das forças Coulombianas e de LennardJones entre todos os sítios das moléculas de $\mathrm{H}_{2} \mathrm{O}$ do modelo SPC/E e todos os sítios que formam a placa de $\beta$-cristobalita. Vale relembrar que a placa hidrofóbica $k=0$ não possui grupos 
silanois em contato com as pontes SA e ST, e portanto não existe interação Coulombiana entre as moléculas de $\mathrm{H}_{2} \mathrm{O}$ e placa. Então, calculamos as médias $\vec{F}_{\text {placa,i }}$ das pontes SA e ST durante os últimos 2 ns de cada simulação, e os valores das médias das componentes dessa $\left\langle\vec{F}_{\text {placa,i }} \cdot \hat{i}\right\rangle$, $\left\langle\vec{F}_{\text {placa,i }} \cdot \hat{j}\right\rangle$ e $\left\langle\vec{F}_{\text {placa,i }} \cdot \hat{k}\right\rangle$ podem ser encontradas na Tab. 3.3 para a ponte SA, e na Tab. 3.4 para a ponte ST. Verifica-se que a média temporal de $\left\langle\vec{F}_{\text {placa,i }} \cdot \hat{i}\right\rangle$ e $\left\langle\vec{F}_{\text {placa,i }} \cdot \hat{j}\right\rangle$ converge para zero para longos tempos de simulação, como é esperado.

Tabela 3.3: Média temporal da força exercida pela ponte SA na placa superior $\left\langle\vec{F}_{\text {placa, } 1}\right\rangle$ e inferior $\left\langle\vec{F}_{\text {placa, } 2}\right\rangle$ medidas durante 2 ns de simulação. Observa-se as componentes dessas nas direções $\hat{i}, \hat{j}$ e $\hat{k}$.

\begin{tabular}{ccccccc}
\hline \hline & \multicolumn{3}{c}{$\left\langle\vec{F}_{\text {placa }, 1}\right\rangle(\mathrm{nN})$} & \multicolumn{3}{c}{$\left\langle\vec{F}_{\text {placa }, 2}\right\rangle(\mathrm{nN})$} \\
\hline$k$ & $\hat{k}$ & $\hat{i}$ & $\hat{j}$ & $\hat{k}$ & $\hat{i}$ & $\hat{j}$ \\
0,0 & $0,316(6)$ & $-0,005(6)$ & $-0,007(6)$ & $-0,315(6)$ & $0,004(6)$ & $0,008(6)$ \\
0,1 & $0,325(6)$ & $0,003(6)$ & $0,001(6)$ & $-0,325(6)$ & $-0,003(6)$ & $0,000(6)$ \\
0,2 & $0,355(7)$ & $0,004(6)$ & $0,003(6)$ & $-0,355(7)$ & $-0,004(6)$ & $-0,003(6)$ \\
0,3 & $0,417(7)$ & $0,000(6)$ & $-0,003(6)$ & $-0,417(7)$ & $0,000(6)$ & $0,003(6)$ \\
0,4 & $0,501(7)$ & $-0,004(6)$ & $0,004(6)$ & $-0,501(7)$ & $0,003(6)$ & $-0,004(6)$ \\
0,5 & $0,598(7)$ & $-0,001(6)$ & $0,011(6)$ & $-0,598(7)$ & $0,001(6)$ & $-0,011(6)$ \\
0,6 & $0,702(7)$ & $0,009(6)$ & $0,005(6)$ & $-0,702(7)$ & $-0,009(6)$ & $-0,004(6)$ \\
0,65 & $0,723(7)$ & $0,009(6)$ & $0,007(6)$ & $-0,723(7)$ & $-0,009(6)$ & $-0,006(6)$ \\
\hline \hline
\end{tabular}

Tabela 3.4: Média temporal da força exercida pela ponte ST na placa superior $\left\langle\vec{F}_{\text {placa, } 1}\right\rangle$ e inferior $\left\langle\vec{F}_{\text {placa, } 2}\right\rangle$ medidas durante 2 ns de simulação. Observa-se as componentes dessas nas direções $\hat{i}, \hat{j}$ e $\hat{k}$.

\begin{tabular}{ccccccc}
\hline \hline & \multicolumn{3}{c}{$\left\langle\vec{F}_{\text {placa }, 1}\right\rangle(\mathrm{nN})$} & \multicolumn{3}{c}{$\left\langle\vec{F}_{\text {placa, } 2}\right\rangle(\mathrm{nN})$} \\
\hline$k$ & $\hat{k}$ & $\hat{i}$ & $\hat{j}$ & $\hat{k}$ & $\hat{i}$ & $\hat{j}$ \\
0,0 & $1,1(2)$ & $0,00(1)$ & $-0,01(1)$ & $-1,1(2)$ & $0,00(1)$ & $0,01(1)$ \\
0,1 & $1,1(2)$ & $0,01(1)$ & $0,00(1)$ & $-1,1(2)$ & $-0,01(1)$ & $0,00(1)$ \\
0,2 & $1,2(2)$ & $0,00(1)$ & $0,00(1)$ & $-1,2(2)$ & $0,00(1)$ & $0,00(1)$ \\
0,3 & $1,4(2)$ & $0,01(1)$ & $0,00(1)$ & $-1,4(2)$ & $-0,01(1)$ & $0,00(1)$ \\
0,4 & $1,6(2)$ & $0,00(1)$ & $0,00(1)$ & $-1,6(2)$ & $0,00(1)$ & $0,00(1)$ \\
0,5 & $1,9(2)$ & $-0,01(1)$ & $0,01(1)$ & $-1,9(2)$ & $0,01(1)$ & $-0,01(1)$ \\
0,6 & $2,3(2)$ & $0,02(1)$ & $0,00(1)$ & $-2,3(2)$ & $-0,02(1)$ & $0,00(1)$ \\
0,65 & $2,5(2)$ & $-0,02(2)$ & $0,00(2)$ & $-2,5(2)$ & $0,02(2)$ & $0,00(2)$ \\
\hline \hline
\end{tabular}

A partir das médias de $\left\langle\vec{F}_{\text {placa,i }}\right\rangle, i=1,2$, calculamos o valor de $\gamma$ da interface líquido-gás das pontes SA e ST formadas por $\mathrm{H}_{2} \mathrm{O}$ do modelo SPC/E. Assumindo que $\left\langle\vec{F}_{\text {placa,i }} \cdot \hat{k}\right\rangle$ seja análogo à força de adesão capilar, podemos calcular uma força de adesão capilar a partir das 
simulações $F_{\text {z,placa }}$ como:

$$
F_{\text {z,placa }}=\frac{1}{2}\left(\left|\left\langle\vec{F}_{\text {placa }, 1} \cdot \hat{k}\right\rangle\right|+\left|\left\langle\vec{F}_{\text {placa }, 2} \cdot \hat{k}\right\rangle\right|\right) \text {. }
$$

Observando que as pontes SA e ST estão em equilíbrio mecânico e termodinâmico, podemos concluir que as forças das interações intermoleculares em qualquer seção transversal ao longo do eixo $z$ devem ser iguais. Assim, utilizando a Eq. 2.4, podemos escrever que a força resultante na região do "pescoço" das pontes SA e ST devem ser iguais às forças de adesão capilar nas placas $F_{\mathrm{z}, \text { pço }}=F_{\mathrm{z} \text {,placa }}$, em que $F_{\mathrm{z} \text {,placa }}$ é dada por Eq. 3.1, e $F_{\mathrm{z}, \mathrm{pço}}$ é dada pela Eq. 2.25 para a ponte SA e Eq. 2.72 para a ponte ST. $F_{\text {z,pço }}$ pode ser calculada a partir de $\gamma$ e do parâmetro $\mathcal{C}$.

O parâmetro $\mathcal{C}$ está relacionado às deformações dos "pescoços" das pontes SA e ST, e pode ser calculado com os conjuntos de parâmetros de ajuste do perfil analítico $r(z)-\left(H\left(r_{0}, R_{2}\right), r_{0}\right)$ para a ponte $\mathrm{SA}$ e $\left(R, r_{\mathrm{c}}\right)$ para a ponte $\mathrm{ST}-\operatorname{mostrados}$ na Tab. 3.2. Observa-se que $\mathcal{C}=\mathcal{C}(k)$ depende somente da polaridade $k$, e que os raios $r_{0}$ dos "pescoços" das ponte SA e ST se tornam mais estreitos quanto maior o valor de $k$. Assim, calculamos o valor de $\gamma$ da água do modelo SPC/E a partir de um ajuste com um modelo de equação da forma $y=a x$ aos valores $F_{\text {z,placa }}$ e $\mathcal{C}(k)$ conhecidos. A Figura 3.6 mostra os dados $\left(F_{\text {z,placa }}, \mathcal{C}(k)\right)$ e o ajuste realizado para as pontes SA e ST. O valor da tensão superficial do modelo da água SPC/E calculado pelo ajuste para os dois casos foi: $\gamma=0,054 \pm 0,001 \mathrm{~N} / \mathrm{m}$. Esse valor é consistente com valores da tensão superficial da interface líquido-vapor formado pelo modelo de água SPC/E encontrados na literatura [166, 167].

Uma vez determinado o valor de $\gamma$, calculamos em seguida a força de adesão capilar e a pressão de Laplace das pontes SA e ST sobre as placas de $\beta$-cristobalita com polaridade $k$. As forças de adesão capilar das pontes SA e ST $F_{z \text {,base }}$ foram calculadas utilizando, respectivamente, as Eqs. 2.22 e 2.71, e empregando os parâmetros obtidos dos ajustes dos perfis $r(z)$, mostrados na Tab. 3.2. Para efeito de comparação, as forças no "pescoço" das pontes SA e ST $F_{z, \text { p̧o }}$ também foram calculadas utilizando, respectivamente, as Eqs. 2.25 e 2.72. Esses resultados podem ser observados nas Figs. 3.7(a) e (b), as quais mostram, respectivamente, as forças em função do ângulo de contato $\theta_{c}$ e da polaridade das placas $k$. Nessas figuras também são 


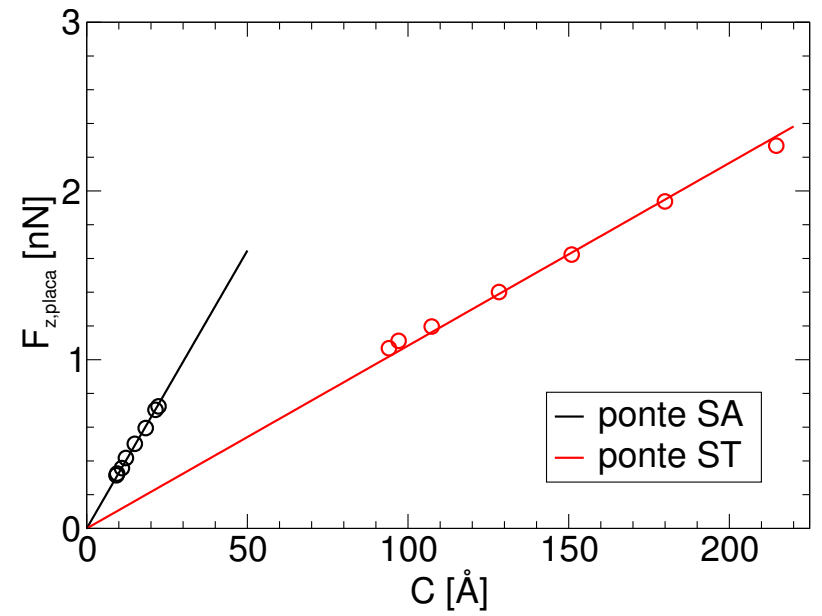

Figura 3.6: Cálculo da tensão superficial $\gamma$ da $\mathrm{H}_{2} \mathrm{O}$ do modelo SPC/E. No eixo da ordenada têm-se as forças de adesão capilar $F_{z \text { zplaca }}$ calculadas com a Eq.3.1 e na abscissa têm-se o parâmetro referente à deformação do "pescoço" das pontes SA $\left(\mathcal{C}=r_{0}-H r_{0}^{2}\right)$ e ST $\left(\mathcal{C}=D-2 H D r_{0}\right)$, ver Eqs. 2.25 e 2.72, respectivamente. $\mathcal{C}$ pode ser calculado com os dados da Tab. 3.2

mostrados os valores de $F_{\mathrm{z} \text {,placa }}$ e podemos observar que esses valores são bem descritos pela TC quando comparados com $F_{z, \text { base }}$. Ademais, observamos que a condição $F_{z, \text { p̧o }}=F_{z \text {,base }}$ é satisfeita.
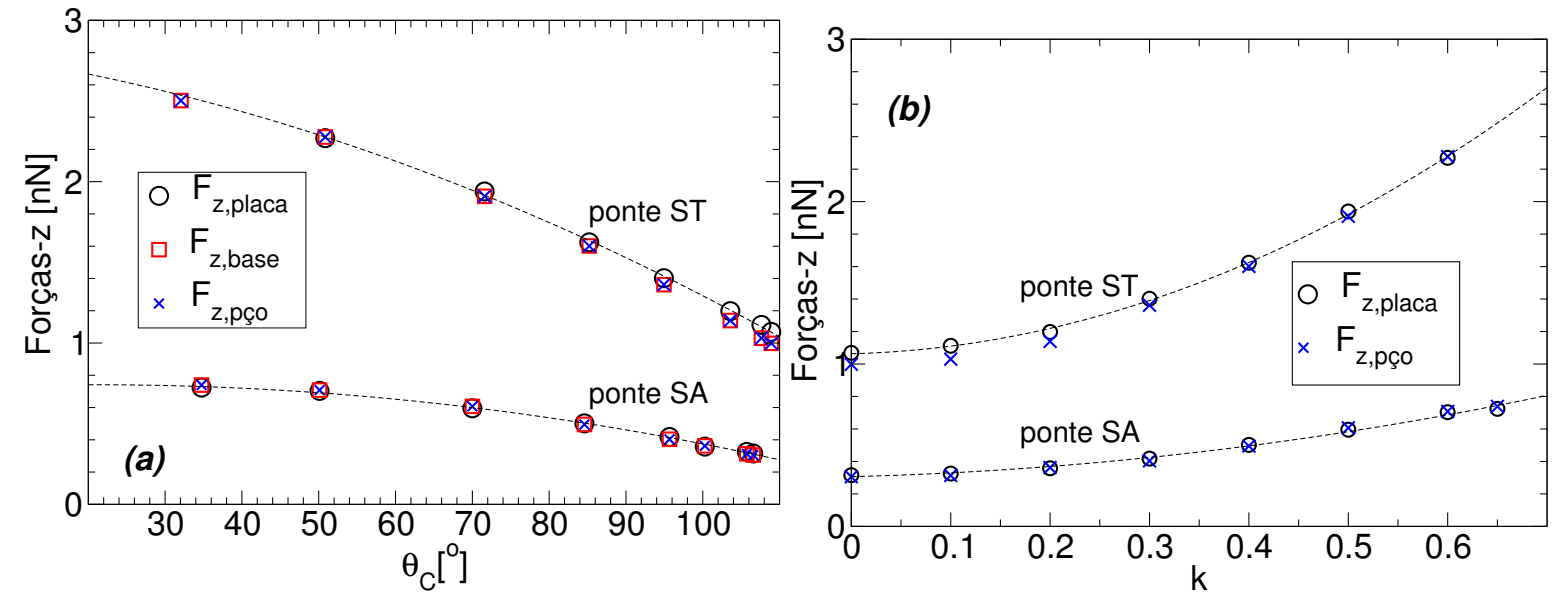

Figura 3.7: Comparação das forças na direção $\hat{k}$ das pontes SA e ST em função (a) do ângulo de contato $\theta_{\mathrm{c}} \mathrm{e}$ (b) da polaridade das placas $k$. $F_{\text {z,base }}^{\prime}$ (círculos) são as forças de adesão capilar medidas

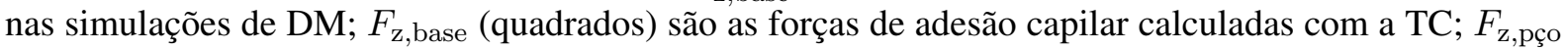
(sinais de vezes) são as forças nos "pescoços" calculados com a TC. Como é esperado, $F_{z \text {,placa }}=F_{z \text {,base }}$, e $F_{z, \text { base }}=F_{z, \text { pço }}$ uma vez que o sistema esta em equilíbrio.

Posteriormente, calculamos a pressão de Laplace $P_{\mathrm{L}}$ no interior das interfaces das pontes SA e ST utilizando, respectivamente, as Eqs. 2.26 e 2.73, e empregando as forças de adesão capilar $F_{z, \text { base }}$ medidas nas simulações de DM, ver Tabs. 3.3 e 3.4. Uma outra maneira de calcular a pressão de Laplace $\left(P_{\mathrm{L}_{\mathrm{Y}}}\right)$ é através da equação de Young-Laplace Eq. 2.3, em que 
consideramos a pressão na fase de vapor $P_{\mathrm{ex}} \approx 0$; portanto $P_{\mathrm{L}_{\mathrm{YL}}}=P_{\mathrm{in}}=\gamma 2 H$. Para os dois cálculos utilizamos o valor de $\gamma$ calculado anteriormente e os parâmetros de ajuste de $r(z)$ mostrados nas Tab. 3.2. As Figuras 3.8(a) e (b) mostram, respectivamente, a pressão de Laplace calculada pelos dois modos em função do ângulo de contato $\theta_{c}$ e da polaridade das placas $k$. Verifica-se que as Eqs. 2.26 e 2.3 reproduzem os mesmo valores mostrando mais uma vez a consistência da TC macroscópica na escala $2-10 \mathrm{~nm}$. Notamos um fato interessante nas Figs. 3.8(a) e (b) que é pressão negativa para $\theta_{\mathrm{c}}<37,0^{\circ}$ no caso da ponte SA, e $\theta_{\mathrm{c}}<90^{\circ}$ no caso da ponte ST. Essa verificação é consistente com observações experimentais no AFM [94] e em canais na escala nanométrica [38, 95-97]. Essa pressão negativa indica que as moléculas de $\mathrm{H}_{2} \mathrm{O}$ que formam as pontes SA e ST podem estar sob tensão na escala $2-10 \mathrm{~nm}$, o que é intensificado pelo fato dos átomos de $\mathrm{O}$ e Si das superfícies de $\beta$-cristobalita estarem fixos. Um ajuste linear sobre os valores de $P_{\mathrm{L}}$ da Fig. 3.8(a) mostra que é possível obter grandes pressão negativas, como $-276 \mathrm{~atm}$ para a ponte $\mathrm{ST} \operatorname{com} \theta_{\mathrm{c}}=10^{\circ}$, e positivas, como $271 \mathrm{~atm}$ para a ponte SA com $\theta_{c}=110^{\circ}$. Ressaltamos que a pressão de Laplace no interior de pontes capilares na escala macroscópica é sempre positiva, e portanto este é um fenômeno inerente à escala nanométrica nas dimensões exploradas. Podemos empregar um raciocínio análogo a esse para prever as forças de adesão capilar $F_{z \text {,base }}$, e pode ser mostrado que para grandes valores de $\theta_{\mathrm{c}}$ a $F_{\text {z,base }}$ pode ser negativa, ver Fig. 3.7.
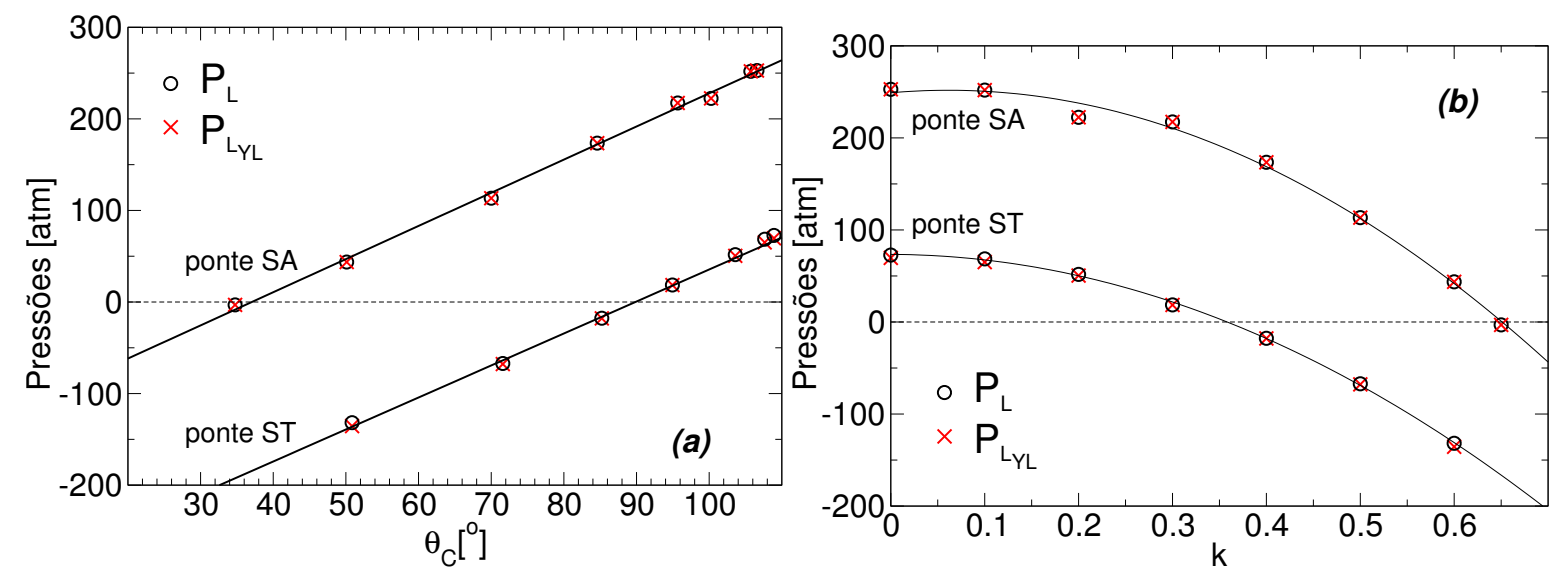

Figura 3.8: Comparação entre as pressões de Laplace das pontes SA e ST em função (a) do ângulo de contato $\theta_{\mathrm{c}} \mathrm{e}(\mathrm{b})$ da polaridade das placas $k$. A pressão de Laplace foi medida com dois métodos, por meio da equação de Young-Laplace Eq. $2.3\left(\left(_{\mathrm{L}_{\mathrm{YL}}}\right)\right.$ e da Eq. $2.26\left(P_{\mathrm{L}}\right)$, que se baseia no cálculo das forças exercidas sobre as placas $F_{z \text {,palca }}$ medida nas simulações de DM. Nota-se que a pressão pode ser negativa para placas hidrofílicas, indicando que as pontes capilares estão sob tensão. 


\subsubsection{Cálculo da tensão superficial utilizando o método KB}

Nessa seção aplicaremos o método KB, discutido na Sec.2.5, para ratificar o cálculo da tensão superficial $\gamma$ realizado da seção anterior, em que foi utilizado o fato de que nas pontes SA e ST $F_{z, \text { base }}=F_{z, p c ̧ o}$. Nesse método é preciso criar duas interfaces líquido-vapor planas na caixa de simulação, e a partir das médias das medidas dos tensores de pressão $\left\langle P_{\mathrm{xx}}\right\rangle,\left\langle P_{\mathrm{yy}}\right\rangle$ e $\left\langle P_{\mathrm{zz}}\right\rangle$ foi possível calcular $\gamma$ utilizando a Eq. 2.93. Calculamos dois valores de $\gamma$ utilizando duas caixas de simulação com dimensões diferentes, $50 \times 50 \times 140 \AA^{3}$ e $66 \times 66 \times 160 \AA^{3}$, e no centro de cada caixa foram dispostas $N=3375$ moléculas de $\mathrm{H}_{2} \mathrm{O}$, como mostrado nas Figs. 3.9(a) e (b), respectivamente. As simulações foram executadas por $5 \mathrm{~ns}$ aplicando os mesmos algoritmos e procedimentos empregados para as gotas e pontes SA e ST, e somente os últimos $2 \mathrm{~ns}$ da simulação foram utilizados para as médias. A Tabela 3.5 mostra os tensores $\left\langle P_{\mathrm{xx}}\right\rangle,\left\langle P_{\mathrm{yy}}\right\rangle \mathrm{e}\left\langle P_{\mathrm{zz}}\right\rangle$ calculados para as duas caixas. Utilizando a Eq. 2.93 calculamos $\gamma=0,056 \pm 0,001 \mathrm{~N} / \mathrm{m}$ para a caixa $50 \times 50 \times 140 \AA^{3}$, e $\gamma=0,0560 \pm 0,0007 \mathrm{~N} / \mathrm{m}$ para a caixa $66 \times 66 \times 160 \AA^{3}$. Esses valores de $\gamma$ estão de acordo com aqueles obtidos nos estudos das pontes SA e ST da seção anterior, assim como com valores conhecidos da literatura para o modelo de água SPC/E [156, 166, 167].
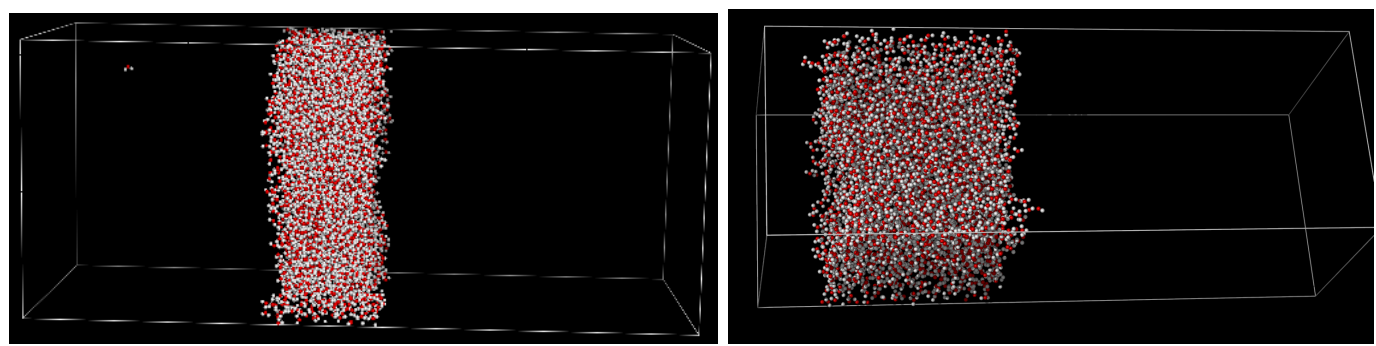

Figura 3.9: Imagens da última configuração das duas caixas de simulação com tamanhos (a) $50 \times$ $50 \times 140 \AA$ e (b) $66 \times 66 \times 160 \AA$ utilizadas para calcular a tensão superficial $\gamma$ com o método KB na temperatura $\mathrm{T}=300 \mathrm{~K}$, e as $N=3375$ moléculas de $\mathrm{H}_{2} \mathrm{O}$ do modelo SPC/E.

\subsection{Estudo sobre o aumento da altura das pontes SA}

Nessa segunda etapa, focaremos nas pontes SA aderidas às placas de $\beta$-cristobalita com polaridades $0 \leq k \leq 0,67$, que foram alongadas $50 \leq h \leq 75 \AA$ até ocorrer a ruptura. Dessa forma, exploramos todo o diagrama de fase $\left(h_{\max }, \theta_{\mathrm{c}}\right)$ das pontes SA, inclusive para $h>h_{\max }\left(\theta_{\mathrm{c}}\right)$ que separa a região de estabilidade e instabilidade, e os resultados obtidos serão apresentados conforme cada região. 
Tabela 3.5: Valores dos tensores de pressão $P_{\mathrm{xx}}, P_{\mathrm{yy}}$ e $P_{\mathrm{zz}}$ utilizados para o cálculo da tensão superficial $\gamma$ do modelo de água SPC/E para $\mathrm{T}=300 \mathrm{~K}$ com o método KB . Para o mesmo número de moléculas $N=3375$ foram utilizadas duas caixas de simulação de tamanhos diferentes $50 \times 50 \times 140 \AA^{3}$ e $66 \times 66 \times$ $160 \AA^{3}$, e as tensões superficiais calculadas foram $\gamma=0,056 \pm 0,001 \mathrm{~N} / \mathrm{m}$ e $\gamma=0,0560 \pm 0,0007 \mathrm{~N} / \mathrm{m}$, respectivamente.

\begin{tabular}{ccc}
\hline \hline$[\mathrm{atm}]$ & $50 \times 50 \times 140 \AA^{3}$ & $66 \times 66 \times 160 \AA^{3}$ \\
\hline$\left\langle P_{\mathrm{xx}}\right\rangle$ & $-2,8 \pm 1,3$ & $-0,3 \pm 0,7$ \\
$\left\langle P_{\mathrm{yy}}\right\rangle$ & $-81,7 \pm 1,7$ & $-69,6 \pm 0,8$ \\
$\left\langle P_{\mathrm{zz}}\right\rangle$ & $-81,9 \pm 1,4$ & $-69,2 \pm 0,8$ \\
\hline \hline
\end{tabular}

Na Seção 3.2.1, empregamos os mesmos procedimentos da Secs. 3.1.1 e 3.1.2 da primeira etapa para as pontes SA em alturas estáveis $h \leq h_{\mathrm{S}}$, e avaliamos mais uma vez os fundamentos da TC: comparamos os perfis analíticos $r(z)$ com aqueles $r_{\mathrm{p}}(z)$ calculados das médias das configurações $\vec{r}_{\mathrm{H}_{2} \mathrm{O}}$; analisamos em função de $h$, o ângulo de contato $\theta_{\mathrm{c}}$ para cada polaridade $k$, as áreas das interface líquido-gás $A_{\mathrm{R}}$ e líquido-solido $A_{\mathrm{B}}$, e o volume $\Omega$; calculamos a tensão superficial $\gamma$ do modelo de água SPC/E, a força exercida sobre as placas $F_{\text {placa,z }}$, a força de adesão capilar $F_{\text {base,z }}$, e a pressão de Laplace medida a partir de $F_{\text {placa,z }}\left(P_{\mathrm{L}}\right)$ e pela equação de Young-Laplace $\left(P_{\mathrm{L}_{\mathrm{YL}}}\right)$. Além disso, as grandezas $F_{\mathrm{base}, \mathrm{z}}, P_{\mathrm{L}_{\mathrm{YL}}}$ e $P_{\mathrm{L}}$ também foram calculadas analiticamente e assim são designadas como $\mathcal{F}^{\prime} F_{\text {base }, \mathrm{z}}^{\prime}, P_{\mathrm{L}_{\mathrm{Y}}}^{\prime}$ e $P_{\mathrm{L}}^{\prime}$. Para esse cálculo é necessário somente os valores de $\Omega, h, \theta_{\mathrm{c}}$ e $\gamma$.

Para todas as alturas $h \leq h_{\mathrm{S}}$, a ponte SA não se rompe no tempo de simulação executado $\Delta t_{\text {sim }}$. Paralelamente a essa analise, avaliamos do mesmo modo as pontes SA instáveis com alturas críticas $h=h_{\mathrm{C}}$ e $h_{\mathrm{C}^{\prime}}$, mas somente aquelas que se rompem depois de um tempo de simulação que permitam o cálculo de $r_{\mathrm{p}}(z)$.

Na Seção 3.2.2, consideramos a região de instabilidade $h>h_{\mathrm{S}}$ em que a ponte SA se rompe, mais especificamente nas alturas críticas $h_{\mathrm{C}}$ e $h_{\mathrm{C}^{\prime}}$. Então, analisamos o mecanismo de ruptura da ponte SA para os diferentes valores do ângulo de contato $\theta_{\mathrm{c}}(k)$ avaliando a proporção $\Delta N_{\mathrm{g}} / N$ do número de moléculas de $\mathrm{H}_{2} \mathrm{O}$ constituindo cada uma das gotas formadas após a ruptura; comparamos $h_{\mathrm{C}}$ e $h_{\mathrm{C}^{\prime}}$ com o cálculo analítico $h_{\max }$, e analisamos as flutuações nos raios da base $r_{\mathrm{B}}$, nos raios $r_{0}$ e das alturas $z_{0}$ dos "pescoços" das pontes SA, comparando-os com os respectivos valores teóricos $r_{\mathrm{B}}^{\prime}, r_{0}^{\prime}$ e $z_{0}^{\prime}$. 


\subsubsection{Perfis das pontes capilares com simetria axial, força de adesão capilar e pressão de}

\section{Laplace induzidas nas placas de $\beta$-cristobalita}

Primeiramente, mostraremos que o equilíbrio das pontes SA após a movimentação das placas com polaridade $k$ ocorre rapidamente. A Figura 3.10 mostra as componentes das forças exercidas pelas pontes SA sobre as placas superior e inferior, $\vec{F}_{\text {placa, } 1}$ e $\vec{F}_{\text {placa, } 2} \cdot \hat{k}$ logo após um incremento de $5 \AA$ na separação entre as placas com polaridade $k$. Podemos observar que as componentes nas coordenadas $\hat{i}$ e $\hat{j}$ flutuam em torno de 0 como é de se esperar. Entretanto, as componentes na direção $\hat{k}$ das placas superior e inferior possuem sentidos opostos, e no inicio possui um pico e logo depois volta para a posição de equilíbrio. Vale ressaltar que esses dados mostram a média sucessiva de dez dados para que a flutuação diminua e possa ser observado o equilíbrio. Esse comportamento é observado para todas as movimentações realizadas nas pontes SA aderidas às placas com polaridade $k$.



Figura 3.10: Gráfico mostrando o equilíbrio da ponte SA aderida à placa de $\beta$-cristobalita com polaridade $k=0,4$ a partir das medidas das forças $\vec{F}_{\mathrm{i}}$, em que $i=1,2$ representam cada uma das placas. Para amenizar as flutuações são mostrados os dados a cada dez médias.

A TC macroscópica prevê que as pontes SA estáveis são simétricas em relação ao "pescoço", como ilustrado na Fig. 2.3(a), e tal fato foi observado nas simulações de DM da ponte SA na escala nanométrica na região estável, $h \leq h_{\mathrm{S}}$. No entanto, na região de instabilidade das pontes SA, mais especificamente nas alturas críticas $h_{\mathrm{C}}$ e $h_{\mathrm{C}^{\prime}}$, os perfis dessas flutuam com 
o tempo e podem ficar assimétricos, dependendo da polaridade $k$ das placas de $\beta$-cristobalita. Nesses casos, calculamos as propriedades das pontes SA até o tempo $\tau_{\mathrm{S}}$, tal que $\tau_{\mathrm{S}}<\Delta t_{\text {sim }}$, em que a ponte SA permanece aproximadamente simétrica $z_{0} \approx 0$.

As Figuras 3.11(a)-(j) mostram os perfis $r_{\mathrm{p}}(z)$ (círculos) adquiridos das médias das configurações de $\vec{r}_{\mathrm{H}_{2} \mathrm{O}}$ e os perfis analíticos $r(z)$ (linhas contínuas) obtidos com os ajustes dos parâmetros $\left(H, r_{0}\right)$ da Eq. 2.19 das pontes SA aderidas às placas com polaridades $0,0<k<0,67$. Também são mostrados os perfis $r(z)$ das pontes SA instáveis nas alturas $h_{\mathrm{C}}$ e $h_{\mathrm{C}^{\prime}}$ que possuíam $\tau_{\mathrm{S}}>$ 0, ver Tab. 3.9. Em todos os casos os ajustes $r(z)$ descrevem bem os perfis $r_{\mathrm{p}}(z)$. Os parâmetros $\left(H, r_{0}\right)$ são mostrados nas Tabs. 3.6 e 3.7, e a Tab. 3.9 mostra os parâmetros relacionados à ruptura da ponte $\mathrm{SA}$.

Uma vez determinados os parâmetros $\left(H, r_{0}\right)$ e os perfis analíticos $r(z)$ das pontes SA, calculamos outras propriedades importantes dessa, como o ângulo de contato $\theta_{\mathrm{c}}$, as áreas das interfaces líquido-sólido $A_{\mathrm{B}}$ e líquido-gás $A_{\mathrm{R}}$, e o volume $\Omega$ das pontes $\mathrm{SA}$. A TC macroscópica prevê que $\theta_{\mathrm{c}}$ depende das tensões superficiais das interfaces, sendo que $\gamma_{\mathrm{SL}}$ é proporcional à polaridade $k$ da placa, e pode depender das dimensões das pontes SA, uma vez que $\theta_{c}$ depende da tensão de linha através do raio da base $r_{\mathrm{B}}$, como mostra a Eq. 2.2. A Figura 3.12(a) mostra que $\theta_{\text {c }}$ é praticamente independente de $h$ para todas as placas com polaridade $0,0<k<$ 0,67. As Figuras 3.12(b) e (c) mostram, respectivamente, a média $\left\langle\theta_{c}\right\rangle$, para os valores de $h$ de uma mesma placa com polaridade $k$, e $\cos \left\langle\theta_{c}\right\rangle$ em função de $k$. Observar-se que $\theta_{c}$ das pontes SA estão de acordo com os correspondentes valores encontrados nos estudos da Sec.3.1.1 em que consideramos gotas e pontes SA e ST. Mostramos mais uma vez que nas condições estudadas $\theta_{c}$ é independente da geometria da interface, que foi alterada variando $h$. Vale destacar que no cálculo de $\theta_{\mathrm{c}}$ não foi utilizado o conceito de tensão de linha $\kappa$, que pode ser considerada desprezível dada as flutuações dos sistemas, como discutimos na Sec.3.1.1 Com relação a outros trabalhos com pontes capilares aderidas a placas planas e paralelas, Ko et al. [117] observaram que $\theta_{c}$ decresce entre para $1,5<h<2,0 \mathrm{~nm}$, e se torna constante para $h>3,5 \mathrm{~nm}$. Esse comportamento foi atribuído à diminuição das forças de interação entre a ponta do AFM e as moléculas de água. Eles utilizaram 1906 moléculas de água do modelo TIP3P, e na região $1,5<h<2,0 \mathrm{~nm}$ onde houve a diminuição $\theta_{\mathrm{c}}$ pode ter havido formação 

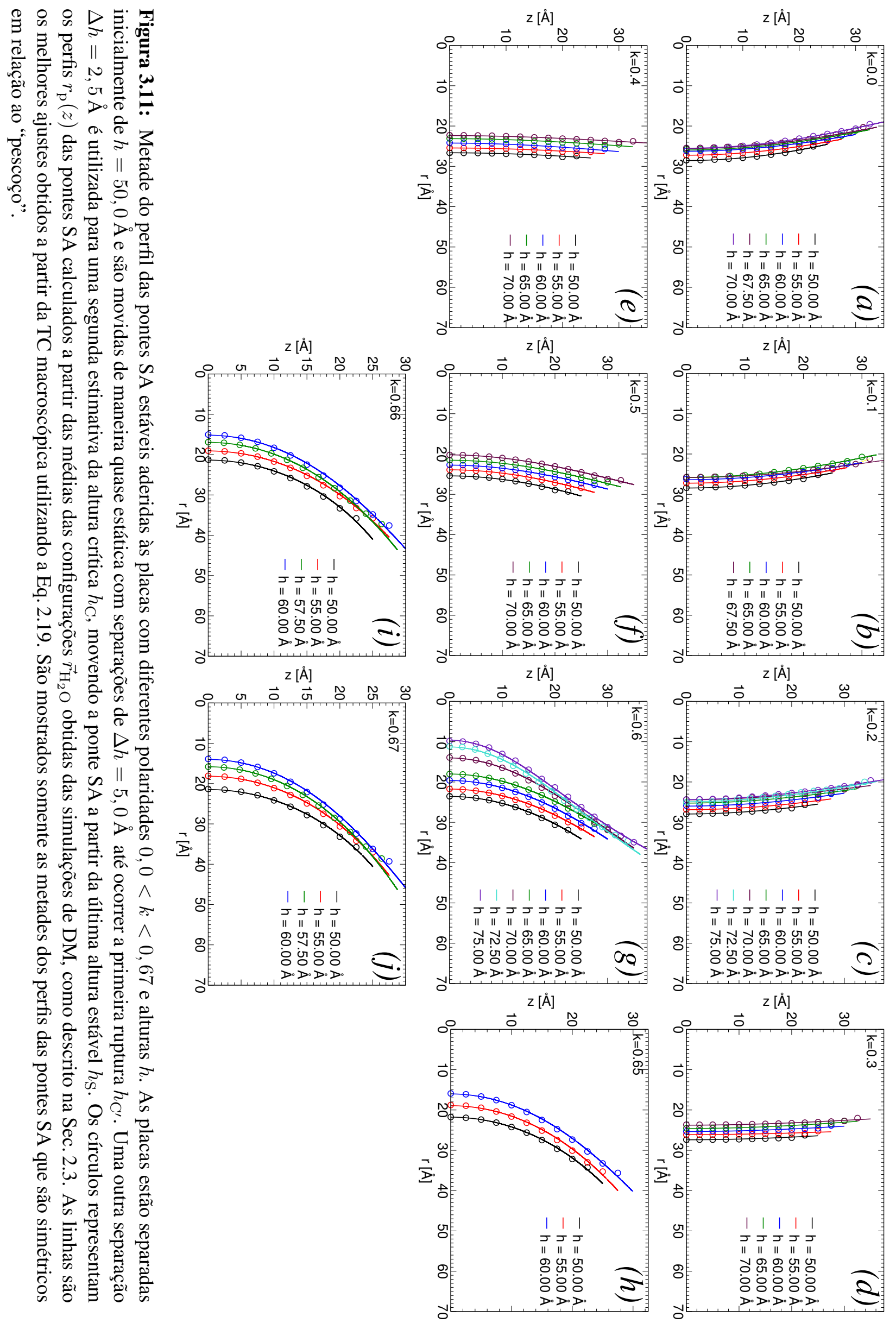


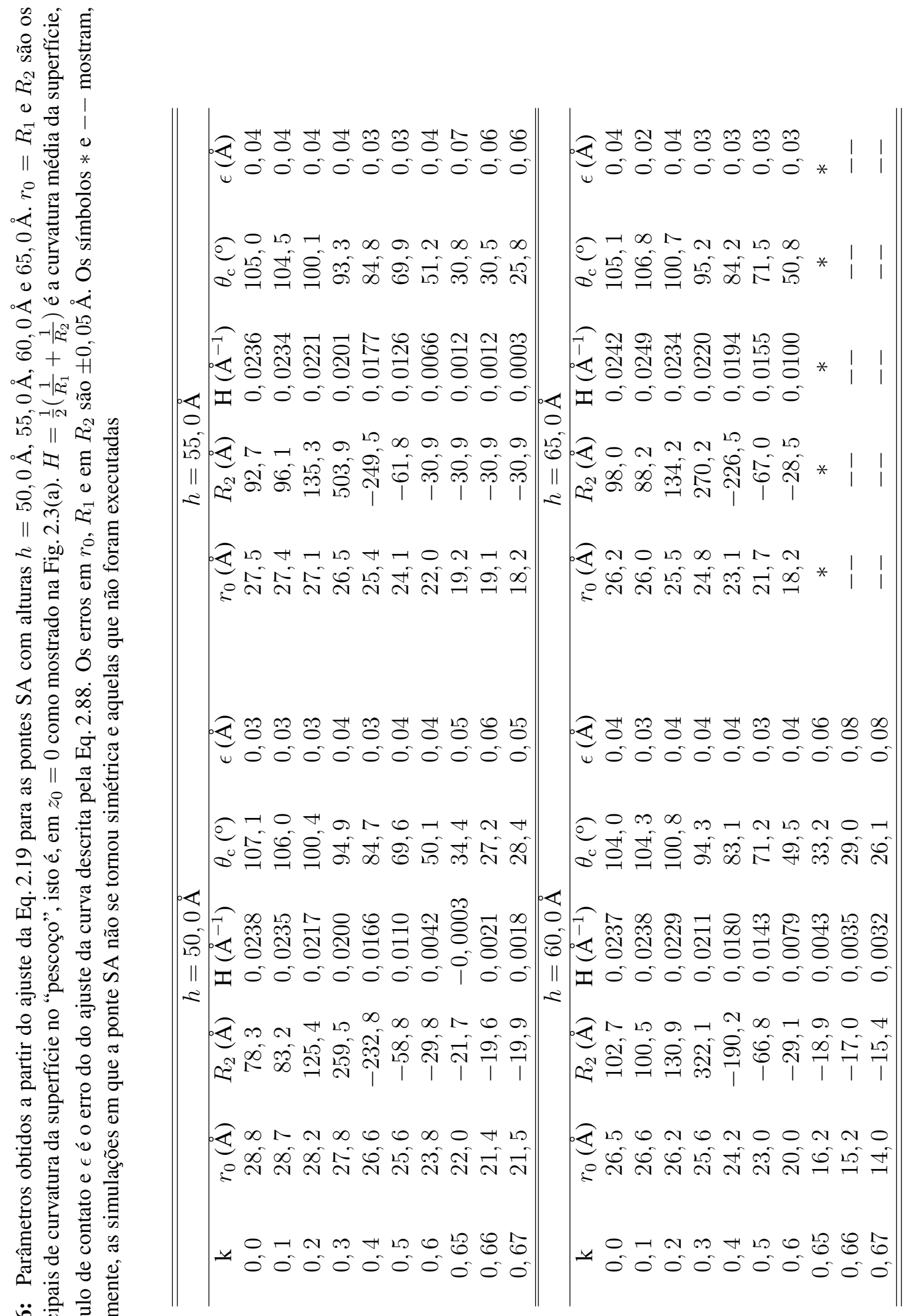




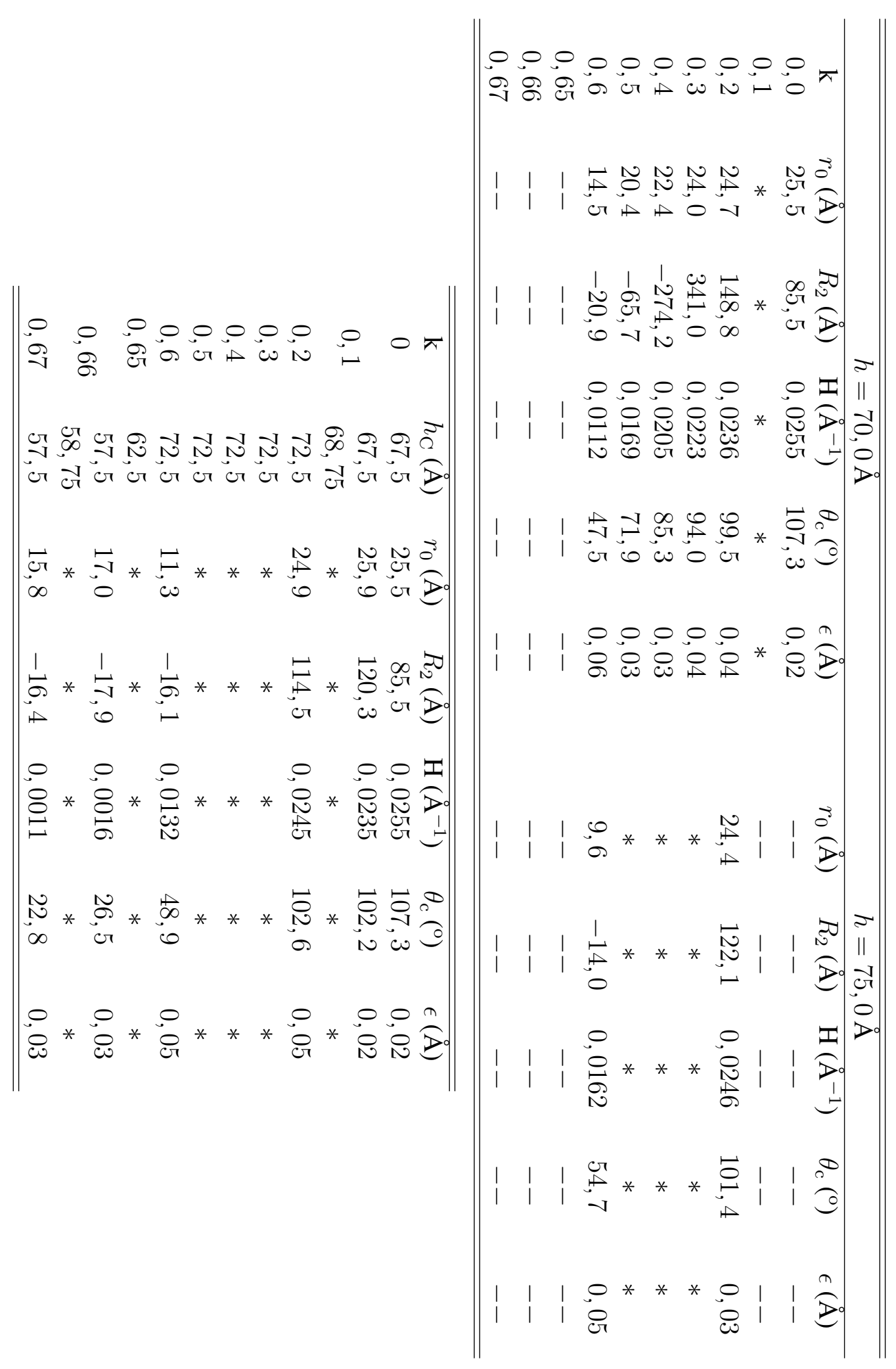

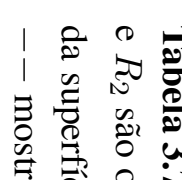

苛. ○) 象 0.

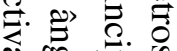

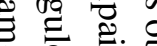
20 0 $\approx 8 \approx$

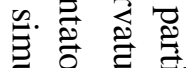
듀요

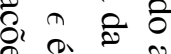
क 0 क 马

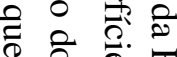
\% के ซ

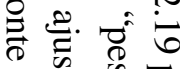
थ के है 융

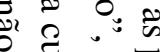
है 5 के के के 용. 용 क. शे हरे के

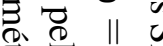
ㅋ. तु i $\overline{0}$ $\infty$ के है 気

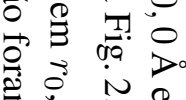
वृ

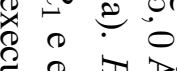
$\cong \approx$

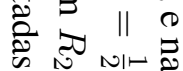

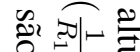
$++\stackrel{5}{*}$ 넨 舟证 P. 0.2 ○ฏ I 害 ? 它 잉 * 
de camadas moleculares, invalidando a aplicação da TC. Valenzuela et al. [100], utilizando 500 moléculas de água do modelo TIP4P/2005, mostrou que na região $h<1,0 \mathrm{~nm}$ a TC não pode ser aplicada devido à formação de camadas moleculares.
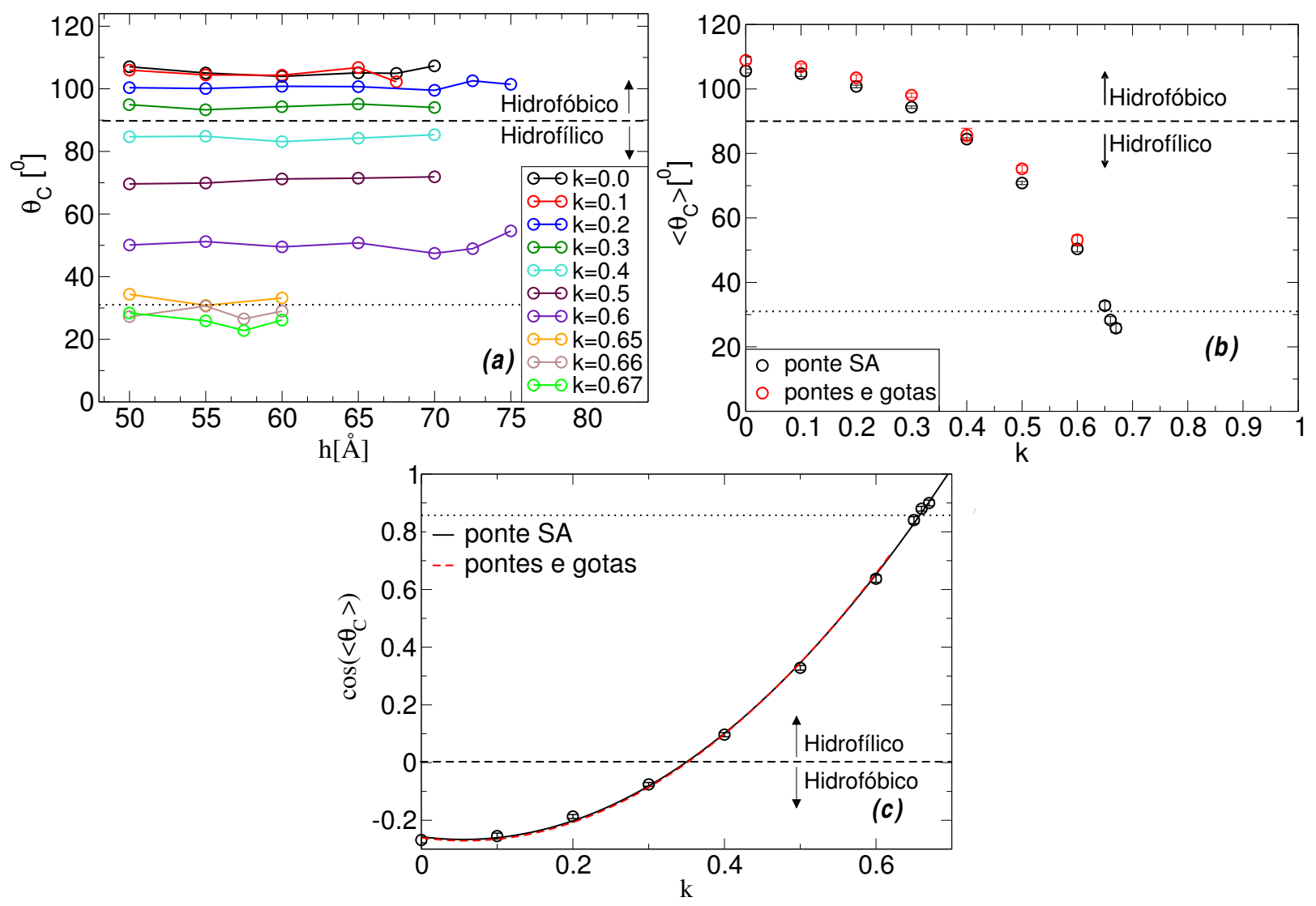

Figura 3.12: (a) Ângulos de contato $\theta_{c}$ das pontes SA com altura $h$ aderidas às placas com polaridade $k$ calculados com a Eq. 2.20 a partir do ajuste de $r(z)$, ver Fig. 3.11. (b) Médias $\left\langle\theta_{\mathrm{c}}\right\rangle$ e (c) $\cos \left\langle\theta_{\mathrm{c}}\right\rangle$, de $\theta_{\mathrm{c}}$ nas diferentes alturas $h$, em função das polaridades $k$ das placas. Para efeito de comparação, estão incluídos os valores de $\theta_{c}$ obtidos nas análises de gotas e pontes SA e ST da Sec.3.1. Em (a) e (b), as linhas tracejadas pretas (pontilhadas) indicam $\theta_{\mathrm{c}}=90^{\circ}\left(\theta_{\mathrm{c}}=31^{\circ}\right)$. O padrão de cores utilizados para designar cada placa com polaridade $k$ permanecem os mesmo para as demais figuras dessa seção e da Sec. 3.2.2. 
Posteriormente, calculamos as áreas $A_{\mathrm{B}}$ e $A_{\mathrm{R}}$, e o volume $\Omega$ utilizando, nesta ordem, as Eqs. 2.89 e 2.90 e a Eq. 2.91. A Figura 3.13(a) mostra $A_{\mathrm{B}}$, a Fig. 3.13(b) mostra $A_{\mathrm{R}}$ e a Fig. 3.13(c) mostra $\Omega$ em função de $h$ para cada uma das placas com polaridade $k$. Observa-se que $A_{\mathrm{B}}$ e $A_{\mathrm{R}}$ variam conforme $h$ é aumentada. Especificamente, $A_{\mathrm{R}}$ aumenta monotonicamente com o aumento de $h$, e varia de até $\approx 15 \%$ para as placas com $k \leq 0,6$ e de até $\sim 25 \%$ para $k=0,65,0,66$ e 0,67 . De outro modo, $A_{\mathrm{B}}$ pode aumentar ou diminuir com o aumento da altura $h$, dependendo da polaridade $k$ das placas. $A_{\mathrm{B}}$ diminui em até $15-17 \%$ para as placas com $k \leq 0,6$; e aumenta em até $28 \%$ para as placas com $k=0,65,0,66$ e 0,67 . Já $\Omega$, embora exiba flutuações, pode ser considerado constante, pois o desvio padrão de $\Omega$ está dentro de $3,2 \%$ da média correspondente. A Figura 3.13(d) mostra o cálculo da energia livre da superfície $\mathcal{F}$ utilizando a Eq. 2.12 e os valores de $\theta_{\mathrm{c}}$ da Tab.3.8, e os respectivos valores analíticos $\mathcal{F}^{\prime}$ obtidos com as Eqs. 2.37 e 2.66. É interessante observar que $\mathcal{F}$ é calculada utilizando os dados das Figs. 3.13(a) e (b), e praticamente não observa-se nenhuma flutuação como nas demais figuras. Os valores obtidos se adequam bem ao resultado teórico.

Tabela 3.8: Médias dos ângulos de contato $\theta_{\mathrm{c}}$ e dos volumes $\Omega$ das pontes SA, obtidos dos perfis mostrados nas Figs. 3.11(a)-(j), em função da polaridade de superfície $k$.

\begin{tabular}{ccc}
\hline \hline $\mathrm{k}$ & $\theta_{\mathrm{c}}\left(^{\mathrm{o}}\right)$ & $\Omega\left(\AA^{3}\right)$ \\
0,0 & 105,6 & 118264,8 \\
0,1 & 104,8 & 120076,0 \\
0,2 & 100,8 & 119603,8 \\
0,3 & 94,3 & 118866,0 \\
0,4 & 84,4 & 116493,9 \\
0,5 & 70,8 & 119066,1 \\
0,6 & 50,4 & 121256,0 \\
0,65 & 32,8 & 122326,4 \\
0,66 & 28,3 & 125617,5 \\
0,67 & 25,8 & 127405,2 \\
\hline \hline
\end{tabular}

Seguindo os mesmos procedimentos da Sec. 3.1.2 da primeira etapa, examinamos agora todas as grandezas associadas às forças que as pontes SA exercem sobre as placas com polaridades $k$ nas alturas $50 \leq h \leq 75 \AA$ A. Assim, medimos a tensão superficial $\gamma$ do modelo de água SPC/E a partir da média $F_{\text {z,placa }}$ das forças $\vec{F}_{\text {placa,i }}$ exercidas pelas moléculas de $\mathrm{H}_{2} \mathrm{O}$ so- 

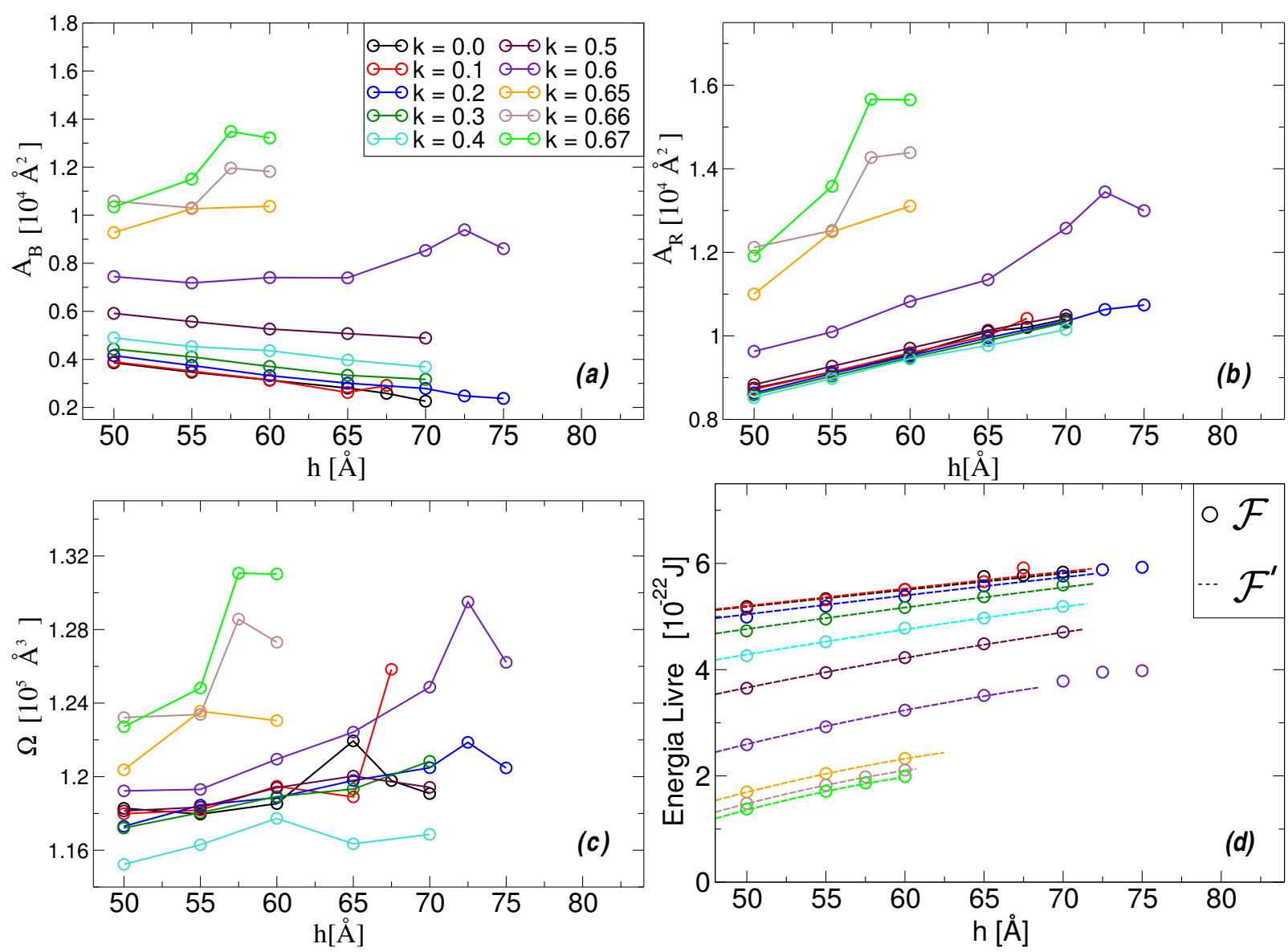

Figura 3.13: Áreas das interfaces (a) líquido-sólido $A_{\mathrm{B}}$, (b) líquido-gás $A_{\mathrm{R}}$, (c) volume $\Omega$ e da energia livre da superfície $\mathcal{F}$, calculadas, respectivamente, pelas Eqs. 2.89, 2.90, 2.91 e 2.13, das pontes SA aderidas às placas com diferentes polaridades $k$ e alturas $h$. As grandezas $A_{\mathrm{B}}, A_{\mathrm{R}}, \Omega$ foram obtidas a partir da integração numérica dos ajustes da Eq. 2.19 e mostrados na Fig. 3.11. Pode-se observar também o valor da energia livre $\mathcal{F}^{\prime}$ calculada analiticamente com as Eqs. 2.37 e 2.66.

bre as placas de $\beta$-cristobalita durante a simulação de DM; relembrando, $\vec{F}_{\text {placa,i }}$ são devidas às interações Coulombianas e de Lennard-Jones. Depois, calculamos as forças no "pescoço" da ponte SA $F_{z, p c ̧ o}$, as forças de adesão capilar $F_{z \text {,base }}$ e as componentes dessa devido à tensão superficial $F_{\gamma}$ e à pressão de Laplace $F_{\mathrm{P}}$; calculamos também as pressões de Laplace no interior das pontes SA por meio da $F_{z, p l a c a}\left(P_{\mathrm{L}}\right)$ e por meio da equação de Young-Laplace $\left(P_{\mathrm{L}_{\mathrm{YL}}}\right)$. Avaliamos também $F_{z \text {,base }}, F_{\gamma}, F_{\mathrm{P}}$ e $P_{\mathrm{L}}$ com o cálculo analítico que elvolve integrais elípticas, e essas grandezas são designadas, nessa ordem, por $F_{\text {z,base }}^{\prime}, F_{\gamma}^{\prime}, F_{\mathrm{P}}^{\prime}$ e $P_{\mathrm{L}}^{\prime}$, ver Sec. 2.1.2.

Para calcular $\gamma$ utilizamos o fato de que as pontes SA estão em equilíbrio mecânico e termodinâmico, e portanto $F_{\text {z,p̧̧o }}=F_{\text {z,base }}$ O valor de $F_{z \text {,base }}$ é estimado a partir da Eq.3.1, assumindo que $F_{\text {z,base }}=F_{\text {z,placa }}$. A Figura 3.15(a) mostra as forças $F_{\text {z,placa }}$ obtidas das simulações DM de todas as pontes SA em função do parâmetro da deformação do "pescoço" $\mathcal{C}(k)$, que 
é calculado com os parâmetros de ajuste $\left(H, r_{0}\right)$ mostrados nas Tabs. 3.6 e 3.7. Observa-se que $F_{\text {z,placa }} \propto \mathcal{C}(k)$, como previsto pela Eq. 2.25, e como já discutido na Fig 3.6 da primeira etapa. Fazendo-se o ajuste do modelo $y=a x$, obtém-se que $\gamma=0,053 \pm 0,002 \mathrm{~N} / \mathrm{m}$. Devemos destacar que não incluímos os dados das placas com polaridade $k=0,65,0,66$ e 0,67 para calcular $\gamma$. A Figura 3.14 mostra uma análise mais detalhada sobre $\gamma$. Observa-se os valores de $\gamma$ calculado como discutido anteriormente $0,053 \pm 0,002 \mathrm{~N} / \mathrm{m}$ (linha contínua azul), calculado a partir das pontes SA e ST na Sec. 3.1.2 (linha tracejada preta), utilizando o método KB na Sec.3.1.3 (linha pontilhada preta), calculado com a equação de Young-Laplace Eq. 2.3 para cada altura $h$ (círculos pretos), calculado com o ajuste do modelo $y=a x$ para cada placa com polaridade $k$ (pontos grandes pretos), e encontrados na literatura [166, 167] (linhas vermelhas). Observamos que os valores de $\gamma$ das placas com polaridades $k=0,65,0,66$ e 0,67 (círculos pretos) apresentam grandes desvios, quando comparados com os outros valores, e por isso os dados dessas placas não foram utilizados no ajuste para calcular $\gamma$, cujo valor será empregado nas demais análises dessa seção. Nossa hipótese para o surgimento dessa discrepância é que existem mais moléculas de água, que não pertencem à ponte $\mathrm{SA}$, espalhadas sobre as placas de $\beta$-cristobalita hidrofílicas com polaridades $k=0,65-0,67$, o que ocasionaria um erro no cálculo das forças $\vec{F}_{\text {placa,i. }}$ Todavia, a inclusão desses pontos resulta em $\gamma=0,052 \pm 0,002 \mathrm{~N} / \mathrm{m}$.

A Figura 3.15(b) mostra as componentes no eixo-z, para todos os valores de $h$ e placas com polaridade $k$, das forças $F_{z, \text { base }}, F_{z, \text { p̧o }}$ e $F_{\text {z,base }}^{\prime}$ medidas pela TC macroscópica e $F_{z, \text { placa }}$ medida pela simulação de DM. Primeiramente, observamos que $F_{\text {z,placa }}$ (círculos) é bem descrita pelas previsões da TC macroscópica. Nota-se que $F_{z, p c ̧ o}$, calculado com a Eq. 2.25, é igual a $F_{\text {z,base }}$, calculado com a Eq. 2.22, $F_{\text {z,base }}=F_{\text {z,pço }}$ (sinais de vezes); por isso somente um desses valores foi plotado. Calculamos $F_{z, \text { pço }}$ e $F_{\text {z,base }}$ utilizando os parâmetros $\left(H, r_{\mathrm{B}}, \theta_{\mathrm{c}}\right)$ obtidos do ajuste dos perfis $r(z)$, mostrados nas Tabs. 3.6 e 3.7, e do valor de $\gamma$ calculado anteriormente. Observa-se também a solução analítica da TC para a força de adesão capilar $F_{\text {base }}^{\prime}$ (linha tracejada), que foi calculada utilizando as Eqs. 2.40 e 2.52, que requer como parâmetros apenas os valores de $\Omega, \theta_{\mathrm{c}}, h$ e $\gamma$. Ambos os métodos, Eqs. 2.22, 2.40 e 2.52, são equivalentes, como pode ser verificado quando comparado com os resultados de $F_{\text {z,placa }}$ das simulações de DM. Assim, mostramos que a TC macroscópica pode prever não apenas a geometria das pontes SA 


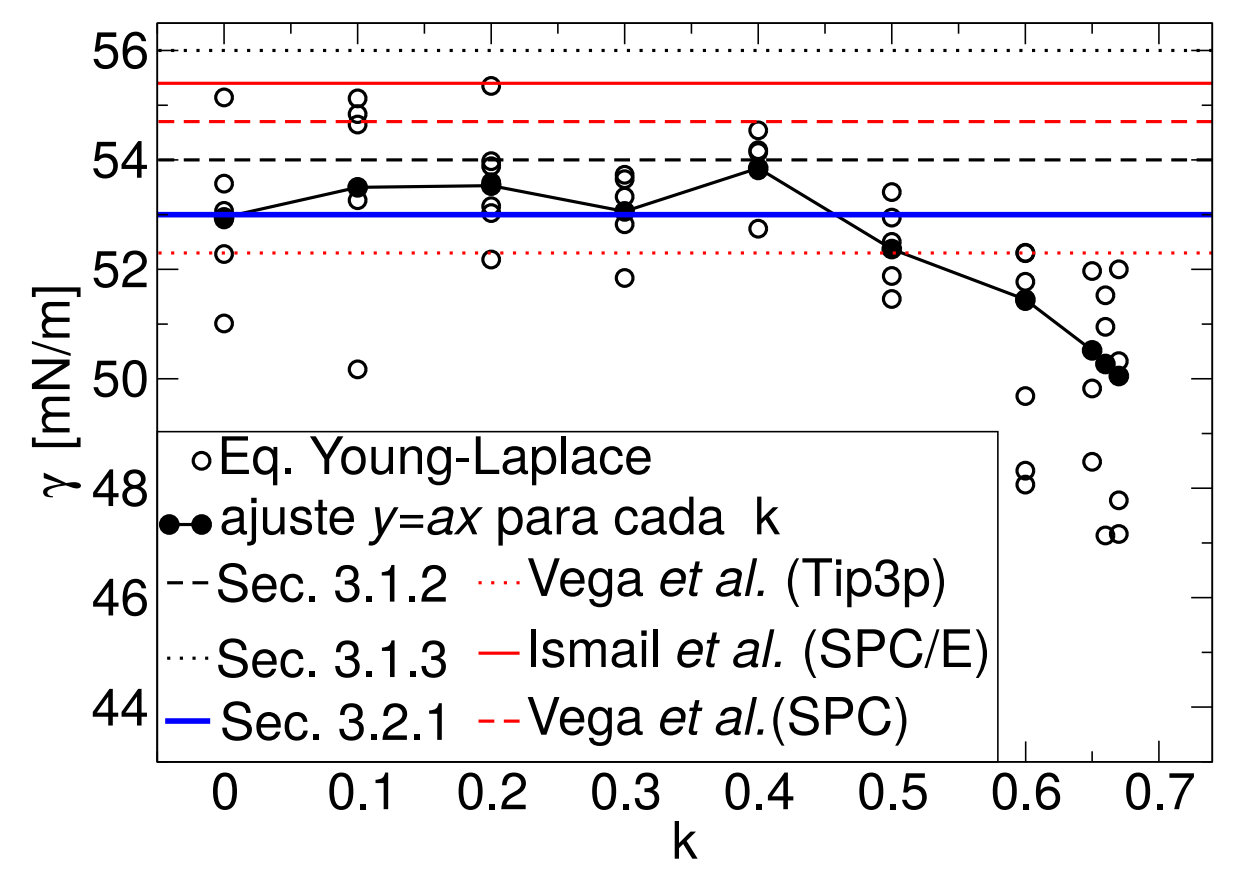

Figura 3.14: Comparação entre as tensões superficiais $\gamma$ calculadas nessa Seção 3.2.1 (linha contínua azul), a partir das pontes SA e ST na Sec.3.1.2 (linha tracejada preta), utilizando o método KB na Sec. 3.1.3 (linha pontilhada preta), com a equação de Young-Laplace Eq. 2.3 para cada altura $h$ (círculos pretos), com o ajuste do modelo $y=a x$ para cada placa com polaridade $k$ (pontos grandes pretos), e encontrados na literatura nos trabalhos de Ismail et al. [166] e Vega et al. [167] (linhas vermelhas). Vega et al. calcularam $\gamma=63,6 \mathrm{mN} / \mathrm{m}$ para o modelo de água SPC/E. Observamos que os valores de $\gamma$ das placas com polaridades $k=0,65,0,66$ e 0,67 (círculos pretos) apresentam grandes desvios dos demais dados, como destacado na região cinza. Por isso esses dados não foram utilizados no para calcular $\gamma$ dessa seção (linha contínua azul).

nanométricas, mas também suas propriedades termodinâmicas, como as forças exercidas sobre as placas. É interessante observar que as previsões da TC são corretas, mesmo para pontes SA nanométricas com dimensões da ordem de $1 \mathrm{~nm}$. Curiosamente, o tamanho da interface líquidovapor típica da água para $T \approx 300 \mathrm{~K}$ é da ordem de $8-10 \AA$ [165, 168], que é compatível com os valores mínimos de $r_{0}$ para as pontes SA estudadas.

A Figura 3.15(c) mostra a componente no eixo $z$ da forças devido à tensão superficial $\gamma$ calculada com a Eq. $2.23 F_{\gamma}$ e calculada com a solução analítica $F_{\gamma}^{\prime}$ com as Eqs. 2.42 e 2.57. A Fig. 3.15(d) mostra as forças devido à pressão de Laplace calculadas com a Eq. $2.24 F_{\mathrm{P}} \mathrm{e}$ calculadas com as soluções analíticas Eqs. 2.44 e $2.59 F_{\mathrm{P}}^{\prime} . F_{\gamma}, F_{\gamma}^{\prime}, F_{\mathrm{P}}$ e $F_{\mathrm{P}}^{\prime}$ foram calculadas para todas as placas com polaridade $k$ e altura $h . F_{\gamma}$, e $F_{\mathrm{P}}$ foram calculadas com os mesmos parâmetros utilizados anteriormente no cálculo de $F_{z \text {,base }}$. Pode-se observar que $F_{\gamma}$ é sempre positiva, como previsto pela Eq. 2.23, e sempre induzirá uma força efetiva atrativa entre as placas 
independentemente de $k$. Por sua vez, $F_{\mathrm{P}}$ pode possuir valores tanto positivos como negativos, ver Eq. 2.24. Para as pontes SA estudadas, $F_{\mathrm{P}}$ se torna atrativa somente para as polaridades $k \geq 0,65$ e aproximadamente $h<50-55 \AA$ A de outro modo, $F_{\mathrm{P}}$ é repulsiva independentemente da hidrofilicidade/hidrofobicidade das placas. Como mostraremos a seguir, as medidas de $F_{\mathrm{P}}$ podem ser somente atrativas devido a pressões de Laplace negativas, e isso é um fato inerente à escala nanométrica do problema.
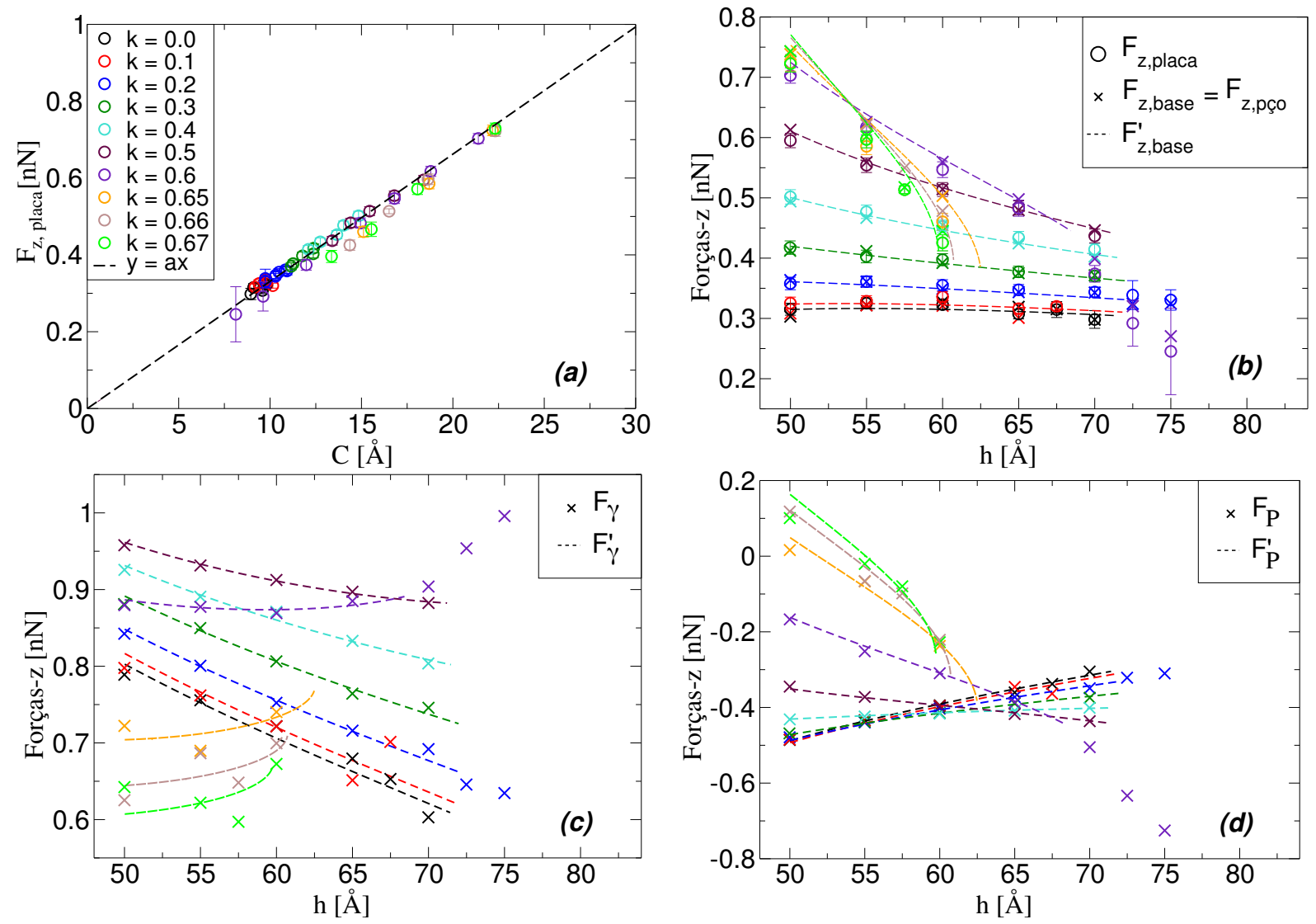

Figura 3.15: (a) Média temporal $F_{z, p l a c a}$ (círculos) das forças $\vec{F}_{\text {placa,i }}$ exercidas pelas moléculas de água sobre as placas em função do parâmetro de deformação de "pescoço" da ponte SA $\mathcal{C}=r_{0}$ $H r_{0}^{2}$. A tensão superficial $\gamma$ foi obtida a partir do ajuste linear com o modelo $y=a x$ (linha tracejada) interceptando a origem; não foram considerados os dados obtidos da simulação para $k=0,65,0,66 \mathrm{e}$ 0,67 ; obtivemos $\gamma=0,053 \pm 0,002 \mathrm{~N} / \mathrm{m}$. (b) Componentes medidas no eixo z das forças de adesão capilar $F_{\text {z,base }}$ calculada com a Eq. 2.22, forças no "pescoço" das pontes SA $F_{\text {z,pço }}$ (sinais de vezes) calculada com a Eq. 2.25 e de $F_{z \text {,placa }}$ em função da altura $h$, e para todas as placas com polaridades $k$. Notamos que $F_{z, p c ̧ o}=F_{z \text {,placa }}$ e por isso somente um conjunto de dados foi plotado. (c) Componente da força de adesão capilar da ponte SA devido a $\gamma F_{\gamma}$ (sinais de vezes), calculado com a Eq. 2.23, e (d) componente devido à pressão de Laplace $F_{\mathrm{P}}$ (sinais de vezes), calculado com a Eq. 2.24, em função de $h$ e k. $\mathcal{C}, F_{\text {z,base }}, F_{\text {z,pço }}, F_{\gamma}$ e $F_{\mathrm{P}}$ foram calculados com os parâmetros de ajuste mostrados nas Tabs. 3.6 e 3.7. Nas Figuras (b)-(d), $F_{z, \text { base }}^{\prime}, F_{\gamma}^{\prime}$ e $F_{\mathrm{P}}^{\prime}$ (linhas tracejadas) mostram as soluções analíticas da TC que envolvem integrais elípticas, ver Eqs. 2.40, 2.52, 2.42, 2.57, 2.44 e 2.59 da Sec. 2.1.2.

Nessa última fase, estudamos a pressão de Laplace no interior das pontes SA medidas de três 
formas diferentes $\left(P_{\mathrm{L}}, P_{\mathrm{L}_{\mathrm{Y}}}\right.$ e $\left.P_{\mathrm{L}}^{\prime}\right)$, e a Fig. 3.16 mostra os valores dessas medidas em função da altura $h$ e para todas as placas com polaridades $k$ estudadas. Calculamos $P_{\mathrm{L}}$ (círculos) a partir das simulações de DM utilizando a Eq. 2.26, em que assumimos que $F_{\text {z,base }}=F_{z \text {,placa }}$, e o raio da base $r_{\mathrm{B}}$ e o ângulo de contato $\theta_{\mathrm{c}}$ foram medidos a partir do ajuste do perfil da ponte SA $r(z)$. Depois, calculamos $P_{\mathrm{LYL}_{\mathrm{Y}}}$ (sinais de vezes) diretamente da equação de Young-Laplace Eq. 2.3 considerando que $P_{\mathrm{ex}}=0, P_{\mathrm{L}_{\mathrm{YL}}}=P_{\mathrm{in}}=\gamma 2 H$, e utilizando o valor da curvatura $H$ obtida do ajuste de $r(z)$. Finalmente, calculamos a solução analítica da pressão de Laplace $P_{\mathrm{L}}^{\prime}$ (linhas tracejadas) dadas pelas Eqs. 2.43 e 2.58, que é baseada em integrais elípticas. Os valores de $r_{\mathrm{B}}, \theta_{\mathrm{c}}$ e $H$ utilizados nos cáculos de $P_{\mathrm{L}}$ e $P_{\mathrm{L}_{\mathrm{Y}}}$ são mostrados nas Tabs. 3.6 e 3.7. Nos três casos utilizamos $\gamma=0,053 \pm 0,002 \mathrm{~N} / \mathrm{m}$, calculando nessa seção. Como esperado, a pressão de Laplace calculada nas três abordagens são consistentes.

A Figura 3.16 mostra mais uma vez, pela análise de $P_{\mathrm{L}}, P_{\mathrm{L}_{\mathrm{YL}}}$ e $P_{\mathrm{L}}^{\prime}$, que a TC macroscópica é bem sucedida para explicar interfaces de gotas e pontes capilares com volumes da ordem de $100 \mathrm{~nm}^{3}$. Um dos resultados mais interessantes dessa figura é que a pressão de Laplace pode ser negativa, comportamento que não pode ser encontrado em pontes SA na escala macroscópica. Isso acontece por conta dos pequenos valores do raio do "pescoço" $r_{0}$ das pontes SA nanométricas, que determinam o sinal da curvatura $H$ na equação de Young-Laplace Eq. 2.3. Outro fato interessante observado é a amplitude de valores que a pressão de Laplace pode atingir. Observa-se que quando a ponte SA é esticada há um aumento considerável da pressão, independentemente da polaridade das placas. Por exemplo, para $k=0,6$, a pressão praticamente dobra quando $h$ aumenta de 50 para $75 \AA$.

\subsubsection{Mecanismos de ruptura e limite da estabilidade da ponte capilar com simetria axial}

Agora, avaliaremos o mecanismo de ruptura das pontes SA, que estão aderidas às placas de $\beta$-cristobalita com diferentes polaridades $k$, nas alturas críticas $h_{\mathrm{C}^{\prime}}$ e $h_{\mathrm{C}}$. As Figuras 3.17(a)-(j) e Figuras 3.19(a)-(j) mostram, respectivamente, a evolução temporal das pontes SA em $h_{\mathrm{C}^{\prime}}$ e $h_{\mathrm{C}}$. Cada linha representa um perfil $r_{\mathrm{p}}(z)$ da ponte SA, calculado com $0,1 \mathrm{~ns}$ de configurações $\vec{r}_{\mathrm{H}_{2} \mathrm{O}}$ geradas nas simulações de DM, como discutido na Sec. 2.3. Vale ressaltar que são observados perfis inteiros porque não calculamos a média de $r_{\mathrm{p}}(z)$ entre as regiões $0<z<h / 2$ e 


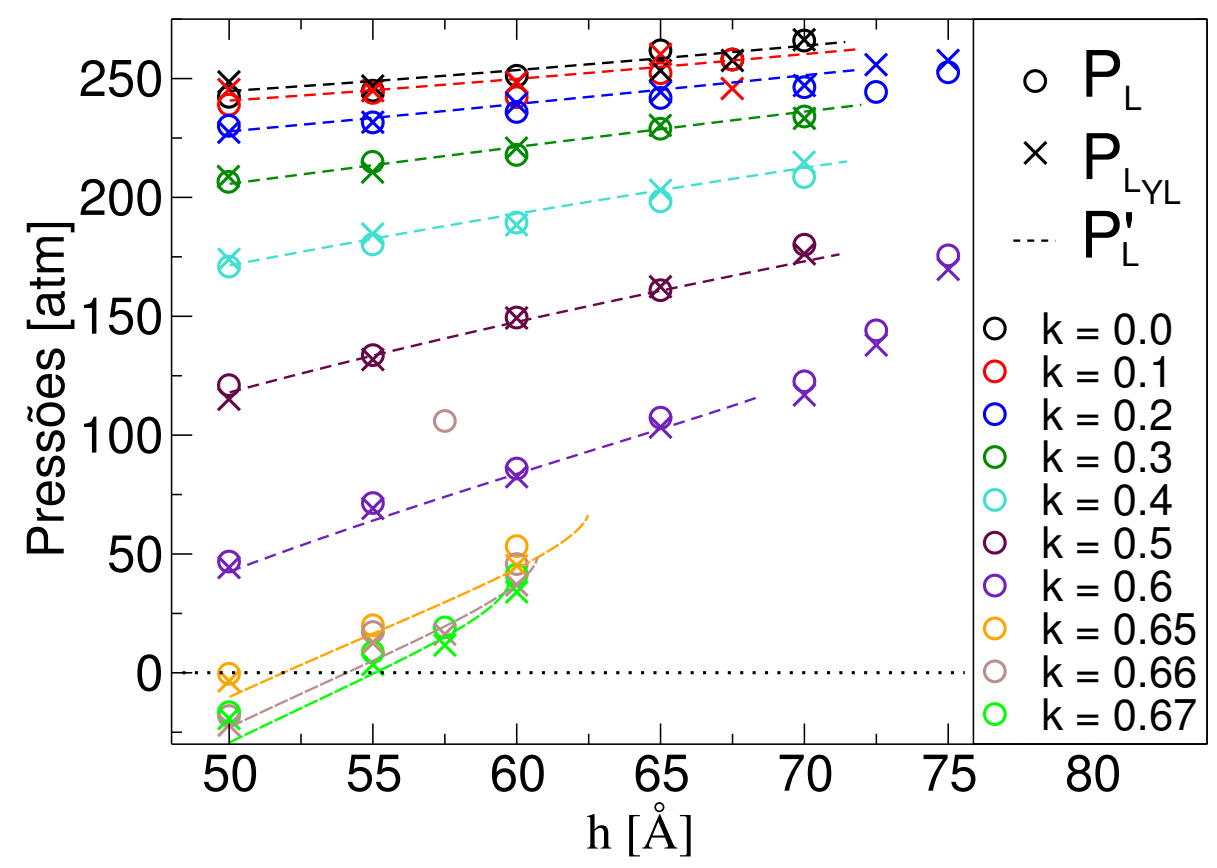

Figura 3.16: Pressão de Laplace no interior das pontes SA em função da altura $h$, e para cada placa com polaridade $k$. Utilizamos três formas de calcular a pressão de Laplace: $P_{\mathrm{L}}$ (círculos) é calculada a partir da Eq. 2.26 e utilizando as médias temporais das forças $F_{\mathrm{z}, \mathrm{placa}}$ nas simulação de DM; $P_{\mathrm{L}_{\mathrm{YL}}}$ (sinais de vezes) é calculada a partir da equação de Young-Laplace Eq. 2.3; $P_{\mathrm{L}}^{\prime}$ (linhas tracejadas) são os cálculos análiticos obtidos com cálculo variacional e com base na minimização da energia livre pelas Eqs. $2.43 \mathrm{e}$ 2.58 .

$0>z>-h / 2$, pois a ponte SA pode se tornar assimétrica. O gradiente de cores de $r_{\mathrm{p}}(z)$, do azul para o magenta, mostra a evolução temporal das pontes SA, em que o azul representa o inicio da simulação. Verifica-se que $r_{\mathrm{p}}(z)$ evolui com o tempo apresentando alterações no formato, o que mostra que os principais parâmetros da ponte $\mathrm{SA}$, como os raios das bases $r_{\mathrm{B}}$, raios $r_{0}$ e alturas $z_{0}$ do "pescoço" possuem flutuações características, que devem se distinguir quanto à região de estabilidade $h<h_{\max }$ e instabilidade $h>h_{\max }$. Verifica-se ainda nessas figuras, que existe um instante $\tau_{\mathrm{s}}$ em que as pontes SA perdem sua simetria e em outros casos a ponte SA já está assimétrica no inicio da simulação. Uma vez que a ponte SA se torna assimétrica é iniciada a ruptura que acontece de maneira abrupta. O tempo $\tau_{\mathrm{r}}$ é o exato instante que ocorre a ruptura, e é caracterizado pela configuração $\vec{r}_{\mathrm{H}_{2} \mathrm{O}}$ que possui uma das densidades nula $\rho_{0}(r)=0$ no interior das caixas de tamanho $L \times L \times 5 \AA^{3}$, ver Sec. 2.3. Os valores de $\tau_{\mathrm{s}} \mathrm{e}$ $\tau_{\mathrm{r}}$ são mostrados na Tab. 3.9, e nos casos em que a ponte SA já estava assimétrica no início da simulação consideramos $\tau_{\mathrm{s}}=0$. Vale enfatizar que o valor de $\tau_{\mathrm{r}}$ calculado é o resultado de uma única simulação. As Figs. 3.18(a)-(j) e Figs. 3.20(a)-(j) mostram as configurações $\vec{r}_{\mathrm{H}_{2} \mathrm{O}}$ para 
todas as pontes SA estudadas no tempo $\tau_{\mathrm{r}}$.

Avaliando os valores de $\tau_{\mathrm{r}}$ nota-se que, em geral, esses são menores para $h_{\mathrm{C}^{\prime}}$. Essa observação pode ser analisada com os trabalhos de Men et al.[110] e Bak et al.[67] que verificaram, respectivamente, por meio de simulações e teorias, que para que haja a ruptura da ponte capilar existe uma barreira de energia livre que deve ser transposta, e que essa diminui com a altura da ponte capilar. Desse modo, pontes capilares em alturas mais baixas, como no caso $h_{\mathrm{C}}<h_{\mathrm{C}^{\prime}}$, podem demorar mais tempo para transpor a barreira de energia livre e romper. Na maioria dos casos, as pontes SA rompem em menos de $20 \mathrm{~ns}$ e somente as pontes SA aderidas às placas com polaridades $k=0,1,0,2$ e 0,3 possuem $\tau_{\mathrm{r}}$ maiores para $h_{\mathrm{C}^{\prime}}$, ao invés de $h_{\mathrm{C}}$. A ponte SA com $h=\left(h_{\mathrm{S}}+2,5\right)+1,25=58,75 \AA$ e aderida à placa com polaridade $k=0,66$ não rompeu mesmo para $20 \mathrm{~ns}$. Vale salientar, que a ruptura é um processo aleatório o que justifica os valores de $\tau_{\mathrm{r}}$ observados.

Com relação ao número e volume das gotas SA formadas após a ruptura da ponte SA, nota-se que essa se rompe em uma única gota SA aderida a uma das placas com polaridade $k \leq 0,4$, ou em duas gotas SA aderidas em cada uma das placas para $k>0,4$. Esse fato pode sugerir que para placas hidrofóbicas as pontes SA se rompem originando uma gotas e para placas hidrofílicas as pontes SA se rompem originando duas gotas. A Figura 3.12(b) mostra esse fato com mais clareza, pois o ângulo de contato para $k=0,4$ é aproximadamente $85^{\circ}$, que é próximo de $\theta_{\mathrm{c}}(k)=90^{\circ}(k \approx 0,37)$, que separa as superfícies de $\beta$-cristobalita em hidrofílicas e hidrofóbicas.

Avaliaremos agora a ruptura das pontes SA que estão aderidas às placas com polaridade $k>0,4$ em que são formadas duas gotas SA após a ruptura, e focaremos nos casos em que $\theta_{\mathrm{c}}<31^{\circ}$, pois, como previsto teoricamente Sec.2.1.2, as duas gotas SA formadas devem ter volumes idênticos a $\Omega / 2$, em que $\Omega$ é o volume da ponte SA. Para estimar o volume de cada gota SA formada, contamos o número de moléculas de água da configuração $\vec{r}_{\mathrm{H}_{2} \mathrm{O}}$ do instante $\tau_{\mathrm{r}}$, mostradas na Figs. 3.18(a)-(j) e Figs.3.20(a)-(j), que estão separadas por uma região de tamanho $L \times L \times 5 \AA^{3}$ com densidade nula $\rho_{0}(r)=0$. Então, calculamos a diferença $\Delta N_{\mathrm{g}}$ entre o número de moléculas de $\mathrm{H}_{2} \mathrm{O}$ da maior e da menor gota $\mathrm{SA}$ formada e normalizamos pelo número total dessas moléculas $N=3375,\left|\Delta N_{\mathrm{g}}\right| / N$. Observa-se que essa grandeza está 

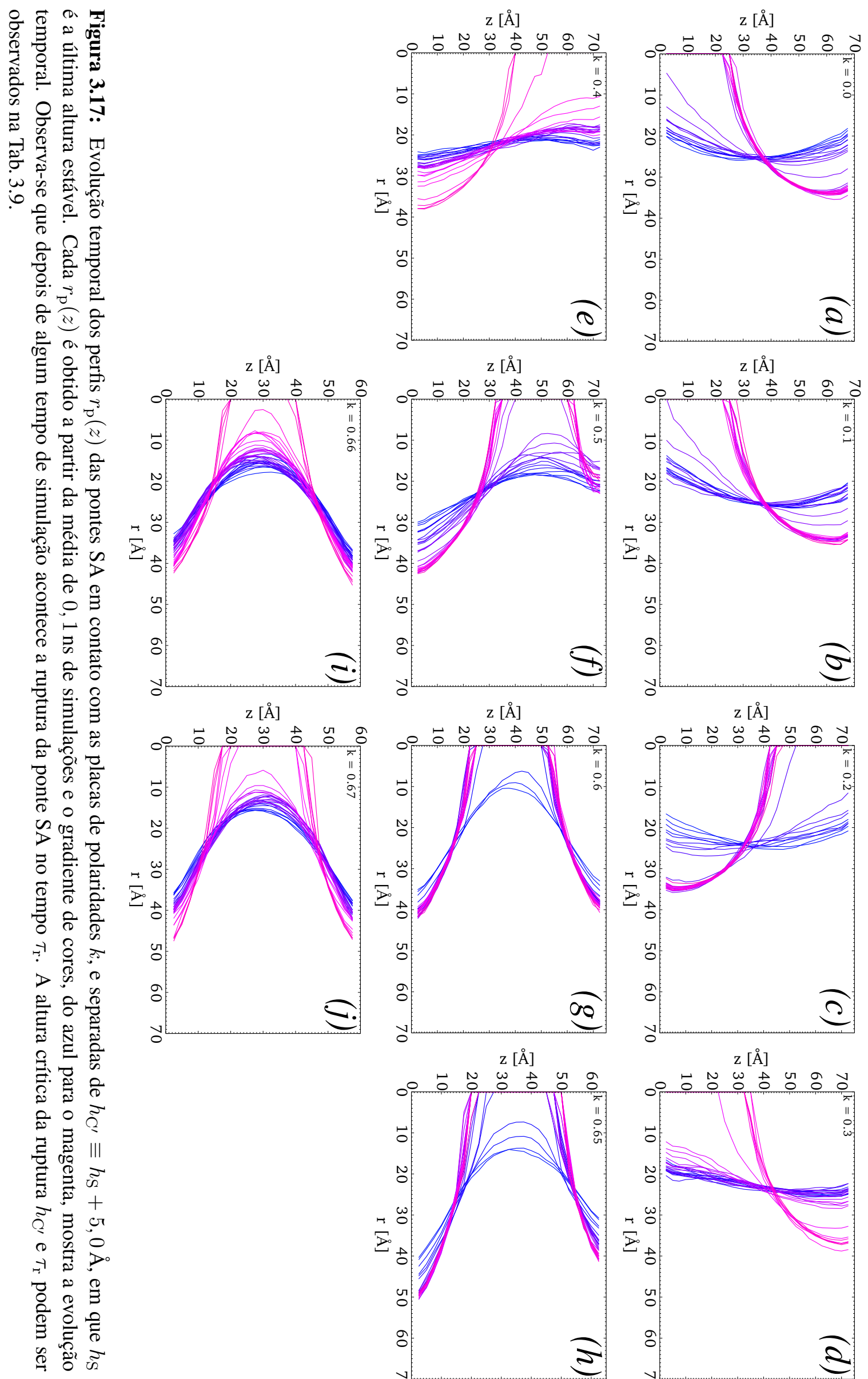

政
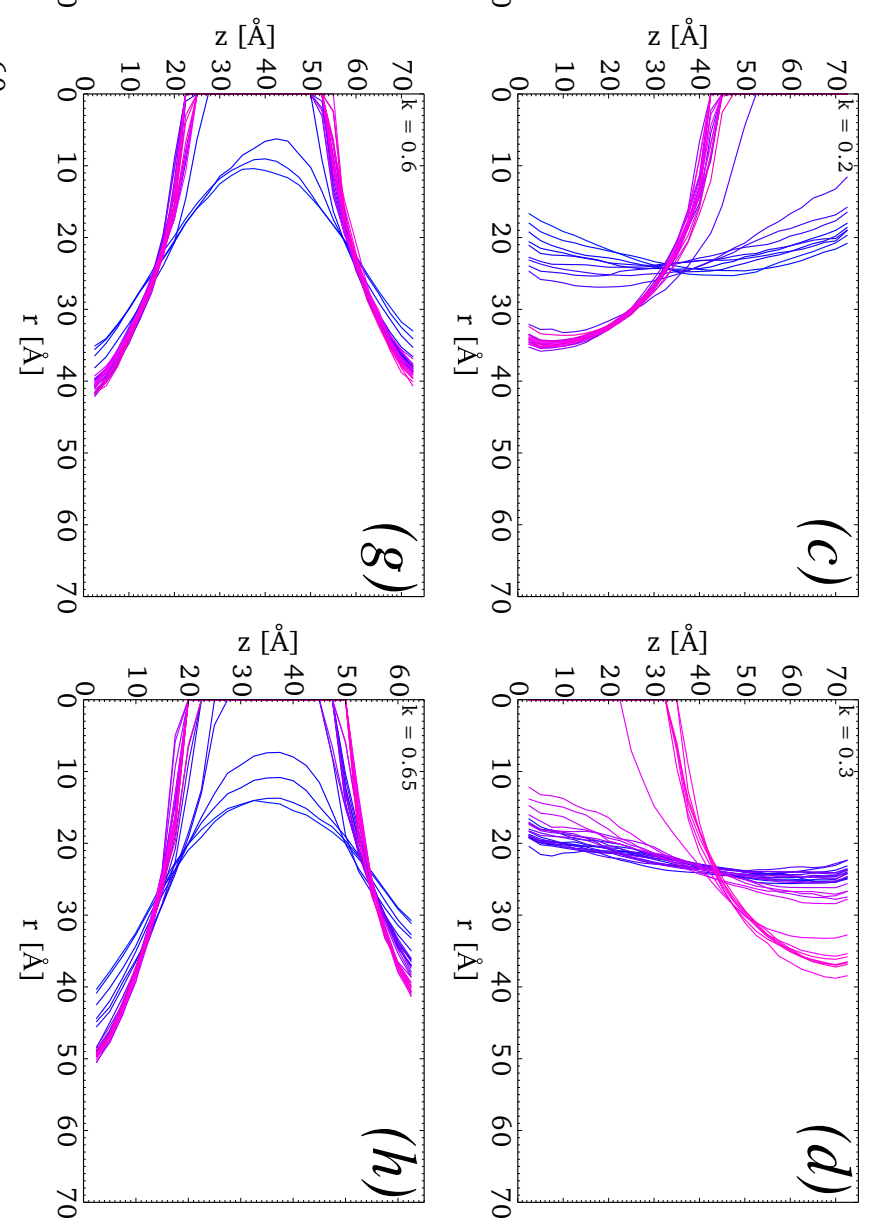
CAPÍTULO 3. RESULTADOS E DISCUSSÕES

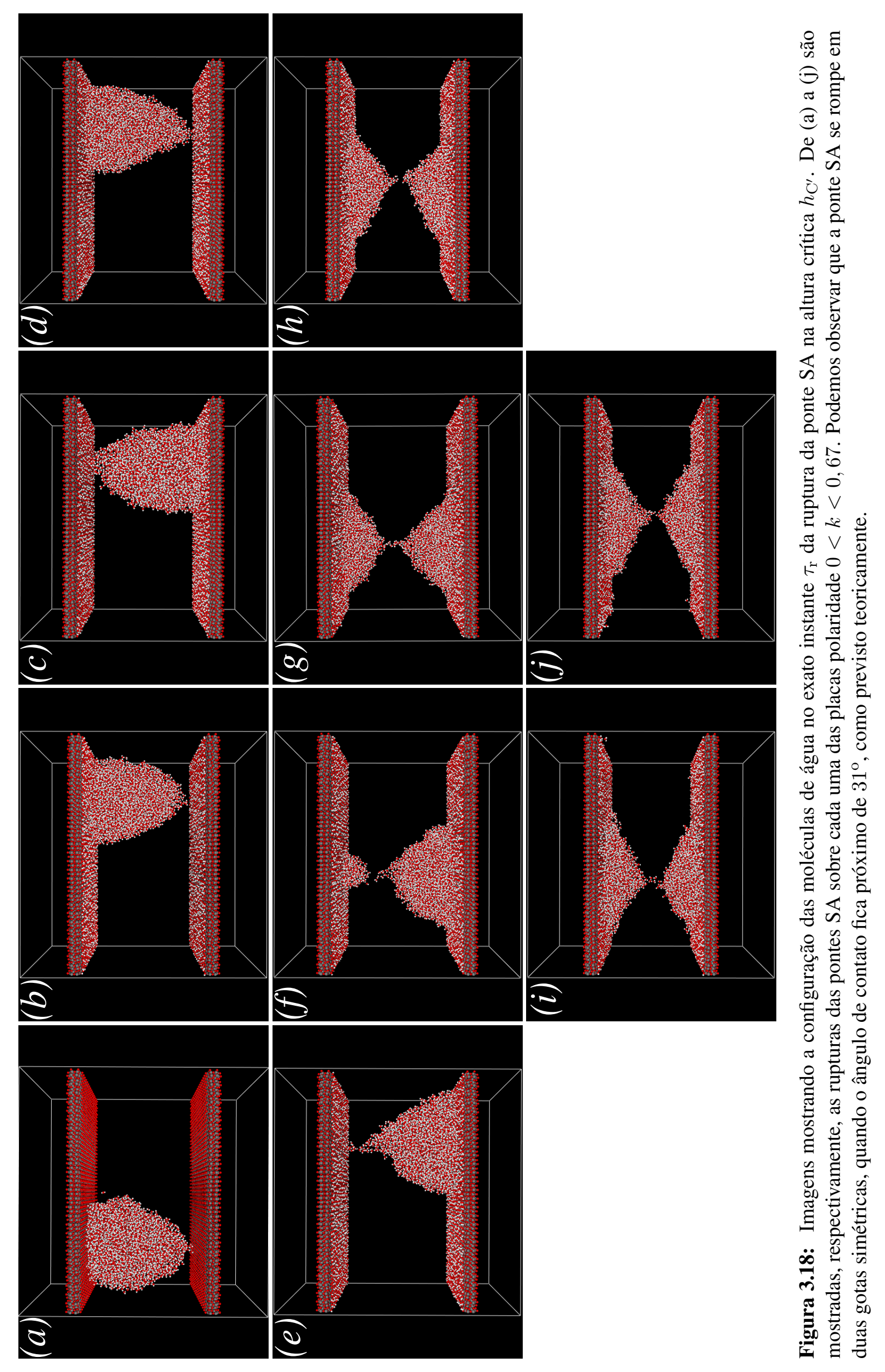



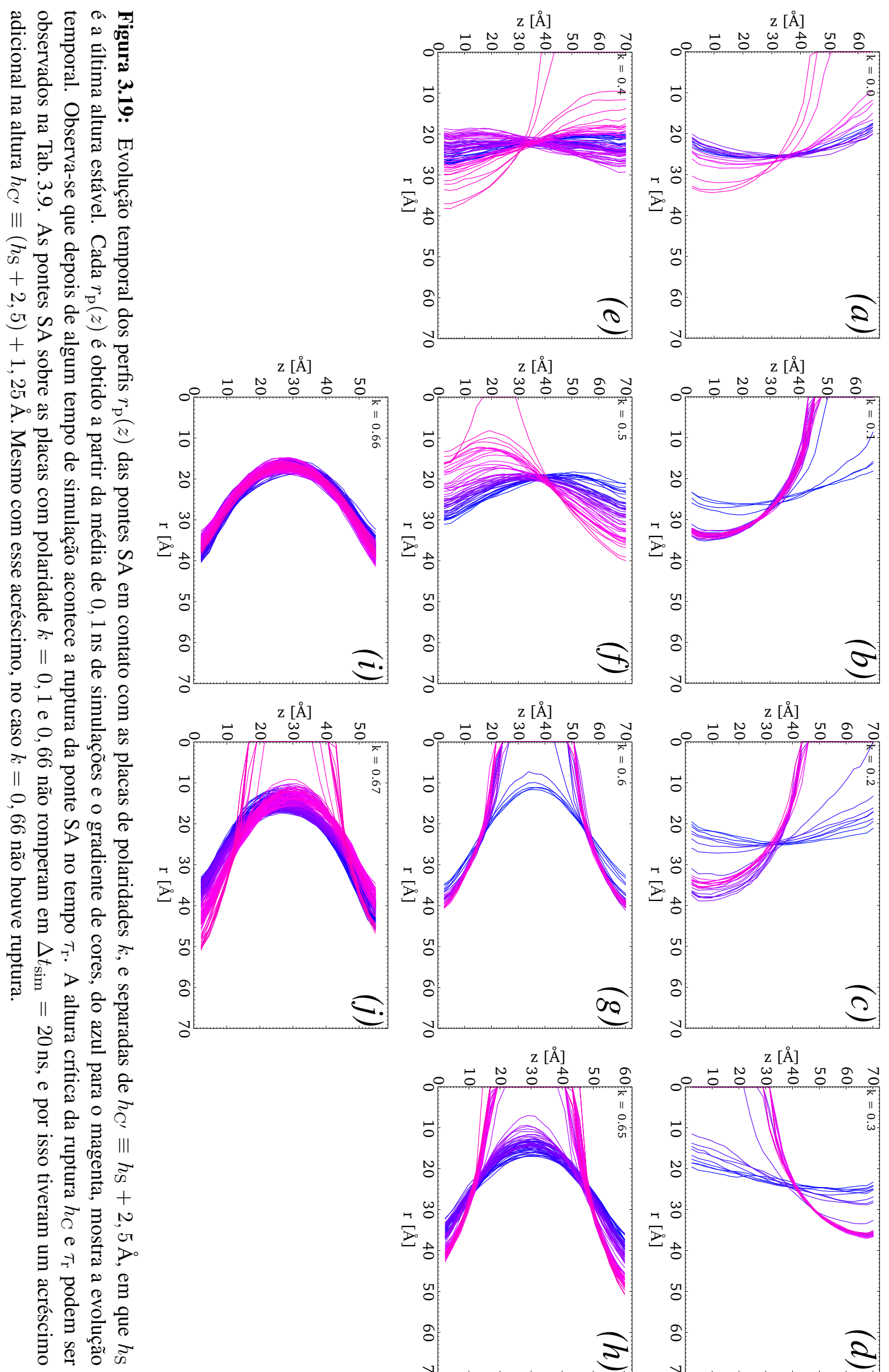

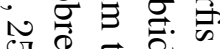
P० की

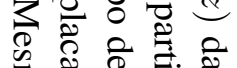
की 5 .

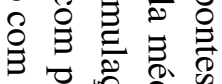
क ०ै है थ ก है के

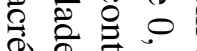
仓. से ठै ठำ के 亏 औ ० 0 की स का कृ

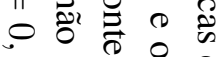
웅 ज्ञ 気营 จ ช

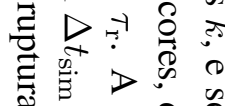
$11 \cong$ \% ธิ๊ 응 क
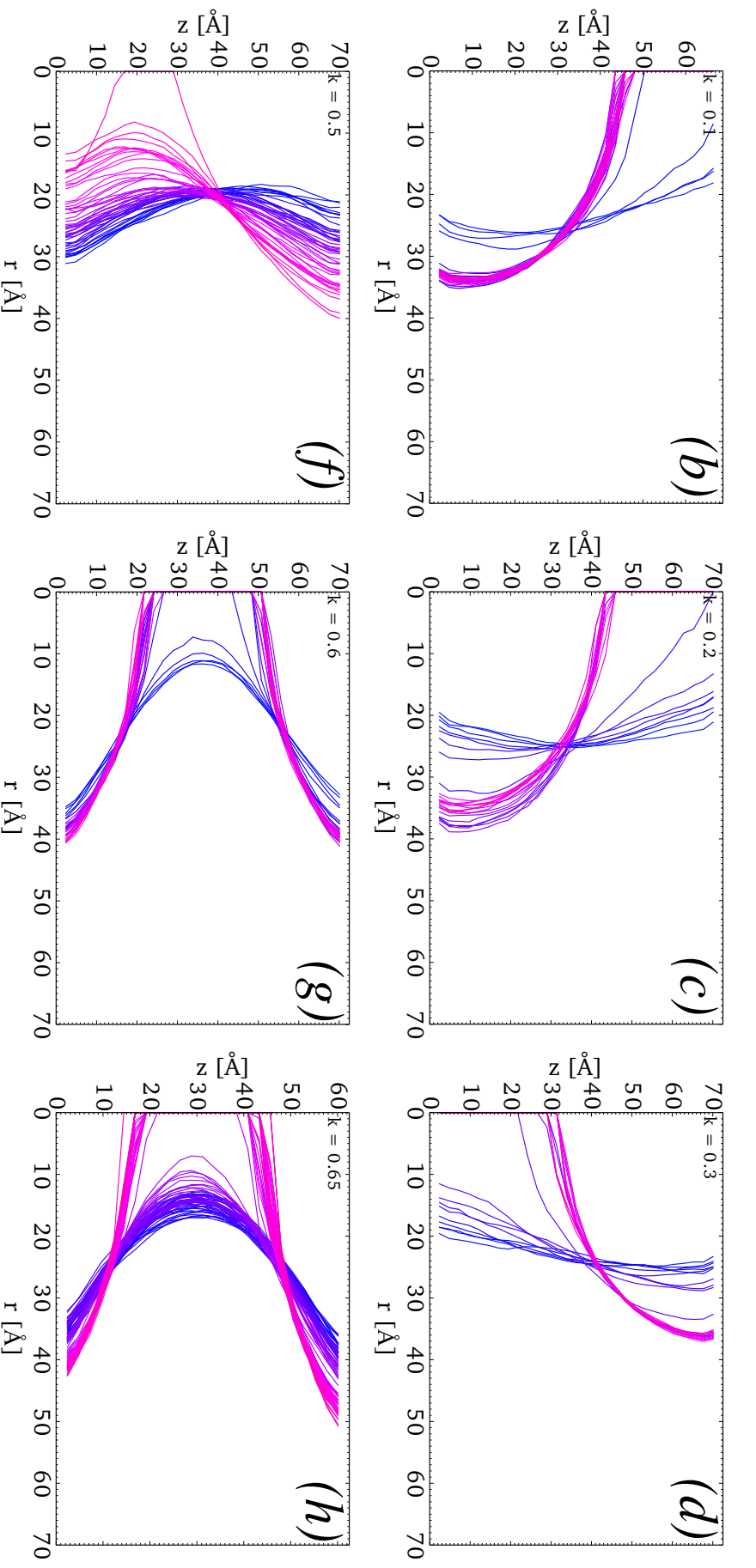
CAPÍTULO 3. RESULTADOS E DISCUSSÕES

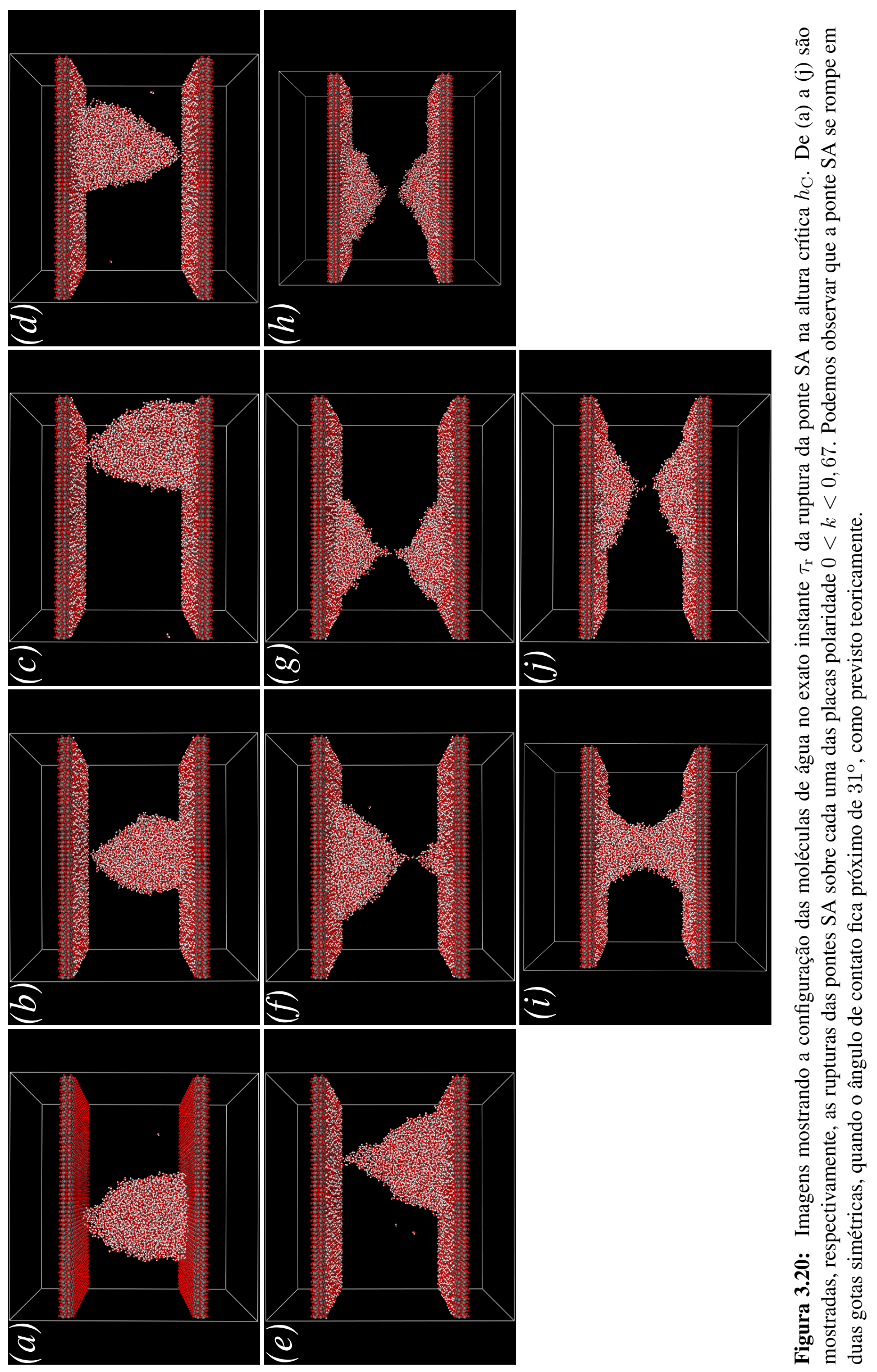


Tabela 3.9: Parâmetros obtidos da análise das configurações $\vec{r}_{\mathrm{H}_{2} \mathrm{O}}$ das pontes SA com alturas críticas $h_{\mathrm{C}}$ e $h_{\mathrm{C}^{\prime}}$ e aderidas às placas de $\beta$-cristobalita com polaridade $k$ formando um ângulo de contato $\theta_{\mathrm{c}}$. $\tau_{\mathrm{s}}$ é o instante em que a ponte SA se torna assimétrica e $\tau_{\mathrm{r}}$ é o instante exato da ruptura. Vale enfatizar que o valor de $\tau_{\mathrm{r}}$ calculado é o resultado de uma única simulação. $\Delta N_{\mathrm{g}} / N$ é medido no instante $\tau_{\mathrm{r}}$ e é a fração entre a diferença $\Delta N_{\mathrm{g}}$ da quantidade de moléculas de $\mathrm{H}_{2} \mathrm{O}$ da maior e da menor gota $\mathrm{SA}$ que se formam após a ruptura da ponte $\mathrm{SA}$, e o número total de moléculas de água $N=3375$. Quando a ponte SA fica assimétrica logo após o movimento da parede, consideramos que $\tau_{\mathrm{s}}=0$.

\begin{tabular}{|c|c|c|c|c|c|}
\hline $\mathrm{k}$ & $\left.\theta_{\mathrm{c}} \mathrm{c}^{\mathrm{o}}\right)$ & $h_{\mathrm{C}^{\prime}}$ e $h_{\mathrm{C}}(\AA)$ & $\Delta N_{\mathrm{g}} / N$ & $\tau_{\mathrm{s}}(\mathrm{ps})$ & $\tau_{\mathrm{r}}(\mathrm{ps})$ \\
\hline \multirow{2}{*}{0} & \multirow{2}{*}{105,6} & 70,0 & 1,000 & 600 & 1234 \\
\hline & & 67,5 & 1,000 & 800 & 1575 \\
\hline \multirow{2}{*}{0,1} & \multirow{2}{*}{104,8} & 70,0 & 1,000 & 0 & 1332 \\
\hline & & 68,75 & 1,000 & 0 & 367 \\
\hline \multirow{2}{*}{0,2} & \multirow{2}{*}{100,8} & 75,0 & 1,000 & 500 & 881 \\
\hline & & 72,5 & 1,000 & 300 & 717 \\
\hline \multirow{2}{*}{0,3} & \multirow{2}{*}{94,3} & 75,0 & 1,000 & 0 & 2094 \\
\hline & & 72,5 & 1,000 & 0 & 889 \\
\hline \multirow{2}{*}{0,4} & \multirow{2}{*}{84,4} & 75,0 & 1,000 & 0 & 2514 \\
\hline & & 72,5 & 1,000 & 0 & 7284 \\
\hline \multirow{2}{*}{0,5} & \multirow{2}{*}{70,8} & 75,0 & 0,873 & 0 & 1402 \\
\hline & & 72,5 & 0,909 & 0 & 4915 \\
\hline \multirow{2}{*}{0,6} & \multirow{2}{*}{50,4} & 75,0 & 0,086 & 150 & 262 \\
\hline & & 72,5 & 0,004 & 350 & 500 \\
\hline \multirow{2}{*}{0,65} & \multirow{2}{*}{32,8} & 65,0 & 0,124 & 0 & 334 \\
\hline & & 62,5 & 0,215 & 4500 & 5687 \\
\hline \multirow{2}{*}{0,66} & \multirow{2}{*}{28,9} & 60,0 & 0,048 & 2500 & 3341 \\
\hline & & 58,75 & --- & --- & --- \\
\hline \multirow{2}{*}{0,67} & \multirow{2}{*}{26,8} & 60,0 & 0,045 & 1800 & 2159 \\
\hline & & 57,5 & 0,149 & 1650 & 18617 \\
\hline
\end{tabular}

restringida ao intervalo $0 \leq \Delta N_{\mathrm{g}} / N \leq 1$. Assim, se a ponte SA se rompe em uma única gota $\Delta N_{\mathrm{g}} / N=1$, e se a pontes $\mathrm{SA}$ se rompe em duas gotas idênticas $\Delta N_{\mathrm{g}} / N=0$. A Tabela 3.9 mostra todos os valores calculados de $\Delta N_{\mathrm{g}} / N$ para todas as placas com polaridades $k$ e a Fig.3.21 mostra $\Delta N_{\mathrm{g}} / N$ em função de $\theta_{\mathrm{c}}$. Embora $\Delta N_{\mathrm{g}} / N$ apresente um certo ruído para $\theta_{c}<90^{\circ}$, os resultados das simulações de DM são consistentes com as previsões da TC. Para $\theta_{\mathrm{c}} \approx 31^{\circ}$ o volume das gotas SA formadas são aproximadamente $\Omega / 2$.

Em seguida, como mostrado na Fig. 3.22, as alturas críticas em que ocorrem as rupturas das ponte SA obtidas a partir das simulações de DM, $h_{\mathrm{C}}$ (sinal de vezes preto) e $h_{\mathrm{C}^{\prime}}$ (sinal de vezes vermelho), foram comparadas com as correspondentes predições da TC das rupturas assimétrica $h_{\max , a}$ (linha contínua), dada pela Eqs. 2.46 e 2.69, e simétricas $h_{\max , \mathrm{s}}$ (linha tracejada- 


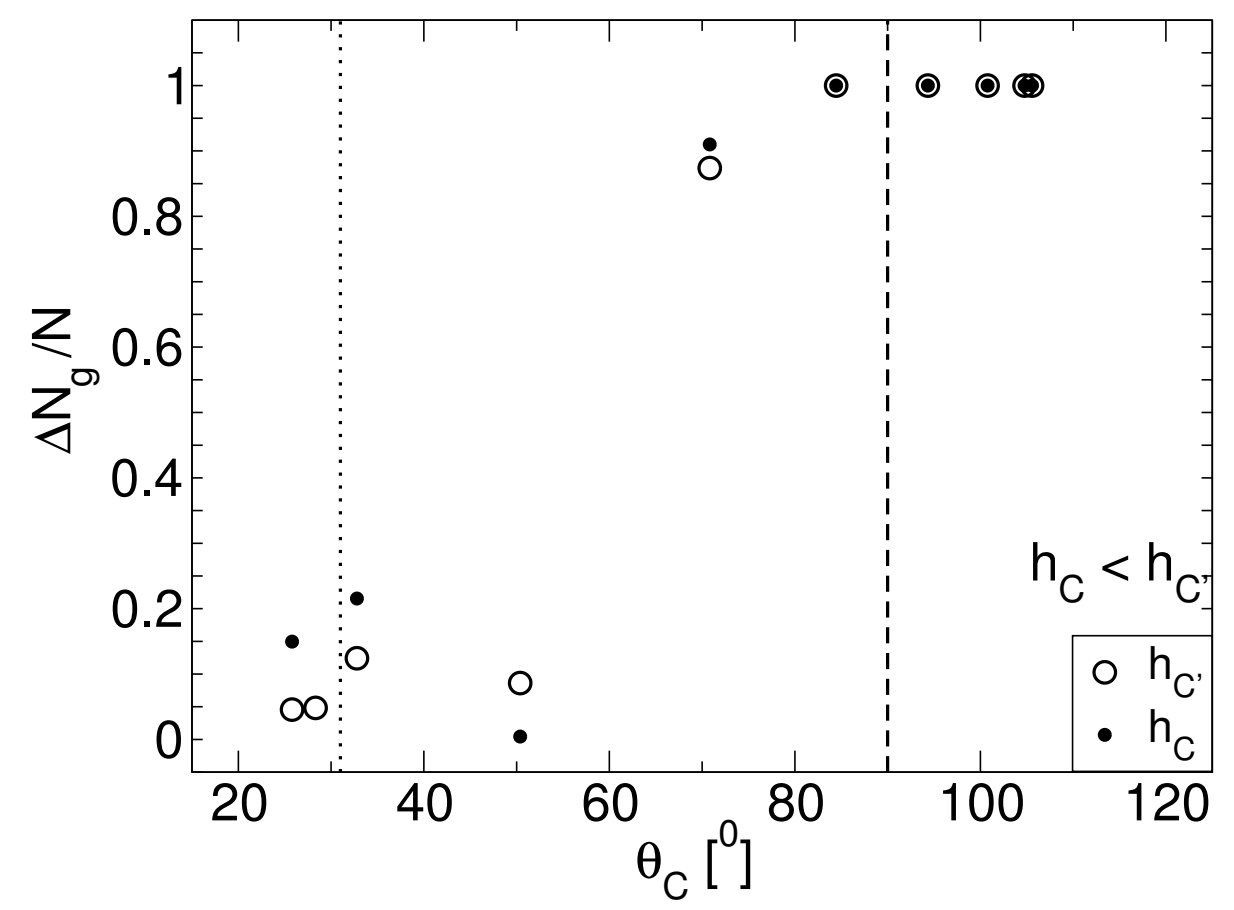

Figura 3.21: Razão $\Delta N_{\mathrm{g}} / N$ entre a diferença $\Delta N_{\mathrm{g}}$ do número de moléculas de $\mathrm{H}_{2} \mathrm{O}$ da maior e menor gota SA formadas após a ruptura da ponte SA nas alturas críticas $h_{\mathrm{C}}$ e $h_{\mathrm{C}^{\prime}}$, e o número total dessas moléculas $N=3375$, em função do ângulo de contato $\theta_{\mathrm{c}}$. Para $\Delta N_{\mathrm{g}} / N=0$ as gotas SA têm o mesmo número de moléculas de água; para $0<\Delta N_{\mathrm{g}} / N<1$ as gotas $\mathrm{SA}$ possuem diferentes números de moléculas de água; para $\Delta N_{\mathrm{g}} / N=1$ é formada apenas uma gota SA após a ruptura com o mesmo número de moléculas de água da ponte $\mathrm{SA}, N=3375$.

pontilhada), dada pela Eq. 2.36, em função de $\theta_{c}$. Para isso, foram calculados $h_{\mathrm{C}} /\left(2\langle\Omega\rangle^{1 / 3}\right)$ e $h_{\mathrm{C}^{\prime}} /\left(2\langle\Omega\rangle^{1 / 3}\right)$, que são a metade das alturas $h_{\mathrm{C}}$ e $h_{\mathrm{C}^{\prime}}$ normalizadas pela média do volume das pontes SA de todas as alturas $h$, em que foi possível fazer o ajuste teórico de $r(z)$, para cada placa com polaridade $k$, ver Tab. 3.8. Para efeito de comparação, também inserimos os dados da última altura em que a ponte SA é estável $h_{\mathrm{S}} /\left(2 \Omega^{1 / 3}\right)$, e utilizamos o volume dessa altura na normalização. Para determinar $h_{\max , \mathrm{a}}$ e $h_{\max , \mathrm{s}}$ calculamos a média dos volumes para todos $h$ e $\theta_{\text {c }}$, como mostrado na Tabela 3.8, e utilizamos o valor de $\gamma$ calculado na Sec. 3.2. Podemos observar na Fig. 3.22 um acordo razoável entre a teoria TC e as simulações de DM. Deve-se ressaltar que as placas foram movidas em passos de $2,5 \AA$ e $5,0 \AA$. Se utilizássemos passos menores e maiores tempos de simulação, poderíamos obter maior coerência no resultado.

Por fim, examinaremos a questão das flutuações que mencionamos anteriormente. A TC macroscópica prevê que o perfil $r(z)$ das pontes SA são estáticos, a menos que essa seja esticada até uma altura crítica superior a $h_{\max }$ que possa ocasionar a ruptura. Diferentemente disso, 


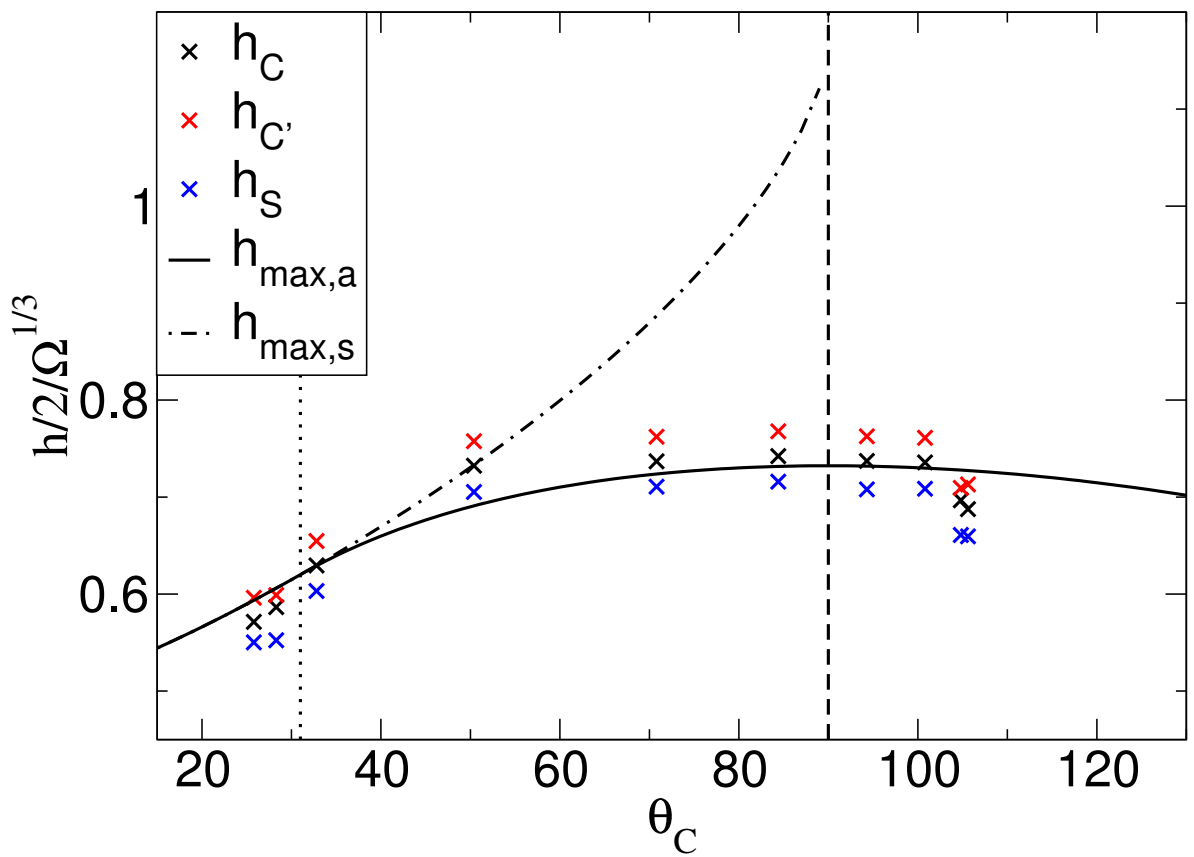

Figura 3.22: Metade da altura da ponte SA normalizada pelo seu volume $h / 2 / \Omega^{1 / 3}$ em função do ângulo de contato $\theta_{\mathrm{c}}$. Os dados de $h_{\mathrm{C}^{\prime}}$ mostram as alturas instáveis em que a ponte $\mathrm{SA}$ se rompe pela primeira vez, quando as placas são separadas de $5,0 \AA$. Os dados de $h_{\mathrm{C}}$ mostram a segunda ruptura, quando as placas são separadas de $2,5 \AA$ ou $1,25 \AA$. A linha contínua é a previsão da TC da ruptura assimétrica $h_{\max , a}$ obtida com as Eqs. 2.46 e 2.69, e linha tracejada-pontilhada é a previsão da ruptura simétrica $h_{\mathrm{max}, \mathrm{s}}$ dada pela Eq. 2.36. A linha pontilhada mostra o ângulo de contato crítico $31^{\circ}$ abaixo do qual a ponte SA se rompe em duas gotas SA. A linha tracejada mostra o ângulo de contato $90^{\circ}$, que é a separação entre placas hidrofílicas e hidrofóbicas.

observamos flutuações nos perfis $r(z)$ nas alturas estáveis $h<h_{\mathrm{S}}$ e instáveis $h>h_{\max }$, no caso $h_{\mathrm{C}^{\prime}}$ e $h_{\mathrm{C}}$, para todas as placas com polaridade $k$. Para observar essas flutuações, calculamos sucessivos perfis $r_{\mathrm{p}}(z)$ das pontes $\mathrm{SA}$, realizando a média de $0,1 \mathrm{~ns}$ de simulação para cada $r_{\mathrm{p}}(z)$, como é exemplificado nas Figs. 3.19(e),(f),(i) e (j).

Avaliamos melhor essas flutuações, para cada altura $h$ e placa com polaridade $k$, calculando as médias e os desvios padrões dos raios $r_{0}$ (círculos) e alturas $z_{0}$ (círculos) do "pescoço", e raios das bases $r_{\mathrm{B}}$ dos perfis $r_{\mathrm{p}}(z)$ das pontes SA, mostrados, respectivamente, nas Figs. 3.23(a), (b) e (c). Nas alturas $h=h_{\mathrm{C}^{\prime}}$ e $h=h_{\mathrm{C}}$ as médias são calculadas até o instante $\tau_{\mathrm{r}}$ em que ocorre a ruptura, ver Tab. 3.9. Vale enfatizar que nessa análise $r_{\mathrm{B}}$ não é calculado exatamente no ponto em a ponte $\mathrm{SA}$ toca as placas nas alturas $\pm h / 2$, mas em uma altura distante de $2,5 \AA$ das placas. Como mostrado na Sec. 2.3, $r_{\mathrm{B}}$ é calculado a partir da função de densidade $\rho_{\mathrm{c}}(z)$ das caixas $L \times L \times 5 \AA^{3}$ que estão encostadas nas placas superior e inferior. Observamos que as flutuações em $r_{\mathrm{B}}$ são grandes e para facilitar a análise dividimos esses dados em dois grupos: 
para cada $r_{\mathrm{p}}(z)$ determinamos o maior $r_{\mathrm{B}, \max }$ (sinal de vezes) e o menor $r_{\mathrm{B} \text {,min }}$ (círculos) raio da base para depois determinar a media e o desvio padrão desses dois conjuntos. Os dados de $r_{\mathrm{B}, \max }$ e $r_{\mathrm{B}, \min }, r_{0}$ e $z_{0}$ foram comparados com os respectivos valores teóricos $r_{\mathrm{B}}^{\prime}, r_{0}^{\prime}$ e $z_{0}^{\prime}=0$ (mostrados por linhas tracejadas), esse calculado com relação ao centro da caixa de simulação $(0,0, L / 2) ; r_{\mathrm{B}}^{\prime}$ é dado pelas Eqs. 2.41 e 2.56 , e $r_{0}^{\prime}$ é dado por $r_{0}^{\prime}=A=a \chi$ para $\theta_{\mathrm{c}}<\pi / 2$, e por $r_{0}^{\prime}=B=b \chi$ para $\theta_{\mathrm{c}}>\pi / 2$. De maneira geral, podemos observar que $r_{0}, z_{0}$ e $r_{\mathrm{B}, \max } \mathrm{e}$ $r_{\mathrm{B}, \min }$ desviam das previsões teóricas $r_{0}^{\prime}, z_{0}^{\prime}$ e $r_{\mathrm{B}}^{\prime}$ à medida que $h \approx h_{\mathrm{max}}$, e além disso, há um aumento do desvio padrão.
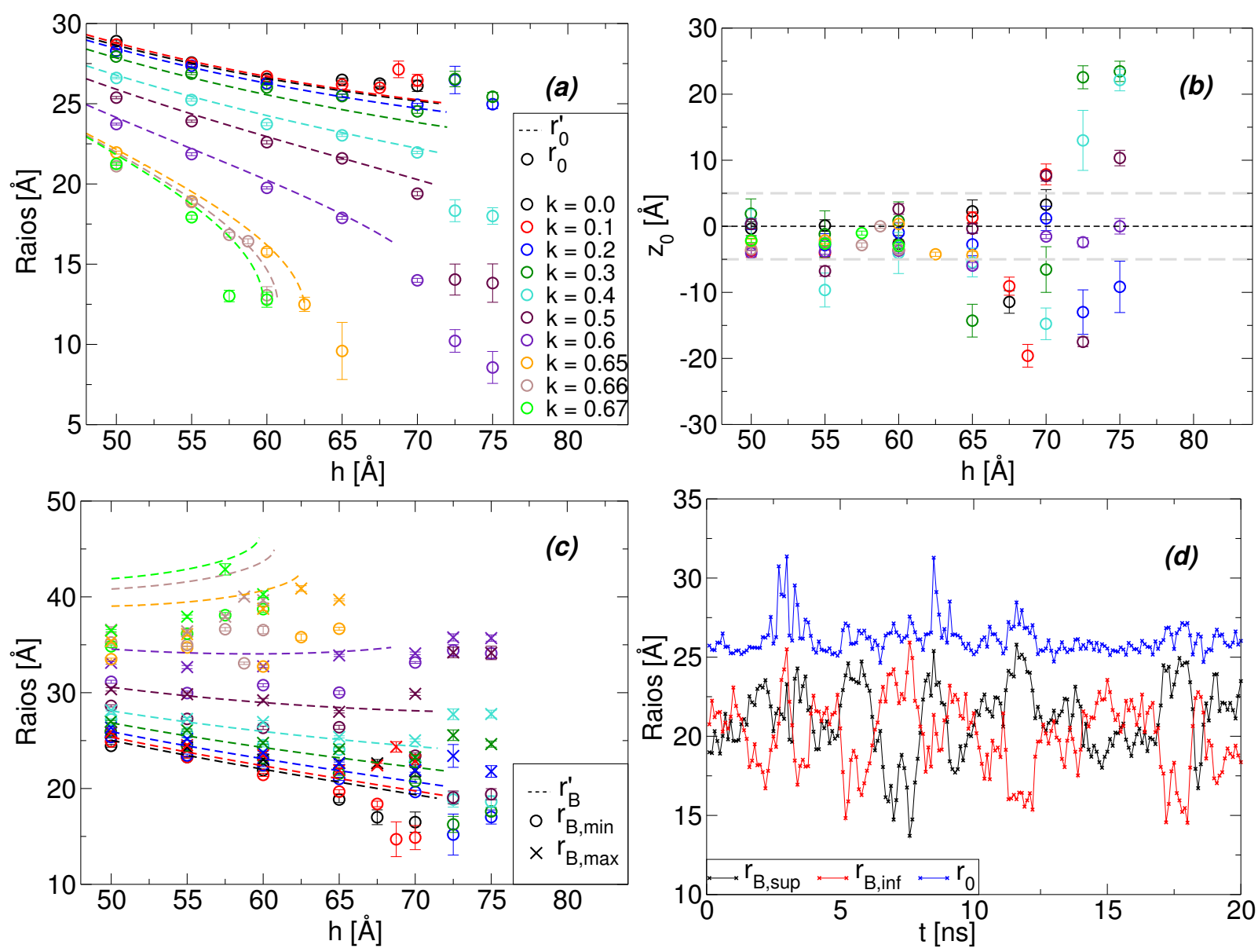

Figura 3.23: (a) Médias dos raios dos "pescoços" $r_{0}$ (círculo), (b) alturas $z_{0}$ dos "pescoço", e (c) raios da base máximo $r_{\mathrm{B}, \max }$ (sinais de vezes) e mínimo $r_{\mathrm{B}, \min }$ (círculos) obtidos a partir dos conjuntos gerados com as médias de $0,1 \mathrm{~ns}$ dos perfis $r_{\mathrm{p}}(z)$ das pontes SA, em função da altura $h$ e polaridade $k$ das placas. Vale ressaltar que $z_{0}$ é calculado com relação ao centro da caixa de simulação $(0,0, L / 2)$, e nas alturas críticas $h=h_{\mathrm{C}^{\prime}}, h_{\mathrm{C}}$ as médias são realizadas até o tempo de ruptura $\tau_{\mathrm{r}}$, ver Tabelas 3.9. Em (b), as linhas tracejadas cinzas mostram a região $0 \pm 5 \AA$. Os valores de $r_{\mathrm{B}, \max } \mathrm{e} r_{\mathrm{B}, \min }, r_{0}$ e $z_{0}$ foram comparados com os respectivos valores teóricos $r_{\mathrm{B}}^{\prime}$ (linha tracejada), $r_{0}^{\prime}$ (linha tracejada) e $z_{0}^{\prime}=0$ (linha tracejada); $r_{\mathrm{B}}^{\prime}$ é dado pelas Eqs. 2.41 e 2.56, e $r_{0}^{\prime}$ é dado por $r_{0}^{\prime}=A=a \chi$ para $\theta_{\mathrm{c}}<\pi / 2$, e por $r_{0}^{\prime}=B=b \chi$ para $\theta_{\mathrm{c}}>\pi / 2$. (d) Séries temporais das flutuações dos raios das bases superior $r_{\mathrm{B}, \text { sup }}$ e inferior $r_{\mathrm{B}, \min }$ e também de $r_{0}$ para a ponte SA com altura $h=67,5 \AA$ e aderida às placas com polaridade $k=0,1$. 
Na Figura 3.23(a) observamos que, das grandezas analisadas, $r_{0}$ é a que mais se aproxima de $r_{0}^{\prime}$ para $h<h_{\mathrm{S}}$ e para todas as placas com polaridade $k$. Para $h$ aproximadamente $h_{\text {max }}$, ou seja $h=h_{\mathrm{C}}$ e $h=h_{\mathrm{C}^{\prime}}, r_{0}$ desvia de $r_{0}^{\prime}$ e há um aumento do desvio padrão indicando um aumento das flutuações. Na Figura 3.23(b) observamos que $z_{0}$ possui uma dependência mais expressiva com a hidrofobicidade/hidrofilicidade das placas. Para as placas hidrofílicas com polaridades $k=$ $0,6-0,67, z_{0}$ desvia pouco do valor teórico $z_{0}^{\prime}=0$, permanecendo dentro da região $0 \pm 5 \AA$ para as alturas $h \leq h_{\mathrm{S}}, h=h_{\mathrm{C}}$ e $h=h_{\mathrm{C}^{\prime}}$; nesse caso, as pontes SA formam gotas SA com volumes aproximadamente iguais após a ruptura, ver Tab. 3.9. Já para as placas hidrofóbicas com polaridades $k \leq 0,4$, os desvios de $z_{0}^{\prime}$ são mais evidentes, e $z_{0}$ permanece dentro da região $0 \pm 5 \AA$ somente para $h<65 \AA$. Para $h \geq 65 \AA, h \approx h_{\max }, z_{0}$ pode ultrapassar a região $0 \pm 5 \AA$ chegando a distanciar de $z_{0}^{\prime}$ de aproximadamente $10-25 \AA$. Esses comportamentos são esperados, pois, após a ruptura, a ponte SA dará origem a uma única gota $\mathrm{SA}$, e, assim, $z_{0}$ deve se deslocar mais no sentido de uma das placas. Na Figura 3.23(c) observamos que mesmo separando o cálculo de $r_{\mathrm{B}}$ em dois grupos $r_{\mathrm{B}, \min }$ e $r_{\mathrm{B}, \max }$, o distanciamento de $r_{\mathrm{B}}^{\prime}$ é grande, e são mais pronunciados nas proximidades de $h_{\max }$. Isso se deve às grandes flutuações dos raios das bases. A Figura 3.23(d) mostra um exemplo de uma série temporal das flutuações em $r_{\mathrm{B}}$ e também em $r_{0}$ para a ponte SA com altura $h=67,5 \AA$ e aderida às placas com polaridade $k=0,1$. Nesse caso, analisamos separadamente $r_{\mathrm{B}}$ em raios superiores $r_{\mathrm{B}, \mathrm{sup}}$ e inferiores $r_{\mathrm{B}, \mathrm{inf}}$, e podemos observar que $r_{\mathrm{B}, \mathrm{sup}}$ e $r_{\mathrm{B}, \text { inf }}$ são anti-correlacionados.

Uma possível explicação para o surgimento das flutuações deve-se ao fato do tamanho da molécula de $\mathrm{H}_{2} \mathrm{O}$ ser da mesma ordem de grandeza que a interface. Assim, as trocas de moléculas entre os meios poderiam fazer com que a interface adquirisse momento e oscilasse. Trabalhos da literatura mostram que os perfis das pontes capilares parecerem flutuar ou são difusos [55, 116], mas não existe um estudo detalhado sobre o assunto.

Dada a discussão sobre as flutuações das pontes SA, surge uma questão interessante sobre a flutuação no perfil de $r(z)$ que poderá ser realizada em trabalhos futuros. A TC macroscópica prevê que para $h_{\mathrm{S}}<h_{\max }$ o perfil $r(z)$ não possui nenhum ponto de inflexão, e para alturas $h_{\mathrm{C}} \geq$ $h_{\max }$ existem pontos de inflexão em $r(z)$, o que torna a ponte SA instável. Somados esses dois fatos, podemos estipular que existe uma função de densidade de probabilidade característica 
que descreve a flutuação da ponte SA, assim como o surgimento de pontos de inflexão próximo à altura $h_{\max }$ que levariam à ruptura. Então, entendendo melhor esse problema, poderíamos avaliar como os pontos de inflexão surgem em $r(z)$ para alturas próximas a $h_{\max }$, e, assim, dar um carácter probabilístico para a ruptura da ponte SA.

Para entender melhor essas flutuações na escala nanométrica, estudamos um problema mais simples que será mostrado na seção a seguir.

\subsection{Flutuação do centro de massa de gotas}

Na terceira etapa apresentaremos os resultados dos estudos das flutuações na escala nanométrica a partir da análise de séries temporais geradas pelas posições do centro de massa CM de dois sistemas simples: uma gota que não está aderida a nenhuma superfície, denominada aqui de gota livre, e uma gota SA aderida à placa de $\beta$-cristobalita. Além das simulações de DM, para efeito de comparação, realizamos também simulações com o modelo gás de rede [50, 52, 157], ver Sec. 2.6. As séries temporais do CM geradas pelas simulações de DM e MC foram calculadas conforme o que foi discutido na Sec. 2.3. O movimento do CM das gotas livre e SA foram decomposto na coordenada $z$ e no plano $x y$, e então fizemos uma análise do expoente de Hurst para entender cada componente do movimento. Nas Seções 3.3.1 e 3.3.2 apresentaremos os resultados da flutuação das gotas livre e SA, respectivamente.

\subsubsection{Flutuação das gotas livres}

Primeiro, estudamos as gotas livres que não estão aderidas às placas com as simulação de DM e MC, como mostrado nas Figs. 3.24(a) e (b), respectivamente. Em ambas as simulações foram utilizados 2575 moléculas de $\mathrm{H}_{2} \mathrm{O}$ e partículas de líquido. A quantidade de pontos gerados das simulações de MC e DM para criar as séries temporais foram 20000 e 10000, respectivamente.

Para a simulação de MC, observamos que a movimentação da gota é Browniano na coordenada $z$ e no plano $x y$ com expoente de Hurst, obtido da Eq. 2.96, igual a $\lambda=0,51$. Para a gota simulada com DM é observado que $\left\langle B\left(T_{\mathrm{S}}\right)^{2}\right\rangle \approx 0$ independente de $T_{\mathrm{S}}$, em outras palavras, a gota não se move na escala de tempo considerada. Esses resultados são mostrados na Fig 3.25, e podemos concluir que a interação de primeiros vizinhos e a dinâmica de Kawasaki na simula- 

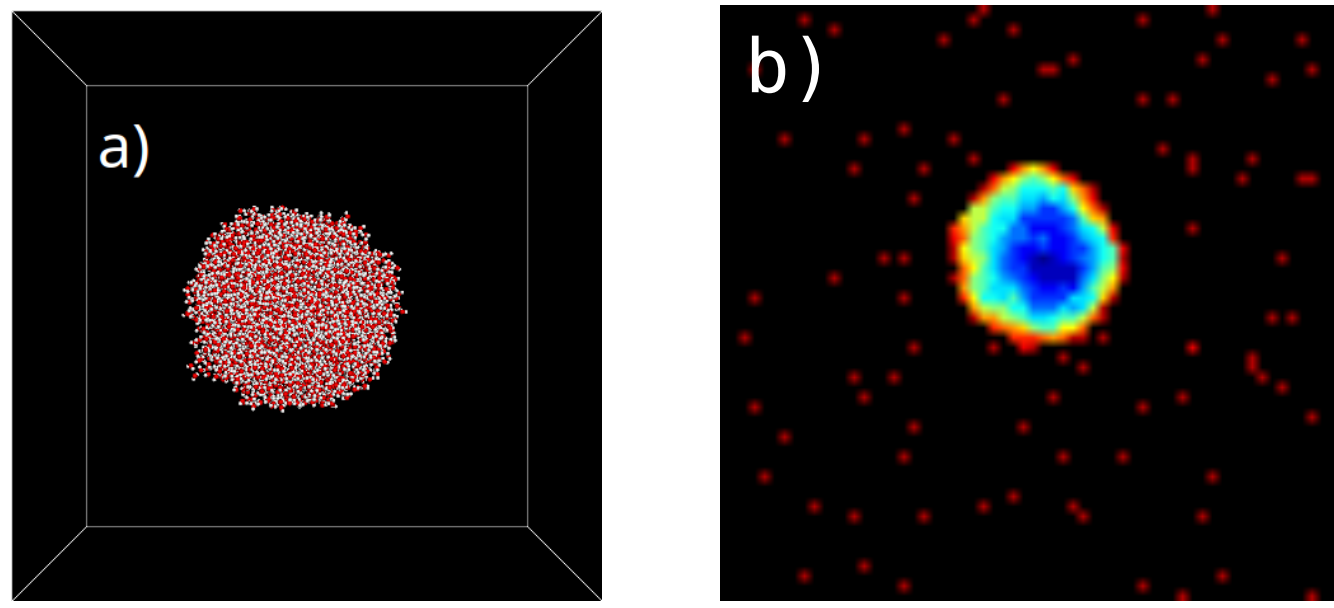

Figura 3.24: Imagens de gotas lívres simuladas com (a) modelo atomístico com DM e com (b) modelo gás de rede implementado com MC. O gradiente de cores em (b) indica a densidade de partículas de líquido, em que azul significa maior quantidade.

ção de MC é o fator responsável pelo deslocamento do CM. Na dinâmica de Kawasaki ocorre a troca entre partículas de líquido e gás que podem estar localizadas em quaisquer sítios da rede, o que gera o comportamento Browniano da gota. Entretanto, o mesmo comportamento não é observado pelas simulações de DM, pois as forças intermoleculares são forças internas, e sendo assim não podem causar o deslocamento do CM.

\subsubsection{Flutuação de gotas SA}

Em seguida, estudamos o movimento do CM da gota SA na simulação de MC e observamos um comportamento interessante, como mostrado na Fig. 3.26. O movimento do CM da gota SA muda seu regime em torno de $T_{\mathrm{S}} \propto \mathrm{e}^{4} \tau_{\mathrm{MC}} ; \tau_{\mathrm{MC}}$ é a unidade de tempo na simulação de MC. Como a gota SA esta aderida a uma superfície, o deslocamento do CM na coordenada $z$ possui dois regimes: anti-persistente, $\lambda=0,38$, e confinado, $\lambda=0,00$. No plano $x y$, como não existe nenhuma restrição de movimentação, não observamos nenhuma diferença no regime, e esse pode ser considerado Browniano, $\operatorname{com} \lambda=0,53$.

Então, os resultados discutidos anteriormente na Fig. 3.26 foram comparados com os resultados do deslocamento do CM da gota SA simulada com DM. Primeiro, comparamos os deslocamentos na coordenada $z$, como mostrado na Fig. 3.27. Ambas as gotas SA das simulações de MC e DM possuem o mesmo comportamento com dois regimes distintos. Este fato nos permite converter as unidades de tempo e deslocamento entre as simulações de MC e DM 


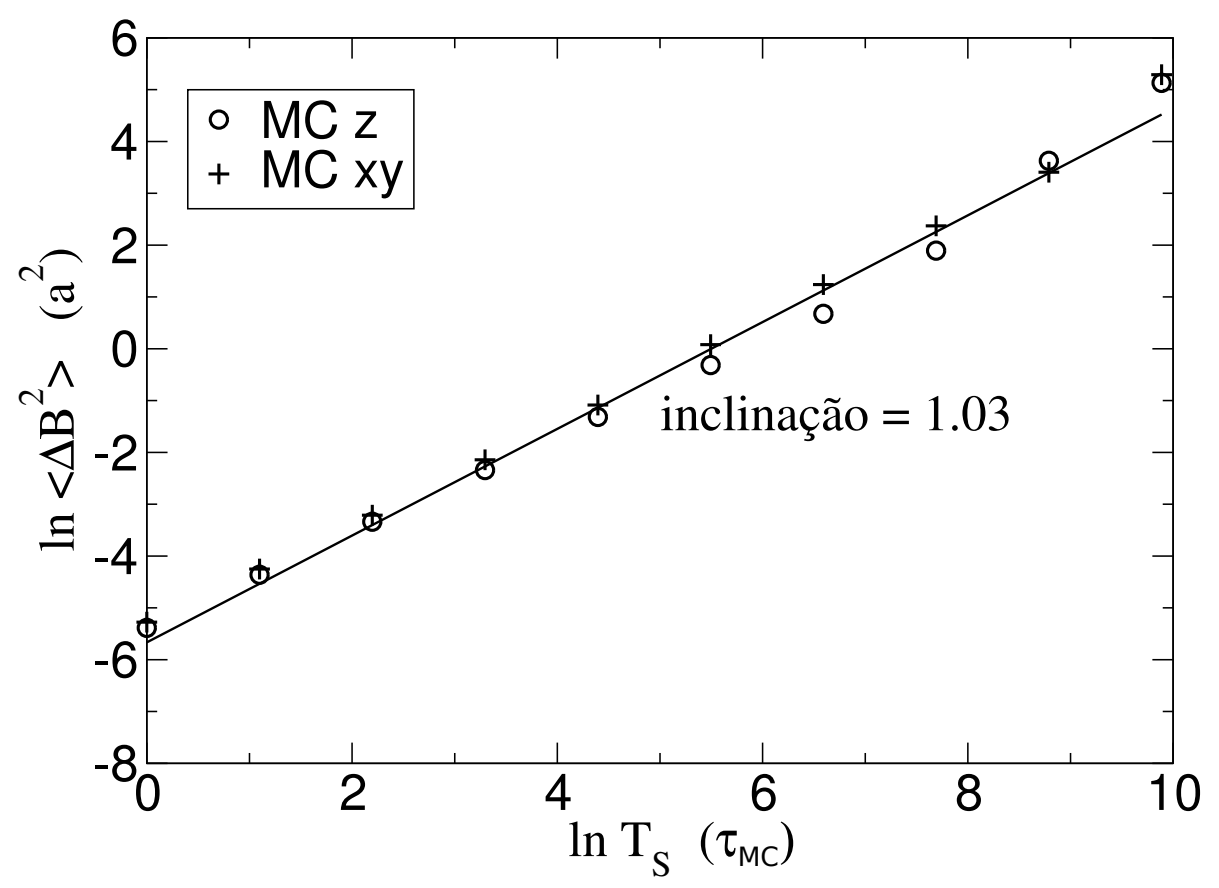

Figura 3.25: Média do quadrado absoluto da separação $\Delta B\left(T_{\mathrm{S}}\right)$ do $\mathrm{CM}$ da gota livre na coordenada $z$ e no plano $x y$ em função da janela temporal $T_{\mathrm{S}}$ para a simulação de MC. A linha é a regressão linear, e o valor do expoente de Hurst calculado da Eq. 2.96 é $\lambda=0,51$.

utilizando as equações abaixo:

$$
\left\{\begin{array}{cc}
\Delta B^{2}\left[\AA^{2}\right]= & \Delta B^{2}\left[a^{2}\right] 1,51\left[\frac{\AA^{2}}{a^{2}}\right]+5,5\left[\AA^{2}\right] \\
T_{\mathrm{S}}[\mathrm{ps}]= & T_{\mathrm{S}}\left[\tau_{\mathrm{MC}}\right] 0,9\left[\frac{\mathrm{ps}}{\tau_{\mathrm{MC}}}\right]+0,8[\mathrm{ps}]
\end{array}\right.
$$

Nos resultados das simulações de MC apresentados na Fig. 3.27 já está empregado essa conversão, e podemos observar que os regimes são persistente, $\lambda=0,67$, e confinado, $\lambda=0,01$. Vale enfatizar que na DM só é possível observar a movimentação na coordenada $z$ porque a placa de $\beta$-cristobalita está fixa e os átomos dessa não podem se mover.

Finalmente, comparamos o deslocamento no plano $x y$ aplicando a Eq. 3.2. Observamos um comportamento interessante, como pode ser verificado na Fig. 3.28. Diferentemente das simulações com MC, as simulações de DM mostram que o deslocamento do CM no plano $x y$ também possui dois regimes, persistente $\lambda=0,85$ e anti-persistente $\lambda=0,31$.

\subsection{Outros estudos realizados}

Apresentaremos agora outros estudos que realizamos que complementam o que foi discutido na primeira, segunda e terceira etapas. Na Seção 3.4.1 apresentaremos uma tentativa 


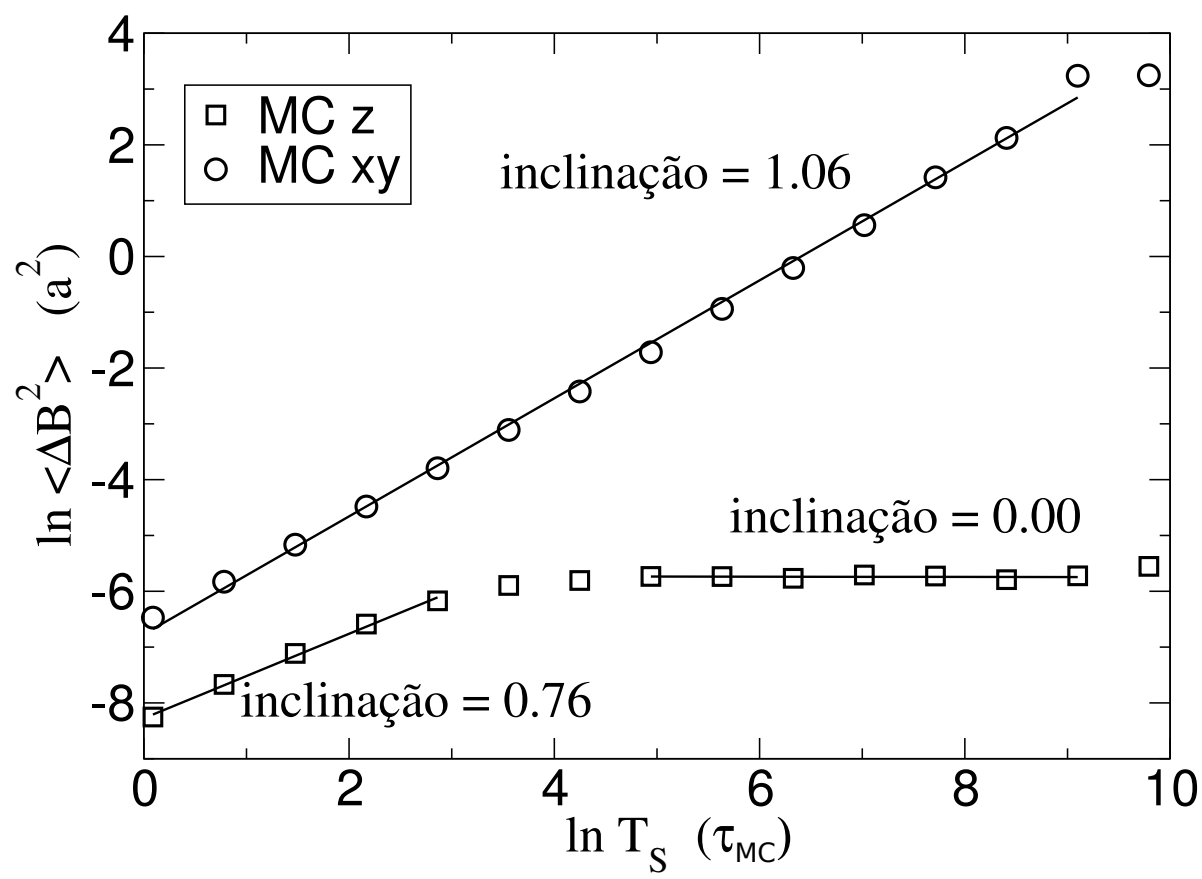

Figura 3.26: Média do quadrado absoluto da separação $\Delta B\left(T_{\mathrm{S}}\right)$ do $C M$ da gota $\mathrm{SA}$ na coordenada $z \mathrm{e}$ no plano $x y$ em função da janela temporal $T_{\mathrm{S}}$ para a simulação de MC. A linha mostra a regressão linear. O movimento no plano $x y$ é Browniano, e os expoentes de Hurst obtidos da Eq. 2.96 foram $\lambda=0,53$; na coordenada $z$ existem dois regimes: anti-persistente, $\lambda=0,38$, e confinado, $\lambda=0,00$.

de calcular a tensão de linha utilizando somente os dados da primeira etapa. Na Seção 3.4.2 apresentaremos resultados que complementam os estudos da primeira etapa sobre a pressão de Laplace $P_{\mathrm{L}}$ das gotas SAp, SAg e ST. Na Seção 3.4.3 mostraremos resultados que complementam os estudos da segunda e terceira etapas, em que estudamos com o modelo gás de rede as pontes SA aderidas a placas planas e a dois hemisférios.

\subsubsection{Estudo da tensão de linha}

O estudo realizado aqui foi o cálculo da tensão de linha $\kappa$, que complementa a discussão feita na Sec.3.1.1. Calculamos $\kappa$ seguindo o mesmo procedimento da Ref. [133], e plotamos $\cos \theta_{\mathrm{c}}$ em função de $1 / r_{\mathrm{B}}$ para as gotas $\mathrm{SAp}$, gotas $\mathrm{SAg}$ e pontes $\mathrm{SA}$ aderidas às placas com polaridade $k$, utilizando os dados das Tabs. 3.1 e 3.2. Assumindo que o ângulo de contato $\theta_{\mathrm{c}}$ seja independentemente da geometria, esperamos que $\kappa$ atue da mesma maneira para as gotas e pontes SA. Então, a partir de uma regressão linear obtêm-se os parâmetros da Eq. 2.2. Os resultados obtidos para cada $k$ podem ser visualizados na Fig. 3.29 e os parâmetros da regressão linear são mostrados na Tab. 3.10. 


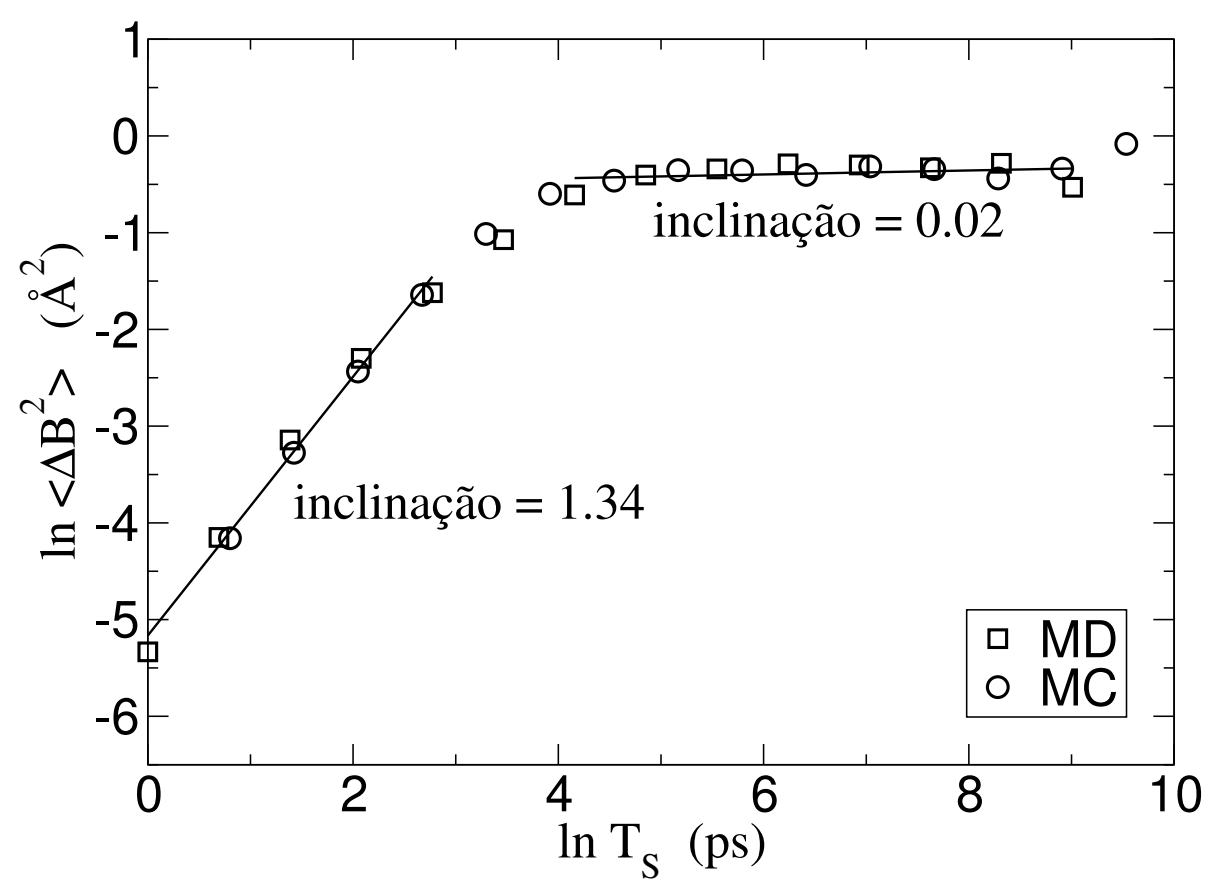

Figura 3.27: Média do quadrado absoluto da separação $\Delta B\left(T_{\mathrm{S}}\right)$ do $\mathrm{CM}$ da gota $\mathrm{SA}$ na coordenada $z$ em função da janela temporal $T_{\mathrm{S}}$ para as simulações de $\mathrm{MC}$ e $\mathrm{DM}$. As linhas mostram a regressão linear, e os expoentes de Hurst obtidos da Eq. 2.96 para os regimes persistente e confinado foram $\lambda=0,67 \mathrm{e}$ $\lambda=0,01$, respectivamente. Os dados da simulação de MC foram obtidos dos resultados apresentados na Fig. 3.26 e aplicando a Eq. 3.2.

Obtivemos $\kappa=-0,216(4) 10^{-10} \mathrm{~J} / \mathrm{m}$, entretanto nota-se que os valores de $\kappa$ medidos são discrepantes, pois foram utilizados somente três pontos para realizar a regressão linear para cada valor de $k$. Além disso, o número de médias utilizadas não é o suficiente para determinar com precisão a influência de $\kappa$ nas gotas SA, como discutido anteriormente. Vale ressaltar dessas observações, que esse é um ponto interessante para ser explorado nos trabalhos futuros.

\subsubsection{Pressão de Laplace no interior de gotas}

Uma vez mostrado nas Secs. 3.2.1 e 3.1.2 que a equação de Young-Laplace Eq. 2.3 é valida na escala nanométrica, utilizamos essa para calcular a pressão de Laplace $P_{\mathrm{L}_{\mathrm{YL}}}$ no interior das gotas SAp, SAg, e ST. O valor de $P_{\mathrm{LYL}_{\mathrm{L}}}$ foi calculado a partir dos parâmetros de ajuste das gotas mostrados na Tab.3.1 e do valor de $\gamma$ calculado na Sec.3.1.2. A Figura 3.30(a) mostra os valores de $P_{\mathrm{L}_{\mathrm{YL}}}$ em função do ângulo de contato $\theta_{\mathrm{c}}$ para as gotas SAp (círculo preto), SAp (círculo vermelho) e ST (círculo azul).

Outro modo de calcular $P_{\mathrm{L}_{\mathrm{YL}}}$ é partir da função $R\left(\theta_{\mathrm{c}}\right)$, que descreve como varia o raio das gotas $R$ em função de $\theta_{\mathrm{c}}$, e para isso é necessário calcular o volume $\Omega$ das gotas. Para as gotas 


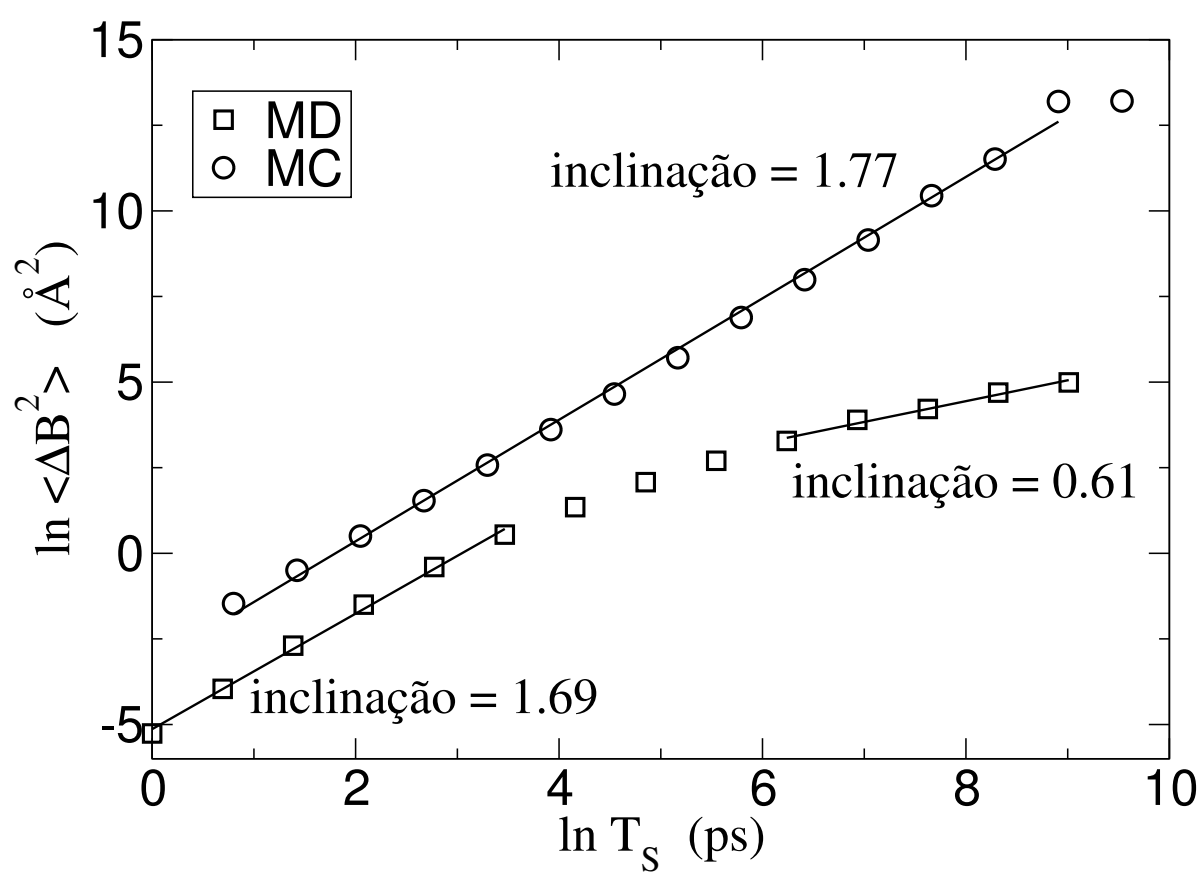

Figura 3.28: Média do quadrado absoluto da separação $\Delta B\left(T_{\mathrm{S}}\right)$ do $\mathrm{CM}$ da gota SA no plano $x y$ em função da janela temporal $T_{\mathrm{S}}$ para as simulações de $\mathrm{MC}$ e DM. A linha mostra a regressão linear. Para a DM, o movimento do CM pode ser persistente ou anti-persistente, e os expoentes de Hurst obtidos da Eq. 2.96 foram $\lambda=0,85$ e $\lambda=0,31$, respectivamente. Para o MC, não é observado nenhuma diferença no regime, e esse pode ser considerado persistente $\operatorname{com} \lambda=0,89$. Os dados da simulação de MC foram calculados dos dados apresentados na Fig. 3.26, e aplicando a Eq. 3.2.

SA, observando a Fig. 2.2(a) e utilizando a Eq. 2.8, podemos escrever $\Omega$ como:

$$
\Omega=\int_{0}^{\mathrm{h}} \pi r(z)^{2} \mathrm{dz}=\frac{\pi \mathrm{R}\left(\theta_{\mathrm{c}}\right)^{3}}{3}\left(2-3 \cos \theta_{\mathrm{c}}+\cos ^{3} \theta_{\mathrm{c}}\right)
$$

em que $h=R-z_{\mathrm{c}}$ é a altura da gota $\mathrm{SA}$, e $z_{\mathrm{c}}=R \cos \theta_{\mathrm{c}}$ é a distância do centro dessa à origem. Para as gotas ST, como verificado na Fig. 2.2(b) e utilizando a Eq. 2.8, $\Omega$ é dado por:

$$
\Omega=2 L \int_{0}^{\mathrm{h}} r(z) \mathrm{d} z=2 \mathrm{R}\left(\theta_{\mathrm{c}}\right)^{2} \mathrm{~L}\left(\frac{\pi}{2}-\cos \theta_{\mathrm{c}} \sin \theta_{\mathrm{c}}-\arcsin \left(\cos \theta_{\mathrm{c}}\right)\right),
$$

em que $L$ é o tamanho do lado da caixa de simulação.

Então, podemos calcular o volume médio das gotas SAp, SAg e ST plotando os valores de $R\left(\theta_{\mathrm{c}}\right)$ encontrados na Tab. 3.1, e ajustando as Eqs. 3.3 e 3.4, como mostrado na Fig. 3.30(b). Assim, uma vez que o $\Omega$ é independente de $\theta_{c}$, como discutido para as pontes SA na Sec. 3.2.1, encontramos os volumes médios das gotas SAp, SAg e ST são iguais, respectivamente, a $\langle\Omega\rangle=$ $123465,9 \AA^{3},\langle\Omega\rangle=241214,6 \AA^{3}$ e $\langle\Omega\rangle=333863,4 \AA^{3}$. 


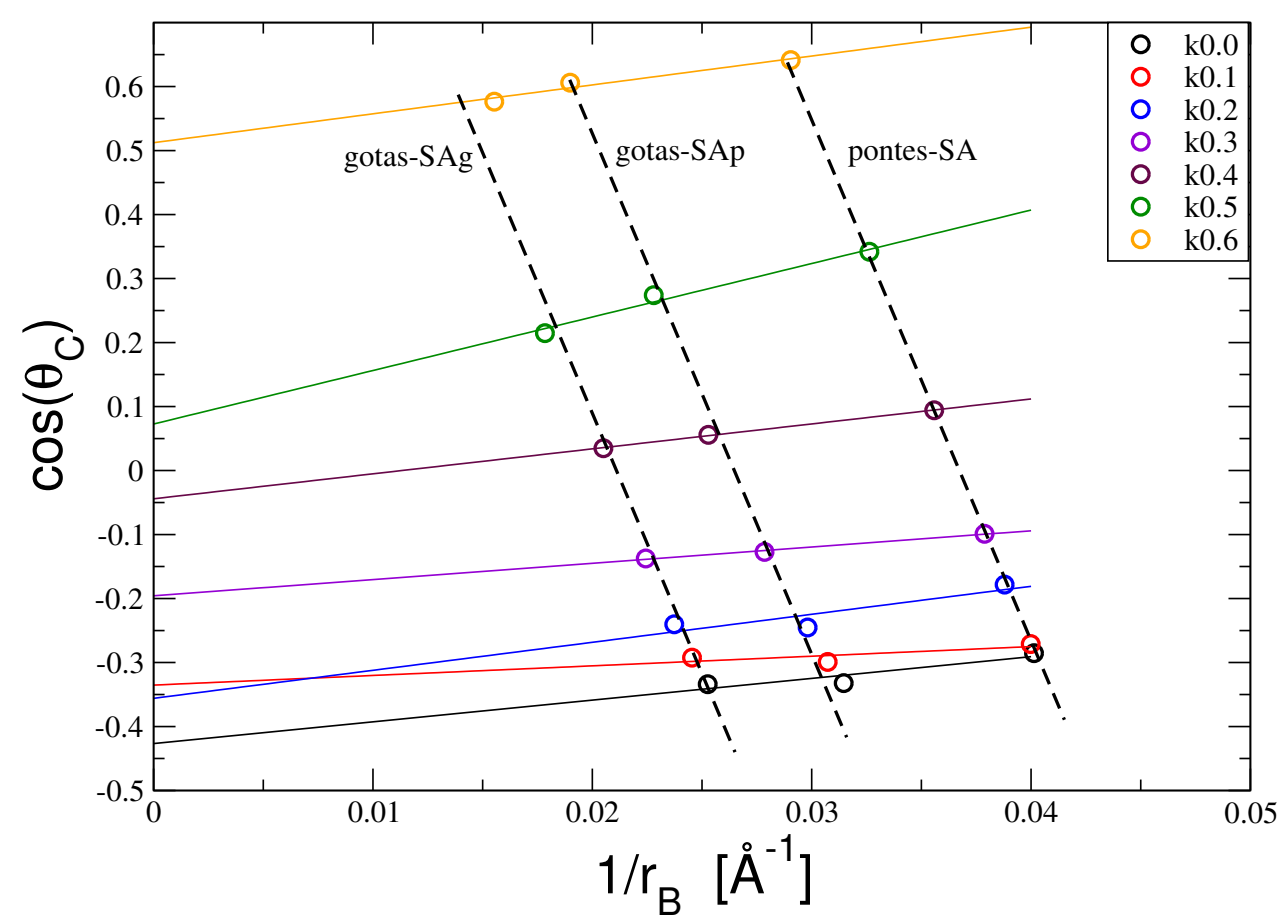

Figura 3.29: Cálculo da tensão linear $\kappa$ e do ângulo de contato na macroescala $\theta_{\infty}$ para cada uma das polaridades $k$ medidos a parir da Eq. 2.2. Os valores de $\cos \theta_{\mathrm{c}}$ e de $1 / r_{\mathrm{B}}$ para pontes SA e gotas SA foram obtidos a partir das Tab.3.1 e Tab. 3.2 e são representados pelos círculos. As linhas contínuas são os ajustes da regressão linear para cada um dos valores de $k$.

Podemos normalizar $\langle\Omega\rangle$ pelas respectivas quantidades de moléculas de água utilizadas em cada caso. Então, obtivemos que os volumes médios de uma molécula de água $\langle\Omega\rangle_{\mathrm{H}_{2} \mathrm{O}}$ pertencente às gotas SAp, SAg e ST são iguais, respectivamente, a $\langle\Omega\rangle_{\mathrm{H}_{2} \mathrm{O}}=36,6 \AA^{3},\langle\Omega\rangle_{\mathrm{H}_{2} \mathrm{O}}=$ $35,7 \AA^{3}$ e $\langle\Omega\rangle_{\mathrm{H}_{2} \mathrm{O}}=33,7 \AA^{3}$.

Assim, utilizando esses valores de $\langle\Omega\rangle$, e as Eqs. 3.3, 3.4 e 2.3, encontramos as expressões analíticas $P_{\mathrm{L}_{\mathrm{YL}}}\left(\theta_{\mathrm{c}}\right)$ (linhas contínuas) que descrevem a pressão de Laplace no interior das gotas SAp, SAg e ST, como mostrado na Fig. 3.30(a). Nesse caso, não é possível observar pressão de Laplace negativa, uma vez que a curvatura da gota é inversamente proporcional ao raio dessa $H \sim R^{-1}$.

\subsubsection{Estudo da pontes SA no modelo gás de rede}

Aqui, apresentaremos os resultados das pontes SA aderidas a duas superfícies planas e a dois hemisférios utilizando o modelo gás de rede, ver Fig. 2.10(b). Diferentemente da maneira que apresentamos os resultados nas seções anteriores, agora utilizaremos unidades normalizadas em todas as análises, da mesma forma que foi empregado nas Ref. [50, 52]. 
Tabela 3.10: Cálculo da tensão linear $\tau$ e do ângulo de contato na macroescala $\theta_{\infty}$ a parir da Eq. 2.2. O modelo utilizado para o ajuste foi: $y=\alpha+\beta x$. Foram utilizados somente os parâmetros para pontes SA, gotas SA e ST, que são as geometrias que podem sofrer algum efeito da tensão linear. A tensão linear $(\tau)$ é obtida a partir da média dos coeficientes $\alpha: \kappa=-0,216(4) 10^{-10} \mathrm{~J} / \mathrm{m}$

\begin{tabular}{ccc}
\hline \hline$k$ & $\alpha$ & $\beta$ \\
\hline 0,0 & $-0,42$ & 3,39 \\
0,1 & $-0,33$ & 1,50 \\
0,2 & $-0,35$ & 4,37 \\
0,3 & $-0,19$ & 2,54 \\
0,4 & $-0,04$ & 3,89 \\
0,5 & 0,07 & 8,35 \\
0,6 & 0,51 & 4,51 \\
\hline \hline
\end{tabular}
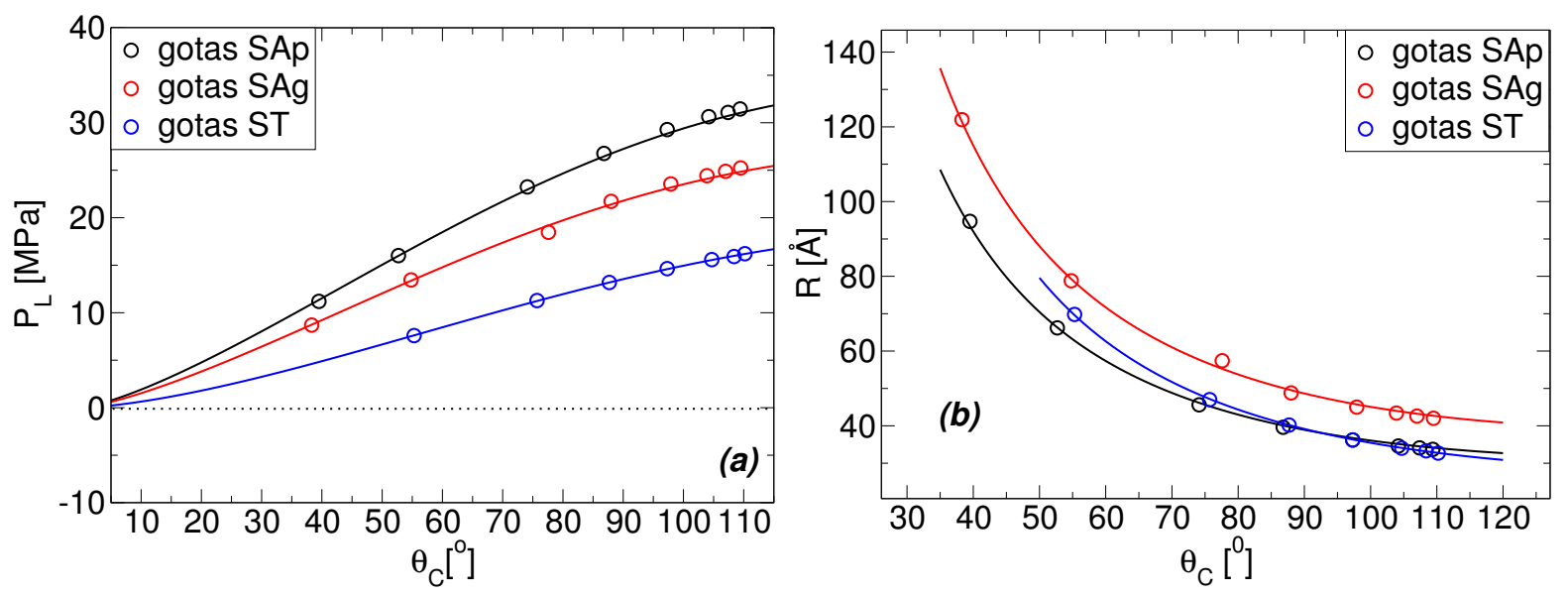

Figura 3.30: (a) Comparação entre as pressões de Laplace $P_{\mathrm{L}_{\mathrm{YL}}}$ no interior das gotas SAp, SAg e ST, medidas a partir do ajuste do perfil teórico $r(z)$ aos perfis medidos nas simulações $r_{\mathrm{p}}(z)$, em função do ângulo de contato $\theta_{c}$. A pressão de Laplace foi medida utilizando a equação de Young-Laplace Eq. 2.3. (b) Cálculo do volume das gotas a partir das Eqs. 3.3 e 3.4.

Nas simulações de MC, no ensemble NVT, para a ponte SA aderida a duas placas planas, usamos uma rede com dimensões $60 \times 60 \times 52$ e um volume total de partículas de líquido $\Omega_{\text {tot }}=10000$. Realizamos uma simulação independente para cada altura $h$, tal que $5<h<40$, e utilizamos quatro ângulos de contatos $\theta_{c}=39^{\circ}, 51^{\circ}, 66^{\circ}$ e $74^{\circ}$, que são determinados a partir da constante de acoplamento $J_{\text {ls }}$ da Eq. 2.94. Para cada simulação, realizamos $2 \times 10^{5}$ passos de MC de termalização e $4 \times 10^{5}$ passos de MC para o cálculo da média dos parâmetros das pontes capilares, como o volume do maior cluster $\Omega$, a energia livre do sistema $\mathcal{F}_{\text {sys }}$, assumindo que seja dada pela média da energia interna $\mathcal{F}_{\text {sys }}=\left\langle\mathcal{H}_{\mathrm{GR}}\right\rangle$; energia livre do maior cluster $\mathcal{F}$, assumindo que seja dada pela média da energia interna do maior cluster $\mathcal{F}_{\text {sys }}=\left\langle\mathcal{H}_{\mathrm{c}}\right\rangle$; áreas das interfaces líquido-sólido $A_{\mathrm{B}}$ e líquido-gás $A_{\mathrm{R}}$ do maior cluster e o perfil $r_{\mathrm{MC}}(z)$ da ponte 
capilar; ver Sec. 2.6 para mais detalhes.

Então, determinamos as médias desses parâmetros do maior cluster e os normalizamos por $\Omega$ para cada altura $h$. As Figuras 3.31(a), (b) e (c) mostram, respectivamente, $\mathcal{F} \Omega^{-2 / 3}, A_{\mathrm{R}} \Omega^{-2 / 3}$ e $A_{\mathrm{B}} \Omega^{-2 / 3}$ em função da metade da altura $h^{\prime}=h / 2$ normalizada $h^{\prime} \Omega^{-1 / 3}$. A Figura 3.31(d) mostra a proporção do volume do maior cluster $\Omega / \Omega_{\text {tot }}$ em função de $h^{\prime} \Omega^{-1 / 3}$.

Com relação aos perfis, calculamos a metade do perfil médio $r_{\mathrm{p}}(z)$ das simulações das pontes SA realizando a média para cada altura $z$ dos perfis $r_{\mathrm{MC}}(z)$ de cada configuração, e depois calculando a média em relação ao "pescoço" das pontes. Então, normalizamos $r_{\mathrm{p}}(z)$ por $\Omega$, obtendo $r_{\mathrm{p}}\left(z \Omega^{-1 / 3}\right) \Omega^{-1 / 3}$. Em seguida, ajustamos o perfil teórico da ponte SA $r(z)$, a partir da integração numérica da Eq. 2.19 discutida na Sec. 2.4, aos perfis $r_{\mathrm{p}}\left(z \Omega^{-1 / 3}\right) \Omega^{-1 / 3}$. As Figuras 3.32(a), (b), (c) e (d) mostram os perfis $r_{\mathrm{p}}\left(z \Omega^{-1 / 3}\right) \Omega^{-1 / 3}$ com os ajustes $r(z)$ para os respectivos $\theta_{\mathrm{c}}=39^{\circ}, 51^{\circ}, 66^{\circ}$ e $74^{\circ}$. Observa-se que a TC macroscópica se adéqua bem aos resultados do modelo gás de rede. Com os ajustes $r(z)$, determinamos outros parâmetros relevantes da ponte SA em função de $h^{\prime} \Omega^{-1 / 3}$, como $\theta_{\mathrm{c}}$ e a curvatura normalizada $H \Omega^{1 / 3}$ mostrados, respetivamente, nas Figs. 3.33(a) e (b), e a força normalizada pela tensão superficial $F_{\text {base,gr }}\left(h^{\prime} \Omega^{-1 / 3}\right) \gamma^{-1} \Omega^{-1 / 3}$ mostrada na Fig.3.34(d) . Observamos que $\theta_{\text {c diminui com o }}$ aumento de $h$, diferente com o que observamos com o modelo atomístico e com DM.

Em seguida, combinando os resultados obtidos das simulações, ver Figs. 3.31(a)-(d), e dos ajustes de $r(z)$, ver Figs.3.32(a)-(d), determinamos a tensão superficial $\gamma$ do líquido, que é descrito pelas constantes de acoplamento $J_{\mathrm{ij}}$, e a energia livre média do bulk $\langle\mathcal{E}\rangle_{\text {bulk }}$. Utilizando as Eq. 2.11 e Eq. 2.13, obtemos:

$$
\begin{array}{r}
\mathcal{E}_{\text {tot }}\left(h^{\prime}\right)=\gamma \xi\left(h^{\prime}\right)-\langle\mathcal{E}\rangle_{\text {bulk }} \\
\xi\left(h^{\prime}\right)=A_{R}\left(h^{\prime}\right)+\cos \theta_{\mathrm{c}} A_{B}\left(h^{\prime}\right)
\end{array}
$$

em que $\langle\mathcal{E}\rangle_{\text {bulk }}=\sum_{\mathrm{h}^{\prime}}^{N_{\mathrm{h}}} \mathcal{E}_{\text {bulk }_{\mathrm{k}\left(\mathrm{h}^{\prime}\right)}} / N_{\mathrm{h}}$ é a média da energia livre do bulk $\mathcal{E}_{\text {bulk }}$ medida para cada $h^{\prime} \Omega^{-1 / 3}, N_{\mathrm{h}}$ é o número total de alturas em que a ponte SA é estável, $k\left(h^{\prime}\right)$ são os índices relativos a cada meia altura $h^{\prime}$. Nesses cálculos, assumimos que $\mathcal{E}_{\text {bulk }}$ é constante e a variação da energia do sistema $\mathcal{E}_{\text {tot }}\left(h^{\prime}\right)$ ocorre devido às variações na energia livre da interface $\mathcal{F}\left(h^{\prime}\right)=$ $\gamma \xi\left(h^{\prime}\right)$. A Figura 3.34(a) mostra $\mathcal{E}_{\text {tot }}\left(h^{\prime}\right) \Omega^{-2 / 3}$ em função de $\xi\left(h^{\prime}\right)$ para cada $\theta_{\text {c }}$ (círculos), e 

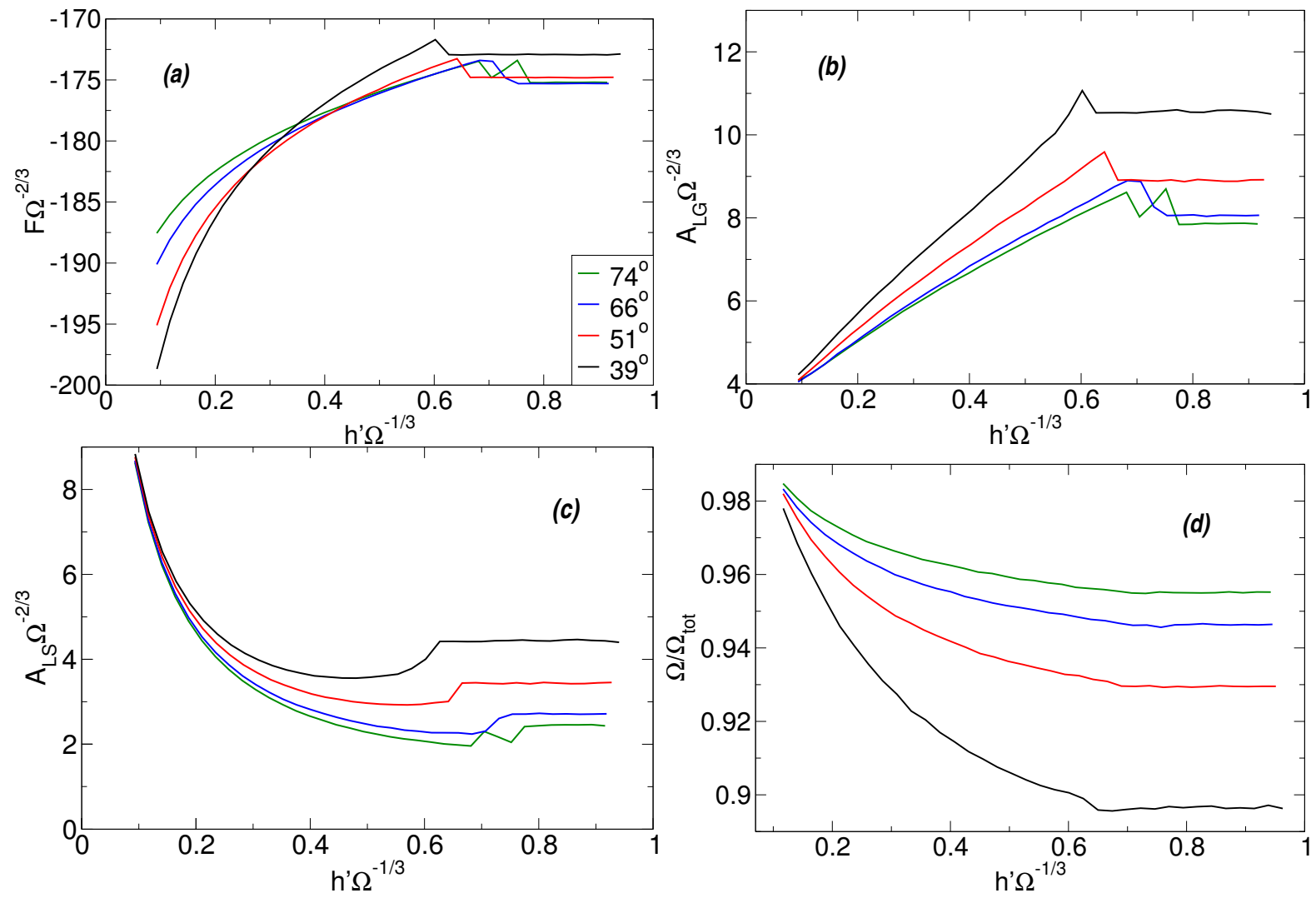

Figura 3.31: Podemos verificar nesses gráficos as propriedades da ponte SA normalizada pelo volume $\Omega$ do maior cluster. Temos (a) a energia livre $\mathcal{F} \Omega^{-2 / 3}$, as áreas das interfaces (b) líquido-gás cluster $A_{\mathrm{R}} \Omega^{-2 / 3}$ e (c) líquido-sólido $A_{\mathrm{B}} \Omega^{-2 / 3}$, e (d) a fração do volume $\Omega / \Omega_{\text {tot }}$ em relação à quantidade total partículas de líquidos $\Omega_{\text {tot }}$ em função da meia altura normalizada $h^{\prime} \Omega^{-1}$, em que ${ }^{\prime}=h / 2$. Essa análise foi realizada para os quatro ângulos de contato $\theta_{\mathrm{c}}$ : $39^{\circ}, 51^{\circ}, 66^{\circ}$ e $74^{\circ}$. A descontinuidade nas curvas representam o instante do rompimento das pontes capilares.

fazendo um ajuste linear (linhas contínuas) calculamos $\gamma \mathrm{e}\langle\mathcal{E}\rangle_{\text {bulk }}$ para cada conjunto de dados. Assim, para $\theta_{\mathrm{c}}=74^{\circ}, 66^{\circ}, 51^{\circ}$ e $39^{\circ}$ obtivemos os respectivos valores de $\langle\mathcal{E}\rangle_{\text {bulk }}$ e $\gamma:-192,17$ e 2,$4355 ;-190,93$ e 2,$1999 ;-190,57$ e 2,$5598 ;-190,88$ e 2,3941 . Observa-se que $\langle\mathcal{E}\rangle_{\text {bulk }}$ e $\gamma$ possuem valores muito semelhantes. Vale ressaltar, que devido ao efeito de tamanhos finitos, os três primeiros pontos para cada ângulo de contato não foram considerados no ajuste.

Depois, conhecendo o valor de $\gamma$, calculamos a variação da energia livre do bulk $\mathcal{E}_{\text {bulk }}\left(h^{\prime}\right)$ subtraindo da energia livre total $\mathcal{E}_{\text {tot }}\left(h^{\prime}\right)$ o termo relativo à energia livre da superfície $\mathcal{F}\left(h^{\prime}\right)=$ $\gamma \xi\left(h^{\prime}\right):$

$$
\mathcal{E}_{\text {bulk }}\left(h^{\prime}\right)=\mathcal{E}_{\text {tot }}\left(h^{\prime}\right)-\gamma \xi\left(h^{\prime}\right) .
$$

A Figura 3.34(b) mostra esse resultado em que a energia livre do bulk foi normalizada pela 

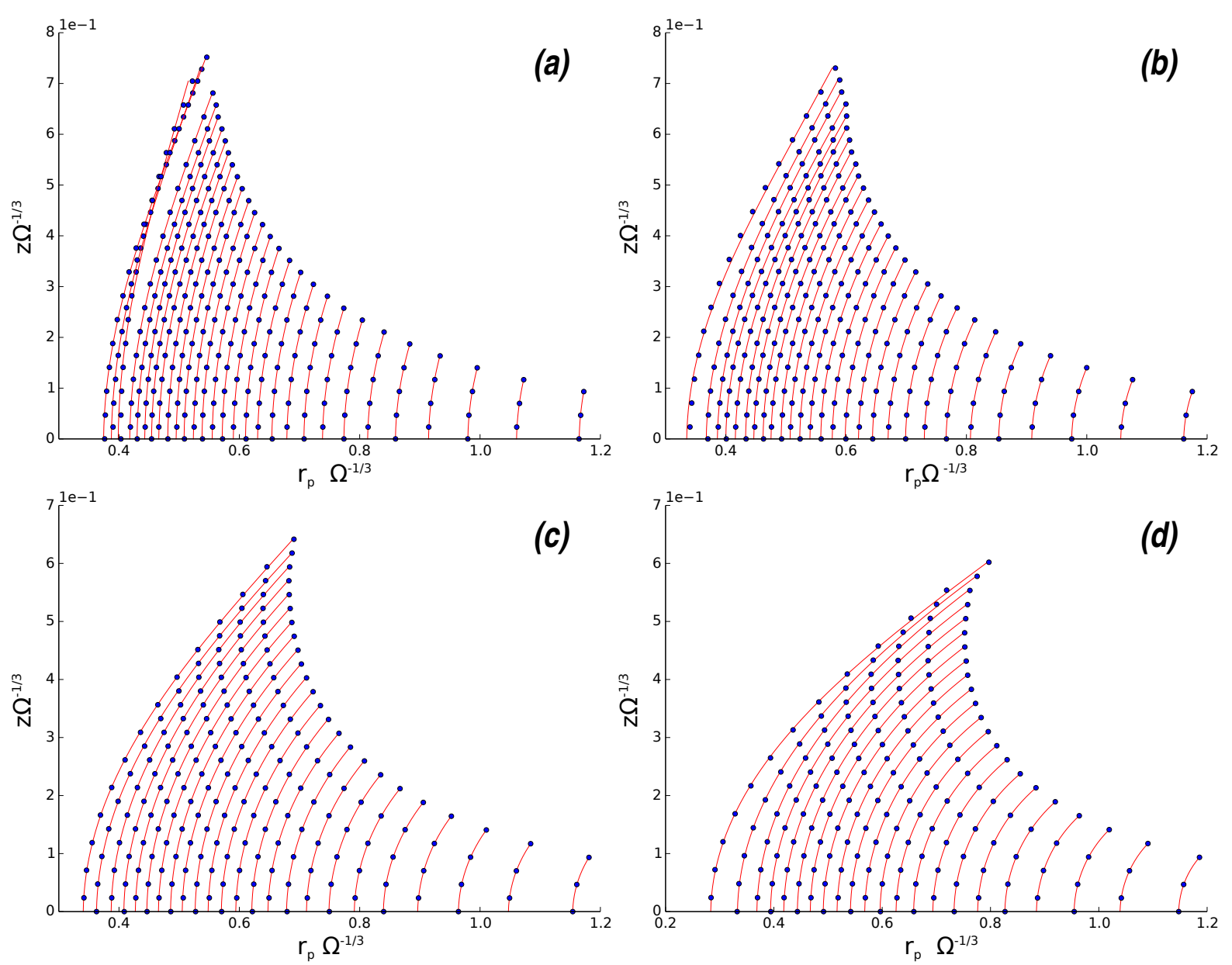

Figura 3.32: Podemos observar os perfis normalizados $r_{\mathrm{p}}\left(z \Omega^{-1 / 3}\right) \Omega^{-1 / 3}$ (pontos azuis) e os ajustes $r(z)$ (linhas contínuas vermelhas) das pontes SA em alturas estáveis $h<h_{\mathrm{S}}$, e para para quatro valores diferentes de $\theta_{\mathrm{c}}$ : (a) $74^{\circ}$, (b) $66^{\circ}$, (c) $51^{\circ}$ e (d) $39^{\circ}$.

média do volume do maior cluster para cada $h^{\prime}$. Verificamos que $\mathcal{E}_{\text {bulk }} \Omega^{-1}$ é da mesma ordem de grandeza do valor obtido analiticamente com a Eq. 2.94, em que uma partícula de líquido interage com outras partículas de líquido em seus sítios vizinhos: $(6 \times-1,0 J)+(12 \times-0,7 J)+$ $(8 \times-0,4 J)) / 2=-8,8 J$.

A partir do cálculo de $\mathcal{E}_{\text {bulk }}\left(h^{\prime}\right)$, foi possível calcular somente a energia livre da superfície $\mathcal{F}\left(h^{\prime}\right) \Omega^{-2 / 3}$, como mostrado na Fig. 3.34(c), por meio de dois modos: no primeiro (linhas contínuas), subtraímos $\langle\mathcal{E}\rangle_{\text {bulk }}$ da energia livre total $\mathcal{E}_{\text {tot }}\left(h^{\prime}\right)$, e no segundo (sinais de mais), utilizamos $\mathcal{F}\left(h^{\prime}\right)=\gamma \xi\left(h^{\prime}\right)$ (Eq. 2.13). Podemos observar que os dois modos são compatíveis.

Por fim, calculamos as forças de adesão capilar normalizadas pelo volume e tensão superficial $F_{\text {base,gr }} \gamma^{-1} \Omega^{-1 / 3}$ das pontes SA como mostrado na Fig. 3.34(d). Utilizamos dois métodos para calcular a força de adesão capilar. No primeiro, utilizamos os parâmetros obtidos dos per- 



Figura 3.33: (a) Ângulo de contato $\theta_{\mathrm{c}}$ e (b) curvatura média da superfície normalizada $H \Omega^{1 / 3} \mathrm{em}$ função da meia altura normalizada $h^{\prime} \Omega^{-1}$, em que $h^{\prime}=h / 2$. Essas curvas foram calculadas a partir do ajuste $r(z)$ da Eq. 2.19 aos perfis $r_{\mathrm{p}}\left(z \Omega^{-1 / 3}\right) \Omega^{-1 / 3}$. Os valores de $\theta_{\mathrm{c}}$ mostrados nas legendas são as médias dos valores obtidos na Fig. 3.33(a): $74^{\circ}, 66^{\circ}, 51^{\circ}$ e $39^{\circ}$.

fis $r(z)$ e aplicamos as Eqs. 2.25 e 2.22 (linha contínua), e, no segundo, calculamos a diferença de energia entre duas alturas consecutivas Eq. 2.95 (círculos). Observamos mais uma vez que a força de adesão capilar medida no "pescoço" e na base são iguais. Verificamos que a força de adesão capilar calculada com o primeiro modo não coincide com o segundo, Eq. 2.95. Aplicando um fator de correção $y=0,35 y^{\prime}$ à força de adesão capilar calculada com a Eq.2.95 para todos os valores de $\theta_{\mathrm{c}}$, os resultados corroboram. Ainda estamos trabalhando para entender essa discrepância, e uma das hipóteses é que o fator 0,35 possa estar relacionada à unidade de energia $J$ do sistema.

Finalmente, utilizamos o mesmo modelo gás de rede para estudar pontes SA aderidas a dois hemisférios de força a simular o processo de sinterização, ver Fig. 2.10(c). O número de partículas de líquido utilizado nas simulações dos dois hemisférios $\Omega_{\text {tot }} 11500$. Esse valor foi escolhido para que o volume médio do cluster fosse $\Omega=9860 \pm 21$, o mesmo valor obtido para as pontes SA aderidas a placas planas. $\mathrm{O}$ raio $R$ dos hemisférios correspondem a 25 sítios da rede, e o tamanho da rede utilizada para essas simulações foi de $60 \times 60 \times 100$. Vale ressaltar que os resultados apresentados estão em unidades de sítios da rede.

Nesses estudos utilizamos três valores de $\theta_{\mathrm{c}}: 39^{\circ}, 66^{\circ}$, e $74^{\circ}$. Para cada ângulo de contato, foram realizadas seis simulações diferentes, e para cada altura $h$ realizaram-se dez medidas das propriedades do sistema, e cada medida corresponde a médias de 4000 passos de Monte Carlo. Nessas simulações, a distância entre os hemisférios era aumentada até que ocorresse a ruptura 
da ponte capilar.

As Figuras 3.35 mostram, respectivamente, o perfil $r_{\mathrm{p}}(z)$ (linha contínua azul) das pontes SA com ângulos de contato $\theta_{\mathrm{c}}=39^{\circ}, 66^{\circ}$, e $74^{\circ}$ aderidas a dois hemisférios (linhas contínuas pretas). Pode-se observar a variação no perfil $r_{\mathrm{p}}(z)$, para os três valores de $\theta_{\mathrm{c}}$ utilizados, à medida que a distância $h$ entre os hemisférios era aumentada até ocorrer a ruptura da ponte SA. Os hemisférios estão representados pela

A partir da analise das Figs. 3.35(a)-(c) pode-se verificar que o valore de $\theta_{c}$ é alterado quando a ponte capilar é esticada, quebrando uma hipótese da TC. O perfil deixa de ser convexo e se torna concavo. Isso ocorre devido à rugosidade dos hemisférios aos quais a pontes SA está aderida, que altera $\theta_{\mathrm{c}}$. Desse modo, o modelo gás de rede não é um bom modelo para descrever o perfil de pontes-SA presas em hemisférios, ou outras superfícies que não sejam planas. 

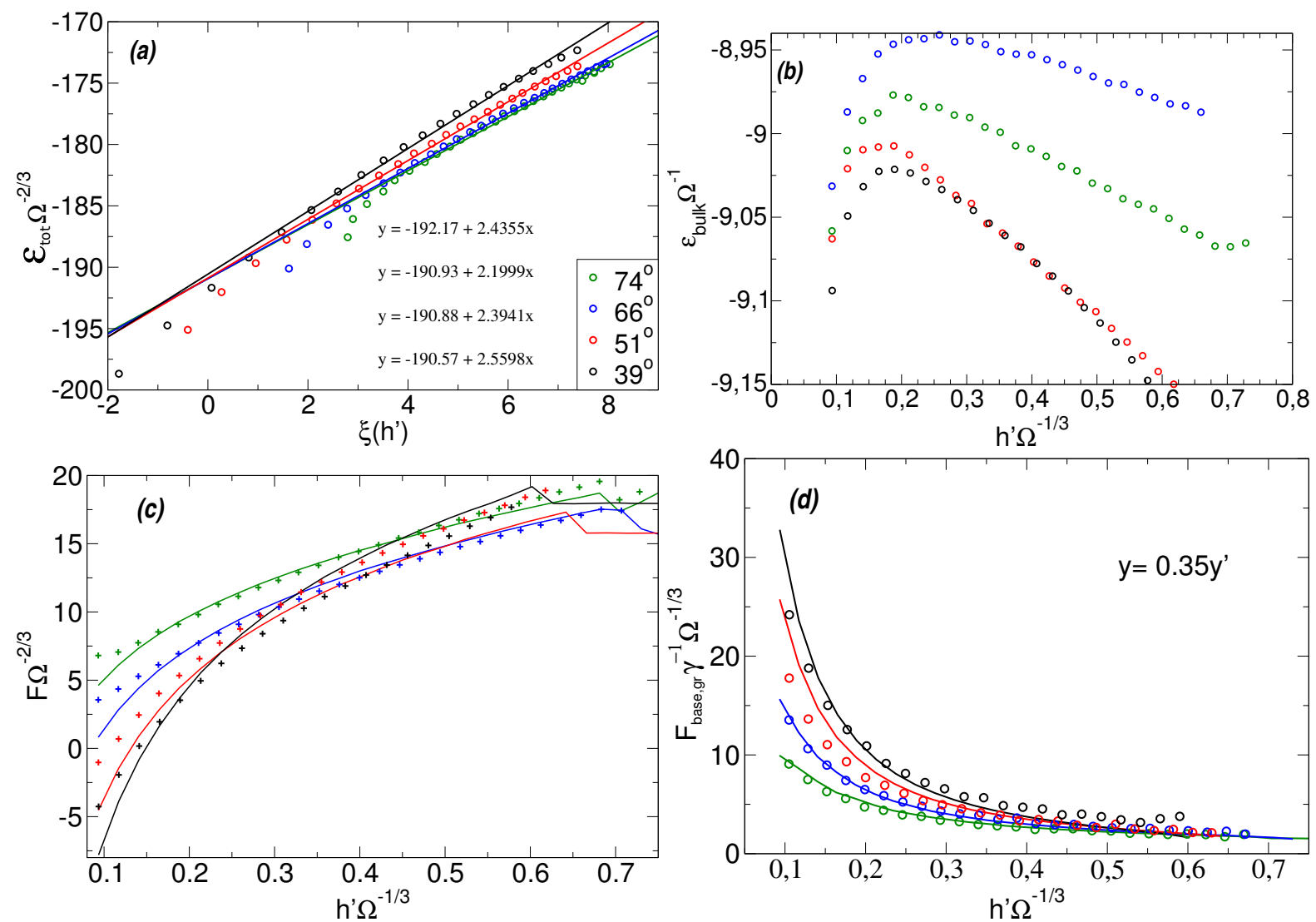

Figura 3.34: (a) Cálculo da tensão superficial $\gamma$ e da energia livre média do bulk $\langle\mathcal{E}\rangle_{\text {bulk }}$ para cada ângulo de contato $\theta_{\mathrm{c}}$ a partir do ajuste (linhas contínuas) da Eq. 3.6 aos valores de $\mathcal{E}_{\text {tot }}\left(h^{\prime}\right) \Omega^{-2 / 3}$ (círculos) em função de $\xi\left(h^{\prime}\right)$. Vale ressaltar, que devido ao efeito de tamanhos finitos, os três primeiros pontos de cada conjunto de $\theta_{\mathrm{c}}$ não foram considerados nos ajustes. (b) Cálculo da energia livre do bulk normalizada $\mathcal{E}_{\text {bulk }}\left(h^{\prime}\right) \Omega^{-1}$ (círculos) em função da meia altura normalizada $h^{\prime} \Omega^{-1}$, com $h^{\prime}=h / 2$, obtidos a partir da Eq. 3.6. (c) Cálculo da energia livre da superfície normalizada $\mathcal{F} \Omega^{-2 / 3}$ em função de $h^{\prime} \Omega^{-1}$ utilizando dois métodos: no primeiro (linhas contínuas), calculamos $\mathcal{F}=\mathcal{E}_{\text {tot }}-\left\langle\mathcal{E}_{\text {bulk }}\right\rangle$, em que $\left\langle\mathcal{E}_{\text {bulk }}\right\rangle$ é obtido a partir da regressão linear da Eq. 3.6 mostrada em (a), e no segundo (sinais de mais), utilizamos a Eq. 2.13, em que $\gamma$ é obtida da regressão linear da Eq. 3.6 mostrada em (a). (d) Cálculo da força de adesão capilar normalizada $F_{\text {base,gr }} \gamma^{-1} \Omega^{-1 / 3}$ em função da meia altura normalizada $h^{\prime} \Omega^{-1}$, em que $h^{\prime}=h / 2$, utilizando dois métodos diferentes: Eq. 2.95 (círculos) e Eqs. 2.22 e 2.25 (linhas contínuas). Um fator de correção $\left(y=0,35 y^{\prime}\right)$ foi aplicado à força calculada com a Eq. 2.95 para que essa coincidisse com a Eq. 2.25. 

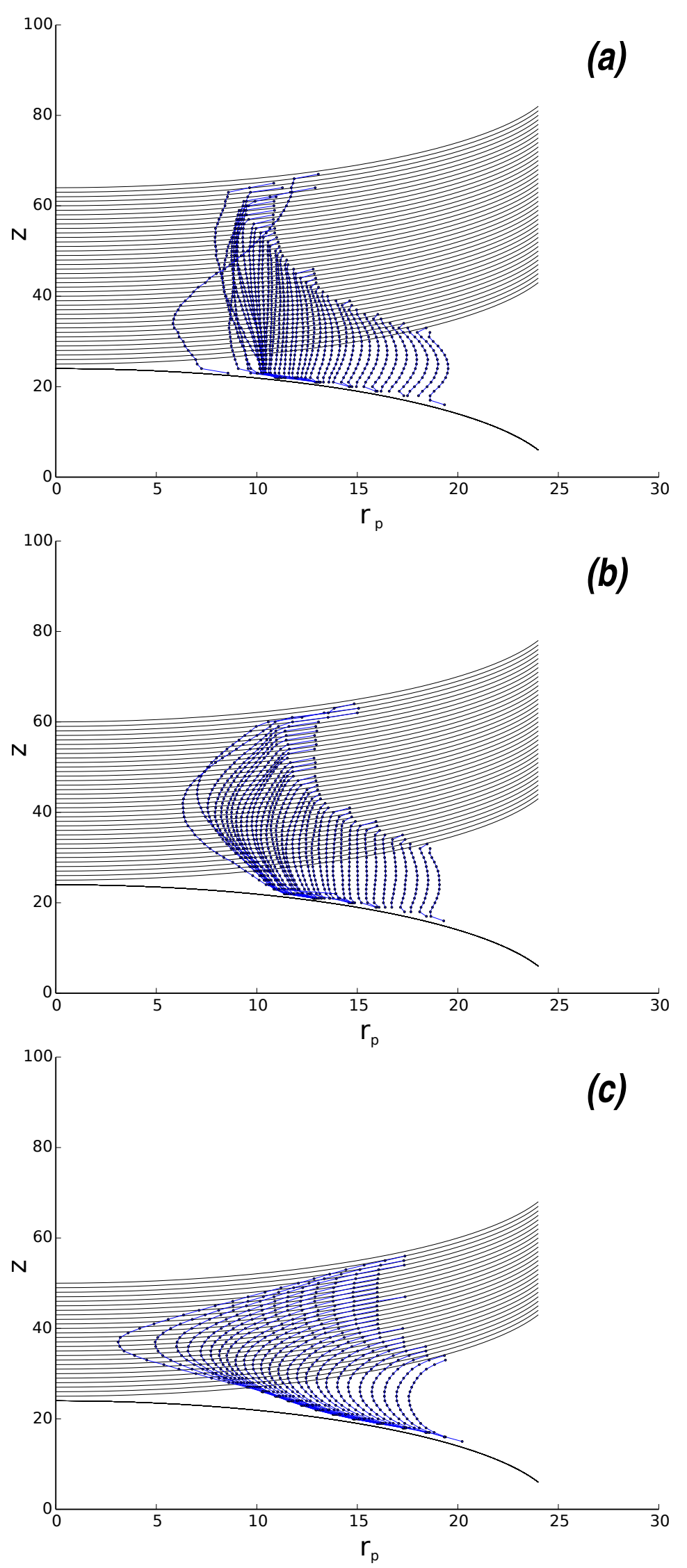

Figura 3.35: Observa-se como variam os perfis das ponte $\mathrm{SA} r_{\mathrm{p}}(z)$ aderidas a dois hemisfério para três ângulos de contato $\theta_{\mathrm{c}}$ : (a) $39^{\circ}$, (b) $66^{\circ}$ e (c) $74^{\circ}$. Pode-se observar que $\theta_{\mathrm{c}}$ é alterado para diferentes distâncias dos hemisférios, e o perfil da ponte SA pode alterar de uma superfície côncava para uma superfície convexa. Isso acontece devido às rugosidades das superfícies dos hemisférios. 


\section{Capítulo 4}

\section{Conclusões}

Em resumo, na primeira etapa, mostramos que o perfil $r_{\mathrm{p}}(z)$ das gotas e pontes SA e ST, constituídas de água do modelo SPC/E e aderidas às placas de $\beta$-cristobalita hidrofílicas/hidrofóbicas, obtidos a partir das simulações de DM são bem descritos pelos ajustes das curvas teóricas $r(z)$ da TC macroscópica com as Eqs. 2.8, 2.19 e 2.70, como verificamos na Sec. 3.1.1. A partir $r(z)$ medimos todos os parâmetros das gotas e pontes capilares como os raios das gotas $R$, a distância do centro da gota à origem $z_{\mathrm{c}}$, os raios das bases $r_{\mathrm{B}}$, os raios dos "pescoços" das pontes $r_{0}$, a curvatura média $H$ e o ângulo de contato $\theta_{\mathrm{c}}$, ver Sec. 2.1. Mostramos que o valor de $\theta_{\mathrm{c}}$ das interfaces das gotas e pontes SA e ST, em que as pontes possuíam altura $h=50 \AA$, são os mesmos, como é fundamentado pela TC macroscópica.

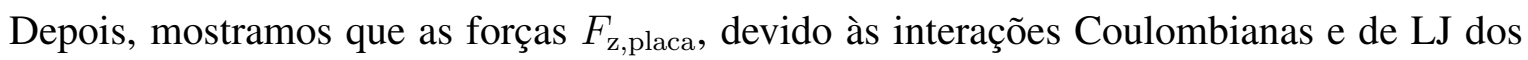
átomos das moléculas de $\mathrm{H}_{2} \mathrm{O}$ sobre os átomos das placas, correspondem às forças de adesão capilar $F_{z, \text { base }}$ das pontes SA e ST. Isso permitiu calcular o valor da tensão superficial $\gamma$ da água do modelo SPC/E, pois, uma vez que as pontes SA e ST estão em equilíbrio tem-se que a força no "pescoço" $F_{z, \text { p̧̧o }}$ e $F_{z \text {,base }}$ são iguais. Utilizando as Eqs. 2.25, 2.72 e 3.1 e os dados obtidos das Tabs. 3.2, 3.3 e 3.4, calculamos $\gamma=0,054 \pm 0,001 \mathrm{~N} / \mathrm{m}$ para as pontes SA e ST. Esse resultado foi confirmado pelo cálculo de $\gamma$ com o método $\mathrm{KB}$, em que utilizando uma caixa de simulação de tamanho $50 \times 50 \times 140 \AA^{3}$ e outra com tamanho $66 \times 66 \times 160 \AA^{3}$ obtivemos $\gamma$ iguais a, respectivamente, $0,056 \pm 0,001 \mathrm{~N} / \mathrm{m}$ e $0,0560 \pm 0,0007 \mathrm{~N} / \mathrm{m}$, que também estão de acordo a literatura $[156,166]$. Com isso, calculamos $F_{z, p c ̧ o}$ e $F_{z, \text { base }}$ com as Eqs. 2.25 e 2.22 para a ponte SA, e $F_{z, p c ̧ o}$ e $F_{z, \text { base }}$ com as Eqs. 2.71 e 2.72 para as pontes ST, e calculamos 
a pressão de Laplace com a equação de Young-Laplace Eq. $2.3\left(\left(_{\mathrm{L}_{\mathrm{YL}}}\right)\right.$ e a partir das forças $F_{\text {z,placa }}\left(P_{\mathrm{L}}\right)$ utilizando a Eq. 2.26 para a ponte SA e a Eq. 2.73 para a ponte ST. Observamos que $F_{\mathrm{z}, \mathrm{pço}}$ e $F_{\mathrm{z}, \text { base }}$ corroboram com as medidas das simulações $F_{\mathrm{z}, \text { placa }}$, e $P_{\mathrm{L}}$ e $P_{\mathrm{L}_{\mathrm{Y}}}$ corroboram nas medidas de pressão. Nossas medidas mostram pressão negativa de aproximadamente de -150 atm, que é uma característica da escala nanométrica, evidenciando que as moléculas de água nesses sistemas podem estar sob tensão. Esses resultados confirmam que a energia livre $\mathcal{F}$ pode ser expressa somente em termos de $\gamma$ e das áreas $A$ das interfaces para cada geometria, uma vez que $\gamma=\partial \mathcal{F} / \partial A$. Assim, mostramos na primeira etapa que os fundamentos da TC macroscópica são válidos na escala nanométrica permitindo, assim, a aplicação dessa teoria para interfaces com diversos formatos.

Na segunda etapa, estudamos a capilaridade nas pontes SA nanométricas aderidas às placas com polaridade $k$, mas agora incrementando $h$ até ocorrer a ruptura da ponte SA, de forma a explorar todo o diagrama de fase $\left(\theta_{\mathrm{c}}, h\right)$. Para a região em que a ponte SA é estável $h \leq h_{\mathrm{S}}$, realizamos a mesma análise da primeira etapa, e para a região instável $h>h_{\max }$, nas respectivas alturas críticas $h_{C}$ e $h_{C^{\prime}}$, tal que $h_{C}<h_{C^{\prime}}$, avaliamos outro aspecto da TC macroscópica relacionado ao mecanismo de ruptura das pontes SA, proporcionando mais um teste importante da aplicabilidade da TC na escala nanométrica. Para a região estável $h \leq h_{\mathrm{S}}$, observamos mais uma vez que os perfis $r_{\mathrm{p}}(z)$ são bem descritos pelos perfis teóricos $r(z)$, o que permitiu calcular os parâmetros, como as áreas das interfaces líquido-sólido $A_{\mathrm{B}}$ e líquido-gás $A_{\mathrm{R}}$, o volume $\Omega$, a energia livre da superfície $\mathcal{F}$, a altura do "pescoço" $z_{0}, r_{0}, r_{\mathrm{B}}, H$ e $\theta_{\mathrm{c}}$. Observamos novamente que $\theta_{c}$ permanece constante para alterações no formato da interface realizados com incremento em $h$, corroborando com as observações da primeira etapa. Verificamos que $\Omega$ mantém-se constante para todas as alturas $h$ apresentando um desvio de $3,2 \%$, satisfazendo outro fundamento da TC macroscópica. Depois, calculamos $\gamma=0,053 \pm 0,002 \mathrm{~N} / \mathrm{m}$ com os dados da ponte SA, Eqs. 2.25 e 3.1 e Tabs. 3.6 e 3.7, e constatamos que $\gamma$ confirma os valores obtidos na primeira etapa. As demais grandezas como as componentes de $F_{z \text {,base relativas à }}$ pressão de Laplace $F_{\mathrm{P}}$ e à tensão superficial $F_{\gamma}, F_{\mathrm{z}, \text { placa }}, F_{\mathrm{z}, \mathrm{pço}}, P_{\mathrm{L}}, P_{\mathrm{L}_{\mathrm{YL}}}$, corroboraram satisfatoriamente com um teste mais rigoroso da TC macroscópica, em que a ponte SA foi resolvida analiticamente, e cujos cálculos são baseados no uso de integrais elípticas. Nessas análises, 
observamos que a componente $F_{\mathrm{P}}$ possui valores negativos indicando, assim, pressão negativa de aproximadamente $-25 \mathrm{~atm}$, como observado nas placas com polaridades $0,65-0,67 \mathrm{e}$ $h<55 \AA$ A , mostrando uma característica da escala nanométrica do problema. Outra observação importante deve ser destacada dessas análises. O ajuste da Eq.2.19 para as pontes SA, que permaneceram por um tempo $\tau_{\mathrm{s}}$ simétricas na região de instabilidade $\left(h_{\mathrm{C}^{\prime}}\right.$ e $\left.h_{\mathrm{C}}\right)$, foi capaz de prever as medidas das forças e das pressões de Laplace realizadas durante as simulações. Já a solução da ponte SA baseada em integrais elípticas não é capaz de fazer previsões nessas regiões. Assim, a análise por meio do ajuste se mostra uma ferramenta importante para explorar a ponte SA na região de instabilidade.

Ainda com relação às pontes SA nas regiões de instabilidades $h>h_{\max , \mathrm{a}}$ e $h>h_{\text {max,s }}$, observamos que o tempo de ruptura $\tau_{\mathrm{r}}$, em geral, é maior para $h_{\mathrm{C}}$, uma vez que este está mais próximo da altura máxima de estabilidade $h_{\max , \mathrm{a}}$ e $h_{\max , \mathrm{s}}$. Como previsto pela TC, as simulações de DM também mostraram que a ponte SA rompe em uma ou duas gotas, com volumes iguais ou diferentes, dependendo de $\theta_{c}$. Os resultados das simulações mostram que para superfícies hidrofóbicas $\left(\theta_{\mathrm{c}}>90^{\circ}\right)$ as pontes SA originam uma única gota SA aderidas às placas. Para a região $50,4^{\circ}<\theta_{\mathrm{c}}<90^{\circ}$ observamos que após a ruptura são originadas gotas SA com volumes diferentes, e para $\theta_{\mathrm{c}}<50,4^{\circ}$ o volume das gotas SA são aproximadamente iguais. Esse resultado é muito próximo do ângulo de contato $31^{\circ}$, obtido pela solução analítica da TC macroscópica, para a formação de duas gotas SA com volumes iguais [50]. Nota-se que essa discrepância ocorre devido às flutuações no perfil da ponte SA. Verificamos que as flutuações ocorrem para qualquer $h$ e são mais evidentes para $h \approx h_{\max , \mathrm{a}}$ e $h \approx h_{\max , \mathrm{s}}$, e para superfícies hidrofóbicas, visto pelas análises das médias de $r_{0}, z_{0} \mathrm{e} z_{\mathrm{B}}$ determinadas a partir dos perfis $r_{\mathrm{p}}(z)$ que foram calculados com médias de 0,1 ns de simulação. Uma análise particular da ponte SA aderida à placa com polaridade $k=0,1$ e com altura $h=67,5 \AA$ mostra que os raios da base $z_{\mathrm{B}}$ superior e inferior são anti-correlacionados. Concluímos os estudos da segunda etapa mostrando novamente que a TC macroscópica, mesmo com o teste mais rigoroso baseado nas soluções analíticas dessa, é bem sucedida para explicar as propriedades medidas da ponte SA em toda a região do diagrama de fase $\left(\theta_{c}, h\right)$. Além disso, observamos as flutuações que não são previstas pela TC, e que serviram de motivação para estudos futuros. 
Na terceira etapa apresentamos já uma iniciativa desse estudo das flutuações. Utilizando simulações de DM e um modelo gás de rede implementado com MC, avaliamos as flutuações nas séries temporais geradas com o deslocamento do centro de massa CM no eixo $z$ e no plano $x y$ de gotas livres, que não estão aderidas a superfície, e gotas SA. O cálculo do expoente de Hurst mostrou que esses deslocamentos possuem diferentes regimes, e o comportamento do eixo $z$ das gotas SA simuladas com DM e MC são muito parecidos, o que permitiu escalar as dimensões entre os dois modelos. Assim, a terceira etapa foi uma iniciativa de entender melhor essas flutuações, que se mostrou um modo de escalar os dois modelos.

Por fim, podemos concluir dessa tese que o modelo atomístico implementado com DM pode ser utilizado para estudar fenômenos capilares mais complexos das escalas do micrometro e milimetro, como feito na Ref. [20], reproduzindo-os na escala nanométrica, uma vez que a TC se mostrou habilidosa na explicação das gotas e pontes SA e ST. Tais fenômenos complexos seriam normalmente avaliados por meio de soluções analíticas e métodos de elementos finitos. Entretanto, esses métodos não são triviais de serem implementados, e, portanto, as simulações com DM lidariam facilmente com essas situações. Com relação à TC macroscópica, as propriedades das gotas e pontes SA e ST foram determinadas a partir dos perfis $r(z)$, utilizando o método de ajuste de $r(z)$ aos perfis $r_{\mathrm{p}}(z)$ obtidos das simulações de DM do modelo atomístico. Utilizando outro método mais rigoroso, obtivemos as propriedades das pontes SA pela solução analítica dessa, utilizando integrais elípticas e conhecendo os parâmetros $\Omega, \theta_{\mathrm{c}}$ e $h$, para $\Omega \approx 100 \mathrm{~nm}^{3}, h \geq 50 \AA$ e $25,8^{\circ} \leq \theta_{\mathrm{c}} \leq 105,6^{\circ}$. Os dois modos de avaliação foram bem sucedidos, e tiveram suas respectivas limitações. O método do cálculo analítico não é capaz de avaliar as propriedades das pontes SA na região de instabilidade, mas o método do ajuste é capaz. Surpreendentemente, o método do cálculo analítico fez previsões notáveis das propriedades das pontes SA, como no caso das pressão de Laplace negativa, com o conhecimento dos parâmetros $\left(\Omega, \theta_{\mathrm{c}}\right.$ e $\left.h\right)$, mostrando-se, assim, uma ferramenta importante para analisar problemas na escala nanométrica. Assim, mostramos que os fundamentos da TC macroscópica são mantidos na escala nanométrica, e a solução analítica pode ser uma poderosa ferramenta para realizar previsões da capilaridade em nanotubos, nanocanais, nanobolhas e no AFM, em que o meio líquido deve possuir volumes $\Omega \geq 100 \mathrm{~nm}^{3}$ ou mais de 3375 moléculas de água. 


\section{Capítulo 5}

\section{Referências Bibliográficas}

[1] P.G. De Gennes, F. Brochard-Wyart, e D. Quéré. Capillarity and wetting phenomena: drops, bubbles, pearls, waves. Springer, 2004.

[2] T. Young. An essay on the cohesion of fluids. Philosophical Transactions of the Royal Society of London, 95:65-87, 1805.

[3] C. Py, P. Reverdy, L. Doppler, J. Bico, B. Roman, e C.N. Baroud. Capillary origami: spontaneous wrapping of a droplet with an elastic sheet. Physical Review Letters, 98:156103, 2007.

[4] N. Vandewalle, M. Poty, e G. Lumay. Customizing mesoscale self-assembly with 3d printing. In APS Division of Fluid Dynamics Meeting Abstracts, volume 1, page 6002, 2013.

[5] F. Bresme e M. Oettel. Nanoparticles at fluid interfaces. Journal of Physics: Condensed Matter, 19:413101, 2007.

[6] D.L. Hu, B. Chan, e J.W.M. Bush. The hydrodynamics of water strider locomotion. Nature, 424:663-666, 2003.

[7] D.L. Hu e J.W.M. Bush. Meniscus-climbing insects. Nature, 437:733-736, 2005.

[8] E. Bormashenko. Surface tension supported floating of heavy objects: why elongated bodies float better? Journal of Colloid and Interface Science, 463:8-12, 2016. 
[9] P. Galatola. Capillary force and torque on spheroidal particles floating at a fluid interface beyond the superposition approximation. Physical Review E, 93:022604, 2016.

[10] D-X Feng e A.V. Nguyen. A novel quantitative analysis of the local deformation of the air-water surface by a floating sphere. Colloids and Surfaces A: Physicochemical and Engineering Aspects, 504:407-413, 2016.

[11] Z. Peng, C. Wang, e S. Chen. The microstructure morphology on ant footpads and its effect on ant adhesion. Acta Mechanica, 227:2025-2037, 2016.

[12] J-H. Dirks. Physical principles of fluid-mediated insect attachment-shouldn't insects slip? Beilstein Journal of Nanotechnology, 5:1160-1166, 2014.

[13] L. Heepe, J.O. Wolff, e S.N. Gorb. Influence of ambient humidity on the attachment ability of ladybird beetles (coccinella septempunctata). Beilstein Journal of Nanotechnology, 7:1322-1329, 2016.

[14] S.J. Kim, J. Hasanyan, B.J. Gemmell, S. Lee, e S. Jung. Dynamic criteria of plankton jumping out of water. Journal of The Royal Society Interface, 12:20150582, 2015.

[15] M. Prakash, D. Quéré, e J.W.M. Bush. Surface tension transport of prey by feeding shorebirds: the capillary ratchet. Science, 320:931-934, 2008.

[16] J.W.M. Bush. Capillary feeding in shorebirds. http://math.mit.edu/ bush/ ? $\mathrm{p}=77$. Online, acessado em 25/04/2017.

[17] H. Zhu, Z. Guo, e W. Liu. Biomimetic water-collecting materials inspired by nature. Chemical Communications, 52:3863-3879, 2016.

[18] J. Hong, J.K. Park, B. Koo, K.H. Kang, e Y.K. Suh. Drop transport between two nonparallel plates via ac electrowetting-driven oscillation. Sensors and Actuators B: Chemical, 188:637-643, 2013.

[19] X. Heng e C. Luo. Liquid drop runs upward between two nonparallel plates. Langmuir, $31: 2743-2748,2015$. 
[20] L. Wang, H. Wu, e F. Wang. Efficient transport of droplet sandwiched between saw-tooth plates. Journal of Colloid and Interface Science, 462:280-287, 2016.

[21] R.H. Notter. Lung surfactants: basic science and clinical applications. Marcel Dekker, 2000.

[22] S. Baoukina e D.P. Tieleman. Computer simulations of lung surfactant. Biochimica et Biophysica Acta (BBA)-Biomembranes, 1858:2431-2440, 2016.

[23] J.J. Fredberg e S.K. Holford. Discrete lung sounds: crackles (rales) as stress-relaxation quadrupoles. The Journal of the Acoustical Society of America, 73:1036-1046, 1983.

[24] A.M. Alencar, S.V. Buldyrev, A. Majumdar, H.E. Stanley, e B. Suki. Avalanche dynamics of crackle sound. Physical Review Letters, 87:088101, 2001.

[25] C.D. Ahrens. Meteorology today: an introduction to weather, climate, and the environment. Cengage Learning, 2012.

[26] D.J. Hornbaker, R. Albert, I. Albert, A.L. Barabasi, e P. Schiffer. What keeps sandcastles standing? Nature, 387:765-765, 1997.

[27] A. Fall, B. Weber, M. Pakpour, N. Lenoir, N. Shahidzadeh, J. Fiscina, C. Wagner, e D. Bonn. Sliding friction on wet and dry sand. Physical Review Letters, 112:175502, 2014.

[28] B. Qian e K.S. Breuer. The motion, stability and breakup of a stretching liquid bridge with a receding contact line. Journal of Fluid Mechanics, 666:554-572, 2011.

[29] H.W. Kang, H.J. Sung, T-M. Lee, D-S. Kim, e C-J. Kim. Liquid transfer between two separating plates for micro-gravure-offset printing. Journal of Micromechanics and Microengineering, 19:015025, 2009.

[30] H. Chen, T. Tang, H. Zhao, K-Y. Law, e A. Amirfazli. How pinning and contact angle hysteresis govern quasi-static liquid drop transfer. Soft Matter, 12:1998-2008, 2016. 
[31] R.M. German, P. Suri, e S.J. Park. Review: liquid phase sintering. Journal of Materials Science, 44:1-39, 2009.

[32] W.J Huppmann e H. Riegger. Modelling of rearrangement processes in liquid phase sintering. Acta Metallurgica, 23:965-971, 1975.

[33] B. Bhushan, C.A. Kotwal, e S.K. Chilamakuri. Kinetic meniscus model for prediction of rest stiction. Journal of Tribology, 120:42-50, 1998.

[34] Y.S. Ma, W.D. Zhou, S.K. Yu, e W. Hua. Adsorbed water film and heat conduction from disk to slider in heat-assisted magnetic recording. Tribology Letters, 56:93-99, 2014.

[35] D.W. Langbein. Capillary surfaces: shape-stability-dynamics, in particular under weightlessness. Springer, 2002.

[36] P.J. Canfield, P.M. Bronowicki, Y. Chen, L. Kiewidt, A. Grah, J. Klatte, R. Jenson, W. Blackmore, M.M. Weislogel, e M.E. Dreyer. The capillary channel flow experiments on the international space station: experiment set-up and first results. Experiments in fluids, 54:1-14, 2013.

[37] M.M. Weislogel. Capillary flow experiment - 2. http://www.nasa.gov/ mission_pages/station/research/experiments/459.html. Online, acessado em 25/04/2017.

[38] J.W. van Honschoten, N. Brunets, e N.R. Tas. Capillarity at the nanoscale. Chemical Society Reviews, 39:1096-1114, 2010.

[39] N.V. Zarate, A.J. Harrison, J.D. Litster, e S.P. Beaudoin. Effect of relative humidity on onset of capillary forces for rough surfaces. Journal of Colloid and Interface Science, 411:265-272, 2013.

[40] R.D. Piner, J. Zhu, F. Xu, S. Hong, e C.A. Mirkin. "dip-pen"nanolithography. Science, 283:661-663, 1999. 
[41] K.A. Brown, D.J. Eichelsdoerfer, X. Liao, S. He, e C.A. Mirkin. Material transport in dip-pen nanolithography. Frontiers of Physics, 9:385-397, 2014.

[42] N. Kurra, R.G. Reifenberger, e G.U. Kulkarni. Nanocarbon-scanning probe microscopy synergy: fundamental aspects to nanoscale devices. ACS Applied Materials \& Interfaces, 6:6147-6163, 2014

[43] B.P. Pozniak e R.B. Cole. Perspective on electrospray ionization and its relation to electrochemistry. Journal of The American Society for Mass Spectrometry, 26:369-385, 2015.

[44] C. Trejo-Soto, E. Costa-Miracle, I. Rodriguez-Villarreal, J. Cid, T. Alarcón, e A. Hernández-Machado. Capillary filling at the microscale: control of fluid front using geometry. PloS one, 11:0153559, 2016.

[45] D. Bonn, J. Eggers, J. Indekeu, J. Meunier, e E. Rolley. Wetting and spreading. Reviews of Modern Physics, 81:739-805, 2009.

[46] J.R. Castrejon-Pita, C.J. Howland, A. Antkowiak, S.D. Howison, J.M. Oliver, R.W. Style, e A.A. Castrejon-Pita. It's harder to splash on soft solids. Physical Review Letters, $117: 184502,2016$.

[47] R. Finn, J. McCuan, e H. Wente. Thomas young's surface tension diagram: its history, legacy, and irreconcilabilities. Journal of Mathematical Fluid Mechanics, 18:1-9, 2006.

[48] I. Riva e I. Martinez. Floating liquid zones. Naturwissenschaften, 73:345-347, 1986.

[49] B.L. Weeks, M.W. Vaughn, e J.J. DeYoreo. Direct imaging of meniscus formation in atomic force microscopy using environmental scanning electron microscopy. Langmuir, 21:8096-8098, 2005.

[50] A.M. Alencar, E. Wolfe, e S.V. Buldyrev. Monte carlo simulation of liquid bridge rupture: Application to lung physiology. Physical Review E, 74:026311, 2006. 
[51] A.M. Alencar, S.P. Arold, S.V. Buldyrev, A. Majumdar, D. Stamenovic, H.E. Stanley, e B. Suki. Physiology: dynamic instabilities in the inflating lung. Nature, 417:809-811, 2002.

[52] A.B. Almeida, S.V. Buldyrev, e A.M. Alencar. Crackling sound generation during the formation of liquid bridges: A lattice gas model. Physica A: Statistical Mechanics and its Applications, 392:3409-3416, 2013.

[53] A. Urtizberea e M. Hirtz. A diffusive ink transport model for lipid dip-pen nanolithography. Nanoscale, 7:15618-15634, 2015.

[54] M. Schenk, M. Füting, e R. Reichelt. Direct visualization of the dynamic behavior of a water meniscus by scanning electron microscopy. Journal of Applied Physics, 84:48804884, 1998.

[55] H. Kim, L.C. Saha, J.K. Saha, e J. Jang. Molecular simulation of the water meniscus in dip-pen nanolithography. Scanning, 32:2-8, 2010.

[56] D.J. Eichelsdoerfer, K.A. Brown, e C.A. Mirkin. Capillary bridge rupture in dip-pen nanolithography. Soft Matter, 10:5603-5608, 2014.

[57] R. Proksch, M. Kocun, D. Hurley, M. Viani, A. Labuda, W. Meinhold, e J. Bemis. Practical loss tangent imaging with amplitude-modulated atomic force microscopy. Journal of Applied Physics, 119:134901, 2016.

[58] T. Thundat, X.-Y. Zheng, G.Y. Chen, e R.J. Warmack. Role of relative humidity in atomic force microscopy imaging. Surface Science, 294:L939-L943, 1993.

[59] D.L. Sedin e K.L. Rowlen. Adhesion forces measured by atomic force microscopy in humid air. Analytical Chemistry, 72:2183-2189, 2000.

[60] L. Chen, X. Gu, M.J. Fasolka, J.W. Martin, e T. Nguyen. Effects of humidity and sample surface free energy on afm probesample interactions and lateral force microscopy image contrast. Langmuir, 25:3494-3503, 2009. 
[61] J. Yu, L. Chen, L. Qian, D. Song, e Y. Cai. Investigation of humidity-dependent nanotribology behaviors of si( 100$) /$ sio2 pair moving from stick to slip. Applied Surface Science, 265:192-200, 2013.

[62] H.K. Christenson e N.H. Thomson. The nature of the air-cleaved mica surface. Surface Science Reports, 71:367-390, 2016.

[63] B. Sung, J. Kim, C. Stambaugh, S-J. Chang, e W. Jhe. Direct measurement of activation time and nucleation rate in capillary-condensed water nanomeniscus. Applied Physics Letters, 103:213107, 2013.

[64] E. Sahagún, P. García-Mochales, G.M. Sacha, e J.J. Sáenz. Energy dissipation due to capillary interactions: hydrophobicity maps in force microscopy. Physical Review Letters, 98:176106, 2007.

[65] R. Szoszkiewicz e E. Riedo. Nucleation time of nanoscale water bridges. Physical Review Letters, 95:135502, 2005.

[66] L. Bocquet, E. Charlaix, S. Ciliberto, e J. Crassous. Moisture-induced ageing in granular media and the kinetics of capillary condensation. Nature, 396:735-737, 1998.

[67] W. Bak, B. Sung, J. Kim, S. Kwon, B. Kim, e W. Jhe. Time-resolved observation of thermally activated rupture of a capillary-condensed water nanobridge. Applied Physics Letters, 106:013102, 2015.

[68] F. Restagno, L. Bocquet, e T. Biben. Metastability and nucleation in capillary condensation. Physical Review Letters, 84:2433-2436, 2000.

[69] F. Restagno, L. Bocquet, J. Crassous, e E. Charlaix. Slow kinetics of capillary condensation in confined geometry: experiment and theory. Colloids and Surfaces A: Physicochemical and Engineering Aspects, 206:69-77, 2002.

[70] L. Sirghi, R. Szoszkiewicz, e E. Riedo. Volume of a nanoscale water bridge. Langmuir, 22:1093-1098, 2006. 
[71] P. Prokopovich e V. Starov. Adhesion models: From single to multiple asperity contacts. Advances in Colloid and Interface Science, 168:210-222, 2011.

[72] F.L. Leite, C.C. Bueno, A.L. Da Róz, E.C. Ziemath, e O.N. Oliveira. Theoretical models for surface forces and adhesion and their measurement using atomic force microscopy. International Journal of Molecular Sciences, 13:12773-12856, 2012.

[73] H.C. Hamaker. The london—van der waals attraction between spherical particles. Physica, 4:1058-1072, 1937.

[74] M. Farshchi-Tabrizia, M. Kappl, e H-J. Butt. Influence of humidity on adhesion: an atomic force microscope study. Journal of Adhesion Science and Technology, 22:181203, 2008.

[75] L. Yang, J. Hu, e J. Qin. The van der waals force between arbitrary-shaped particle and a plane surface connected by a liquid bridge in humidity environment. Granular Matter, 16:903-909, 2014.

[76] A.J. Harrison, D.S. Corti, e S.P. Beaudoin. Capillary forces in nanoparticle adhesion: a review of afm methods. Particulate Science and Technology, 33:526-538, 2015.

[77] L. Yang, J. Hu, e K. Bai. Capillary and van der waals force between microparticles with different sizes in humid air. Journal of Adhesion Science and Technology, 30:566-578, 2016.

[78] H-J Butt e M. Kappl. Normal capillary forces. Advances in Colloid and Interface Science, $146: 48-60,2009$.

[79] H.J. Butt, K. Graf, e M. Kappl. Physics and chemistry of interfaces. Wiley-VCH, 2006.

[80] M. Sedighi, V.B. Svetovoy, e G. Palasantzas. Capillary-force measurement on sic surfaces. Physical Review E, 93:062803, 2016.

[81] L. Yang, Y. Tu, e H. Fang. Modeling the rupture of a capillary liquid bridge between a sphere and plane. Soft Matter, 6:6178-6182, 2010. 
[82] X. Xiao e L. Qian. Investigation of humidity-dependent capillary force. Langmuir, $16: 8153-8158,2000$.

[83] O.H. Pakarinen, A.S. Foster, M. Paajanen, T. Kalinainen, J. Katainen, I. Makkonen, J. Lahtinen, e R.M. Nieminen. Towards an accurate description of the capillary force in nanoparticle-surface interactions. Modelling and Simulation in Materials Science and Engineering, 13:1175, 2005.

[84] L. Yang, Y-S. Tu, e H-L. Tan. Influence of atomic force microscope (afm) probe shape on adhesion force measured in humidity environment. Applied Mathematics and Mechanics, pages 1-8, 2014.

[85] R. Ardito, A. Corigliano, A. Frangi, e F. Rizzini. Advanced models for the calculation of capillary attraction in axisymmetric configurations. European Journal of Mechanics A/Solids, 47:298-308, 2014.

[86] D.B. Asay, M.P. de Boer, e S.H. Kim. Equilibrium vapor adsorption and capillary force: exact laplace-young equation solution and circular approximation approaches. Journal of Adhesion Science and Technology, 24:2363-2382, 2010.

[87] S. Ogata, K. Fukuzawa, Y. Mitsuya, e Y. Ohshima. Molecular dynamics simulation of ultra-thin liquid bridging between surfaces having two-dimensional roughness. $M i$ crosystem Technologies, 11:1146-1153, 2005.

[88] A.F. Payam e M. Fathipour. A capillary force model for interactions between two spheres. Particuology, 9:381-386, 2011.

[89] G. Lian e J. Seville. The capillary bridge between two spheres: New closed-form equations in a two century old problem. Advances in Colloid and Interface Science, 227:53-62, 2016.

[90] A.C. Mitropoulos. The kelvin equation. Journal of Colloid and Interface Science, 317:643-648, 2008. 
[91] F. Caupin, F. Herbert, S. Balibar, e M.W. Cole. Comment on 'nanoscale water capillary bridges under deeply negative pressure' [chem. phys. lett. 451 (2008) 88]. Chemical Physics Letters, 463:283-285, 2008.

[92] S-H. Yang, M. Nosonovsky, H. Zhang, e K-H. Chung. Response to the comment on 'nanoscale water capillary bridges under deeply negative pressure' by caupin et al. Chemical Physics Letters, 463:286-287, 2008.

[93] M. Nosonovsky e B. Bhushan. Phase behavior of capillary bridges: towards nanoscale water phase diagram. Physical Chemistry Chemical Physics, 10:2137-2144, 2008.

[94] S.H. Yang, M. Nosonovsky, H. Zhang, e K-H. Chung. Nanoscale water capillary bridges under deeply negative pressure. Chemical Physics Letters, 451:88-92, 2008.

[95] N.R. Tas, P. Mela, T. Kramer, J.W. Berenschot, e A. van den Berg. Capillarity induced negative pressure of water plugs in nanochannels. Nano Letters, 3:1537-1540, 2003.

[96] N.R. Tas, M. Escalante, J.W. van Honschoten, H.V. Jansen, e M. Elwenspoek. Capillary negative pressure measured by nanochannel collapse. Langmuir, 26:1473-1476, 2010.

[97] S. Kelly, C. Torres-Verdín, e M.T. Balhoff. Anomalous liquid imbibition at the nanoscale: the critical role of interfacial deformations. Nanoscale, 8:2751-2767, 2016.

[98] K. Cho, I.G. Hwang, Y. Kim, S.J. Lim, J. Lim, J.H. Kim, B. Gim, e B.M. Weon. Low internal pressure in femtoliter water capillary bridges reduces evaporation rates. Scientific Reports, 6:22232, 2016.

[99] N. Giovambattista, P. Rossky, e P. Debenedetti. Effect of pressure on the phase behavior and structure of water confined between nanoscale hydrophobic and hydrophilic plates. Physical Review E, 73:041604, 2006.

[100] G.E. Valenzuela, J.H. Saavedra, R.E. Rozas, e P.G. Toledo. Force exerted by a nanoscale capillary water bridge between two planar substrates. Physical Chemistry Chemical Physics, 18:11176-11183, 2016. 
[101] S. Cheng e M.O. Robbins. Capillary adhesion at the nanometer scale. Physical Review E, 89:062402, 2014.

[102] S. Cheng e M.O. Robbins. Nanocapillary adhesion between parallel plates. Langmuir, 32:7788-7795, 2016.

[103] J. Jang, G.C. Schatz, e M.A. Ratner. Liquid meniscus condensation in dip-pen nanolithography. The Journal of Chemical Physics, 116:3875-3886, 2002.

[104] J. Jang, G.C. Schatz, e M.A. Ratner. Capillary force on a nanoscale tip in dip-pen nanolithography. Physical Review Letters, 90:156104, 2003.

[105] J. Jang, G.C. Schatz, e M.A. Ratner. How narrow can a meniscus be? Physical Review Letters, 92:085504, 2004.

[106] J. Jang, G.C. Schatz, e M.A. Ratner. Capillary force in atomic force microscopy. The Journal of Chemical Physics, 120:1157-1160, 2004.

[107] J. Jang, M.A. Ratner, e G.C. Schatz. Atomic-scale roughness effect on capillary force in atomic force microscopy. The Journal of Physical Chemistry B, 110:659-662, 2006.

[108] J. Jang, J. Jeon, e S. Hwang. Monte carlo study on the water bridge that produces the pull-off force in atomic force microscopy. Colloids and Surfaces A: Physicochemical and Engineering Aspects, 300:60-64, 2007.

[109] A.J. Harrison, S.P. Beaudoin, e D.S. Corti. Wang-landau monte carlo simulation of capillary forces at low relative humidity in atomic force microscopy. Journal of Adhesion Science and Technology, 30:1165-1177, 2016.

[110] Y. Men, X. Zhang, e W. Wang. Capillary liquid bridges in atomic force microscopy: formation, rupture, and hysteresis. The Journal of Chemical Physics, 131:184702, 2009.

[111] Y. Men, Q. Yan, G. Jiang, X. Zhang, e W. Wang. Nucleation and hysteresis of vaporliquid phase transitions in confined spaces: effects of fluid-wall interaction. Physical Review E, 79:051602, 2009. 
[112] Y. Men, X. Zhang, e W. Wang. Rupture kinetics of liquid bridges during a pulling process: a kinetic density functional theory study. The Journal of Chemical Physics, 134:124704, 2011.

[113] Y. Chen, J-g. Weng, J.R. Lukes, A. Majumdar, e C-L. Tien. Molecular dynamics simulation of the meniscus formation between two surfaces. Applied Physics Letters, 79:12671269, 2001.

[114] M. Chaplin. Water structure and science. http://www1.1sbu.ac.uk/water/. Online, acessado em 25/04/2017.

[115] C-D. Wu e T-H. Fang. Simulation of deposition of ink molecules on rough substrates in dip-pen nanolithography. Modelling and Simulation in Materials Science and Engineering, 19:065008, 2011.

[116] H.J. Choi, J.Y. Kim, S.D. Hong, M.Y. Ha, e J. Jang. Molecular simulation of the nanoscale water confined between an atomic force microscope tip and a surface. Molecular Simulation, 35:466-472, 2009.

[117] J-A. Ko, H-J. Choi, M-Y. Ha, S-D. Hong, e H-S. Yoon. A study on the behavior of water droplet confined between an atomic force microscope tip and rough surfaces. Langmuir, 26:9728-9735, 2010.

[118] H. Kim, B. Smit, e J. Jang. Monte carlo study on the water meniscus condensation and capillary force in atomic force microscopy. The Journal of Physical Chemistry $C$, 116:21923-21931, 2012.

[119] S. Leroch e M. Wendland. Influence of capillary bridge formation onto the silica nanoparticle interaction studied by grand canonical monte carlo simulations. Langmuir, 29:12410-12420, 2013.

[120] S. Salameh, J. Schneider, J. Laube, A. Alessandrini, P. Facci, J.W. Seo, L.C. Ciacchi, e L. Madler. Adhesion mechanisms of the contact interface of tio2 nanoparticles in films and aggregates. Langmuir, 28:11457-11464, 2012. 
[121] J. Laube, S. Salameh, M. Kappl, L. Madler, e L.C. Ciacchi. Contact forces between tio2 nanoparticles governed by an interplay of adsorbed water layers and roughness. Langmuir, 31:11288-11295, 2015.

[122] K. Sepehrinia e A. Mohammadi. Wettability alteration properties of fluorinated silica nanoparticles in liquid-loaded pores: An atomistic simulation. Applied Surface Science, $371: 349-359,2016$.

[123] F. Bresme, H. Lehle, e M. Oettel. Solvent-mediated interactions between nanoparticles at fluid interfaces. The Journal of Chemical Physics, 130:214711, 2009.

[124] H.J.C. Berendsen, J.R. Grigera, e T.P. Straatsma. The missing term in effective pair potentials. Journal of Physical Chemistry, 91:6269-6271, 1987.

[125] J. Liu, C. Wang, P. Guo, G. Shi, e H. Fang. Linear relationship between water wetting behavior and microscopic interactions of super-hydrophilic surfaces. The Journal of Chemical Physics, 139:234703, 2013.

[126] S. Khan e J.K. Singh. Wetting transition of nanodroplets of water on textured surfaces: a molecular dynamics study. Molecular Simulation, 40:458-468, 2014.

[127] Z. Zhang, H. Kim, M.Y. Ha, e J. Jang. Molecular dynamics study on the wettability of a hydrophobic surface textured with nanoscale pillars. Physical Chemistry Chemical Physics, 16:5613-5621, 2014.

[128] J. Li, E. Liepinsh, A. Almlén, J. Thyberg, T. Curstedt, H. Jornvall, e J. Johansson. Structure and influence on stability and activity of the n-terminal propeptide part of lung surfactant protein c. FEBS Journal, 273:926-935, 2006.

[129] V. Kumar e J.R. Errington. Wetting behavior of water near nonpolar surfaces. The Journal of Physical Chemistry C, 117:23017-23026, 2013.

[130] N. Giovambattista, P.G. Debenedetti, e P.J. Rossky. Effect of surface polarity on water contact angle and interfacial hydration structure. The Journal of Physical Chemistry B, 111:9581-9587, 2007. 
[131] M. Yan, X. Yang, e Y. Lu. Wetting behavior of water droplet on solid surfaces in solvent environment: A molecular simulation study. Colloids and Surfaces A: Physicochemical and Engineering Aspects, 429:142-148, 2013.

[132] M. Iwamatsu. Line tension and morphology of a sessile droplet on a spherical substrate. Physical Review E, 93:052804, 2016.

[133] T. Werder, J.H. Walther, R.L. Jaffe, T. Halicioglu, e P. Koumoutsakos. On the watercarbon interaction for use in molecular dynamics simulations of graphite and carbon nanotubes. The Journal of Physical Chemistry B, 107:1345-1352, 2003.

[134] S. Gravelle, C. Ybert, L. Bocquet, e L. Joly. Anomalous capillary filling and wettability reversal in nanochannels. Physical Review E, 93:033123, 2016.

[135] Z. Guo, Y. Liu, Q. Xiao, H. Schonherr, e X. Zhang. Modeling the interaction between afm tips and pinned surface nanobubbles. Langmuir, 32:751-758, 2016.

[136] T. Koishi, S. Yoo, K. Yasuoka, X. C. Zeng, T. Narumi, R. Susukita, A. Kawai, H. Furusawa, A. Suenaga, N. Okimoto, N. Futatsugi, e T. Ebisuzaki. Nanoscale hydrophobic interaction and nanobubble nucleation. Physical Review Letters, 93:185701, 2004.

[137] T. Koishi, K. Yasuoka, T. Ebisuzaki, S. Yoo, e X.C. Zeng. Large-scale moleculardynamics simulation of nanoscale hydrophobic interaction and nanobubble formation. The Journal of chemical physics, 123:204707, 2005.

[138] J.S. Rowlinson e B. Widom. Molecular theory of capillarity. Courier Corporation, 2013.

[139] J.Y. Wang, S. Betelu, e B.M. Law. Line tension approaching a first-order wetting transition: Experimental results from contact angle measurements. Physical Review E, 63:031601, 2001.

[140] A.D. Myshkis. Low-gravity fluid mechanics: mathematical theory of capillary phenomena. Springer-Verlag, 1987. 
[141] T.I. Vogel. Stability of a liquid drop trapped between two parallel planes ii: general contact angles. SIAM Journal on Applied Mathematics, 49:1009-1028, 1989.

[142] T.I. Vogel. Local energy minimality of capillary surfaces in the presence of symmetry. Pacific Journal of Mathematics, 206:487-509, 2002.

[143] M. Athanassenas. A variational problem for constant mean curvature surfaces with free boundary. Journal für Mathematik, 1987.

[144] L. Zhou. On stability of a catenoidal liquid bridge. Pacific Journal of Mathematics, 178:185-198, 1997.

[145] L. Jørgensen, M. Le Merrer, H. Delanoë-Ayari, e C. Barentin. Yield stress and elasticity influence on surface tension measurements. Soft Matter, 11:5111-5121, 2015.

[146] T.I. Vogel. Stability of a liquid drop trapped between two parallel planes. SIAM Journal on Applied Mathematics, 47:516-525, 1987.

[147] S. Plimpton. Fast parallel algorithms for short-range molecular dynamics. Journal of Computational Physics, 117:1-19, 1995.

[148] R.W. Hockney e J.W. Eastwood. Computer simulation using particles. CRC Press, 1988.

[149] M. Deserno e C. Holm. How to mesh up ewald sums. ii. an accurate error estimate for the particle-particle-particle-mesh algorithm. The Journal of Chemical Physics, 109:7694$7701,1998$.

[150] S. Nosé. A molecular dynamics method for simulations in the canonical ensemble. Molecular Physics, 52:255-268, 1984.

[151] W. Shinoda, M. Shiga, e M. Mikami. Rapid estimation of elastic constants by molecular dynamics simulation under constant stress. Physical Review B, 69:134103, 2004.

[152] A.R. Leach. Molecular modelling: principles and applications. Pearson education, 2001. 
[153] D. Frenkel e B. Smit. Understanding molecular simulation: from algorithms to applications. Academic Press, 2002.

[154] M.P. Allen e D.J. Tildesley. Computer simulation of liquids. Oxford university press, 1989.

[155] J.A. Ritchie, J.S. Yazdi, D. Bratko, e A. Luzar. Metastable sessile nanodroplets on nanopatterned surfaces. The Journal of Physical Chemistry C, 116:8634-8641, 2012.

[156] J. Wang e X.C. Zeng. Computer simulation of liquid-vapor interfacial tension: Lennardjones fluid and water revisited. Journal of Theoretical and Computational Chemistry, 8:733-763, 2009.

[157] A.B. Almeida. Análise e modelagem termodinâmica de um modelo de gás de rede para pontes líquidas. Master’s thesis, Instituto de Física da Universidade de São Paulo, 2012.

[158] N. Metropolis e S. Ulam. The monte carlo method. Journal of the American Statistical Association, 44:335-341, 1949.

[159] N. Metropolis, A.W. Rosenbluth, M.N. Rosenbluth, A.H. Teller, e E. Teller. Equation of state calculations by fast computing machines. The Journal of Chemical Physics, 21:1087-1092, 1953.

[160] D.P. Landau e K. Binder. A guide to Monte Carlo simulations in statistical physics. Cambridge University Press, 2005.

[161] A.M. Alencar, D.G.V. da Silva, C.B. Oliveira, A.P. Vieira, H.T. Moriya, e G. LorenziFilho. Dynamics of snoring sounds and its connection with obstructive sleep apnea. Physica A: Statistical Mechanics and its Applications, 392:271-277, 2013.

[162] P.S. Addison. Fractals and chaos: an illustrated course. CRC Press, 1997.

[163] N. Giovambattista, A.B. Almeida, A.M. Alencar, e S.V. Buldyrev. Validation of capillarity theory at the nanometer scale by atomistic computer simulations of water droplets 
and bridges in contact with hydrophobic and hydrophilic surfaces. The Journal of Physical Chemistry C, 120:1597-1608, 2016.

[164] D. Kashchiev. Determining the curvature dependence of surface tension. The Journal of Chemical Physics, 118:9081-9083, 2003.

[165] R-V.S. Castrillon, N. Giovambattista, I.A. Aksay, e P.G. Debenedetti. Structure and energetics of thin film water. The Journal of Physical Chemistry C, 115:4624-4635, 2011.

[166] A.E. Ismail, G.S. Grest, e M.J. Stevens. Capillary waves at the liquid-vapor interface and the surface tension of water. The Journal of Chemical Physics, 125:014702, 2006.

[167] C. Vega e E. de Miguel. Surface tension of the most popular models of water by using the test-area simulation method. The Journal of Chemical Physics, 126:154707, 2007.

[168] A.P. Willard e D. Chandler. Instantaneous liquid interfaces. The Journal of Physical Chemistry B, 114:1954-1958, 2010. 
Apêndices 


\section{Apêndice A}

\section{Arquivo de entrada do LAMMPS}

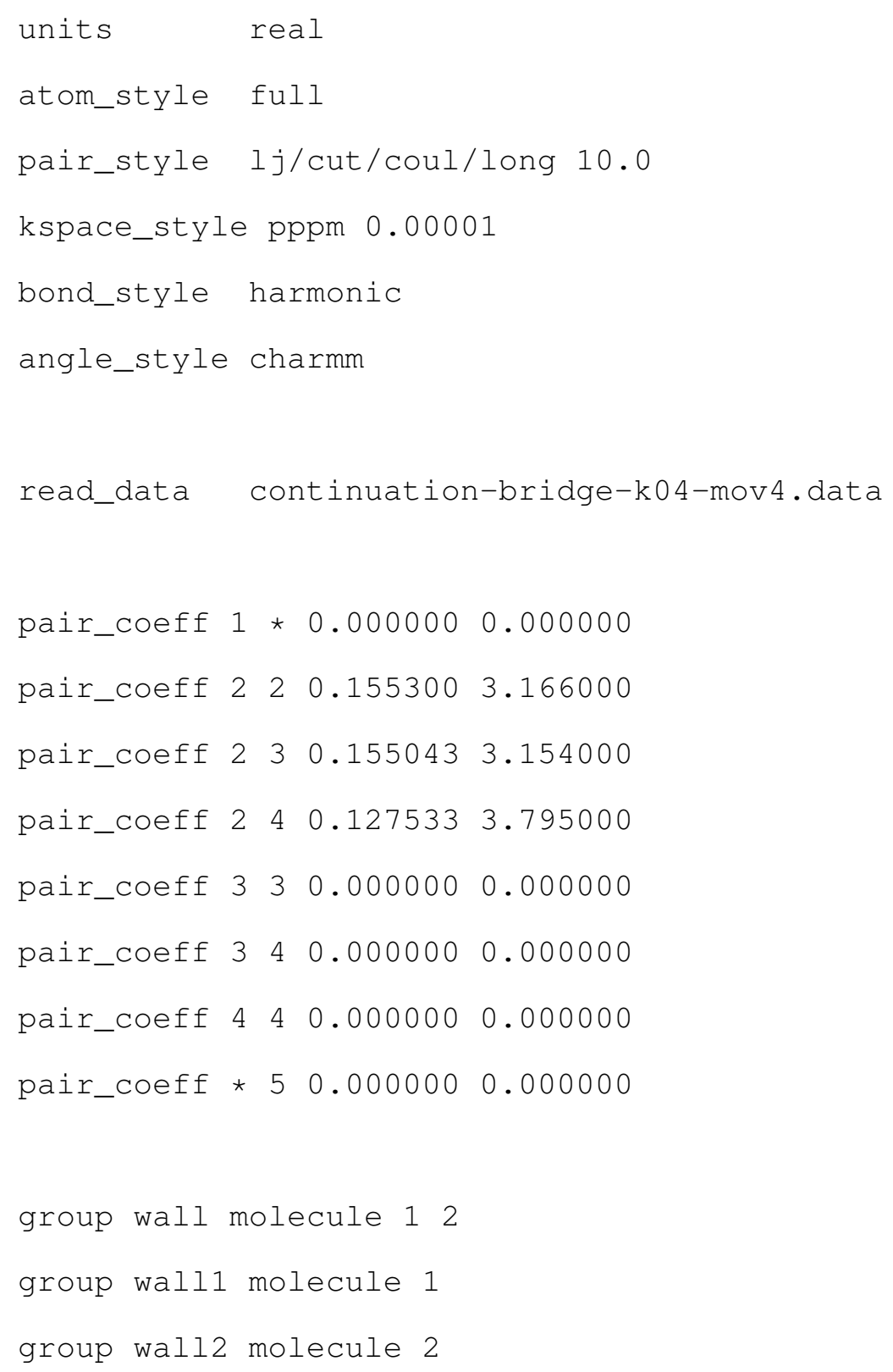


group wallH type 5

group water type 12

neighbor 2.0 bin

neigh_modify delay 0 every 1 check yes

compute wallHTemp wallH temp

compute waterTemp water temp

thermo_style custom step etotal ke temp c_waterTemp c_wallHTemp pe ebond eangle evdwl ecoul elong press vol

thermo_modify flush yes line one \# norm yes

thermo 1000

fix 1 wallH nvt temp 300.0300 .0100 .0 tchain 1

fix 2 water nvt temp 300.0 300.0 100.0 tchain 1

fix 3 all shake 0.000011000 b 123 a 1

compute fl walli reduce sum fx fy $f z$

compute f2 wall2 reduce sum fx fy fz

fix 4 wall1 ave/time 110001000 c_f1[1] c_f1[2] c_f1[3] file fW1.out fix 5 wall2 ave/time 110001000 c_f2[1] c_f2[2] c_f2[3] file fW2.out

dump POS water custom 1000 *.pos id type x y z

dump VEL water custom 1000 * vel id type vx vy vz

dump wallpos wall custom $1000 \star$-wall.pos id type x y z

dump wallHPOS wall custom 1000 *wall-H.pos id type x y z 
dump wallHVEL wall custom 1000 *wall-H.vel id type vx vy vz

dump_modify POS sort id flush yes

dump_modify VEL sort id flush yes

dump_modify wallpos sort id flush yes

dump_modify wallHPOS flush yes

dump_modify wallHVEL flush yes

fix 6 wall1 move linear -0.010 .00 .0$

fix 7 wall 2 move linear 0.010 .00 .0

$\operatorname{run} 125$

unfix 6

unfix 7

restart 1000000 continuation_ASbridgek04_moviment5a.restart run 3000000 upto 


\section{Apêndice B}

\section{Arquivo de configuração do LAMMPS}

LAMMPS data file via write_data, version 10 Feb 2015, timestep = 3000000

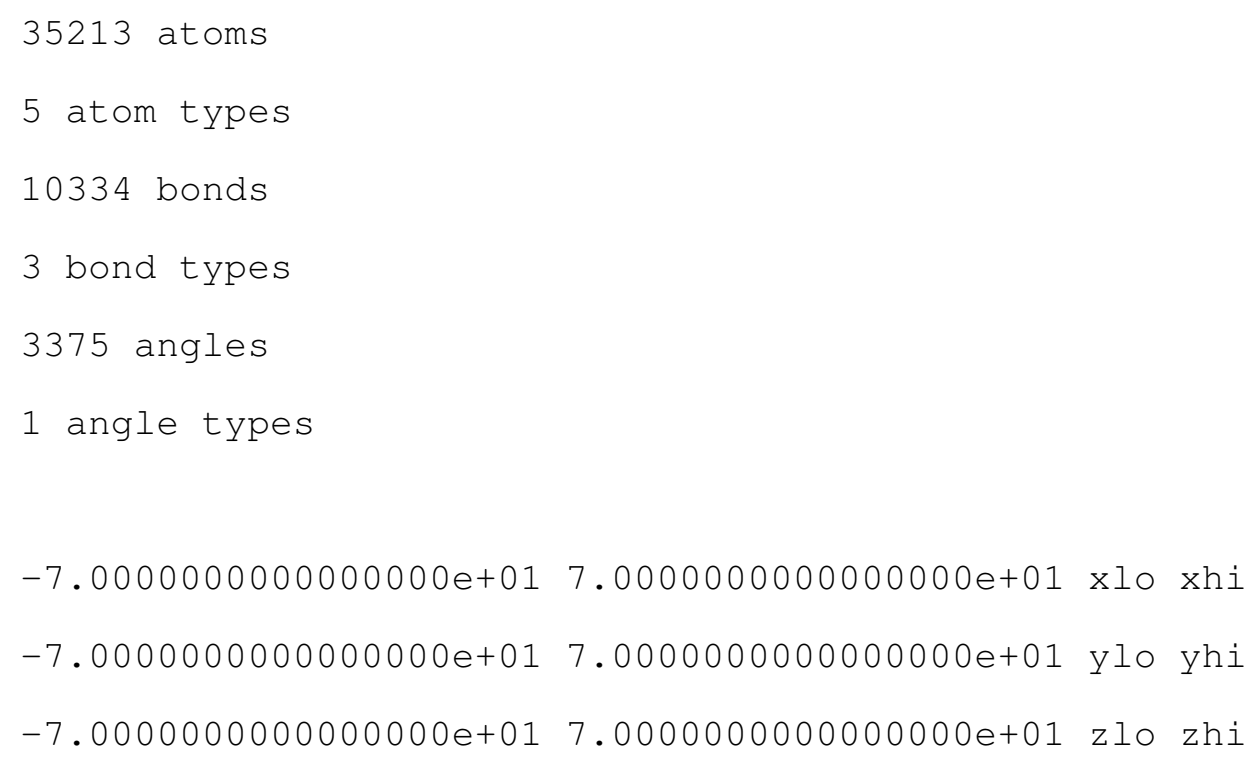
11.008
$2 \quad 15.9994$
31
41
51.008 
Pair Coeffs \# lj/cut/coul/long
$\begin{array}{lll}1 & 0 & 0\end{array}$
$20.1553 \quad 3.166$
300
$4 \quad 0 \quad 0$
500

Bond Coeffs \# harmonic
14501
24501
34502.06802

Angle Coeffs \# charmm

$1450109.47 \quad 0 \quad 0$

Atoms \# full

$8130.0000000000000000 e+00-4.3413350000000001 e+01$ $-6.8059030000000007 e+01-6.8578130000000002 e+01000$

$11130.0000000000000000 e+00-4.3413350000000001 e+01$ $-6.5584149999999994 e+01-6.4246880000000004 e+01000$

$7140.0000000000000000 e+00-4.1897810000000000 e+01$ $-6.8059030000000007 e+01-6.8578130000000002 e+01000$

$10140.0000000000000000 e+00-4.1897810000000000 e+01$

$-6.5584149999999994 e+01-6.4246880000000004 e+01000$

$1130.0000000000000000 e+00-4.1392629999999997 e+01$ 


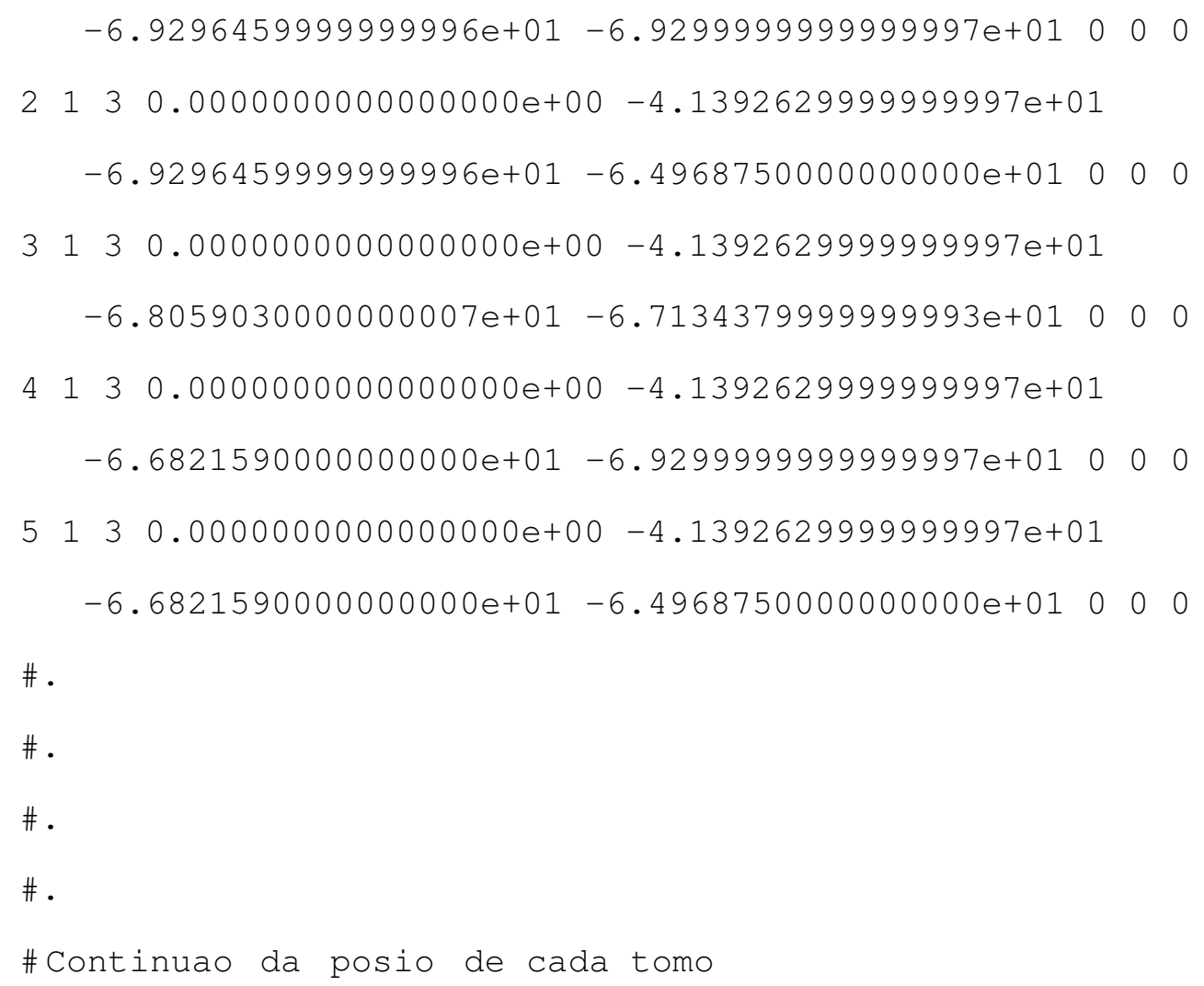




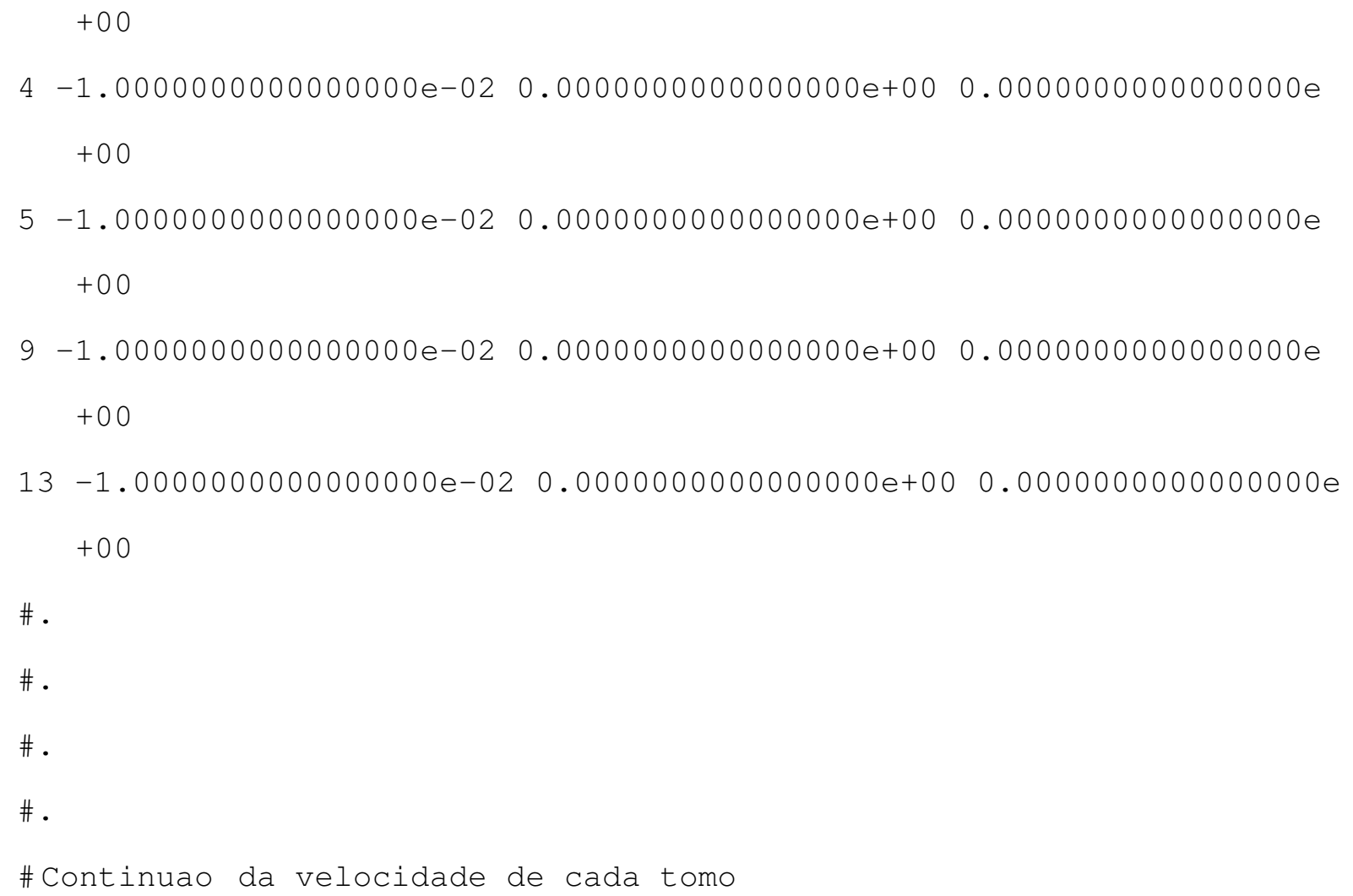




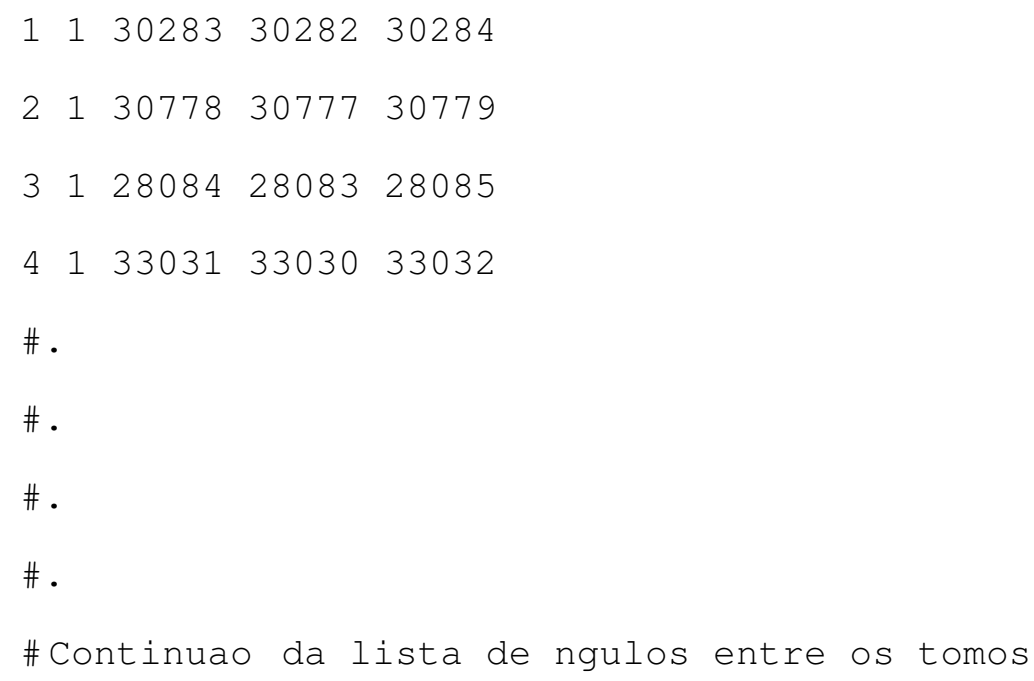




\section{Apêndice C}

\section{Atividades acadêmicas}

\section{Produção bibliográfica:}

- Artigos publicados (anexado):

- Nicolas Giovambattista, Alexandre B. Almeida, Adriano M. Alencar, Sergey V. Buldyrev. Validation of Capillarity Theory at the Nanometer Scale by Atomistic Computer Simulations of Water Droplets and Bridges in Contact with Hydrophobic and Hydrophilic Surfaces. Journal of Physical Chemistry. C. 120(3):1597-1608, 2016.

- Artigos em processo de submissão (anexado):

- Alexandre B. Almeida, Nicolas Giovambattista, Sergey V. Buldyrev, Adriano M. Alencar. Rupture of water capillary bridges in contact with hydrophobic and hydrophilic surfaces: an study by atomistic computer simulations. (to be submitted) The Journal of PhysicalChemistry C, 2016.

- Trabalhos apresentados em conferências:

- Alexandre B. Almeida, Nicolas Giovambattista, Sergey V. Buldyrev, Adriano M. Alencar. Monte Carlo and molecular dynamics simulations of capillary bridges. 26th IUPAP International conference on Statistical Physics, 2016, Lyon - França.

- Alexandre B. Almeida, Adriano M. Alencar. A liquid bridge model of complex fluid trapped in different geometries: the effect of amphiphilic particles. XXXVII 
Encontro Nacional de Física da Matéria Condensada, 2014, Costa do Sauípe - BA.

- Alexandre B. Almeida, Adriano M. Alencar. Study of surface free energy on a lattice-gas model applied to liquid bridge. XXXVI Encontro Nacional de Física da Matéria Condensada, 2013, Águas de Lindoia - SP.

- Resumo expandido (anexado):

- Alexandre B. Almeida, Nicolas Giovambattista, Sergey V. Buldyrev, Adriano M. Alencar. Irregular dynamics of the center of mass of droplets. 6th International Conference on Nonlinear Science and Complexity, 2016, São Jose dos Campos SP.

\section{Estágio de doutorado sanduíche:}

- No período de Setembro de 2014 até Agosto de 2015 fiz um estágio de doutorado sanduíche com o Prof. Dr. Sergey V. Buldyrev da Yeshiva University em Nova Iorque. O Prof. Sergey é um pesquisador de renome na área de mecânica estatística, atuando em diversos campos como Física de Polímeros, Agregação e Enovelamento de Proteínas, Física do Pulmão, etc. Nesse período, também pude trabalhar com o Prof. Dr. Nicolas Giovambattista do City University of New York - Brooklyn College, com quem publicamos um artigo (anexado) sobre pontes líquidas e gotas na escala nanométrica, momento em que iniciei os estudos com dinâmica molecular. Além disso, temos outro artigo que esta em fase final de submissão e temos a perspectiva de publicar mais dois artigos em conjunto. Além disso, trabalhamos com outras metodologias para o calculo de energia livre, e participei dos seminários da universidade e pude apresentar meu trabalho em um deles.

\section{Artigos publicados e submetidos:}




\title{
Validation of Capillarity Theory at the Nanometer Scale by Atomistic Computer Simulations of Water Droplets and Bridges in Contact with Hydrophobic and Hydrophilic Surfaces
}

\author{
Nicolas Giovambattista, ${ }^{*},+\neq$ Alexandre B. Almeida, ${ }^{\S}, \|$ Adriano M. Alencar," and Sergey V. Buldyrev ${ }^{\S}$ \\ †Department of Physics, Brooklyn College of the City University of New York, Brooklyn, New York 11210, United States \\ ${ }^{\ddagger}$ Ph.D. Programs in Chemistry and Physics, The Graduate Center of the City University of New York, New York, New York 10016, \\ United States \\ ${ }^{\S}$ Department of Physics, Yeshiva University, 500 West 185th Street, New York, New York 10033, United States \\ "Instituto de Física, Universidade de São Paulo, 05508-090, São Paulo, SP, Brazil
}

ABSTRACT: Capillarity is the study of interfaces between two immiscible liquids or between a liquid and a vapor. The theory of capillarity was created in the early 1800 s, and it is applicable to mesoscopic and macroscopic $(>1 \mu \mathrm{m})$ systems. In general, macroscopic theories are expected to fail at the $<10 \mathrm{~nm}$ scales where molecular details may become relevant. In this work, we show that, surprisingly, capillarity theory (CT) provides satisfactory predictions at 2-10 nm scales. Specifically, we perform atomistic molecular dynamics (MD) simulations of water droplets and capillary bridges of different symmetry in contact with various surfaces. The

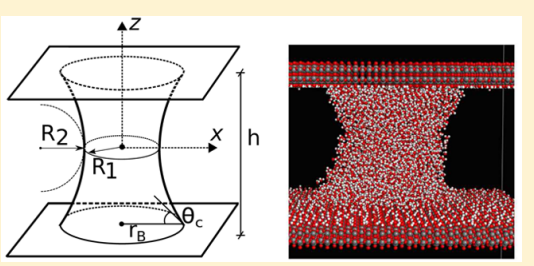
underlying structure of the surfaces corresponds to hydroxilated (crystalline) silica which is modified to cover a wide range of hydrophobicity/hydrophilicity. In agreement with CT, it is found that water contact angle is independent of the droplet/bridge geometry and depends only on the hydrophobicity/hydrophilicity of the surface employed. In addition, CT provides the correct droplet/bridge profile for all (hydrophobic/hydrophilic) surfaces considered. Remarkably, CT works even for the very small droplets/bridges studied, for which the smallest dimension is $\approx 2 \mathrm{~nm}$. It follows that the concepts of surface tension and contact angle are indeed meaningful at $2-10 \mathrm{~nm}$ scales even when, macroscopically, such concepts are not justified. In order to confirm the self-consistency of CT at $2-10 \mathrm{~nm}$ scales, we also calculate the capillary forces between different surfaces induced by water capillary bridges. These forces depend on the liquid-vapor surface tension of water, $\gamma$. Using CT, the calculated forces indicate that $\gamma=0.054 \pm 0.001 \mathrm{~N} / \mathrm{m}^{2}$. This is in agreement with the value $\gamma=0.056 \pm 0.001 \mathrm{~N} / \mathrm{m}^{2}$ obtained independently using the Kirkwood-Buff method, and it is consistent with values of $\gamma$ reported in the literature for the present water model. Confirming the validity of CT at $2-10 \mathrm{~nm}$ scales has relevant implications in scientific applications, such as in our understanding of selfassembly processes at interfaces. We discuss briefly this and other consequences of the present results.

\section{INTRODUCTION}

Capillarity is the study of deformable interfaces formed between a liquid and a vapor or between immiscible liquids. ${ }^{1}$ Examples of capillarity phenomena are abundant. For example, it is the formation of water bridges (capillary bridges) between grains of sands that allows sand castles to stand still. ${ }^{2}$ In biology, e.g., capillarity phenomena allow insects to "walk" on water $^{3}$ and provide insects with adhesion pads in their legs to attach to surfaces. ${ }^{4,5}$ In medicine, capillary bridges may form during inflammatory processes of lungs. ${ }^{6,7}$ Capillarity plays a major role in diverse technological and scientific applications, such as in soil science and climate as well as in textiles production and the treatment of glass surfaces. ${ }^{1}$

The field of capillarity was developed in the early 19th century by Laplace and Young. ${ }^{1}$ The classical theory of capillarity is well-developed and is based on the concept of surface tension. Capillarity theory (CT) is a macroscopic approach applicable to liquid volumes in the $>1 \mu \mathrm{m}$ scales. Extending CT to the nanoscale is desirable partially due to its relevance in scientific and technological applications. ${ }^{8}$ For example, humidity can induce the formation of capillary bridges of nanoscale dimensions between the tip of atomic force microscopes (AFM) and the surface of interest. ${ }^{9-11}$ Such nanoscale liquid bridges may affect AFM measurements, ${ }^{12,13}$ and quantifying such capillary bridge forces is hence necessary. Similar liquid bridges play relevant roles in "dip pen" nanolithografy techniques, ${ }^{14}$ industrial processes such as sintering, ${ }^{15}$ and ink transfer processes in contact printers. ${ }^{16-18}$

As the typical length scale is reduced below $100 \mathrm{~nm}$, deviations from CT are expected, particularly at $<10 \mathrm{~nm}$ scales where molecular details become relevant. Remarkably, computer simulation studies of $<10 \mathrm{~nm}$ size droplets are consistent with macroscopic predictions of CT; for example, these studies show that the average profile of nanoscale droplets is indeed spherical (as predicted by CT) (see, e.g., refs 19-21). Similarly, detailed studies of nanoparticles immersed in a liquid

Received: October 23, 2015

Revised: December 15, 2015

Published: December 31, 2015 


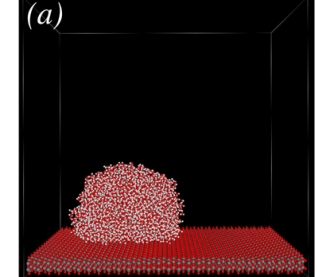

(e)

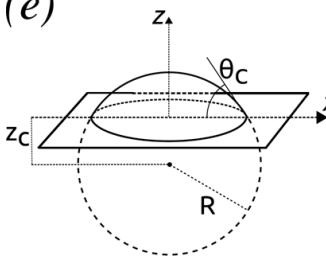

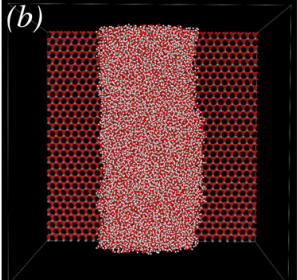

(f)

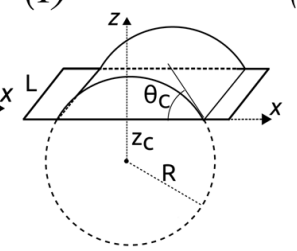

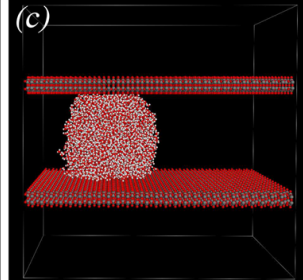

$(g)$
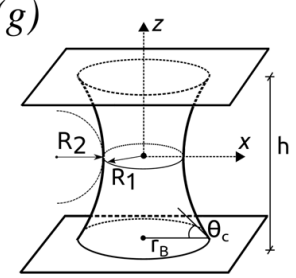

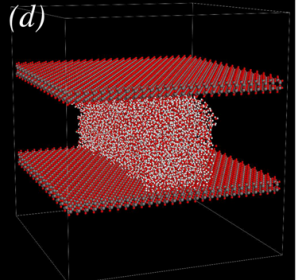

(h)

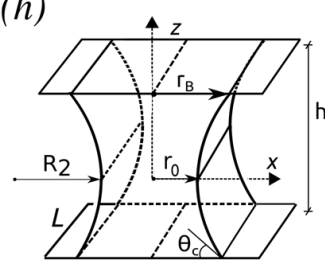

Figure 1. Snapshots from computer simulations of (a) AS droplet (side view), (b) TS droplet (top view), (c) AS bridge (side view), and (d) TS bridge (side view) for hydrophobic surfaces with surface polarity $k=0.0$. Panels $\mathrm{e}, \mathrm{f}, \mathrm{g}$, and $\mathrm{h}$ are, respectively, the schematic diagrams indicating the relevant parameters used in the present work for each of the systems in (a), (b), (c), and (d) (see text).

and vapor phase show that the solvent-mediated interactions between $(\approx 2 \mathrm{~nm}$ size $)$ particles are consistent with $\mathrm{CT} .{ }^{22} \mathrm{We}$ note that theoretical and computer simulation studies show that CT can be used to describe accurately the adsorption behavior of nonspherical nanoparticles at liquid-liquid interfaces. ${ }^{23,24}$ Many of these computational studies are based on idealized liquids and/or surfaces where, for example, the liquid and/or surfaces are composed of Lennard-Jones particles (see, e.g., ref 25). Yet, computer simulations show that expressions obtained from CT, in general, hold at the nanoscale. In a different context, macroscopic thermodynamics has been applied successfully to study nanoconfined fluids. ${ }^{26-28}$ However, in many of these cases, the expressions from CT are employed to fit simulation data using quantities, such as surface tensions, as free fitting parameters. In other cases, successful application of $\mathrm{CT}$ to describe nanoscale systems requires additional concepts, such as line tension, which play no role at the macroscale (see, e.g., refs 19, 22, 24, and 29). In some situations, application of $\mathrm{CT}$ to small systems requires additional nontrivial approximations. ${ }^{30}$ It follows that although expressions from CT may hold at the nanoscale, it is not evident whether the basic hypothesis of CT hold at nanometer-scale dimensions and, hence, whether the theory is self-consistent.

The goal of this work is to test whether the fundamental hypothesis of CT hold at the $2-10 \mathrm{~nm}$ scales. Specifically, macroscopic $(>1 \mu \mathrm{m}) \mathrm{CT}$ assumes that (i) the surface tension of a given liquid (in contact with a another liquid, vapor, or solid) is universal, i.e., it is independent of the liquid interface geometry (e.g., liquid droplet vs liquid bridge), and (ii) the free energy of the system can be expressed solely in terms of the surface tensions of the liquid of interest (in contact with a vapor, solid, or other relevant phase), the geometry of the liquid interface, and the free energy of the bulk liquid. To test point $i$, we perform molecular dynamics (MD) simulations to study droplets and capillary bridges of $<10 \mathrm{~nm}$ scale dimensions in contact with hydrophobic and hydrophilic surfaces. We use a realistic full-atomistic model system where the droplet/bridges are composed of water molecules and the walls correspond to hydroxilated silica (see section II.A). We find that CT predicts remarkably well the profiles of all the droplet/bridge studied. Remarkably, for a given surface, we recover the same liquidvapor surface tension and water contact angles, confirming the validity of point $i$. To test point ii, we focus on the water capillary bridges between the same surfaces employed in point $\mathrm{i}$ and study the forces induced by the capillary bridges on the walls. These forces are simple derivatives of the system free energy. Remarkably, the forces obtained from simulations are in quantitative agreement with the predictions of CT. In particular, the relevant quantities that define these capillary forces, such as surface tension and contact angle, are in agreement with the corresponding values obtained in the studies of point i. Our results confirm that points $i$ and ii hold quantitatively at $2-10 \mathrm{~nm}$ scales and, hence, that $\mathrm{CT}$ is selfconsistent at such small dimensions.

This paper is structured as follows. In section II, we discuss the simulation details and, in particular, the methodology followed to calculate the droplet and bridge properties from both MD simulations and CT. Section III presents the main findings of this work, i.e., a detailed comparison of computer simulation results and the corresponding predictions from CT. A summary and discussion are included in section IV.

\section{COMPUTER SIMULATIONS AND NUMERICAL METHODS}

A. Simulation Details. Our findings are based on $\mathrm{MD}$ simulations of water nanodroplets and bridges in contact with surfaces of different hydrophobicity/hydrophilicity. We consider two kinds of droplets: axis symmetric (AS) and translationally symmetric (TS) (see Figure 1). The AS droplets are symmetric under rotations around the $z$-axis, which is perpendicular to the surface (see Figure 1a,e). The TS droplets are symmetric under translations along the $y$-axis ${ }^{31}$ (see Figure $1 \mathrm{~b}, \mathrm{f})$. In all cases, periodic boundary conditions are applied along the $x$-, $y$-, and $z$-axes, and the walls expand across the entire $x y$-plane. Similarly, we consider capillary bridges formed between parallel surfaces that are axis symmetric and translationally symmetric [see Figures $1 \mathrm{c}, \mathrm{g}$ and $1 \mathrm{~d}, \mathrm{~h}$ ]. By considering TS droplets and TS bridges, we remove any effect due to (vapor-solid-liquid) line tensions that may play a relevant role in the case of nanoscale AS droplets/bridges (see, e.g., refs 19 and 32).

All simulations are performed for a cubic system of side length $L$, at constant volume, number of water molecules $N$, and temperature $T=300 \mathrm{~K}$. Simulations are performed using the LAMMPS software package ${ }^{33}$ with water molecules being represented by the SPC/E model. ${ }^{34}$ Coulomb and Lennard- 
Jones interactions are cut off at distance $r_{\text {cutoff }}=10 \AA$, and longrange electrostatic interactions are calculated using a particleparticle particle-mesh solver ${ }^{35}$ with an accuracy value of $10^{-5}$. The temperature is controlled using a Nosé-Hoover style thermostat employing the equations of motion described by Shinoda et al. ${ }^{36}$ All simulations are run for $5 \mathrm{~ns}$, and the last 2 $\mathrm{ns}$ of the simulation is used for data analysis.

In the case of AS droplets, we consider two system sizes: $N=$ $3375(L=138.6 \AA)$ and $N=6750(L=277.2 \AA)$. This allows us to test for size effects in our calculations. AS bridges are composed of $N=3375(L=138.6 \AA)$. In these cases, the starting water droplet/bridge configuration is a cubic configuration taken from an independent simulation of bulk water at $\rho=1 \mathrm{~g} / \mathrm{cm}^{3}$ and $T=300 \mathrm{~K}$. The TS droplets and TS bridges are composed of $N=9897$ molecules $(L=138.6 \AA)$. In these cases, the starting water configuration is orthorhombic (obtained from an independent simulation of bulk water equilibrated at $\rho=1 \mathrm{~g} / \mathrm{cm}^{3}$ and $T=300 \mathrm{~K}$ ) that extends across the system along the $y$-axis. In the case of bridges, the starting water configuration is sandwiched by two identical walls separated by a distance $h=50 \AA$, which is maintained constant during the whole simulation. We note that in all cases the starting configuration is not relevant since it takes a few picoseconds for the water molecules to reorganize in a spherical (AS droplet), cylindrical (TS droplets), or bridge-like geometry.

For each droplet and bridge system, we consider a family of walls that vary in the degree of hydrophobicity/hydrophilicity. These walls have been used previously and are described in detail in refs 37 and 38. Briefly, the wall structure corresponds to four layers of $\mathrm{SiO}_{2}$, reproducing the $(1,1,1)$ face of $\beta$ cristobalite. The walls are orthogonal to the $z$-axis, span the entire system, and are periodic along the $x$ - and $y$-directions. The wall surface in contact with the water droplet/bridge is hydroxylated by attaching a hydrogen $(\mathrm{H})$ atom to each surface oxygen. The $\mathrm{Si}$ and $\mathrm{O}$ atoms are fixed during the simulation, but the OH bonds, of fixed length $1 \AA$, are allowed to rotate in a plane parallel to the wall. In LAMMPS, this is done by fixing simultaneously the $\mathrm{H}-\mathrm{Si}$ and $\mathrm{H}-\mathrm{O}$ distances of the surface silanol groups (i.e., by fixing the distances of the $\mathrm{H}$ atom to the closest $\mathrm{O}$ and $\mathrm{Si}$ atoms). As a result, $\mathrm{H}$ and $\mathrm{O}$ atoms of the silanol groups are located in planes separated by $\Delta z \approx 0.33 \AA$ from each other. In all simulations we measure the distance to a given wall as the distance to the plane of the wall's $\mathrm{H}$ atoms.

All wall atoms, with the exception of the $\mathrm{H}$ atoms, interact with water via a Lennard-Jones potential. Only the $\mathrm{Si}, \mathrm{O}$, and $\mathrm{H}$ atoms of the surface silanol groups have a nonzero partial charge, and hence, they interact with water via Coulomb interactions. The wall structure, LJ parameters of the wall atoms, and the corresponding partial charges are provided in ref 38. In the hydroxylated silica surface, the silanol group partial charges are $q_{0, \mathrm{Si}}=0.31 e, q_{0, \mathrm{O}}=-0.71 e$, and $q_{0, \mathrm{H}}=0.40 e$ and the surface is hydrophilic, as expected. In order to vary the hydrophilicity of the surface, we follow ref 37 and rescale the silanol group partial charges by a factor $0 \leq k \leq 1$, i.e., $q_{i} \rightarrow k \times$ $q_{0, i}$ where $i=\mathrm{O}, \mathrm{Si}$, and $\mathrm{H}$. It can be easily shown that $k$ is an adimensional factor that quantifies the surface polarity. ${ }^{37}$

In the case $k=1$, one recovers the original hydroxylated silica walls. For $k=0$ the surface is hydrophobic; surface atoms have no partial charges, and the $\mathrm{H}$ atoms effectively vanish since they have no interactions with water. In ref 37 , it is shown that the surfaces are hydrophobic; i.e., the contact angle of SPC/E water is $>90^{\circ}$, for approximately $k<0.4$. We note that the simulations of ref 37 were performed using an in-house MD code, while the present simulations are performed using the LAMMPS package and simulations time scales are much longer. As shown below, the present results show that the contact angles of water in contact with the different surfaces studied are in agreement with the values reported originally in ref 37 .

B. Methods and Numerical Calculations. In this section, we describe how the droplets/bridges profiles and density contour maps reported in this work are calculated from the MD simulations. We also describe the procedure followed to fit the $\mathrm{MD}$ simulation profiles using the corresponding equations from CT.

1. Droplet and Bridge Profiles from MD Simulations. For AS droplets and AS bridges, the corresponding profiles are built from 2000 snapshots obtained from the last 2 ns of the simulation and taken every 1 ps. For each snapshot, we first define a $z$-axis passing through the center of mass of the droplet/bridge, perpendicular to the wall(s). The droplet/ bridge is then covered with overlapping slabs of thickness $5 \AA$ parallel to the wall(s) and shifted vertically by $2.5 \AA$ with respect to each other. For each slab, centered at a distance $z$ from the wall (or from the midpoint between the walls in the case of AS capillary bridges; see Figure $1 \mathrm{~g}$ ), we calculate the average density $\rho_{\text {slab }}(r)$ as a function of the distance $r$ from the $z$-axis. Specifically, we divide the slab into thin rings of inner and outer radii $r$ and $r+\Delta r$, respectively, where $\Delta r=0.5 \AA$, and calculate the average number of water $\mathrm{O}$ atoms in the ring. As expected, $\rho_{\text {slab }}(r)$ is constant within the droplet/bridge, and it decays abruptly to practically zero in the vapor phase. Hence, we define the droplet/bridge radius at height $z, r_{\text {prof }}(z)$, as the distance $r$ at which $\rho_{\text {slab }}(r)=\rho_{0}=0.2 \mathrm{~g} / \mathrm{cm}^{3}$ (our results are not sensitive to slight variations in $\left.\rho_{0}\right)$. The function $r_{\text {prof }}(z)$ provides the droplet/bridge profile for the given snapshot. By averaging $r_{\text {prof }}(z)$ over the 2000 snapshots, we obtain the final droplet/bridge profile.

A similar procedure is employed to calculate the profiles of TS droplets and TS bridges (Figure 1f,h). As before, for each snapshot, we identify the droplet/bridge center of mass and define a $z$-axis passing through it, perpendicular to the wall(s). The droplet/bridge is divided into slabs, as explained previously and for each slab, centered at a distance $z$ from the wall (or from the midpoint between the walls in the case of TS capillary bridges; see Figure $1 \mathrm{~h})$, we calculate the average density $\rho_{\text {slab }}(r)$. However, for TS droplets/bridges, we divide the slab into rods parallel to the $y$-axis, with inner and outer coordinates $r$ and $r+$ $\Delta r$, respectively, where $\Delta r=0.5 \AA$ (note that in these cases $r$ is defined as the distance to the $x=0$ plane). The distance $r$ at which $\rho_{\text {slab }}(r)=\rho_{0}=0.2 \mathrm{~g} / \mathrm{cm}^{3}$ defines the boundary of the droplet/bridge. By averaging $r_{\text {prof }}(z)$ over the last 2000 snapshots of the simulation, we obtain the final droplet/bridge profile.

In the case of AS and TS bridges, the liquid bridge must be symmetric with respect to its middle-height point (i.e., the bridge neck) which is located at the midpoint between the walls, $z=0$ (Figure 1g,h). Accordingly, for bridge profile calculations, we take the average of $r_{\text {prof }}(z)$ and $r_{\text {prof }}(-z)$ and report the profile only for $0 \leq z \leq h / 2$.

2. Droplet and Bridge Profiles from Capillarity Theory. Based on the concept of surface tension, CT predicts that the density profiles of AS droplets on a surface are spherical

$$
r(z)^{2}+\left(z-z_{c}\right)^{2}=R^{2}
$$

where $r(z)$ is the radius of the droplet at height $z$ and $R$ is the radius of the droplet profile (see Figure 1e). The spherical 

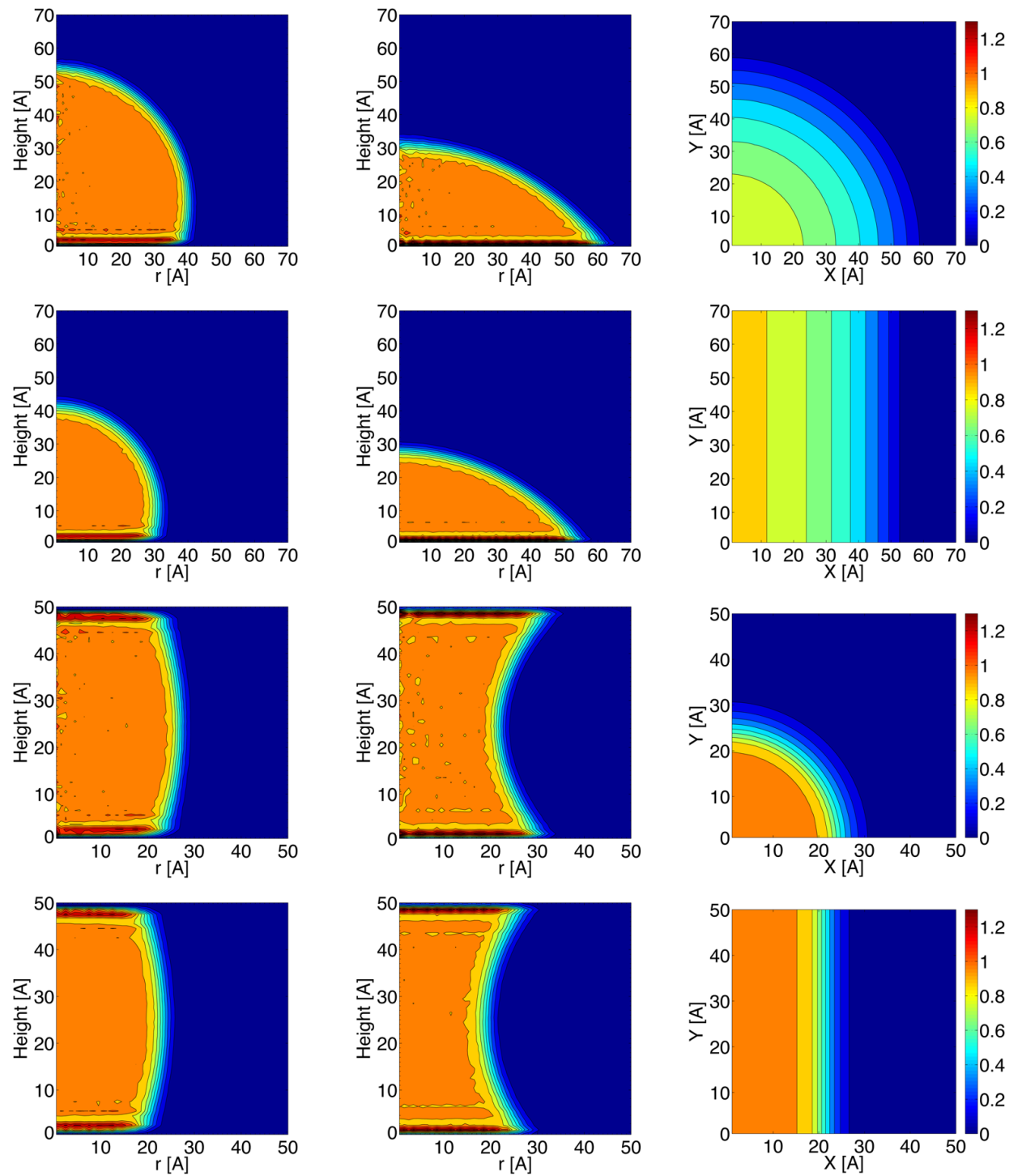

Figure 2. Density contour maps for the droplets and bridges in contact with hydrophobic $(k=0.0$, left column $)$ and hydrophilic $(k=0.6$, middle column) surfaces. The right column shows the top view of the droplet/bridges in contact with the hydrophilic $(k=0.6)$ surface. The first and second row are the density contour maps of the large AS and TS droplets, respectively; the density contour maps of AS and TS bridges are shown in the third and fourth row, respectively. Color bars indicate the density scale in $\mathrm{g} / \mathrm{cm}^{3}$ [for comparison, we note that the density of bulk SPC/E water at the present temperature $(T=300 \mathrm{~K})$ and $P=0.1 \mathrm{MPa}$ is $\approx 1 \mathrm{~g} / \mathrm{cm}^{341}$ ].

profile is centered on the $z$-axis, at height $z_{\mathcal{c}}$ and the wall is located at $z=0$. Equation 1 is also valid for TS droplets provided that $r(z)$ is defined as half the thickness of the droplet at height $z$ (Figure 1f).

In the case of AS bridges, the expression for $r(z)$ is not trivial and involves special functions (see, e.g., ref 39). In this case, the following differential equation can be used to define the density profile (see Appendix)

$$
\left|\frac{\mathrm{d} z}{\mathrm{~d} r}\right|=\frac{\left|H\left(r^{2}-r_{0}{ }^{2}\right)+r_{0}\right|}{\sqrt{r^{2}-\left[H\left(r^{2}-r_{0}{ }^{2}\right)+r_{0}\right]^{2}}}
$$

where $r(z)$ is the radius of the AS bridge at height $z, H=\left(1 / R_{1}\right.$ $\left.+1 / R_{2}\right) / 2$ is the average surface curvature of the bridge, ${ }^{1} R_{1}$ and $R_{2}$ are the surface radii of curvature, and $r_{0}$ is the bridge radius at $z=0$, i.e., at half the bridge's height (Figure $1 \mathrm{~g}$ ). We follow the sign convention of ref 1 , where $R_{1}$ and $R_{2}$ can be positive or negative. For given values of $H$ and $r_{0}$, eq 2 can be integrated numerically and the bridge profile $r(z)$ can be calculated.

For TS bridges, the average surface curvature is $H=1 /\left(2 R_{2}\right)$, i.e., $R_{1}=\infty$ (compare Figures $1 \mathrm{~g}$ and $1 \mathrm{~h}$ ). Since the average surface curvature of the TS bridge is constant, it follows that the TS bridge profile is a circle of radius $R_{2}$. The circular profile is centered at $z_{\mathrm{c}}=0$ and $r_{\mathrm{c}}=r_{0}-R_{2}$, where $r_{0}$ is half the thickness of the bridge at $z=0$, i.e.,

$$
\left[r(z)-r_{\mathrm{c}}\right]^{2}+z^{2}=R_{2}^{2}
$$

The theoretical profiles $r(z)$ resulting from eqs $1-3$ are used to fit the droplets/bridge profiles obtained from MD simulations. The theoretical profiles only require the parameters $\left(R, z_{\mathrm{c}}\right)$ for the case of AS and TS droplets and $\left(H, r_{0}\right)$ for the case of AS and TS bridges. In order to identify the parameters that best fit the simulation profiles, we use the 
following procedure. (i) On the basis of the MD simulations droplet/bridge profile, we define a reasonable range for the fitting parameters $\left(R, z_{\mathrm{c}}\right)$, for the case of droplets, and $\left(H, r_{0}\right)$, for the case of bridges. We set these parameters to the corresponding lowest values to be explored and calculate the theoretical profiles $r(z)$ using eq 1, 2, or 3. (ii) For each point $i$ of the droplet/bridge profile, $\left(r_{i}, z_{i}\right)$, obtained from the MD simulation, we calculate the corresponding distance $d_{i}$ to the theoretical profile $r(z)$. Specifically, from each point $\left(r_{i}, z_{i}\right)$ we find a line which crosses the curve $r(z)$ at a right angle and measure the distance between the crossing point and point $\left(r_{i}\right.$, $z_{i}$ ). (iii) We calculate the error between the theoretical and MD simulation profile as

$$
\epsilon=\sqrt{\frac{1}{N_{\mathrm{p}}} \sum_{i=1}^{N_{\mathrm{p}}} d_{i}^{2}}
$$

where $N_{\mathrm{p}}$ is the number of points of the droplet/bridge profile obtained from the MD simulation. (iv) We change the parameters $\left(R, z_{\mathrm{c}}\right)$ (droplets) or $\left(H, r_{0}\right)$ (bridges) by small increments and repeat steps ii-iv until the whole range of the parameters is covered.

For each set of values $\left(R, z_{\mathrm{c}}\right)$ or $\left(H, r_{0}\right)$ we obtain a value of $\epsilon$. The set of parameters for which $\epsilon$ is minimum provides together with eqs $1-3$, the theoretical droplet/bridge profiles.

We note that knowledge of the parameters $\left(R, z_{\mathrm{c}}\right)$ or $\left(H, r_{0}\right)$ allows one to calculate any geometrical property of the droplets and bridges. For example, the contact angles for the AS and TS droplets can be obtained from the $\left(R, z_{\mathrm{c}}\right)$ parameters using eq 21 of the Appendix. Similarly, the contact angle between a TS bridge and the wall can be calculated using eq 3 , and it is given by

$$
\theta_{\mathrm{c}}=90^{\circ}+\frac{180^{\circ}}{\pi} \arcsin (h H)
$$

The contact angle for the AS bridges is obtained from the derivative of the profile given by eq 2 evaluated at $z= \pm h / 2$, i.e., at one of the surfaces.

3. Density Contour Maps. The density contour maps (DCMs) provide complementary information to the droplets/ bridges profiles. To obtain the DCM, we divide the system box into cells of dimensions $1 \times 1 \times 1 \AA^{3}$. For each cell $i$ centered at location $\left(x_{i}, y_{i}, z_{i}\right)$, we calculate the average local density $\rho\left(x_{i}, y_{i}, z_{i}\right)$. As for the density profile, $\rho\left(x_{i}, y_{i}, z_{i}\right)$ is calculated by averaging over the last 2 ns of the simulation.

For AS droplets and AS bridges, we average the density field $\rho\left(x_{i}, y_{i}, z_{i}\right)$ over boxes in the $z=z_{i}$ plane, intersected by cylinders of radii $r_{i}$, and generate a radial density map $\rho\left(r_{i}, z_{i}\right)$. Specifically, $\rho\left(r_{i}, z_{i}\right)$ is the density averaged over boxes with coordinates $\left(x_{j}\right.$, $\left.y_{j}, z_{j}\right)$ that satisfy $r_{i}=\left(x_{j}^{2}+y_{j}^{2}\right)^{1 / 2}$ and $z_{j}=z_{i}$. The set of values $\rho\left(r_{i}, z_{i}\right)$ are used to construct the side view of the DCM, $\rho_{\text {side }}(r, z)$. The first and third rows of Figure 2, columns one and two, show $\rho_{\text {side }}(r, z)$ for AS droplets and AS bridges.

In the case of TS droplets and TS bridges, the side view of the DCM $\rho_{\text {side }}(r, z)$ is constructed by averaging $\rho\left(x_{i}, y_{i} z_{i}\right)$ over all boxes in the $z=z_{i}$ plane and intersected by vertical planes perpendicular to the $x$-axis (the TS droplets and TS bridges are periodic along the $y$-axis). Specifically, $\rho\left(r_{i} z_{i}\right)$ is the density averaged over boxes with coordinates $\left(x_{j}, y_{j}, z_{j}\right)$ that satisfy $\left|x_{j}\right|=$ $r_{i}$ and $z_{j}=z_{i}$. The second and fourth rows of Figure 2, columns one and two, show $\rho_{\text {side }}(r, z)$ for TS droplets and TS bridges.

For all droplets and bridges, we also calculate the projection of the density field $\rho\left(x_{i} y_{i} z_{i}\right)$ on the $x y$-plane. This provides a top view of the density map, $\rho_{\text {top }}(x, y)$; see, e.g., third column of Figure 2. This is done by averaging the density field $\rho\left(x_{i}, y_{i}, z_{i}\right)$ over all $z_{i}$ values, for fixed $x_{i}$ and $y_{i}$. We note that the density map $\rho_{\text {top }}(x, y)$ is sensitive on the range of values of $z_{i}$ used to average $\rho\left(x_{i}, y_{i}, z_{i}\right)$. In the case of capillary bridges, this range is clearly the bridge height, $h=50 \AA$. In the case of droplets, we use the height of the drop at $z=0$, as defined from the corresponding $\rho_{\text {side }}(r, z)$.

\section{RESULTS}

A. Droplets and Bridges Profiles and Density Contour Maps. Figure 2 shows the density maps for different geometries and two values of the surface polarity $k$. The first and second columns show the side view of the DCM of (top to bottom) AS droplets, TS droplets, AS bridges, and TS bridges for $k=0.0$ and $k=0.6$, respectively. The third column shows the top view of the DCM for the same geometries and for $k=$ 0.6. Two main observations follow from Figure 2. (i) In all cases, the liquid-vapor interface is rather sharp, 5-10 $\AA$ thick, and the density of water decreases monotonically as the vapor phase is approached. Instead, water at the solid interface is rather structured with nonmonotonic density changes along the $z$-direction (perpendicular to the wall), which is consistent with previous studies. $^{38,40}$ (ii) The density of bulk SPC/E water is $\approx 1 \mathrm{~g} / \mathrm{cm}^{3}$ at $P \approx 0$ and $T=300 \mathrm{~K}^{41}$ Interestingly, all DCMs in Figure 2 exhibit regions where the density is $\approx 1 \mathrm{~g} / \mathrm{cm}^{3}$, suggesting that all bridges/droplets have a domain of bulk-like water. That this should be the case is not evident given the small dimensions of some of the geometries studied, $2-3 \mathrm{~nm}$, and the presence of interface fluctuations inherent to liquidvapor interfaces.

Next, we compare the density profiles obtained from MD simulations and the corresponding predictions from CT (eqs $1-3)$. The profiles for AS and TS droplets are shown in Figures $3 a$ and $3 b$ while the profiles for AS and TS bridges are shown in Figures $4 \mathrm{a}$ and $4 \mathrm{~b}$. The agreement between $\mathrm{CT}$ and MD simulations is remarkable, for all droplets/bridges and surface hydrophobicity/hydrophilicity. The fitting parameters of the density profiles in Figures 3 and 4, for all geometries and values of $k$, are presented in Tables 1 and 2 .

One of the most important assumptions of (macroscopic) $\mathrm{CT}$ is that the contact angle of a liquid is independent of the geometry of the interfaces involved. To test this point, we include in Tables 1 and 2 the contact angles $\theta_{c}$ of the water droplets and bridges studied, for all values of $k$; the corresponding values of $\theta_{c}$ as a function of $k$ are shown in Figure 5a. Our MD simulations indicate that indeed water contact angle is independent of the geometry of the interfaces involved and it depends solely on the walls considered (i.e., $\theta_{\mathrm{c}}=$ $\left.\theta_{c}(k)\right)$. Similar findings have been reported for nanodroplets sitting above hydrophilic patches of heterogeneous surfaces. ${ }^{32}$ In particular, since water contact angle depends on the liquidliquid, liquid-solid, and liquid-vapor surface tensions, the present results also suggest that at $2-10 \mathrm{~nm}$ scales the surface tensions can be treated as independent of the interfaces' curvature, a rather nontrivial result (see, e.g., ref 42).

We also stress that in the comparison of the density profiles from theory and simulations we did not include any line tension. Indeed, our results indicate that for $>2 \mathrm{~nm}$ scales droplets/bridges the line tension plays a minor role. To show this, we focus on the values of $\theta_{\mathrm{c}}$ obtained from the small AS, large AS, and TS droplets (Table 1). The correction in the calculated values of $\theta_{\mathrm{c}}(k)$ due to a nonzero line tension $\tau(k)$ 

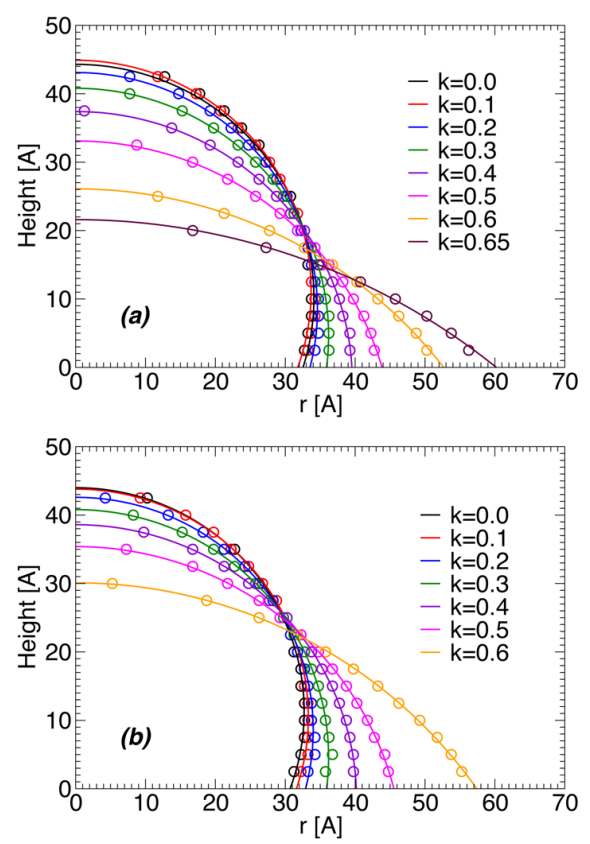

Figure 3. Profiles of (a) small AS and (b) TS droplets in contact with surfaces of different surface polarities, $k$, from MD simulations (circles). $r$ in (a) is the AS-droplet radius; $r$ in (b) is half the TSdroplet thickness. Lines are the best fits obtained using eq 1 , predicted by CT. In (a) and (b), the simulation box side length is $L=138.6 \AA$, and only one-half of the droplet is shown. The theoretical profiles from CT fit remarkably well the drop profiles of the AS and TS droplets even for the $\approx 20 \AA$ height droplet in (a), i.e., at dimensions where the concept of surface tension is not evident. Small $(N=3375$, $L=138.6 \AA)$ and large $(N=6750, L=277.2 \AA)$ AS droplets wet the surface for $k \geq 0.7$. The TS droplets in (b) wet the surface for $k \geq$ 0.65 , instead of $k \geq 0.7$, due to periodic boundary conditions and large number of molecules composing the droplet $(N=9897, L=138.6 \AA)$.

can be obtained from the modified Young equation, ${ }^{19,43}$ and it is given by $\cos \theta_{\mathrm{c}}\left(r_{\mathrm{B}}\right)-\cos \theta_{\infty}=-\tau /\left(\gamma_{\mathrm{LV}}+r_{\mathrm{B}}\right)$, where $\gamma_{\mathrm{LV}}$ is the liquid-vapor surface tension, $r_{\mathrm{B}}$ is the radius of the droplet base (Figure 1e,f), and $\theta_{\infty}$ is the macroscopic contact angle given by Young's equation, $\cos \theta_{\infty}=\left(\gamma_{\mathrm{SV}}-\gamma_{\mathrm{SL}}\right) / \gamma_{\mathrm{LV}}$. Thus, the contact angle obtained from the TS droplet is the true, i.e., macroscopic, water contact angle $\left(r_{\mathrm{B}}=\infty\right)$. In particular, a nonzero $\tau(k)$ implies that the values of $\theta_{c}(k)$ should differ among the small AS, large AS, and TS droplets. However, a comparison of the values of $\theta_{c}$ given in Table 1 indicates that $\left|\Delta \theta_{c}(k)\right| \leq 3.5^{\circ}$. This is close to the difference in $\theta_{c}$ between the small and large AS droplets (Table 1). Therefore, any effect of $\tau$ in the studied systems is within the error bars in the calculated $\theta_{c}$. Negligible line tensions have been also found in the case of water droplets in contact with amorphous silica surfaces. ${ }^{44}$

It follows from this discussion that the concept of contact angle and surface tension hold even at the $2-10 \mathrm{~nm}$ scale, which is surprising given the small length scales of the systems considered. For example, the smallest droplet studied in contact with the $k=0.65$ surface is only $2 \mathrm{~nm}$ high while the thickness of the liquid-vapor interface is $0.8-1 \mathrm{~nm}$ and the typical thickness of the solid-water interface is $\approx 1-1.4 \mathrm{~nm} .{ }^{40}$ Hence, there is very little space left within this droplet to contain bulklike water.
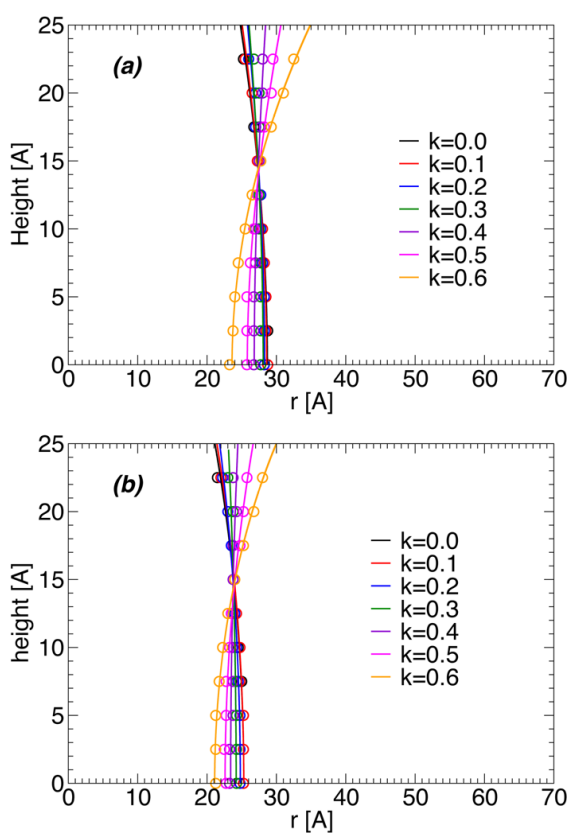

Figure 4. Profiles of (a) AS and (b) TS bridges in contact with surfaces of different surface polarities, $k$, from MD simulations (circles). $r$ in (a) is the AS-bridge radius; $r$ in (b) is half the TS-bridge thickness. Lines are the best fits obtained using eqs 2 and 3, predicted by CT. In (a) and (b), the walls are separated by $50 \AA$, and only the upper half of the bridge is shown. The theoretical profiles from CT fit remarkably well the profile of the AS and TS bridges even for bridges with minimum radius/half thickness (at zero height) of $\approx 20 \AA$, i.e., at dimensions where the concept of surface tension is not evident. AS ( $N$ $=3375, L=138.6 \AA)$ and TS bridges $(N=9897, L=138.6 \AA)$ wet the surface for $k \geq 0.7$.

The functional form of $\cos \theta_{\mathrm{c}}(k)$ [Figure $5 \mathrm{~b}$ ] can be fitted very well by a quadratic polynomial $\cos \theta_{c}(k)=-0.31-0.18 k$ $+2.82 k^{2}$. Such a quadratic dependence on $k$ can be rationalized in terms of the Young equation which states that $\cos \theta_{c}=\left(\gamma_{\mathrm{SG}}\right.$ $\left.-\gamma_{\mathrm{LS}}\right) / \gamma_{\mathrm{LG}}$, where $\gamma_{\mathrm{SG}}, \gamma_{\mathrm{LS}}$, and $\gamma_{\mathrm{LG}}$ are the solid-gas, liquidsolid, and liquid-gas surface tensions. We can assume that $\gamma_{\mathrm{LG}}$ is independent of $k$ while $\gamma_{\mathrm{SG}}$ should depend only weakly on $k$ due to the low density of the vapor. The dominant dependence on $k$ is thus given by the liquid-solid interface energy. This surface energy should behave as $\gamma_{\mathrm{LS}}(k)=a-b k^{2}$, where $a$ and $b$ are some constants. This is because the main contribution to the solid-liquid energy is the dipole-dipole interactions between the water molecules and the surface silanol groups. Since the surface dipole moment causes polarization of the water layer next to the interface (see ref 37), which is proportional to $k$, then the interaction energy of the surface and the water layer at the interface should be proportional to $-k^{2}$. A similar argument is presented in ref 1 . However, the argument in ref 1 is based on the concept of polarizability which occurs due to van der Waals interactions. In our MD simulations, polarizabilities are omitted. Accordingly, the dependence of cos $\theta_{\mathrm{c}}$ on $k$ in our model system is different from the corresponding expression presented in page ref 1 .

B. Force, Pressure and Surface Tension for Water AS and TS Bridges. In this section, we focus on AS and TS bridges and study the forces and pressures that the water bridges exert on walls with different surface polarities, $k$. This is important for practical applications, e.g., to quantify forces 
Table 1. Fitting Parameters for the AS and TS Droplet Profiles (see Figure 1e,f) ${ }^{a}$ Using Eq 1

\begin{tabular}{|c|c|c|c|c|c|c|c|c|c|c|c|c|}
\hline \multirow[b]{2}{*}{$k$} & \multicolumn{4}{|c|}{ small AS droplets } & \multicolumn{4}{|c|}{ large AS droplets } & \multicolumn{4}{|c|}{ TS droplets } \\
\hline & $\bar{R}$ & $z_{\mathrm{c}}$ & $\theta_{c}$ & $\epsilon$ & $\bar{R}$ & $z_{\mathrm{c}}$ & $\theta_{\mathrm{c}}$ & $\bar{\epsilon}$ & $R(\AA)$ & $z_{\mathrm{c}}(\AA)$ & $\theta_{c(\operatorname{deg})}(\operatorname{deg})$ & $\epsilon(\AA)$ \\
\hline 0.0 & 33.7 & 11.2 & 109.4 & 0.15 & 42.0 & 14.0 & 109.5 & 0.18 & 32.7 & 11.3 & 110.2 & 0.15 \\
\hline 0.1 & 34.1 & 10.2 & 107.4 & 0.21 & 42.6 & 12.5 & 107.0 & 0.15 & 33.3 & 10.5 & 108.4 & 0.18 \\
\hline 0.2 & 34.6 & 8.5 & 104.2 & 0.21 & 43.4 & 10.4 & 103.9 & 0.21 & 34.0 & 8.6 & 104.7 & 0.19 \\
\hline 0.3 & 36.2 & 4.6 & 97.3 & 0.10 & 45.0 & 6.2 & 97.9 & 0.18 & 36.2 & 4.6 & 97.3 & 0.20 \\
\hline 0.4 & 39.6 & -2.2 & 86.8 & 0.15 & 48.8 & -1.7 & 88.0 & 0.19 & 40.2 & -1.6 & 87.7 & 0.12 \\
\hline 0.5 & 45.6 & -12.5 & 74.1 & 0.15 & 57.4 & -16.2 & 77.6 & 0.18 & 47.0 & -11.6 & 75.7 & 0.13 \\
\hline 0.6 & 66.2 & -40.1 & 52.7 & 0.14 & 78.8 & -45.4 & 54.8 & 0.16 & 69.8 & -39.7 & 55.3 & 0.15 \\
\hline 0.65 & 94.7 & -73.1 & 39.5 & 0.21 & 121.9 & -95.7 & 38.3 & 0.12 & & & & \\
\hline
\end{tabular}

${ }^{a} \epsilon$ is the error in of the fitting curve from eq 4. Errors in $R$ and $z_{\mathrm{c}}$ are $\pm 0.05 \AA$. TS droplets wet the surface for $k \geq 0.65$.

Table 2. Fitting Parameters for the AS and TS Bridge Profiles see Figure 1g,h) Using Eqs 2 and $3^{a}$

\begin{tabular}{|c|c|c|c|c|c|c|c|c|c|c|}
\hline \multirow[b]{2}{*}{$k$} & \multicolumn{5}{|c|}{ AS bridges } & \multicolumn{5}{|c|}{ TS bridges } \\
\hline & $R_{1}(\AA)$ & $R_{2}(\AA)$ & $H\left(\AA^{-1}\right)$ & $\theta_{2}(\operatorname{deg})$ & $\epsilon(\AA)$ & $r_{0}(\AA)$ & $R_{2}(\AA)$ & $H\left(\AA^{-1}\right)$ & $\theta_{\mathrm{c}}(\mathrm{deg})$ & $\epsilon(\AA)$ \\
\hline 0.0 & 28.8 & 80.4 & 0.0236 & 106.6 & 0.18 & 25.3 & 77.1 & 0.0065 & 108.9 & 0.20 \\
\hline 0.1 & 28.7 & 84.4 & 0.0233 & 105.7 & 0.14 & 25.3 & 82.5 & 0.0061 & 107.6 & 0.12 \\
\hline 0.2 & 28.2 & 126.6 & 0.0217 & 100.3 & 0.12 & 24.8 & 106.4 & 0.0047 & 103.6 & 0.08 \\
\hline 0.3 & 27.8 & 225.9 & 0.0202 & 95.7 & 0.09 & 24.2 & 290.0 & 0.0017 & 94.9 & 0.18 \\
\hline 0.4 & 26.8 & -229.0 & 0.0165 & 84.6 & 0.18 & 23.4 & -300.0 & -0.0017 & 85.2 & 0.24 \\
\hline 0.5 & 25.7 & -60.0 & 0.0111 & 70.0 & 0.15 & 22.6 & -79.2 & -0.0063 & 71.6 & 0.12 \\
\hline 0.6 & 23.8 & -29.8 & 0.0042 & 50.11 & 0.12 & 21.1 & -39.6 & -0.0126 & 50.9 & 0.12 \\
\hline 0.65 & 22.2 & -21.9 & -0.0003 & 34.75 & 0.16 & & & & & \\
\hline
\end{tabular}

${ }^{a} R_{1}$ and $R_{2}$ are the radii of curvature of the bridge neck (i.e., at its middle-height point) on the $x-y$-plane and $x-z$-plane, respectively (see Figure 1g,h). $H=(1 / 2)\left(1 / R_{1}+1 / R_{2}\right)$ is the average surface curvature of the bridge, $\theta_{\mathrm{c}}$ is the contact angle, and $\epsilon$ is the error of the fitting curve from eq 4 . For TS bridges, $R_{1}=\infty$; $r_{0}$ is the thickness of the bridge neck. Errors in $r_{0}, R_{1}$, and $R_{2}$ are $\pm 0.05 \AA$.

induced by capillary bridges in AFM experiments and in granular materials where humidity can induce the formation of capillary bridges between surfaces. Yet, the main motivation of this section is to perform another test of CT at the $2-10 \mathrm{~nm}$ scale. Specifically, the forces and pressures on the surfaces induced by the bridges can be calculated directly from our MD simulations for different values of $k$ (or contact angles $\theta_{c}$ ), and these quantities can be compared with the corresponding predictions from CT.

During the MD simulations, we measure the force produced by the AS and TS bridges on each wall by calculating the sum of the forces between all water molecules and all atoms in the given wall. We evaluate the components $F_{x}, F_{y}$, and $F_{z}$ of the total force averaged over time. For both AS and TS droplets, the time averages of $F_{x}$ and $F_{y}$ converge to zero for large times, as expected, and hence, their deviations from zero provide an estimation of the force error bars. In addition, due to the symmetry of the system, we average the normal components of the force acting on the two walls: $F_{z}=\left(\vec{F}_{1} \cdot \breve{n}_{1}+\vec{F}_{2} \cdot \breve{n}_{2}\right) / 2$, where $\vec{F}_{i}$ is the force acting on wall $i=1,2$ and $\breve{n}_{i}$ is a unit vector perpendicular to wall $i$, pointing toward the bridge. We note that from the calculated $F_{z}$ we are able to measure other properties, such as the surface tension of water and the pressure inside the water bridges.

The net force along the $z$-axis at any cross section of the bridge must be constant, ${ }^{1}$ independently of whether the bridge is AS or TS. Hence, if $F_{z \text {,neck }}$ is the force acting on a plane perpendicular to the bridge and passing through the capillary bridge's neck (i.e., at $z=0$ ), it must be that $F_{z \text {,neck }}=F_{z}$. It can be shown that ${ }^{1}$

$$
F_{z}=F_{\gamma}+F_{P}
$$

where $F_{\gamma}$ is the force on the wall due the liquid-vapor surface tension $\gamma$ and $F_{P}=P A_{\mathrm{b}}$ is the force on the wall due to the pressure $P$ within the water bridge; here, $A_{\mathrm{b}}$ is the area of the bridge's base. For AS bridges, $F_{\gamma}=2 \pi \gamma r_{\mathrm{b}} \sin \theta_{\mathrm{c}}$ and $F_{P}=P\left(\pi r_{\mathrm{b}}{ }^{2}\right)$ (Figure $1 \mathrm{~g}$ ). For the TS bridges, $F_{\gamma}=2 L \gamma \sin \theta_{\mathrm{c}}$ and $F_{P}=$ $P\left(2 L r_{\mathrm{b}}\right)$, where $L$ is the bridge's length (equal to the box side length) and $r_{\mathrm{b}}$ is half the thickness of the bridge's base (see Figure $1 \mathrm{~h}$ ). Using Young-Laplace equation and assuming $P \approx$ 0 in the vapor phase, one can write $P=-2 \gamma H$. Therefore, the forces produced by the bridges on the walls are

$$
F_{z}=2 \pi r_{\mathrm{b}} \gamma \sin \theta_{\mathrm{c}}-2 \pi r_{\mathrm{b}}^{2} \gamma H
$$

for AS bridges and

$$
F_{z}=2 L \gamma \sin \theta_{c}-4 L r_{b} \gamma H
$$

for TS bridges.

Similarly, the force at the neck of the AS bridge is given by

$$
F_{z, \text { neck }}=2 \pi r_{0} \gamma-2 \pi r_{0}{ }^{2} \gamma H=2 \pi \gamma C
$$

where $C=r_{0}-H r_{0}^{2}$. For TS bridges, we obtain

$$
F_{z, \text { neck }}=2 L \gamma-4 L r_{\mathrm{b}} \gamma H=2 \gamma C
$$

where $C=L-2 L r_{\mathrm{b}} H$. $C$ is the neck parameter and can be obtained from Table 2 . We note that since we are considering different surface polarities, $C=C(k)$.

The condition $F_{z \text {,neck }}=F_{z}$ together with eqs 9 and 10 provide strong tests of CT for the MD simulations of the AS and TS bridges. Specifically, CT predicts that for AS bridges the force $F_{z}$ from MD simulations must be a linear function of $C(k)$ and that the slope of this line should be $2 \pi \gamma$. Similarly, for TS bridges, the force $F_{z}$ must be a linear function of $C(k)$ with slope $2 \gamma$. Figure 6 shows that our MD simulations are fully 

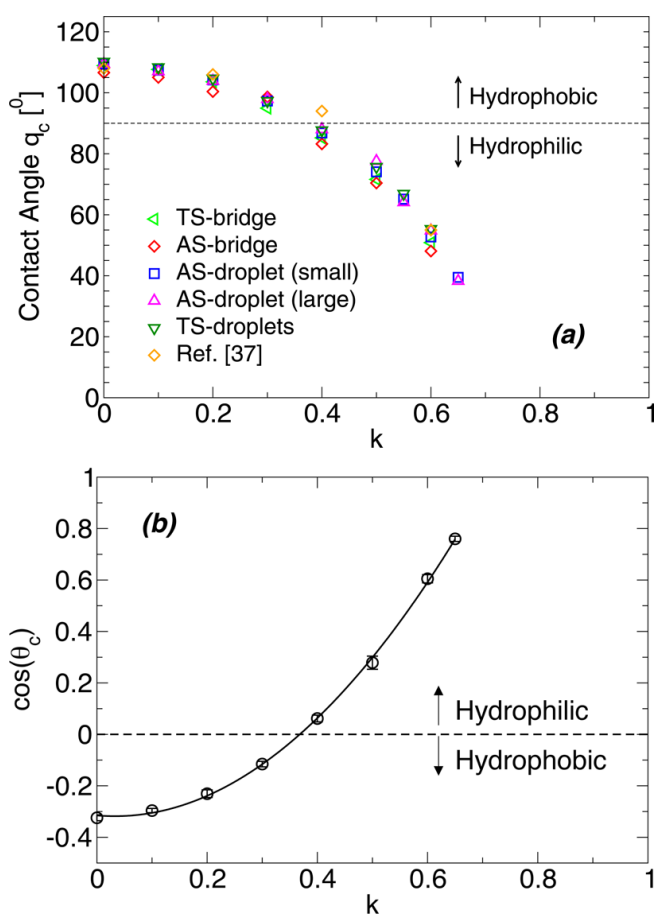

Figure 5. (a) Contact angles as a function of the surface polarity $k$ obtained from the profiles in Figures $3 \mathrm{a}, \mathrm{b}$ and $4 \mathrm{a}, \mathrm{b}$. For comparison, we also include the contact angles from the large droplet profiles (not shown $(N=6750, L=277.2 \AA)$. Simulations for AS and TS droplets and bridges provide similar contact angles for all the walls considered. (b) Cosine of the average contact angle obtained from (a) as a function of $k$. The solid line is a quadratic fit. Dashed lines indicate $\theta_{c}$ $=90^{\circ}$. Surfaces for which $\theta_{\mathrm{c}}>90^{\circ}\left(\theta_{\mathrm{c}}<90^{\circ}\right)$ are hydrophobic (hydrophilic).

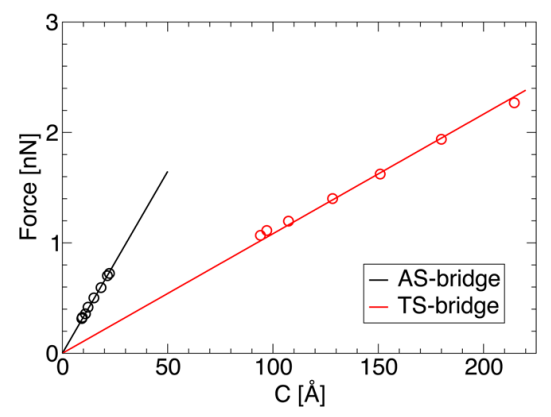

Figure 6. Force between walls induced by AS bridges and TS bridges as a function of the neck parameter C. C $=r_{0}-H r_{0}{ }^{2}$ for AS bridges and $C=L-2 L H r_{\mathrm{b}}$ for TS bridges (see text); values of $C$ are obtained from Table 2. Lines are the best linear regression intercepting the origin. Error bars are smaller than the symbol size.

consistent with these predictions. Remarkably, the linear fits in Figure 6 (with zero intercept) for AS and TS bridges give, in both cases, $\gamma=0.054 \pm 0.001 \mathrm{~N} / \mathrm{m}^{2}$. This value of $\gamma$ is consistent with the values of the liquid-vapor surface tension of SPC/E water available in the literature ${ }^{45,46}$ (see also next section).

We also test that the forces on the walls obtained from MD simulations obey eqs 7 and 8 for the case $\gamma=0.054 \mathrm{~N} / \mathrm{m}^{2}$. Figures $7 \mathrm{a}$ and $7 \mathrm{~b}$ show, for both AS and TS bridges, the forces acting on the walls measured directly from the MD simulations and the corresponding values from eqs 7 and 8 (in these cases,
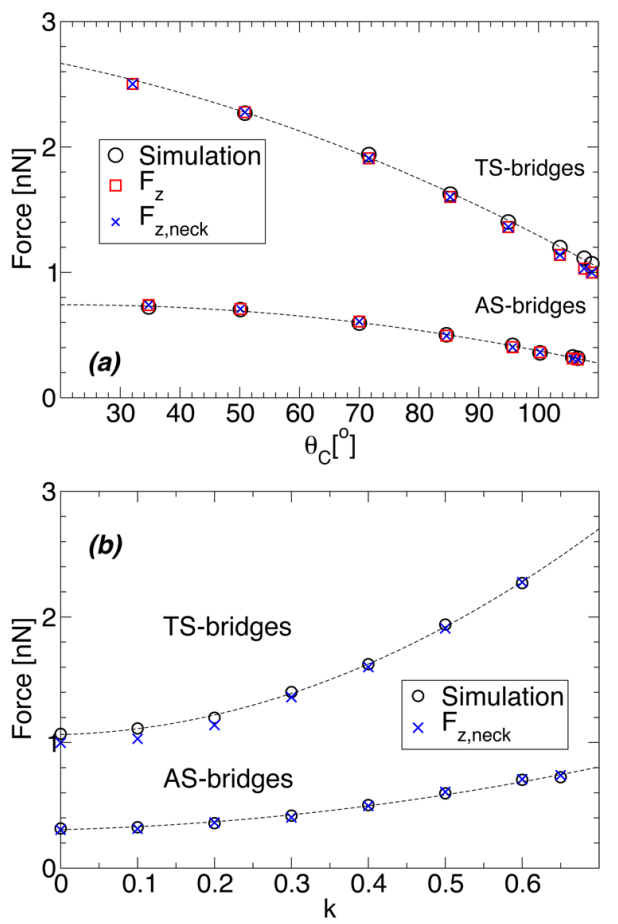

Figure 7. Forces induced by AS bridges and TS bridges formed between parallel walls as a function of (a) water contact angle and (b) normalized surface dipole moment $k . F_{z}$ is the force that the water bridge exerts on the walls; black circles are results from MD simulations, and red squares are the predictions from CT. $F_{z, \text { neck }}$ (blue crosses) is the force at the bridge neck predicted by CT (see text). Error bars are smaller than the symbol size. Lines are quadratic polynomial fittings. For TS bridges in contact with surfaces with polarity $k=0.65$, we observe large fluctuations of the liquid-vapor interface next to the walls leading to large errors in $\theta_{c}$. Accordingly, the corresponding value of the force is omitted in (a) and (b).

the values of $r_{\mathrm{b}}$ are obtained from the bridge profiles in Figure 4). Again, the agreement between MD simulations and CT is excellent.

We also calculate the hydrostatic pressure that the water bridge exerts on the walls as a function of the contact angle $\theta_{c}$ and surface polarity $k$. From eq 6 , it follows that the pressure in the water bridge is given by

$$
P=\frac{F_{\gamma}-F_{z}}{A_{\mathrm{b}}}
$$

which can be rewritten as

$$
P=\frac{2 \pi \gamma r_{\mathrm{b}} \sin \theta_{\mathrm{c}}-F_{z}}{\pi r_{\mathrm{b}}{ }^{2}}
$$

for the case of AS bridges and

$$
P=\frac{2 L \gamma \sin \theta_{\mathrm{c}}-F_{z}}{2 r_{\mathrm{b}} L}
$$

for the case of TS bridges. We use these expressions to compute the pressures within AS and TS bridges from MD simulations (i.e., with $\gamma=0.054 \mathrm{~N} / \mathrm{m}^{2}, r_{\mathrm{b}}$ obtained from Figure 4 , and $F_{z}$ obtained from MD simulations). The theoretical value for the pressure is obtained from Young-Laplace equation, eq 14 , considering that the pressure outside the water bridge is equal to zero and using the corresponding value of $H$ from 
Table 2. We verify that eqs 12 and 13 yield the same value of pressure predicted by eq 14; the corresponding values of $P$ as a function of $k$ and $\theta_{c}$ are shown in Figures $8 \mathrm{a}$ and $8 \mathrm{~b}$.
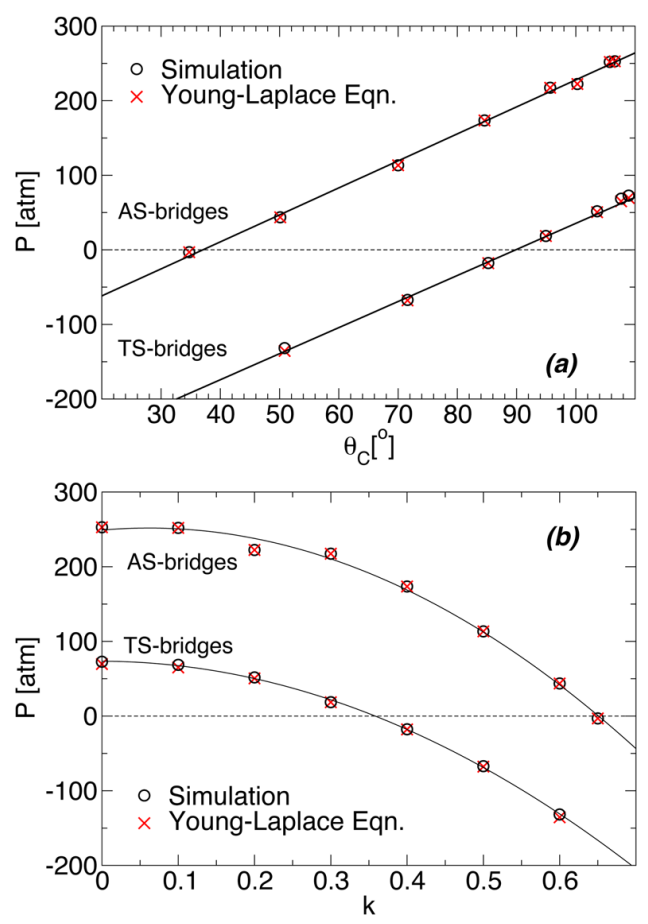

Figure 8. Pressure inside the AS and TS bridges as a function of (a) water contact angle and (b) normalized surface dipole moment $k$. Red crosses are the pressures from CT derived using Young-Laplace equation; circles are the pressures obtained from the forces acting on the walls calculated from the MD simulations. Solid lines in (a) are linear interpolations; solid lines in (b) are quadratic polynomials fittings. For hydrophilic surfaces, pressures become negative (i.e., water is under tension) for $\theta_{\mathrm{c}}<37^{\circ}$ and $\theta_{\mathrm{c}}<90^{\circ}$ in the case of AS bridges and TS bridges, respectively. For hydrophobic surfaces, pressures become very large; e.g., for $\theta_{\mathrm{c}} \approx 106^{\circ}(k=1), P \approx 250$ and $70 \mathrm{~atm}$ for AS bridges and TS bridges, respectively.

A surprising result follows from Figure $8 \mathrm{a}$. The results from MD simulations indicate that for $\theta_{c}<37^{\circ}$ and $\theta_{c}<90^{\circ}$, for the case of AS and TS bridges, respectively, the pressure on the walls is negative. Therefore, nanoscale bridges in the $2-10 \mathrm{~nm}$ range formed between hydrophilic surfaces may contain water under tension. This is consistent with recent experiments of nanoscale water bridges were the internal water pressure was estimated to be $-160 \mathrm{MPa}^{47-49}$ We stress that the pressure inside macroscopic AS bridges is always positive, and hence, this is a phenomenon inherent to the nanoscale dimensions explored. We also note the pressure inside the bridges can be very large (Figure $8 \mathrm{a}$ ), $\approx 250 \mathrm{~atm}$, which is 2 orders of magnitude larger than the pressure of water bridges of $\approx 1 \mu \mathrm{m}$ in size. It follows from this discussion that similar conclusions may hold for the forces that the water bridges exerts on the walls. For example, Figure 7 suggests that for large $\theta_{c}$ one may find that $F_{z}<0$.

C. Calculating the Surface Tension with KirkwoodBuff (KB) Method. We used the Kirkwood-Buff (KB) method $^{50}$ to test the self-consistency of $\mathrm{CT}$ at the nanometer scale. In this method, an orthorhombic simulation box $\left(L_{x}=L_{y}\right.$ $\left.<L_{z}\right)$ is created, and a slab of water molecules is placed at the middle of the box, parallel to the $x y$-plane, with a vacuum space above and below the water slab. Hence, the two liquid-vapor interfaces exist during the $\mathrm{MD}$ simulation. The surface tension $\gamma$ can be calculated using the expression $\gamma=L_{z}\left\langle 2 P_{z z}-P_{x x}-\right.$ $\left.P_{y y}\right\rangle / 4$, where $P_{x x}, P_{y y}$ and $P_{z z}$ are the diagonal components of the stress tensor. To calculate $\gamma$ using the KB method, we simulate a water slab of $N=3375$ water molecules in an orthorhombic box with dimensions $L_{x}=L_{y}=50 \AA$ and $L_{z}=140$ $\AA$. The simulation is run for $5 \mathrm{~ns}$ using the LAMMPS package and the principal component of the pressure tensor are calculated. At $T=300 \mathrm{~K}$, we obtain $\left\langle P_{z z}\right\rangle=-2.8 \pm 1.3 \mathrm{~atm}$, $\left\langle P_{y y}\right\rangle=-81.7 \pm 1.7 \mathrm{~atm}$, and $\left\langle P_{x x}\right\rangle=-81.9 \pm 1.4 \mathrm{~atm}$, resulting in a value of $\gamma=0.056 \pm 0.001 \mathrm{~N} / \mathrm{m}^{2}$. This value is in good agreement with the value obtained from the studies of the nanoscale AS and TS bridge as well as with the values known from the literature for SPC/E water. ${ }^{50}$

\section{SUMMARY AND DISCUSSION}

In summary, we present results from MD simulations of water droplets and bridges in contact with a family of hydrophobic/ hydrophilic surfaces characterized by different surface polarities. Our study is based on four different geometries: AS droplets, TS droplets, AS bridges, and TS bridges. From the MD simulations, we calculate the profile of the different droplets/ bridges and compare them with the corresponding prediction of macroscopic CT. We find an excellent agreement between the theory and simulations, even when the droplets/bridges studied are very small, with dimensions as small as $2 \mathrm{~nm}$. We also calculate the contact angle of the droplets/bridges in contact with different walls and confirm that as assumed by CT, these contact angles are independent of the droplets/bridges geometry and depend solely on the walls considered.

In order to test the self-consistency of CT at $2-10 \mathrm{~nm}$ scales, we also calculate the capillary forces of AS and TS bridges formed between parallel walls. These forces are calculated directly from MD simulations and compared with the corresponding expressions of CT. Again, we find an excellent agreement between theory and simulations. We note that the physical quantities involved in these expressions are consistent with independent calculations. For example, the expressions for the forces produced by the bridges on the walls are correct if the liquid-vapor tension of SPC/E water is $\gamma \approx 0.054 \mathrm{~N} / \mathrm{m}^{2}$. This value is in good agreement with the value of $\gamma$ obtained using the Kirkwood-Buff method for a flat interface, and it is also consistent with the values of $\gamma$ for SPC/E water reported in the literature. ${ }^{50}$

Our MD simulations clearly demonstrate that the predictions of the macroscopic CT are correct at the nanoscale when the dimensions of the droplets/bridges are only several nanometers. This makes an important statement that CT can be successfully used to e.g. interpret results of the AFM experiments. We note that our simulations indicate that in order to describe the behavior of $2-10 \mathrm{~nm}$ size droplets and bridges, the surface tensions can be assumed to be independent of the droplets/bridges size and, hence, of the large surface curvature of these interfaces. In addition, we find no need to include line tensions to describe the geometries of the droplets/ bridges studied, i.e., at $2-10 \mathrm{~nm}$ scales.

Another important conclusion is that straightforward MD simulations of a scaled down model can successfully describe the capillarity phenomena in the system of the same geometry at micron and millimeter scales. These macroscopic phenomena can be simulated by various analytical and finite element 
methods. However, these methods are not easy to implement for a particular geometry, and hence $\mathrm{MD}$ simulations can provide a useful consistency check in these complex situations.

Beside these practical problems, our simulations suggests that CT may be applicable to fundamental problems involving the emergence of surface tension at the nanoscales where the characteristic lengths of the interface density fluctuations are comparable to the system size, such as in the case of homogeneous/heterogeneous nucleation and critical phenomena, ${ }^{51-54}$ capillary condensation in nanoscale confinement, and dynamics of contact line spreading. ${ }^{55,56}$

\section{APPENDIX. DROPLET/BRIDGE PROFILES FROM MACROSCOPIC CAPILLARITY THEORY}

In this section, we outline a derivation for the expressions from CT that describe the profiles of AS and TS droplets as well as AS bridges (eqs 1 and 2); the corresponding expression from CT for the case of TS bridges (eq 3) is trivial (see section II.B.2).

There are two fundamental expressions in classical CT: the Young-Laplace equation and the Young equation. The Young-Laplace equation relates the difference in pressure across an interface, $\Delta P=P_{\text {in }}-P_{\text {out }}$ where $P_{\text {in }}$ and $P_{\text {out }}$ are the pressures on both sides of the interface. Specifically, it states that

$$
\Delta P=\gamma_{\mathrm{LG}} 2 H \quad \text { with } H=\frac{1}{2}\left(\frac{1}{R_{1}}+\frac{1}{R_{2}}\right)
$$

Here, $\gamma_{\mathrm{LG}}$ is the surface tension of the interface (gas-liquid interface, in our case), $H$ is the mean curvature of the interface, and $R_{1}$ and $R_{2}$ are the principal radii of curvature $\left(R_{1}\right.$ and $R_{2}$ can be negative or positive; see ref 1$)$. Since the pressure in a liquid or gas at equilibrium must be constant at any point, the average curvature $H$ must be constant over the entire interface.

The Young equation relates the equilibrium surface tensions of the liquid-gas (LG), liquid-solid (LS), and solid-gas (SG) interfaces at the three phase line, and it is given by

$$
\cos \theta_{c}=\frac{\gamma_{\mathrm{SG}}-\gamma_{\mathrm{LS}}}{\gamma_{\mathrm{LG}}}
$$

where $\theta_{\mathrm{c}}$ is the contact angle and $\gamma_{\mathrm{LG}}, \gamma_{\mathrm{LS}}$, and $\gamma_{\mathrm{SG}}$ are the different surface tensions involved.

Next, we describe how to obtain analytically the liquid profile for AS droplets, TS droplets, and AS bridges.

Profiles for AS and TS Droplets. We consider an AS droplet as shown in Figure 1e where $r(z)$ is the droplet radius at height $z$. For the volume of the droplet above a given height $z$, the net force along the $z$-axis must be zero. Hence, the pressures inside and outside the droplet and the surface tension must satisfy

$$
2 \pi r \gamma \cos \theta+P_{\text {out }} r^{2} \pi-P_{\text {in }} \pi r^{2}=0
$$

where $\gamma=\gamma_{\mathrm{LG}}$ and $\theta$ is the angle formed between the line tangent to the drop profile at height $z$ and the $z$-axis, i.e., $\mathrm{d} r / \mathrm{d} z$ $=\tan \theta$. It can be shown ${ }^{1}$ that

$$
\cos \theta=\frac{1}{\sqrt{1+\dot{r}^{2}}}
$$

Then, eq 16 can be written as

$$
\frac{2 \gamma}{\sqrt{1+\dot{r}^{2}}}=\Delta P r
$$

or, equivalently, using eq 14

$$
\left(\frac{\mathrm{d} r}{\mathrm{~d} z}\right)^{2}=\frac{1}{(H r)^{2}}-1
$$

Simple substitution shows that the solution of this equation is a sphere

$$
r(z)=\left(R^{2}-\left(z-z_{c}\right)^{2}\right)^{1 / 2}
$$

where $R=1 / H$ and $z_{\mathrm{c}}$ is a constant (equal to the distance from the center of the sphere to the origin). Considering that $\left.r(z)\right|_{z=0}$ $\equiv r_{0}=R \sin \theta_{\mathcal{c}}$, where $\theta_{\mathrm{c}}$ is the droplet contact angle, one gets $z_{\mathrm{c}}$ $=-R \cos \theta_{c}$. Equation 20 is the same as eq 1 . From the parameters $R$ and $z_{\mathrm{c}}$ we can obtain the contact angle $\theta_{\mathrm{c}}$ of the droplet

$$
\theta_{\mathrm{c}}=180^{\circ}-\frac{180^{\circ}}{\pi} \arccos \left(\frac{z_{\mathrm{c}}}{R}\right)
$$

A similar analysis shows that eq 20 holds for the case of TS droplets provided that $r(z)$ is half the thickness of the bridge at height $z$ (see Figure 1f). In this case, eq 16 is replaced by

$$
2 L \gamma \cos \theta+P_{\text {out }} L 2 r-P_{\text {in }} L 2 r=0
$$

which leads to an equation similar to eq 19 (with different coefficeints), and hence, it has eq 20 as solution.

Profile for AS Bridges. We consider an AS bridge as shown in Figure 1g. The origin of the system is at $z=0$, i.e., at the bridge's neck; the bridge radius at its neck is $r_{0}$.

Consider the volume of the AS bridge between two transverse sections at heights $z=0$ and $z$. Since the bridge is not displacing with time, the net force acting on such a volume of the bridge must add to zero. Again, the main forces acting on this volume are due to the surface tension and the pressures inside and outside the bridge. Therefore, it must be that

$$
\begin{aligned}
& -\gamma 2 \pi r_{0}+\gamma 2 \pi r \cos \theta+\left(\pi r_{0}^{2}\right) P_{\text {in }}-\left(\pi r^{2}\right) P_{\text {in }} \\
& \quad+\left[\pi\left(r^{2}-r_{0}{ }^{2}\right)\right] P_{\text {out }}=0
\end{aligned}
$$

Using eqs 14 and 17, eq 23 implies that

$$
\frac{\mathrm{d} z}{\mathrm{~d} r}= \pm \frac{\left|H\left(r^{2}-r_{0}{ }^{2}\right)+r_{0}\right|}{\sqrt{r^{2}-\left[H\left(r^{2}-r_{0}{ }^{2}\right)+r_{0}\right]^{2}}}
$$

which is eq 2 that describe the profile of the AS bridge between hydrophilic (sign + ) and hydrophobic (sign -) surfaces.

\section{AUTHOR INFORMATION}

\section{Corresponding Author}

*E-mail ngiovambattista@brooklyn.cuny.edu (N.G.).

Notes

The authors declare no competing financial interest.

\section{ACKNOWLEDGMENTS}

We thank Guillaume Stirnemann and Pablo G. Debenedetti for their contributions in the early stages of this project and for enlightening discussions. Support for this project was provided by a PSC-CUNY Award, jointly funded by The Professional Staff Congress and The City University of New York. A.B.A. acknowledge the Coordenação de Aperfeiçoamento de Pessoal de Nivel Superior (CAPES) for support. This research was supported, in part, by a grant of computer time from the City University of New York High Performance Computing Center under NSF Grants CNS-0855217, CNS-0958379, and ACI- 
1126113. S.V.B. thanks the Dr. Bernard W. Gamson Computational Science Center at Yeshiva College for support.

\section{REFERENCES}

(1) de Gennes, P.; Brochard-Wyart, F.; Quéré, D. Capillarity and Wetting Phenomena: Drops, Bubbles, Pearls, Waves; Springer: 2004.

(2) Hornbaker, D. J.; Albert, R.; Albert, I.; Barabasi, A. L.; Schiffer, P. What Keeps Sandcastles Standing? Nature 1997, 387, 765-765.

(3) Hu, D. L.; Chan, B.; Bush, J. W. M. The Hydrodynamics of Water Strider Locomotion. Nature 2003, 424, 663-666.

(4) Eisner, T.; Aneshansley, D. J. Defense by Foot Adhesion in a Beetle (Hemisphaerota cyanea). Proc. Natl. Acad. Sci. U. S. A. 2000, 97, 6568-6573.

(5) Federle, W.; Riehle, M.; Curtis, A. S.; Full, R. J. An Integrative Study of Insect Adhesion: Mechanics and Wet Adhesion of Pretarsal Pads in Ants. Integr. Comp. Biol. 2002, 42, 1100-1106.

(6) Grotberg, J. B. Respiratory Fluid Mechanics. Phys. Fluids 2011, 23, 021301.

(7) Alencar, A. M.; Buldyrev, S. V.; Majumdar, A.; Stanley, H. E.; Suki, B. Avalanche Dynamics of Crackle Sound. Phys. Rev. Lett. 2001, $87,088101$.

(8) van Honschoten, J. W.; Brunets, N.; Tas, N. R. Capillarity at the Nanoscale. Chem. Soc. Rev. 2010, 39, 1096-1114.

(9) Bonn, D.; Eggers, J.; Indekeu, J.; Meunier, J.; Rolley, E. Wetting and Spreading. Rev. Mod. Phys. 2009, 81, 739-805.

(10) Weeks, B. L.; Vaughn, M. W.; DeYoreo, J. J. Direct Imaging of Meniscus Formation in Atomic Force Microscopy Using Environmental Scanning Electron Microscopy. Langmuir 2005, 21, 80968098.

(11) Schenk, M.; Füting, M.; Reichelt, R. Direct Visualization of the Dynamic Behavior of a Water Meniscus by Scanning Electron Microscopy. J. Appl. Phys. 1998, 84, 4880-4884.

(12) Sedin, D. L.; Rowlen, K. L. Adhesion Forces Measured by Atomic Force Microscopy in Humid Air. Anal. Chem. 2000, 72, 21832189.

(13) Yang, L.; Tu, Y.-s.; Tan, H.-1. Influence of Atomic Force Microscope (AFM) Probe Shape on Adhesion Force Measured in Humidity Environment. Appl. Math. Mech., Engl. Ed. 2014, 35, 567.

(14) Piner, R. D.; Zhu, J.; Xu, F.; Hong, S.; Mirkin, C. A. "Dip-Pen" Nanolithografy. Science 1999, 283, 661-663.

(15) Huppmann, W.; Riegger, H. Modelling of Rearrangement Processes in Liquid Phase Sintering. Acta Metall. 1975, 23, 965-971.

(16) Qian, B.; Breuer, K. S. The Motion, Stability and Breakup of a Stretching Liquid Bridge with a Receding Contact Line. J. Fluid Mech. 2011, 666, 554-572.

(17) Darhuber, A. A.; Troian, S. M.; Wagner, S. Physical Mechanisms Governing Pattern Fidelity in Microscale Offset Printing. J. Appl. Phys. 2001, 90, 3602-3609.

(18) Kang, H. W.; Sung, H. J.; Lee, T.-M.; Kim, D.-S.; Kim, C.-J. Liquid Transfer Between Two Separating Plates for Micro-GravureOffset Printing. J. Micromech. Microeng. 2009, 19, 015025.

(19) Werder, T.; Walther, J. H.; Jaffe, R. L.; Halicioglu, T.; Koumoutsakos, P. On the Water-Carbon Interaction for Use in Molecular Dynamics Simulations of Graphite and Carbon Nanotubes. J. Phys. Chem. B 2003, 107, 1345-1352.

(20) Koishi, T.; Yoo, S.; Yasuoka, K.; Zeng, X. C.; Narumi, T.; Susukita, R.; Kawai, A.; Furusawa, H.; Suenaga, A.; Okimoto, N.; Futatsugi, N.; Ebisuzaki, T. Nanoscale Hydrophobic Interaction and Nanobubble Nucleation. Phys. Rev. Lett. 2004, 93, 185701.

(21) Koishi, T.; Yasuoka, K.; Ebisuzaki, T.; Yoo, S.; Cheng, X. C. Large-Scale Molecular-Dynamics Simulation of Nanoscale Hydrophobic Interaction and Nanobubble Formation. J. Chem. Phys. 2005, $123,204707$.

(22) Bresme, F.; Oettel, M. On the Influence of Solute Polarizability on the Hydrophobic Interaction. J. Phys.: Condens. Matter 2007, 19, 413101.

(23) Bresme, F.; Faraudo, J. Orientational Transitions of Anisotropic Nanoparticles at Liquid-Liquid Interfaces. J. Phys.: Condens. Matter 2007, 19, 375110.
(24) Bresme, F.; Oettel, M. Nanoparticles at Fluid Interfaces. J. Phys.: Condens. Matter 2007, 19, 413101.

(25) Bresme, F.; Lehle, H.; Oettel, M. Solvent-Mediated Interactions Between Nanoparticles at Fluid Interfaces. J. Chem. Phys. 2009, 130, 214711.

(26) Lum, K.; Luzar, A. Pathway to surface-induced phase transition of a confined fluid. Phys. Rev. E: Stat. Phys., Plasmas, Fluids, Relat. Interdiscip. Top. 1997, 56, R6283-R6286.

(27) Wang, J.; Kudesia, S.; Bratko, S.; Luzar, A. Computational probe of cavitation events in protein systems. Phys. Chem. Chem. Phys. 2011, 13, 19902-19910.

(28) Vanzo, D.; Bratko, D.; Luzar, A. Dynamic Control of Nanopore Wetting in Water and Saline Solutions under an Electric Field. J. Phys. Chem. B 2015, 119, 8890-8899.

(29) Bresme, F.; Quirke, N. Computer Simulation Study of the Wetting Behavior and Line Tensions of Nanometer Size Particulates at a Liquid-Vapor Interface. Phys. Rev. Lett. 1998, 80, 3791.

(30) Wynveen, A.; Bresme, F. Interactions of Polarizable Media in Water: A Molecular Dynamics Approach. J. Chem. Phys. 2006, 124, 104502.

(31) Vanzo, D.; Bratko, D.; Luzar, A. Wettability of pristine and alkylfunctionalized graphane. J. Chem. Phys. 2012, 137, 034707.

(32) Ritchie, J. A.; Yazdi, J. S.; Bratko, D.; Luzar, A. Metastable Sessile Nanodroplets on Nanopatterned Surfaces. J. Phys. Chem. C 2012, 116, 8634-8641.

(33) Plimpton, S. Fast Parallel Algorithms for Short-Range Molecular Dynamics. J. Comput. Phys. 1995, 117, 1-19.

(34) Berendsen, H. J. C.; Grigera, J. R.; Stroatsma, T. P. The Missing Term in Effective Pair Potentials. J. Phys. Chem. 1987, 91, 6269-6271.

(35) Hockney, R. W.; Eastwood, J. W. Computer Simulation Using Particles; Adam Hilger: New York, 1989.

(36) Shinoda, W.; Shiga, M.; Mikami, M. Rapid Estimation of Elastic Constants by Molecular Dynamics Simulation Under Constant Stress. Phys. Rev. B: Condens. Matter Mater. Phys. 2004, 69, 134103.

(37) Giovambattista, N.; Debenedetti, P. G.; Rossky, P. J. Effect of Surface Polarity on Water Contact Angle and Interfacial Hydration Structure. J. Phys. Chem. B 2007, 111, 9581-9587.

(38) Giovambattista, N.; Rossky, P. J.; Debenedetti, P. G. Effect of Pressure on the Phase Behavior and Structure of Water Confined Between Nanoscale Hydrophobic and Hydrophilic Plates. Phys. Rev. E 2006, 73, 041604

(39) Alencar, A. M.; Wolfe, E.; Buldyrev, S. V. Monte Carlo Simulation of Liquid Bridge Rupture: Application to Lung Physiology. Phys. Rev. E 2006, 74, 026311.

(40) Castrillón, S. R.-V.; Giovambattista, N.; Aksay, I. A.; Debenedetti, P. G. Structure and Energetics of Thin Film Water. J. Phys. Chem. C 2011, 115, 4624-4635.

(41) Starr, F. W.; Sciortino, F.; Stanley, H. S. Dynamics of Simulated Water under Pressure. Phys. Rev. E: Stat. Phys., Plasmas, Fluids, Relat. Interdiscip. Top. 1999, 60, 6757.

(42) Rowlinson, J. S.; Widom, B. Molecular Theory of Capillarity; Dover Publications: New York, 2002.

(43) Wang, J. Y.; Betelu, S.; Law, B. M. Line Tension Approaching a First-Order Wetting Transition: Experimental Results from Contact Angle Measurements. Phys. Rev. E: Stat. Phys., Plasmas, Fluids, Relat. Interdiscip. Top. 2001, 63, 031601.

(44) Cruz-Chu, E. R.; Aksimentiev, A.; Schulten, K. Water-Silica Force Field For Simulating Nanodevices. J. Phys. Chem. B 2006, 110, 21497-21508.

(45) Vega, C.; de Miguel, E. Surface Tension of the Most Popular Models of Water by Using the Test-Area Simulation Method. J. Chem. Phys. 2007, 126, 154707.

(46) Ismail, A. E.; Grest, G. S.; Stevens, M. J. Capillary Waves at the Liquid-Vapor Interface and the Surface Tension of Water. J. Chem. Phys. 2006, 125, 014702.

(47) Yang, S. H.; Nosonovsky, M.; Zhang, H.; Chung, K.-H. Nanoscale Water Capillary Bridges under Deeply Negative Pressure. Chem. Phys. Lett. 2008, 451, 88-92. 
(48) Caupin, F.; Herbert, E.; Balibar, S.; Cole, M. W. Comment on "Nanoscale Water Capillary Bridges under Deeply Negative Pressure" [Chem. Phys. Lett. 451 (2008) 88]. Chem. Phys. Lett. 2008, 463, 283285.

(49) Yang, S. H.; Nosonovsky, M.; Zhang, H.; Chung, K.-H. Response to the Comment on "Nanoscale Water Capillary Bridges under Deeply Negative Pressure" by Caupin et al. Chem. Phys. Lett. 2008, 463, 286-287.

(50) Wang, J.; Zeng, X. C. Computer Simulation of Liquid-Vapor Interfacial Tension: Lennard-Jones Fluid and Water Revisited. J. Theor. Comput. Chem. 2009, 08, 733-763.

(51) Law, B. M. Theory of Nucleated Wetting. Phys. Rev. Lett. 1994, 72, 1698-1701.

(52) Lazaridis, M. The Effects of Surface Diffusion and Line Tension on the Mechanism of Heterogeneous Nucleation. J. Colloid Interface Sci. 1993, 155, 386-391.

(53) Aleksandrov, A.; Toshev, B.; Scheludko, A. Nucleation from Supersaturated Water Vapors on N-Hexadecane: Temperature Dependence of Critical Supersaturation and Line Tension. Langmuir 1991, 7, 3211-3215.

(54) Macdowell, L. G.; Shen, V. K.; Errington, J. R. Nucleation and cavitation of spherical, cylindrical, and slablike droplets and bubbles in small systems. J. Chem. Phys. 2006, 125, 034705.

(55) de Gennes, P. G. Wetting: Statics and Dynamics. Rev. Mod. Phys. 1985, 57, 827-863.

(56) Dussan, E. B. On the Spreading of Liquids on Solid Surfaces: Static and Dynamic Contact Lines. Annu. Rev. Fluid Mech. 1979, 11, 371-400. 


\title{
Validation of Capillarity Theory at the Nanometer-Scale II: Stability and Rupture of Water Capillary Bridges in Contact with Hydrophobic and Hydrophilic Surfaces.
}

\author{
Alexandre B. Almeida ${ }^{1}$, Nicolas Giovambattista ${ }^{2,3}$, \\ Sergey V. Buldyrev ${ }^{4}$, Adriano M. Alencar ${ }^{1}$ \\ 1 Instituto de Física, \\ Universidade de São Paulo, \\ 05508-090, São Paulo, SP, Brazil \\ 2 Department of Physics, \\ Brooklyn College of the City University of New York, \\ Brooklyn, NY 11210 USA \\ 3 Ph.D. Programs in Chemistry and Physics, \\ The Graduate Center of the City University of New York, \\ New York, NY 10016 USA \\ 4 Department of Physics, \\ Yeshiva University, \\ 500 West 185th Street, \\ New York, NY 10033 USA
}




\begin{abstract}
We perfom molecular dynamics (MD) simulations of nanometer-scale water capillary bridges formed between parallel walls. The underlying structure of the surfaces corresponds to hydroxilated (crystalline) silica which is modified to cover a wide range of hydrophobicity/hydrophilicity. The capillary bridges are stretched during the MD simulations, from walls separation $h=5 \mathrm{~nm}$ up to $h \approx 7.5 \mathrm{~nm}$, until they become unstable and break. During the stretching process, we calculate the capillary bridge profiles as well as the force and pressure induced on the walls. We find that, for all walls separations and surface hydrophobicity/hydrophilicity considered, the results from MD simulations are in excellent agreement with the predictions from capillarity theory $(\mathrm{CT})$. In addition, CT is able to predict very closely the limit of stability of the capillary bridges, i.e., the value of $h$ at which the bridges break. We also confirm the CT conditions under which the bridge ruptures forming (i) a single droplet attached to one of the walls, (ii) two identical or (iii) two different droplets, one attached to each wall. This work expands upon a previous study of nanoscale droplets and (stable) capillary bridges where CT was validated at the nanoscale using MD simulations. The validation of $\mathrm{CT}$ at such small scales is remarkable since $\mathrm{CT}$ is a macroscopic theory that is expected to fail at $<10 \mathrm{~nm}$ scales where molecular details may become relevant. In particular, we find that $\mathrm{CT}$ works for capillary bridges that are $\approx 2 \mathrm{~nm}$-thick, comparable to the thickness of the water-vapor interface.
\end{abstract}




\section{INTRODUCTION}

The research on capillary phenomena at the macroscopic scale started in the early 19th century by Laplace and Young, who created the capillary theory (CT) to explain the profile of an interface placed between two immiscible liquids or a vapor and a liquid [1]. The interface of macroscopic CT system is modeled as continuous, once the size of atoms/molecules are much smaller than the radii of curvature of the interface. However, if the scale of the system is comparable with the size of atoms/molecules, the continuum description of the interface may not be suitable to explain the capillarity.

The macroscopic CT is broadly applicable to study the capillarity in different conditions and context $[1,2]$, like the rearrangement processes in liquid phase sintering [3], the study of immiscible fluid transport in porous media [4], to explain the origin of crackling sound generation in inhale [5] and exhale [6]. Over the past few years, the capillarity at the nanoscale [8] have called the attention from scientific community to problems related to capillary filling [10] and imbibition [13] of nanochannels, and to transfer of ink through capillary bridges in the dip-pen nanolithography $[38,39]$. The nanoscale capillary force is also significant when we consider adhesion between colloidal [35] and silica [36] particles, and between the tip and substrate in atomic force microscopy (AFM) experiments in a environment with humidity $[7,14]$. The capillary adhesion force in these last applications emerge from the presence of capillary bridges.

In the AFM experiments, the formation [37] and rupture[15] of capillary bridges are thermally activated stochastic process obeying the Poisson statistic. Usually, a toroidal continuum approach $[7,16,17]$ for the capillary bridges profile allows the calculation of the capillary adhesion force during AFM experiments. However, the implementation of this continuum approach as an alternative to model systems at the nanoscale has imposed a strong test to macroscopic theories. The macroscopic CT could not be applied at the nanoscale, once the curvature radii of the interface has the same magnitude of the atoms/molecules forming it. On the other hand, computer simulations have provided a good understanding of bridges at the nanoscale. Simulations with lattice density functional theory shows that the free energy barrier for the formation and rupture of capillary bridges changes according to the distance of AFM tip from the substrate [18]. Molecular dynamic simulations of capillary bridges, composed of nonvolatille liquid and trapped between a spherical and a planar 
surface, shows that the macroscopic CT predictions agree to the simulations results at the scale 5-10 nm, however it fails to distance lower that $5 \mathrm{~nm}$ [19]. In other study, the capillary adhesion force of water capillary bridge, attached to parallel planar surfaces, exhibits an oscillatory behavior and discontinuities for distances lower than $1 \mathrm{~nm}$ [20]. Giovammbatista et al. performed molecular dynamics simulation of SPC/E water molecules forming interfaces with different geometries [9]. His work compared this interfaces, obtained from 2 ns average profile of droplets and capillary bridges ( $50 \AA$ height), with Delaunay surfaces, which are the continuum profiles calculated from the macroscopic CT [5]. They have shown that the interface, capillary adhesion force, Laplace pressure and surface tension are well explained by the macroscopic CT at the $2-10 \mathrm{~nm}$ scale.

Here, we explore other aspect from the macroscopic capillarity at nanoscale, which is related to the stability of capillary bridges. This problem is well known and summarized details can be found at the ref $[2,5]$. The macroscopic CT predicts that axisymmetric capillary bridges (AS bridges) may be stable or unstable, according to the contact angle $\theta_{c}$ formed to the surface and to the AS bridge's height $h$. The AS bridge has a critical height $h_{c}$, that depends on the contact angle $\theta_{c}$, above which it becomes unstable and breaks. Moreover, the rupture of AS bridges has two states, which are separated by the critical contact angle at $\theta_{c}=31^{\circ}$. The AS bridge breaks, and it generate one droplet or two unequal droplets, if $\theta_{c}>31^{\circ}$, or two equal droplets, if $\theta_{c}<31^{\circ}$. The critical height $h_{c}$ and the contact angle $\theta_{c}$ define a phase diagram $\left(h_{c}, \theta_{c}\right)$ of stable and unstable AS bridge, which is the subject in this work. Specifically, we perform molecular dynamic simulation of AS bridges, composed of SPC/E water molecules, attached to two parallel walls made of $\beta$ cristobalite. We study the AS bridge in a range of $\theta_{c}$ and $h$, and we compare the results according to the stable and unstable predictions from macroscopic CT. For the stable AS bridge, we analyse the capillary adhesion force, the Laplace pressure, the contact angle, the profile of AS bridge, and the surface tension of the SPC/E water model. For the unstable AS bridge, we analyse the critical height, the size of droplets formed after the rupture.

This paper is organized as following. First, we deduce the main properties of AS bridge, and we present some details about the exactly solutions of AS bridges and the calculation of critical height. Then, we describe the simulation details to study the AS bridge, and we explain how to obtain the profile from the molecular dynamics simulations and how to fitting this profiles using differential equation obtained from CT. The results section is divided in 
two parts, in which we first show the results obtained for the liquid bridge stable and then the unstable AS bridges with rupture. Finally, the conclusion of our work.

\section{CAPILLARITY THEORY OF AXIS SYMMETRIC CAPILLARY BRIDGES: EQUILIBRIUM PROPERTIES AND STABILITY LIMIT}

In this section, we summarize the expressions from CT that describe the main properties of AS bridges. In section II A, we present simple expressions for the properties of stable AS bridges derived from CT using the Young-Laplace equation. Equivalent expressions for the AS bridge properties can be derived from CT by minimizing the AS bridge free energy using variational calculus. These expressions are presented in section II B. The variational calculus approach has the advantage of providing important predictions of CT regarding the AS-bridge rupture, such as the maximum walls separation for which the capillary bridge is stable; see section II B.

\section{A. Capillary Bridge Profile and Forces Induced on the Walls}

We consider the schematic AS bridge shown in Figure 1 and provide the expressions for (i) the AS bridge profile as well as the (ii) force and (iii) pressure induced by the AS bridge on the walls.

The AS bridge profile is specified by the function $r(z)$ that gives the radius of the capillary bridge at height z. As explained in detail in Ref. [9] (see also, Ref. [1]), a differential equation for $r(z)$ can be obtained using Young-Laplace equation,

$$
\Delta P=\gamma 2 H
$$

in which $\Delta P=P_{\text {inside }}-P_{\text {outside }}$ i.e., the difference of pressure inside and outside the AS bridge, $\gamma$ is the fluid surface tension, and $H=\left(1 / R_{1}+1 / R_{2}\right) / 2$ is the average curvature of the capillary bridge surface (see Figure 1). It can be shown from eq 1 that the AS bridge profile is defined by

$$
\frac{\mathrm{dz}}{\mathrm{dr}}= \pm \frac{\left|H\left(r^{2}-r_{0}^{2}\right)+r_{0}\right|}{\sqrt{r^{2}-\left[H\left(r^{2}-r_{0}^{2}\right)+r_{0}\right]^{2}}}
$$

where $r_{0}$ is the AS bridge radius at $z=0$, i.e., at half the bridge's height [Figure 1]. We follow the sign convention of Ref. [1] where $R_{1}$ and $R_{2}$ can be positive or negative. The 
signs + and - in eq 2 describe, respectively, the profile of AS bridges between hydrophilic $\left(\theta_{c}<90^{\circ}\right)$ and hydrophobic $\left(\theta_{c}>90^{\circ}\right)$ surfaces. The solution of eq 2 for $r(z)$ is not trivial and involves special functions (see, e.g., Ref. [5], and section IIB). However, for given values of $H$ and $r_{0}$, eq 2 can be easily integrated numerically and the AS bridge profile $r(z)$ predicted by CT can be calculated.

The magnitude of the net force acting on the walls, induced by the AS bridge, is given by [1],

$$
F_{z}=F_{\gamma}+F_{P}
$$

where

$$
F_{\gamma}=2 \pi \gamma r_{b} \sin \theta_{c}
$$

is the force on the wall due the liquid-vapor surface tension $\gamma$ and

$$
F_{P}=-P A_{b}=-P\left(\pi r_{b}^{2}\right)
$$

is the force on the wall due to the pressure $P$ within the AS bridge; $A_{b}$ is the area of the AS bridge's base. Using Young-Laplace equation and assuming $P \approx 0$ in the vapor phase, one can write $P=2 \gamma H$. Therefore, the force produced by the AS bridge on the walls is

$$
F_{z}=2 \pi r_{b} \gamma \sin \theta_{c}-2 \pi r_{b}^{2} \gamma H
$$

An equivalent equation for $F_{z}$ can be obtained by noticing that the net force along the $z$-axis at any cross-section of the AS bridge must be constant [1]. Hence, if $F_{z \text {,neck }}$ is the force acting on a plane perpendicular to the AS bridge and passing through its neck (i.e., at $z=0$ ), it must be that $F_{z \text {,neck }}=F_{z}$. The force at the neck of the AS bridge is given by [1]

$$
F_{z, \text { neck }}=2 \pi r_{0} \gamma-2 \pi r_{0}^{2} \gamma H=2 \pi \gamma C
$$

where $C=r_{0}-H r_{0}^{2}$. As explained in section III, we will consider surfaces with different surface polarities; the surface polarity is quantified by a single parameter, $k$. It follows that in the expression above, $C=C(k)$.

The pressure within the AS bridge follows from eq 3 ,

$$
P=\frac{F_{\gamma}-F_{z}}{A_{b}},
$$

which can be rewritten as

$$
P=\frac{2 \pi \gamma r_{b} \sin \theta_{c}-F_{z}}{\pi r_{b}^{2}}
$$




\section{B. Limit of Stability for Axis Symmetric Bridges}

In this section, we present equivalent expressions from $\mathrm{CT}$ for $r(z), F_{z}$, and $P$ obtained in closed form for a given AS bridge with volume $\Omega$ and for walls separation $h$. This is done by minimizing the free energy of the AS bridge using variational calculus. This approach also provides information on the stability limit of the AS bridge, such as the maximum walls separation at which the AS bridge is stable, and its rupture mechanism, e.g., whether the stable AS bridge breaks into one or two droplets, with equal or different volumes. Derivation of these expressions can be found in the Appendix of Ref. [5] and in Refs. [2, 29-32].

Minimization of the AS bridge free energy provides the following expression for the AS bridge profile (equivalent to eq 2 ),

$$
z(r)= \pm s \int_{A}^{r} \frac{d x\left(A B+x^{2}\right)}{\sqrt{\left(B^{2}-x^{2}\right)\left(x^{2}-A^{2}\right)}}+z_{0},
$$

In this expression, $A$ and $B$ are, respectively, the minimum and maximum distance from the AS bridge profile to the $z$-axis, $s$ is the sign of the mean curvature $H, z_{0}$ is the height of the AS bridge neck, and the $+/-$ signs correspond to the portion of the AS bridge at $z>0$ and $z<0$ (Figure 1), respectively.

The force $F_{z}$ and pressure $P$ induced by the AS bridge on the walls can be expressed in terms of elliptic integrals [5]. These expressions for $F_{z}$ and $P$ depend solely on the AS bridge volume $\Omega$, walls separation $h$, water contact angle $\theta_{c}$, and the ratio $a=r_{0} / r_{b}$, where $r_{0}=R_{1}$ and $r_{b}$ are, respectively, the radii of the capillary bridge neck and base; see Figure 1 . The values of $\Omega, h, \theta_{c}$ are supposed to be known. The quantity a can be determined numerically from the equation

$$
\Omega=\frac{\pi h^{3}}{4} \frac{v(a, 1)}{u(a, 1)^{3}}
$$

where $u(a, 1)$ and $v(a, 1)$ can be expressed in terms of Legendre elliptic integrals $F(\phi, k)$ and $E(\phi, k)$,

$$
\begin{aligned}
u(a, r)= & a \tilde{F}\left(k, \phi_{r}\right)+b \tilde{E}\left(k, \phi_{r}\right), \\
v(a, r)= & {\left[-\mathcal{R}(a, r)-a^{2} b \tilde{F}\left(k, \phi_{r}\right)\right.} \\
& \left.+b\left[3 a b+2\left(a^{2}+b^{2}\right)\right] \tilde{E}\left(k, \phi_{r}\right)\right] / 3,
\end{aligned}
$$


In these expressions,

$$
\begin{array}{ll}
b= & \left(\frac{1-a \sin \theta_{c}}{\sin \theta_{c}-a}\right), \\
k= & s \sqrt{b^{2}-a^{2}} / b, \\
\mathcal{R}(a, r)= & r \sqrt{\left(r^{2}-a^{2}\right)\left(b^{2}-r^{2}\right)}, \\
\phi_{r}= & \arcsin \sqrt{\left(b^{2}-r^{2}\right) /\left(b^{2}-a^{2}\right)}, \\
\tilde{F}(k, \phi)= & F(k, \pi / 2)-F(k, \phi), \\
\tilde{E}(k, \phi)= & E(k, \pi / 2)-E(k, \phi) .
\end{array}
$$

The force exerted by the AS bridge on the walls is given by

$$
F_{z}=\pi \gamma a \frac{h\left(1-a \sin \theta_{c}\right)}{\left(1-a^{2}\right) u(a, 1)}
$$

which is a monotonically decreasing function of $h$.

It can be shown that the radius of the AS bridge base is given by

$$
r_{\mathrm{b}}(a)=u(a, 1)\left(\frac{\Omega}{2 \pi v(a, 1)}\right)^{1 / 3}
$$

This allows one to calculate the pressure within the AS bridge. Specifically, $P$ is obtained by applying eqs 15 and 14 in eq 9 :

$$
P=\frac{2 \pi \gamma u(a, 1)\left(\frac{\Omega}{2 \pi v(a, 1)}\right)^{1 / 3} \sin \theta_{c}-\pi \gamma a \frac{h\left(1-a \sin \theta_{c}\right)}{\left(1-a^{2}\right) u(a, 1)}}{\pi^{2} u(a, 1)^{2}\left(\frac{\Omega}{2 \pi v(a, 1)}\right)^{2 / 3}} .
$$

Relevant to this work are the CT predictions regarding the AS bridge rupture. In particular, we note that analysis of eq 10 indicates that there are two kinds of solutions for $z(r)$ : symmetric solution, for the case $z_{0}=0$, and asymmetric solution, for $z_{0} \neq 0$. According to Vogel's theorem $[29,30]$, only symmetric profiles are stable. The asymmetric profiles have inflection points and are unstable.

Analysis of the asymmetric profiles using variational calculus shows that the rupture mechanism of AS bridges depends on the contact angle $\theta_{c}$. Specifically, for $\theta_{c}>31^{\circ}$, unstable AS bridges break leading to either (i) a single droplet attached to one of the walls [e.g., Figure 4(a)], or (ii) two droplets of different volume attached to each wall [e.g., Figure 4(c)]. In the case $\theta_{c}<31^{\circ}$, the AS bridge breaks into two identical droplets, one on each wall [e.g., Figure 4(d)]. 
CT also predicts the limit of stability of the AS bridge with $h$. Specifically, it is predicted that AS bridges must break at a walls separation $h_{\max }$. For $\theta_{c}>31^{\circ}$,

$$
h_{\max }=\frac{u\left(a_{c}, 1\right)}{2}\left(\frac{\Omega}{2 \pi v\left(a_{c}, 1\right)}\right)^{\frac{1}{3}},
$$

where $a_{c}$ is the critical neck-to-base ratio $a_{c}=\tan \left(\theta_{c} / 2\right)$. For $\theta_{c}<31^{\circ}$,

$$
h_{\max }=\frac{u\left(a_{0}, 1\right)}{2}\left(\frac{\Omega}{2 \pi v\left(a_{0}, 1\right)}\right)^{\frac{1}{3}}
$$

in which $a_{0}$ is the root of a complex transcendental equation (this equation is given in ref [5], eq $A 29)$.

\section{COMPUTER SIMULATIONS AND NUMERICAL METHODS}

\section{A. Simulation Details}

Our findings are based on MD simulations of water capillary bridges in contact with surfaces of different hydrophobicity/hydrophilicity. We consider AS bridges formed between parallel surfaces, as shown in Figure 1. The walls are orthogonal to the $z$-axis, located at $z= \pm h / 2$, and they are periodic along the $x$ and $y$ directions. All simulations are performed for a cubic system of side length $L=138.6 \AA$, at constant volume, number of water molecules $N=3375$, and temperature $T=300 \mathrm{~K}$. Periodic boundary conditions are applied along the $x$ and $y$ directions.

We employ the same system and methodologies used in our previous study of nanoscale water droplets and capillary bridges at fixed $h=50 \AA$ [9]. A detailed description of the computer simulation techniques and methodologies can be found there. To summarize briefly, MD simulations are performed using the LAMMPS software package [21] with water molecules being represented by the SPC/E model [22]. Coulomb and Lennard-Jones interactions are cut off at distance $r_{\text {cutoff }}=10 \AA$ and we calculate the long-range electrostatic interactions using a particle-particle particle-mesh solver [23]. The temperature is controlled using a Nosé-Hoover style thermostat.

We consider a family of walls that vary in the degree of hydrophobicity/hydrophilicity. These walls are described in detail in Refs. [25, 26]. Briefly, the walls structure corresponds to four layers of $\mathrm{SiO}_{2}$, reproducing the $(1,1,1)$ face of $\beta$-cristobalite. The wall surface in 
contact with the capillary bridge is hydroxilated by attaching a hydrogen $(\mathrm{H})$ atom to each surface oxygen. The $\mathrm{Si}$ and $\mathrm{O}$ atoms are fixed during the simulation but the $\mathrm{OH}$ bonds are allowed to rotate in a plane parallel to the wall. In all simulations we measure the distance to a given wall as the distance to the plane of the wall's $\mathrm{H}$ atoms.

All wall atoms, with exception of the $\mathrm{H}$ atoms, interact with water via a Lennard-Jones potential. Only the $\mathrm{Si}, \mathrm{O}$, and $\mathrm{H}$ atoms of the surface silanol groups have a non-zero partial charge and hence, they interact with water via Coulomb interactions. The wall structure, LJ parameters of the wall atoms, and the corresponding partial charges are provided in Ref. [25]. In the hydroxilated silica surface, the silanol group partial charges are $q_{0, S i}=0.31 e$, $q_{0, O}=-0.71 e$, and $q_{0, H}=0.40 e$ and the surface is hydrophilic, as expected. In order to vary the hydrophilicity of the surface, we follow Ref. [26] and re-scale the silanol group partial charges by a factor $0 \leq k \leq 1$, i.e., $q_{i} \rightarrow k \times q_{0, i}$ where $i=\mathrm{O}$, Si, H. It can be easily shown that $k$ is a dimensionless factor that quantifies the surface polarity [26]. In the case $k=1$, one recovers the original hydroxilated surfaces.

In this work, we are interested in the behavior of the AS bridges as the wall-wall distance increases. For a given pair of walls (defined by a specific value of $k$ ), we start the MD simulations with $h=50 \AA$. As we showed previously [9], at this separation the CT is able to predict the AS bridge profiles obtained in MD simulations as well as the forces on the walls induced by the capillary bridge [9]. At $h=50 \AA$, the starting AS bridge configuration is a cubic configuration of water (taken from an independent simulation of bulk water at with $\rho=1 \mathrm{~g} / \mathrm{cm}^{3}$ and $T=300 \mathrm{~K}$ ) sandwiched by two identical surfaces. The system is simulated for $\Delta t_{\text {sim }}=5 \mathrm{~ns}$ during which the bridge profile evolves rapidly acquiring a stable axis symmetric profile.

A sequence of simulations follows with increasing walls separations, $h=55,60,65, \ldots \AA$, until the AS bridge rupture is found. At each $h \geq 55 \AA$, we run a simulation for $\Delta t_{\text {sim }}=3 \mathrm{~ns}$. We find that, as shown below, the resulting stretching rate $\Delta h / \Delta t_{\text {sim }}$ is sufficiently slow that the stretching process of the AS bridge can be considered to be quasi-static. In order to prevent the premature rupture of the AS bridge when $h \rightarrow h^{\prime}=h+5 \AA$, we move the walls during short 250 fs-simulations in which each wall is displaced by $0.01 \AA$ every 1 fs. We note that at a given $h$, the termalization of the AS bridge is very fast; for example, the average forces on the walls become constant in less than 100 ps. During the simulations at a given $h$, the configurations of water molecules and the forces on each wall are saved every 1 ps. Only 
the last 2 ns of the simulated time interval $\Delta t_{\text {sim }}$ are used for data analysis (see Ref. [9]).

With the procedure described above, we identify the maximum separation $h_{S}$ at which the AS bridge is stable and the critical height $h_{C^{\prime}} \equiv h_{S}+5 \AA$ at which the bridge rupture occurs. Since slower stretching rates may lead to smaller values of $h_{\mathrm{C}^{\prime}}$, we perform additional simulations to obtain a second estimation of the critical height $\left(h_{\mathrm{C}}\right)$. Specifically, to obtain $h_{\mathrm{C}}$, we first perform an additional simulation at $h=h_{S}+2.5 \AA$. If the AS bridge does not break in $\Delta_{\text {sim }}=20 \mathrm{~ns}$, the walls are displaced again so $h=\left(h_{S}+2.5\right)+1.25 \AA$ and the simulation is performed until the AS bridge breaks. In most cases, the AS bridges break within $20 \mathrm{~ns}$. The only exception is the case $k=0.66$, for which the AS bridge does not break at $h=\left(h_{S}+2.5\right)+1.25=58.75 \AA$ even for 20 ns. In this case, we consider that $h_{\mathrm{C}}=h_{\mathrm{C}^{\prime}}$. As shown in section IV B, we find that $h_{S}<h_{\max }$, while $h_{C}$ and $h_{C^{\prime}}$ are located around $h_{\max }$.

\section{B. Numerical Methods}

Next, we describe (i) how the profiles of AS bridges are calculated from MD simulations (section III B 1) and (ii) the procedure followed to fit the MD simulation bridge profiles and wall forces using the corresponding equations from CT (section III B 2). We follow the same procedure employed in Ref. [9].

\section{AS Bridge Profiles from MD Simulations}

The AS bridge profiles at fixed height $h \leq h_{S}$ are determined from 2000 snapshots saved every 1 ps during the MD simulation. Snapshots are taken over the last 2 ns of the simulated time $\Delta t_{\text {sim }}$. For each snapshot, we first define a $z$-axis passing through the center of mass of the AS bridge, perpendicular to the walls. The AS bridge is then covered with overlapping slabs of thickness $5 \AA$ parallel to the wall(s) and shifted vertically by $2.5 \AA$ with respect to each other. For each slab, centered at height $z$ [see Figure 1], we calculate the average density $\rho_{\text {slab }}(r)$ as function of the distance $r$ from the $z$-axis. $\rho_{\text {slab }}(r)$ is roughly constant within the AS bridge and it decays abruptly to practically zero in the vapor phase. Hence, we define the bridge radius at height $z, r_{\text {prof }}(z)$, as the distance $r$ at which $\rho_{\text {slab }}(r)=\rho_{0}=0.2 \mathrm{~g} / \mathrm{cm}^{3}$ (our results are not sensitive to slight variations in $\rho_{0}$ ). The function $r_{\text {prof }}(z)$ provides the 
AS bridge profile. The AS bridge must be symmetric with respect to its middle-height point (i.e., the bridge neck) located at $z=0$ [Figure 1]. Accordingly, we take the average of $r_{\text {prof }}(z)$ and $r_{\text {prof }}(-z)$ and report the profile only for $0 \leq z \leq h / 2$.

A similar procedure is followed to calculate the profiles of unstable AS bridges $(h>$ $\left.h_{S}\right)$. However, since at the rupture heights $h_{\mathrm{C}^{\prime}}$ and $h_{\mathrm{C}}$ the AS bridges are not necessarily symmetric, we calculate the AS bridge profile for all $-h / 2 \leq z / 2$, i.e., without averaging over $r_{\text {prof }}(z)$ and $r_{\text {prof }}(-z)$. In addition, since in these cases the AS bridges evolve continuously with time, we calculate the profiles in short time intervals of $0.1 \mathrm{~ns}$ (from 100 snapshots saved every $1 \mathrm{ps}$ ). This allows us to follow the evolution of the AS bridge profile with time until its rupture.

To better describe the AS bridge rupture mechanism, we introduce two characteristic times, $\tau_{s}$ and $\tau_{r}$. $\tau_{s}$ is the time for the bridge to become asymmetric $\left(z_{0} \neq 0\right)$ and to start to break; $\tau_{r}$ is time at which the AS bridge rupture occurs. The time $\tau_{\mathrm{r}}$ is calculated from the configurations saved during the MD simulation. Specifically, for each snapshot, we count the number of water molecules inside the $5 \AA$-slabs. The first snapshot with an empty slab defines the time $\tau_{\mathrm{r}}$ in at which the AS bridge breaks.

\section{Axis symmetric Bridge Profiles from Capillarity Theory}

The theoretical profiles $r(z)$ of the AS bridges are obtained from eq 2 by fitting the corresponding profile obtained from MD simulations. The theoretical profiles are defined solely by the parameters $\left(H, r_{0}\right)$. In order to identify the parameters that best fit the simulation profiles we use the following procedure. (i) Based on the MD simulations AS bridge profile, we define a reasonable range for the fitting parameters $\left(H, r_{0}\right)$. We set these parameters to the corresponding lowest values to be explored and calculate the theoretical profiles $r(z)$ using eq 2. (ii) For each point $i$ of the AS bridge profile, $\left(r_{i}, z_{i}\right)$, obtained from the MD simulation, we calculate the corresponding distance $d_{i}$ to the theoretical profile $r(z)$. Specifically, for each point $\left(r_{i}, z_{i}\right)$ we find the line that intersects the curve $r(z)$ at a right angle and measure the distance between the crossing point and point $\left(r_{i}, z_{i}\right)$. (iii) We calculate the error between the theoretical and MD simulation profile as,

$$
\epsilon=\sqrt{\frac{1}{N p} \sum_{i=1}^{N p} d_{i}^{2}}
$$


where $N p$ is the number of points of the bridge profile obtained from the MD simulation. (iv) We change the parameters $\left(H, r_{0}\right)$ by small increments and repeat steps (ii)-(iv) until the whole range of the parameters is covered. For each set of values $\left(H, r_{0}\right)$ we obtain a value of $\epsilon$. The set of parameters for which $\epsilon$ is minimum provides together with eq 2 the theoretical AS bridge profile.

We note that knowledge of the parameters $\left(H, r_{0}\right)$ allows one to calculate any geometrical property of the AS bridges. For example, the contact angle for the AS bridges is obtained from the derivative of the profile given by eq 2 evaluated at $z= \pm h / 2$, i.e. at one of the wall surface. Similarly, from the numerical profile $r(z)$, we are able to calculate the theoretical values for the AS bridge volume $\Omega$, liquid-gas interface area $A_{L G}$, and liquid-solid interface area $A_{L S}$.

\section{RESULTS}

We present our results in two separate sections. In section IV A, we study the AS bridges before their rupture occur. This includes the stable AS bridges $\left(h \leq h_{S}\right)$ that do not break during the whole simulation time $\Delta t_{\text {sim }}$ and unstable bridges at the rupture walls separation $\left(h=h_{C}, h_{C^{\prime}}\right)$ that break but only after a sufficiently long time window that allows for the calculation of the bridge profile and the forces/pressures on the walls. We consider all surface polarities $0 \leq k \leq 0.67$; values of $h$ are in the range $50-75 \AA$. The aim of section IV A is to compare the predictions of CT (bridge profile and force induced on the walls) with the results from MD simulations. This study extends our previous work [9] where CT predictions were confirmed for nanoscale droplets and bridges at fixed $h=50 \AA$. The AS bridges of Ref. [9] are at least $4 \mathrm{~nm}$-thick. By increasing $h$, we are able to test CT to even smaller scales. We find that CT holds for all the capillary bridges studied here. This is remarkable given the small dimensions of our AS bridges, for example, the radius of the capillary bridge neck can be as small as $r_{0} \approx 10 \AA$, approximately three water molecules in length.

In section IV B, we focus on the AS bridge rupture $\left(h>h_{S}\right)$ at the critical heights $h_{C}$ and $h_{C^{\prime}}$ for all surfaces studied. Specifically, we compare the predictions of CT for the critical walls separation at which the bridge breaks ( $h_{\max }$, see eqs 17 and 18 ) with the corresponding values obtained from MD simulations $\left(h_{C}\right.$ and $\left.h_{C^{\prime}}\right)$. We also study whether the capillary bridges break into one or two (symmetric/asymmetric) droplets and how this 
rupture mechanism depends on the surface hydrophobicity/hydrophilicity. In particular, we test whether the results from MD are in agreement with CT. We find that the agreement between CT and simulations is, again, remarkable.

\section{A. Axis Symmetric bridges profiles and forces induced on the walls}

CT predicts that stable AS bridges are symmetric relative to the origin, see Figure 1. Our MD simulations confirm that this is indeed the case for the nanoscale AS bridges in the stable domain, $h \leq h_{S}$. However, at the critical walls separations $h_{C}$ and $h_{C^{\prime}}$, the AS bridges evolve with time and, depending on the surface polarity, they may become asymmetric. In these cases, we report the properties of the AS bridges during the time $\tau_{S}<\Delta t_{\text {sim }}$ where CT predicts the AS bridge to be symmetric and stable.

Capillary bridges profiles obtained from MD simulations, for selected hydrophobic/hydrophilic surfaces $(k=0.0,0.4,0.5$ and 0.66) are shown in Figure 2(a)-(d) [the profiles for all the surface polarities studied are presented in the Supplementary Information (SI)]. Included in Figure 2(a)-(d) are the profiles from CT (eq 2) that fit the MD simulation results. The agreement between CT and MD simulations is remarkable for all surface hydrophobicity/hydrophilicity and walls separations. The best fitting parameters $\left(H, r_{0}\right)$ in eq 2 for all the surfaces studied are given in Tables I-IV. Table V includes the quantities relevant to the AS bridge rupture process, such as the rupture walls separation and the characteristic times $\tau_{r}$ and $\tau_{s}$, for all the surfaces considered. The unstable profiles included in Figure 2(a)-(d) and SI correspond to the surfaces with polarities $k$ and at walls separations $h$ indicated in Table $\mathrm{V}$ for which $\tau_{S}>0$.

From the fitting parameters shown in Tables I-IV, we can perform additional tests of CT at the nanoscale. Specifically, CT assumes that the contact angle of water depends solely on the surface hydrophobicity/hydrophilicity and hence, that it is independent of the AS bridge dimensions, such as the AS bridge's height $h$. We confirm that this assumption holds for the studied AS bridges. Figure 5(a) shows that indeed $\theta_{c}$ is practically independent of $h$ for all surfaces considered. The values of $\theta_{c}(h)$ deviate by no more than $3-4^{0}$ from the corresponding average which is the typical uncertainty of contact angles measured in computer simulations of nanoscale droplets (see e.g., Ref. [33]). The contact angles for all surface studied, averaged over $h$, are reported in Figure 5(b). Not surprisingly, our 
values of $\theta_{c}$ are in agreement with the corresponding values reported in our previous work Ref. [9] based on nanoscale droplets and capillary bridges in contact with the same surfaces considered here (in Ref. [9], $h=50 \AA$ ). Interestingly, we note that in the comparison of the AS bridge profiles from CT and MD simulations we did not include any line tension. It follows that for the present nanoscale AS bridges, line tensions play a minor role (see also Ref. [9]).

Knowledge of the theoretical profiles, defined by the fitting parameters $\left(H, r_{0}\right)$ in Tables I$\mathrm{IV}$, allows us to calculate geometrical properties of the AS bridges, such as the areas of the liquid-solid and liquid-gas interfaces $\left(A_{L S}\right.$ and $\left.A_{L G}\right)$, and the volume of the capillary bridges $\Omega$. These properties are shown in Figures $6(\mathrm{a})-(\mathrm{c})$ for all surfaces considered. $A_{L S}$ and $A_{L G}$ both vary as the AS bridge is stretched. Specifically, $A_{L G}$ increases monotonically with increasing $h$ and it varies by up to $\approx 15 \%$ for the surfaces with $k \leq 0.6$ and up to $25 \%$ for $k=0.65-0.67$. Instead, $A_{L S}$ may increase or decrease during the stretching process depending on the surface polarity. $A_{L S}$ decreases by up to $15-17 \%$ for the surfaces with $k \leq 0.6$; and increases by up to $28 \%$ for the surfaces with $k=0.65-0.67$. Interestingly, we find that the volume of all the AS bridges considered is rather constant. $\Omega(h)$ exhibits fluctuations for all surfaces studied, however, the standard deviation of $\Omega$ is within $3.2 \%$ of the corresponding average.

Next, we focus on the calculation of the force and pressure that the AS bridge exerts on the walls at different values of $h$ and for the target surface polarities $k$. The forces exerted on the walls by the AS bridge are calculated directly from our MD simulations. Specifically, during the MD simulations, we calculate the sum of the Coulomb and LennardJones forces between all water molecules and all atoms that belongs to each wall. We evaluate the components $F_{x}, F_{y}$, and $F_{z}$ of the total force on each wall averaged over time. The time averages of $F_{x}$ and $F_{y}$ converge to zero for large times, as expected, and hence, their deviations from zero provide an estimation of the force error bars. In addition, due to the symmetry of the system, we average the normal components of the force acting on the two walls: $F_{z}=\left(\vec{F}_{1} \bullet \breve{n}_{1}+\vec{F}_{2} \bullet \breve{n}_{2}\right) / 2$, where $\vec{F}_{i}$ is the force acting on wall $i=1,2$ and $\breve{n}_{i}$ is a unit vector perpendicular to wall $i$, pointing towards the AS bridge. It follows that if $F_{z}>0\left(F_{z}<0\right)$ then the AS bridge induces an effective atractive (repulsive) force between the walls. We note that from the calculated $F_{z}$, we are able to measure other properties, such as the liquid-vapor surface tension of SPC/E water model and the pressure inside the 
water AS bridges.

We first calculate the liquid-vapor surface tension using the net forces obtained from MD simulations and the corresponding prediction from CT given in eq 7. Figure 7a shows the forces obtained from MD simulations, for all wall separations and surface polarities studied, as function of the parameter $C(k)$. Our data clearly indicates that $F_{z} \propto C(k)$ (dashedline) in agreement with eq 7. Small deviations in the MD simulation data are present, for example, for surface polarities $k=0.65,0.66$ and 0.67 . For these surface polarities, however, the AS bridges are close to their critical heights (i.e., $h=50-60 \AA$ and $h_{C}, h_{C^{\prime}} \approx 60 \AA$ ) and hence, fluctuations are not unexpected.

Eq 7 indicates that the slope of the dashed-line in Figure 7(a) should be $2 \pi \gamma$. Using this expression we obtain $\gamma=0.053 \pm 0.002 \mathrm{~N} / \mathrm{m}$. This value of $\gamma$ is consistent with the values of the liquid-vapor surface tension of SPC/E water available in the literature $[27,28]$ and it is also in agreement with the value of $\gamma$ calculated independently using the Kirkwood-Buff method [9].

A more detailed comparison of the forces calculated from MD simulations and CT is included in Figure $7(\mathrm{~b})$ where $F_{z}$ is shown as function of $h$. We include the (equivalent) predictions from CT given eqs 7 and 14. This is important since eq 7 requires only access to the parameters $\left(H, r_{0}\right)$ of Tables I-IV. Instead, eq 14 requieres the calculation of $\Omega$ and $\theta_{c}$, and is based on elliptical integrals. The results of Figure $7(\mathrm{~b})$ clearly show that both expressions from CT (eqs 7 and 14) are equivalent, as one would heave expected. In particular, they are consistent with the results from MD simulations. Therefore, it follows that CT is able to predict not only the geometry of nanoscale AS bridges but their thermodynamic properties, such as the forces on the walls. Again, we note that our nanoscale AS bridges are surprisingly small, with neck radii as small as $\approx 10 \AA$. For comparison, we note that the typical water liquid-vapor interface (at $T \approx 300 \mathrm{~K}$ ) is $\geq 8-10 \AA[40,41]$, i.e., comparable to the minimum values of $r_{0}$ for the studied AS bridges.

The force on the walls is the sum of the force produced by the liquid-vapor interface of the AS bridge (eq 4) and the force due to the Laplace pressure within the AS bridge (Laplace force, eq 5). $F_{\gamma}$ and $F_{P}$ are shown in Figures $7(\mathrm{c})$ and $(\mathrm{d})$, respectively, for all $h$ and $k$ studied. While $F_{\gamma}$ is always positive, as predicted by eq $4, F_{P}$ can be either positive or negative, see eq 5 . In other words, $F_{\gamma}$ always induces an effective attraction between the walls. Instead, for the AS bridges studied, $F_{P}$ induces an effective attraction between the 
walls only for surface polarities $k \geq 0.65$ and approximately $h<50-55 \AA$; otherwise, $F_{P}$ is repulsive, independently of the surface hydophobicities/hydrophilicities. As we will show below, the finding that $F_{P}$ can be attractive is unusual only possible at the nanoscale, and it indicates that the pressure of the AS bridge is negative.

We note that Figure $7(\mathrm{c})-(\mathrm{d})$ include, respectively, the prediction from CT for $\left(F_{\gamma}\right.$ eq 4$)$ and $\left(F_{P}\right.$ eq 5$)$ evaluated by two different approaches. In one case (cross symbols $\times$ ), we calculate $r_{b}$ from the theoretical profile defined by the parameters $\left(H, r_{0}\right)$ given in Tables IIV. In the second approach, $r_{b}$ is obtained from eq 15 which follows by evaluating elliptical integrals (dashed lines). In all cases, Figures 7(b)-(d), we show the value of the resultant force and its components up to the maximum height at which the AS bridges are expected to be stable, based on CT. In Figures $7(\mathrm{~b})-(\mathrm{d})$, both approaches provide consistent values for $F_{\gamma}, F_{P}$ and the net force $F_{z}$.

We conclude this section by discussing the Laplace pressure within the AS bridges. Figure 8 shows $P$ as function of $h$ and for all surface polarities $k$ studied. The Laplace pressure is calculated from MD simulations (dots) using eq 9 . Specifically, we use eq 9 with $F_{z}$ obtained directly from the MD simulations, as explained above, and $r_{b}$ being calculated from the theoretical profile of the AS bridge using the parameters of Tables I- IV. We compare the MD simulation values of $P$ with the corresponding theoretical values. The CT predictions are obtained from two different approaches. In one case, $P$ is calculated from the Young-Laplace equation (eq 1), considering that the pressure outside the water bridge is equal to zero and using the value of $H$ from Tables I-IV (cross symbols). In the second approach, we use the CT expression given in eq 16, based on elliptical integrals (dashed lines). In both cases, we use $\gamma=0.053 \pm 0.002 \mathrm{~N} / \mathrm{m}$. As expected, the pressure calculated following both approached are consistent with one another, validating both methods.

Figure 8 shows a remarkable agreement between CT and MD simulations. One of the most interesting result from this figure is that $P$ can be negative, a behavior not found in macroscale capillary bridges. This is due to the very small values of the neck radius accessible in nanoscale AS bridges which determine the sign of $H$ in Young-Laplace equation (eq 1). Interesting, the range of $P$ in Figure 8 is very large, expanding 275 atm. In particular, we note that stretching an AS bridge can lead to a considerable increase in Laplace pressure, independently of the surface hydrophobicity/hydrophilicity. For example, in the case of $k=0.6, P$ increases by roughly $100 \%$ when $h$ varies from 5 to $7 \mathrm{~nm}$. 


\section{B. Rupture mechanism and Limit of Stability of Axis Symmetric Bridges}

In this section, we analyse the behavior of AS bridges at the critical walls separation during their rupture. Figure 3(a)-(d) show, respectively, the time evolution of the AS bridges in contact with surfaces of polarity $k=0.0,0.4,0.5$ and 0.66 at $h=h_{C^{\prime}}$ (the corresponding figures for all the surface polarities studied are include in the SI). Each line in the panels of Figure 3 represents one AS bridge profile averaged of 0.1 ns (see section III B 1) and the gradient color, from blue to magenta, shows the evolution of the AS bridge with time. The AS bridges evolve monotonically with time and their rupture is rather fast. The AS bridges break into a single droplet attached to one of the walls for $k \leq 0.4$ and they split into two droplets, one attached to each wall, for $k>0.4$. Interestingly, $\theta_{c} \approx 85^{\circ}$ for $k=0.4$ which is close to the critical value $\theta_{c}=90^{\circ}$ for $k \approx 0.37$ (Figure $5 \mathrm{~b}$ ). Hence, it is tempting to conclude that AS bridges break into one droplet for hydrophobic surfaces and into two droplets for hydrophilic surfaces. Snapshots of the AS bridges at the rupture time $\tau_{\mathrm{r}}$, for the surface polarity discussed here, are shown in Figure 4(a)-(d) (the snapshots at time $\tau_{\mathrm{r}}$ for all the surface polarities studied are included in the SI).

As discussed in section II B, CT predicts that AS bridges should break into two identical droplets only for contact angles $\theta_{c}<31^{\circ}$. Next, we test whether our MD simulations are in agreement with this prediction. To do this, we focus on surfaces with $k>0.4$ for which the AS bridges break into two droplets. We estimate the volume of each droplet by counting the number of water molecules at $t=\tau_{\mathrm{r}}$, (in the snapshots shown in Figure 4 ), that are above and below the empty gap. We report $\left|\Delta N_{\text {droplets }}\right| / N$, where $\Delta N_{\text {droplets }}$ is the difference in the number of water molecules of the droplets. It follows that $0 \leq\left|\Delta N_{\text {droplets }}\right| / N \leq 1$ and that the AS bridge breaks into a single droplet for $\left|\Delta N_{\text {droplets }}\right| / N=1$ while $\left|\Delta N_{\text {droplets }}\right| / N=0$ if the AS bridge breaks into two identical droplets (symmetric rupture). Table $\mathrm{V}$ includes the calculated $\left|\Delta N_{\text {droplets }}\right| / N$ for all surface polarities considered and Figure 9 shows $\left|\Delta N_{\text {droplets }}\right| / N$ as function of $\theta_{c}$. Although $\left|\Delta N_{\text {droplets }}\right| / N$ is noisy, the results from MD simulations are close with the CT predictions. Specifically, MD simulations indicate that $\left|\Delta N_{\text {droplets }}\right| / N \approx 0$ for approximately $\theta_{c}<45^{\circ}$, slightly above the CT value of $\theta_{c}=31^{\circ}$.

Next, we compare the critical rupture height obtained from the MD simulations $\left(h_{\mathrm{c}}, h_{\mathrm{c}^{\prime}}\right)$ with the corresponding prediction from CT (eqs 17 and 18). In Figure 10, we show the normalized rupture height, $h_{\max } / 2 /\langle\Omega\rangle$, as a function of $\theta_{c}$ from $\mathrm{CT}$ (solid line) and MD 
simulations (cross symbols). At a given $\theta_{c}$, we use the corresponding AS bridge volume averaged over all values of $h$; see Table VI. For comparison, we also include $h_{S} / 2 /\langle\Omega\rangle$. The main point of Figure 10 is that there is a reasonable agreement between CT theory and MD simulations although some deviations are observable.

Fluctuations are expected to play a relevant role at the nanoscale. In the case of AS bridges, one may expect that fluctuations in the AS bridge profile may become more pronounced as the critical walls separation is approached. In order to study the fluctuations of the AS bridge profiles as $h$ increases, we calculate the average position of the AS bridge neck, $z_{0}$, as function of $h$; see Figure 11(a). Interestingly, we find that the behavior of $z_{0}$ with increasing $h$ depends on the hydophobicity/hydrophilicity of the surface. Specifically, for hydrophilic surfaces with polarity $k=0.65-0.67, z_{0}(h) \sim 0 \pm 5 \AA$. At these surface polarities, the bridge breaks into 2 identical droplets and hence, $z_{0}$ barely fluctuates as the critical walls separation is approached. Instead, for hydrophobic surfaces, e.g. $k=0.1$, $z_{0}(h) \sim 0 \pm 5 \AA$ only for $h<65 \AA$. As the critical walls separation is approached, these bridges break into one droplet and hence, $z_{0}(h)$ fluctuates considerably with increasing $h$; for example, for $h>65 \AA, z_{0}$ can deviate by as much as $10-25 \AA$ from $z=0$.

\section{SUMMARY}

We study the capillarity at the nanoscale using the model of water AS bridges and performing atomistic MD simulations. The AS bridges are in contact with a family of silica surfaces, and we increase the distance between the silica surface until the rupture of AS bridges. The comparison between the results from MD simulations and the macroscopic CT predictions (fitting and exactly calculation) shows good agreement.

In the first study, we analyse the AS bridges in stability regions of the phase diagram $\left(\theta_{c}, h\right)$, for $h \leq h_{S}$. Briefly, we observe that the prediction of profile from macroscopic CT (eq 2) fits very well the MD profile. We calculate other AS bridge properties from the fitting of profile and from the average of adhesion force on walls. We observe that the contact angle is constant for all height, as expected. The surface tension of the SPC/E water model is in agreement with the literature. The capillary adhesion force $F_{z}=F_{\gamma}+F_{P}$ reproduce well the resultant force, obtained from the sum of atom-molecule interaction in MD simulation. The Laplace pressure, which is also calculated from the resultant force, is in agreement with 
the prediction of pressure calculated from Yaung-Laplace equation.

In the second study, we analyse the AS bridge in unstable regions of the phase diagram $\left(\theta_{c}, h\right)$, for $h>h_{S}$, i.e. $h_{C^{\prime}}$ and $h_{C}\left(h_{C^{\prime}}<h_{C}\right)$. First, the critical heights that we study $\left(h_{C^{\prime}}\right.$ and $h_{C}$ ) are close to the theoretical critical height. We observe that even for the region of unstable AS bridge, the fitting profile is able to predict the MD simulation results for force and Laplace pressure. The analysis using fitting may be a powerful tool to study systems in unstable conditions. We observe that close to the critical height the rupture time $\tau_{r}$ is higher than for distance above the critical height. As predicted by macroscopic CT, the MD simulations shows that the AS bridge may break into one or two droplets, equal or unequal, depending on the contact angle of the surface of walls. We observe that contact angles lower than $50.4^{\circ}$ the AS bridge starts to break into symmetrically droplets. This value is very close to $31^{\circ}$, which is predicted by the macroscopic TC. This difference may occur due to the fluctuation on AS bridge profile.

Thereby, our work provide an other strong test to the capillary theory in the nanoscale. It shows that for distance higher than $50 \AA$ the CT theory may be a useful tool to study interfaces at the nanoscale, even for complex problems like the rupture of AS bridges.

[1] de Gennes, P.; Brochard-Wyart, F. and Qur, D. Capillarity and Wetting Phenomena: Drops, Bubbles, Pearls, Waves; Springer, 2004.

[2] Langbein, D. Capillary surfaces: shape-stability-dynamics, in particular under weightlessness; Springer, 2002.

[3] Heady, R.; Cahn, J. An analysis of the capillary forces in liquid-phase sintering of spherical particles Metall. Mater. Trans. B 1970, 1, 185-189.

[4] Niven, R. K. Force stability of pore-scale fluid bridges and ganglia in axisymmetric and nonaxisymmetric configurations. J. Petrol. Sci. Eng., 2006, 52, 1-18.

[5] Alencar, A. M.; Wolfe, E.; Buldyrev, S. V. Monte Carlo Simulation of Liquid Bridge Rupture: Application to Lung Physiology. Phys. Rev. E 2006, 74, 026311.

[6] Almeida, A. B.; Buldyrev, S. V.; Alencar, A. M. Crackling Sound Generation During the Formation of Liquid Bridges: A Lattice Gas Model. Physica A 2013, 392, 3409-3416.

[7] Yang, L.; Tu, Y.-s.; Tan, H.-l. Influence of Atomic Force Microscope (AFM) Probe Shape on 
Adhesion Force Measured in Humidity Environment. Appl. Math. Mech-ENGL 2014, 1-8.

[8] van Honschoten, J. W.; Brunets, N.; Tas, N. R. Capillarity at the nanoscale. Chem. Soc. Rev. 2010, 39, 1096-1114.

[9] Giovambattista, N; Almeida, A. B.; Alencar, A. M.; Buldyrev S. V. Validation of Capillarity Theory at the Nanometer Scale by Atomistic Computer Simulations of Water Droplets and Bridges in Contact with Hydrophobic and Hydrophilic Surfaces. J. Phys. Chem. C, 2016, 120, 1597-1608.

[10] Gravelle, S.; Ybert, C.; Bocquet, L.; Joly, L. Anomalous capillary filling and wettability reversal in nanochannels. Phys. Rev. E 2016, 93, 033123.

[11] Nosonovsky, M.; Bhushan, B. Phase behavior of capillary bridges: towards nanoscale water phase diagram Phys. Chem. Chem. Phys. 2008, 10, 2137-2144.

[12] Yang, S. H.; Nosonovsky, M.; Zhang, H.; Chung, K.-H. Nanoscale Water Capillary Bridges under Deeply Negative Pressure. Chem. Phys. Lett. 2008, 451, 88-92.

[13] Kelly, S.; Torres-Verdin, C.; Balhoff, M. T. Anomalous liquid imbibition at the nanoscale: the critical role of interfacial deformations. Nanoscale 2016, 8, 2751-2767.

[14] Weeks, B. L.; Vaughn, M. W.; DeYoreo, J. J. Direct Imaging of Meniscus Formation in Atomic Force Microscopy Using Environmental Scanning Electron Microscopy. Langmuir 2005, 21, 8096-8098.

[15] Bak, W.; Sung, B.; Kim, J.; Kwon, S.; Kim, B.; Jhe, W. Time-resolved observation of thermally activated rupture of a capillary-condensed water nanobridge. Appl. Phys. Lett. 2015, 106, 013102.

[16] Yang, L.; Hu, J.; Bai, K. Capillary and van der Waals force between microparticles with different sizes in humid air. J. Adhes. Sci. Technol 2016, 30, 566-578.

[17] Butt, H. J.; Kappl, M. Normal capillary forces. Adv. Colloid Interfac 2009, 146, 48-60.

[18] Men, Y.; Zhang, X.; Wang, W. Capillary liquid bridges in atomic force microscopy: Formation, rupture, and hysteresis. J. Chem. Phys. 2009, 131, 184702.

[19] Cheng, S.; Robbins, M. O. Capillary adhesion at the nanometer scale. Phys. Rev. E, 2014, 89, 062402.

[20] Valenzuela, G. E.; Saavedra, J. H.; Rozas, R. E.; Toledo, P. G. Force exerted by a nanoscale capillary water bridge between two planar substrates. Phys. Chem. Chem. Phys. 2016, 18, $11176-11183$. 
[21] Plimpton, S. Fast Parallel Algorithms for Short-Range Molecular Dynamics. J. Comp. Phys. 1995, 117, 1-19.

[22] Berendsen, H. J. C.; Grigera, J. R.; Stroatsma, T. P. The Missing Term in Effective Pair Potentials. J. Phys. Chem. 1987, 91, 6269-6271.

[23] Hockney, R. W.; Eastwood, J. W. Computer Simulation Using Particles; Adam Hilger: New York, 1989.

[24] Shinoda, W.; Shiga, M.; Mikami, M. Rapid Estimation of Elastic Constants by Molecular Dynamics Simulation Under Constant Stress. Phys. Rev. B 2004, 69, 134103.

[25] Giovambattista, N.; Rossky, P. J.; Debenedetti, P. G. Effect of Pressure on the Phase Behavior and Structure of Water Confined Between Nanoscale Hydrophobic and Hydrophilic Plates. Phys. Rev. E 2006, 73, 041604.

[26] Giovambattista, N.; Debenedetti, P. G.; Rossky, P. J. Effect of Surface Polarity on Water Contact Angle and Interfacial Hydration Structure. J. Phys. Chem. B 2007, 111, 9581-9587.

[27] Vega, C.; de Miguel, E. Surface Tension of the Most Popular Models of Water by Using the Test-Area Simulation Method. J. Chem. Phys. 2007, 126, 154707.

[28] Ismail, A. E.; Grest, G. S.; Stevens, M. J. Capillary Waves at the Liquid-Vapor Interface and the Surface Tension of Water. J. Chem. Phys. 2006, 125, 014702.

[29] Vogel, T. I. Stability of a Liquid Drop Trapped between Two Parallel Planes II: General Contact Angles. SIAM J. Appl. Math. 1989, 49, 1009-1028.

[30] Vogel, T. I. Stability of a liquid drop trapped between two parallel planes. SIAM J. Appl. Math. 1987, 47, 516-525.

[31] Athanassenas , M. A variational problem for constant mean curvature surfaces with free boundary. J. Reine Angew. Math. 1987, 1987, 97-107.

[32] Zhou, L. On Stability Of A Catenoidal Liquid Bridge Pac. J. Math 178, 1997, 185-198.

[33] J. Wang, D. Bratko1, and A. Luzar, Proc. Natl. Acad. Sci. USA 108, 2011, 6374-6379.

[34] Maeda, N.; Israelachvili, J. N.; Kohonen, M. M. Evaporation and instabilities of microscopic capillary bridges. Proc. Natl. Acad. Sci. 2003, 100, 803-808.

[35] Kralchevsky, P. A.; Denkov, N. D. Capillary forces and structuring in layers of colloid particles. Curr. Opin. Colloid Interface Sci. 2001, 6, 383-401.

[36] Leroch, S.; Wendland, M. Influence of Capillary Bridge Formation onto the Silica Nanoparticle Interaction Studied by Grand Canonical Monte Carlo Simulations. Langmuir 2013, 29, 12410- 
12420.

[37] Sung, B.; Kim, J.; Stambaugh, C.; Chang, S. J.; Jhe, W. Direct measurement of activation time and nucleation rate in capillary-condensed water nanomeniscus. Appl. Phys. Lett. 2013, $103,213107$.

[38] Eichelsdoerfer, D. J.; Brown, K. A.; Mirkin, C. A. Capillary bridge rupture in dip-pen nanolithography Soft Matter 2014, 10, 5603-5608.

[39] Piner, R. D.; Zhu, J.; Xu, F.; Hong, S.; Mirkin, C. A. "Dip-Pen" Nanolithography. Science 1999, $283,661-663$.

[40] Santiago, R. C.; Giovambattista, N.; Ilhan, A. A.; Pablo, G. D. Structure and energetics of thin film water J. Phys. Chem. C 2011, 115, 4624-4635.

[41] Willard, A. P.; Chandler, D. Instantaneous liquid interfaces J. Phys. Chem. B 2010, 114, $1954-1958$. 
TABLE I: Fitting parameters for the AS bridge profiles using eq $(2) \cdot r_{0}=R_{1}$ and $R_{2}$ are the radii of curvature of the bridge neck (i.e., at its middle-height point) on the $x-y$ plane, respectively [see Figure 1]. $H=\frac{1}{2}\left(\frac{1}{R_{1}}+\frac{1}{R_{2}}\right)$ is the average surface curvature of the bridge, $\theta_{c}$ is the contact angle, and $\epsilon$ is the error of the fitting curve from eq (19). Errors in $r_{0}, R_{1}$ and $R_{2}$ are $\pm 0.05 \AA$.

\begin{tabular}{ccccccccccc}
\hline \hline \multicolumn{1}{c}{ height $=50.0 \AA$} \\
\hline $\mathrm{k}$ & $r_{0}(\AA)$ & $R_{2}(\AA) \mathrm{H}\left(\AA^{-1}\right)$ & $\Theta\left(^{o}\right)$ & $\epsilon(\AA)$ & $r_{0}(\AA)$ & $R_{2}(\AA)$ & $\mathrm{H}\left(\AA^{-1}\right)$ & $\theta_{c}\left({ }^{o}\right)$ & $\epsilon(\AA)$ \\
0.0 & 28.8 & 78.3 & 0.0238 & 107.1 & 0.03 & 27.5 & 92.7 & 0.0236 & 105.0 & 0.04 \\
0.1 & 28.7 & 83.2 & 0.0235 & 106.0 & 0.03 & 27.4 & 96.1 & 0.0234 & 104.5 & 0.04 \\
0.2 & 28.2 & 125.4 & 0.0217 & 100.4 & 0.03 & 27.1 & 135.3 & 0.0221 & 100.1 & 0.04 \\
0.3 & 27.8 & 259.5 & 0.0200 & 94.9 & 0.04 & 26.5 & 503.9 & 0.0201 & 93.3 & 0.04 \\
0.4 & 26.6 & -232.8 & 0.0166 & 84.7 & 0.03 & 25.4 & -249.5 & 0.0177 & 84.8 & 0.03 \\
0.5 & 25.6 & -58.8 & 0.0110 & 69.6 & 0.04 & 24.1 & -61.8 & 0.0126 & 69.9 & 0.03 \\
0.6 & 23.8 & -29.8 & 0.0042 & 50.1 & 0.04 & 22.0 & -30.9 & 0.0066 & 51.2 & 0.04 \\
0.65 & 22.0 & -21.7 & -0.0003 & 34.4 & 0.05 & 19.2 & -30.9 & 0.0012 & 30.8 & 0.07 \\
0.66 & 21.4 & -19.6 & 0.0021 & 27.2 & 0.06 & 19.1 & -30.9 & 0.0012 & 30.5 & 0.06 \\
0.67 & 21.5 & -19.9 & 0.0018 & 28.4 & 0.05 & 18.2 & -30.9 & 0.0003 & 25.8 & 0.06 \\
\hline \hline
\end{tabular}


TABLE II: Fitting parameters for the AS bridge profiles using eq 2. $r_{0}=R_{1}$ and $R_{2}$ are the radii of curvature of the bridge neck (i.e., at its middle-height point) on the $x-y$ plane, respectively [see Figure 1]. $H=\frac{1}{2}\left(\frac{1}{R_{1}}+\frac{1}{R_{2}}\right)$ is the average surface curvature of the bridge, $\theta_{c}$ is the contact angle, and $\epsilon$ is the error of the fitting curve from eq (19). Errors in $r_{0}, R_{1}$ and $R_{2}$ are $\pm 0.05 \AA$. The symbols $*$ and -- show, respectively, the simulations in which the AS bridge did not become symmetric and the one that was not run.

\begin{tabular}{ccccccccccc}
\hline \hline \multicolumn{9}{c}{ height $=60.0 \AA$} \\
\hline $\mathrm{k}$ & $r_{0}(\AA)$ & $R_{2}(\AA) \mathrm{H}\left(\AA^{-1}\right)$ & $\Theta\left(^{o}\right)$ & $\epsilon(\AA)$ & $r_{0}(\AA)$ & $R_{2}(\AA)$ & $\mathrm{H}\left(\AA^{-1}\right)$ & $\theta_{c}\left({ }^{o}\right)$ & $\epsilon(\AA)$ \\
0.0 & 26.5 & 102.7 & 0.0237 & 104.0 & 0.04 & 26.2 & 98.0 & 0.0242 & 105.1 & 0.04 \\
0.1 & 26.6 & 100.5 & 0.0238 & 104.3 & 0.03 & 26.0 & 88.2 & 0.0249 & 106.8 & 0.02 \\
0.2 & 26.2 & 130.9 & 0.0229 & 100.8 & 0.04 & 25.5 & 134.2 & 0.0234 & 100.7 & 0.04 \\
0.3 & 25.6 & 322.1 & 0.0211 & 94.3 & 0.04 & 24.8 & 270.2 & 0.0220 & 95.2 & 0.03 \\
0.4 & 24.2 & -190.2 & 0.0180 & 83.1 & 0.04 & 23.1 & -226.5 & 0.0194 & 84.2 & 0.03 \\
0.5 & 23.0 & -66.8 & 0.0143 & 71.2 & 0.03 & 21.7 & -67.0 & 0.0155 & 71.5 & 0.03 \\
0.6 & 20.0 & -29.1 & 0.0079 & 49.5 & 0.04 & 18.2 & -28.5 & 0.0100 & 50.8 & 0.03 \\
0.65 & 16.2 & -18.9 & 0.0043 & 33.2 & 0.06 & $*$ & $*$ & $*$ & $*$ & $*$ \\
0.66 & 15.2 & -17.0 & 0.0035 & 29.0 & 0.08 & -- & -- & -- & -- & -- \\
0.67 & 14.0 & -15.4 & 0.0032 & 26.1 & 0.08 & -- & -- & -- & -- & -- \\
\hline \hline
\end{tabular}


TABLE III: Fitting parameters for the AS bridge profiles using eq 2. $r_{0}=R_{1}$ and $R_{2}$ are the radii of curvature of the bridge neck (i.e., at its middle-height point) on the $x-y$ plane, respectively [see Figure 1]. $H=\frac{1}{2}\left(\frac{1}{R_{1}}+\frac{1}{R_{2}}\right)$ is the average surface curvature of the bridge, $\theta_{c}$ is the contact angle, and $\epsilon$ is the error of the fitting curve from eq 19. The symbols $*$ and -- show, respectively, the simulations in which the AS bridge did not become symmetric and the one that was not run. Errors in $r_{0}, R_{1}$ and $R_{2}$ are $\pm 0.05 \AA$.

\begin{tabular}{ccccccccccc}
\hline \hline \multicolumn{9}{c}{ height $=70.0 \AA$} \\
\hline $\mathrm{k}$ & $r_{0}(\AA)$ & $R_{2}(\AA)$ & $\mathrm{H}\left(\AA^{-1}\right)$ & $\Theta\left(^{o}\right)$ & $\epsilon(\AA)$ & $r_{0}(\AA)$ & $R_{2}(\AA) \mathrm{H}\left(\AA^{-1}\right)$ & $\theta_{c}\left({ }^{o}\right)$ & $\epsilon(\AA)$ \\
0.0 & 25.5 & 85.5 & 0.0255 & 107.3 & 0.02 & -- & -- & -- & -- & -- \\
0.1 & $*$ & $*$ & $*$ & $*$ & $*$ & -- & -- & -- & -- & -- \\
0.2 & 24.7 & 148.8 & 0.0236 & 99.5 & 0.04 & 24.4 & 122.1 & 0.0246 & 101.4 & 0.03 \\
0.3 & 24.0 & 341.0 & 0.0223 & 94.0 & 0.04 & $*$ & $*$ & $*$ & $*$ & $*$ \\
0.4 & 22.4 & -274.2 & 0.0205 & 85.3 & 0.03 & $*$ & $*$ & $*$ & $*$ & $*$ \\
0.5 & 20.4 & -65.7 & 0.0169 & 71.9 & 0.03 & $*$ & $*$ & $*$ & $*$ & $*$ \\
0.6 & 14.5 & -20.9 & 0.0112 & 47.5 & 0.06 & 9.6 & -14.0 & 0.0162 & 54.7 & 0.05 \\
0.65 & -- & -- & -- & -- & -- & -- & -- & -- & -- & -- \\
0.66 & -- & -- & -- & -- & -- & -- & -- & -- & -- & -- \\
0.67 & -- & -- & -- & -- & -- & -- & -- & -- & -- & -- \\
\hline \hline
\end{tabular}


TABLE IV: Fitting parameters for the AS bridge profiles using eq 2. $r_{0}=R_{1}$ and $R_{2}$ are the radii of curvature of the bridge neck (i.e., at its middle-height point) on the $x-y$ plane, respectively [see Figure 1]. $H=\frac{1}{2}\left(\frac{1}{R_{1}}+\frac{1}{R_{2}}\right)$ is the average surface curvature of the bridge, $\theta_{c}$ is the contact angle, and $\epsilon$ is the error of the fitting curve from eq 19. The symbols $*$ and -- show, respectively, the simulations in which the AS bridge did not become symmetric and the one that was not run. Errors in $r_{0}, R_{1}$ and $R_{2}$ are $\pm 0.05 \AA$.

\begin{tabular}{ccccccc}
\hline \hline $\mathrm{k}$ & height $(\AA)$ & $r_{0}(\AA)$ & $R_{2}(\AA)$ & $\mathrm{H}\left(\AA^{-1}\right)$ & $\Theta\left({ }^{o}\right)$ & $\epsilon(\AA)$ \\
0.0 & 67.5 & 25.5 & 85.5 & 0.0255 & 107.3 & 0.02 \\
0.1 & 67.5 & 25.9 & 120.3 & 0.0235 & 102.2 & 0.02 \\
& 68.75 & $*$ & $*$ & $*$ & $*$ & $*$ \\
0.2 & 72.5 & 24.9 & 114.5 & 0.0245 & 102.6 & 0.05 \\
0.3 & 72.5 & $*$ & $*$ & $*$ & $*$ & $*$ \\
0.4 & 72.5 & $*$ & $*$ & $*$ & $*$ & $*$ \\
0.5 & 72.5 & $*$ & $*$ & $*$ & $*$ & $*$ \\
0.6 & 72.5 & 11.3 & -16.1 & 0.0132 & 48.9 & 0.05 \\
0.65 & 62.5 & $*$ & $*$ & $*$ & $*$ & $*$ \\
0.66 & 57.5 & 17.0 & -17.9 & 0.0016 & 26.5 & 0.03 \\
0.67 & 57.5 & 15.8 & -16.4 & 0.0011 & 22.8 & 0.03 \\
\hline \hline
\end{tabular}


TABLE V: Parameters obtained from the liquid bridge at the rupture height: the normalized absolute difference in the amount of SPC/E water molecules composing the droplets formed over the walls just after the liquid bridge rupture $\left(\Delta N_{\text {droplets }} / N\right)$, the instant of time in which the bridge becomes asymmetric $\left(\tau_{\mathrm{s}}\right)$ and the instant of time in which the bridge breaks $\left(\tau_{\mathrm{r}}\right)$. When the AS bridge gets assymetrical just after the movement of the wall, we consider $\tau_{\mathrm{s}}=0$.

\begin{tabular}{|c|c|c|c|c|c|}
\hline $\mathrm{k}$ & $\theta_{c}\left({ }^{\circ}\right)$ & height $(\AA)$ & $\Delta N_{\text {droplets }} / N$ & $\tau_{\mathrm{s}}(\mathrm{ps})$ & $\tau_{\mathrm{r}}(\mathrm{ps})$ \\
\hline \multirow{2}{*}{0.0} & \multirow{2}{*}{105.6} & 70.0 & 1.000 & 600 & 1234 \\
\hline & & 67.5 & 1.000 & 800 & 1575 \\
\hline \multirow{2}{*}{0.1} & \multirow{2}{*}{104.8} & 70.0 & 1.000 & 0 & 1332 \\
\hline & & 68.75 & 1.000 & 0 & 367 \\
\hline \multirow{2}{*}{0.2} & \multirow{2}{*}{100.8} & 75.0 & 1.000 & 500 & 881 \\
\hline & & 72.5 & 1.000 & 300 & 717 \\
\hline \multirow{2}{*}{0.3} & \multirow{2}{*}{94.3} & 75.0 & 1.000 & 0 & 2094 \\
\hline & & 72.5 & 1.000 & 0 & 889 \\
\hline \multirow{2}{*}{0.4} & \multirow{2}{*}{84.4} & 75.0 & 1.000 & 0 & 2514 \\
\hline & & 72.5 & 1.000 & 0 & 7284 \\
\hline \multirow{2}{*}{0.5} & \multirow{2}{*}{70.8} & 75.0 & 0.873 & 0 & 1402 \\
\hline & & 72.5 & 0.909 & 0 & 4915 \\
\hline \multirow{2}{*}{0.6} & \multirow{2}{*}{50.4} & 75.0 & 0.086 & 150 & 262 \\
\hline & & 72.5 & 0.004 & 350 & 500 \\
\hline \multirow{2}{*}{0.65} & \multirow{2}{*}{32.8} & 65.0 & 0.124 & 0 & 334 \\
\hline & & 62.5 & 0.215 & 4500 & 5687 \\
\hline \multirow{2}{*}{0.66} & \multirow{2}{*}{28.3} & 60.0 & 0.048 & 2500 & 3341 \\
\hline & & 58.75 & --- & --- & --- \\
\hline \multirow{2}{*}{0.67} & \multirow{2}{*}{25.8} & 60.0 & 0.045 & 1800 & 2159 \\
\hline & & 57.5 & 0.149 & 1650 & 18617 \\
\hline
\end{tabular}


TABLE VI: Average of contact angle $\left(\theta_{c}\right)$ and volume $(\Omega)$ of AS bridges as a function of the surface polarity $k$ obtained from the profiles in Figures $2(\mathrm{a})-(\mathrm{d})$ and Figures 1 in SI.

\begin{tabular}{ccc}
\hline \hline $\mathrm{k}$ & $\theta_{c}\left({ }^{\circ}\right)$ & $\Omega\left(\AA^{3}\right)$ \\
0.0 & 105.6 & 118264.8 \\
0.1 & 104.8 & 120076.0 \\
0.2 & 100.8 & 119603.8 \\
0.3 & 94.3 & 118866.0 \\
0.4 & 84.4 & 116493.9 \\
0.5 & 70.8 & 119066.1 \\
0.6 & 50.4 & 121256.0 \\
0.65 & 32.8 & 122326.4 \\
0.66 & 28.3 & 125617.5 \\
0.67 & 25.8 & 127405.2 \\
\hline \hline
\end{tabular}



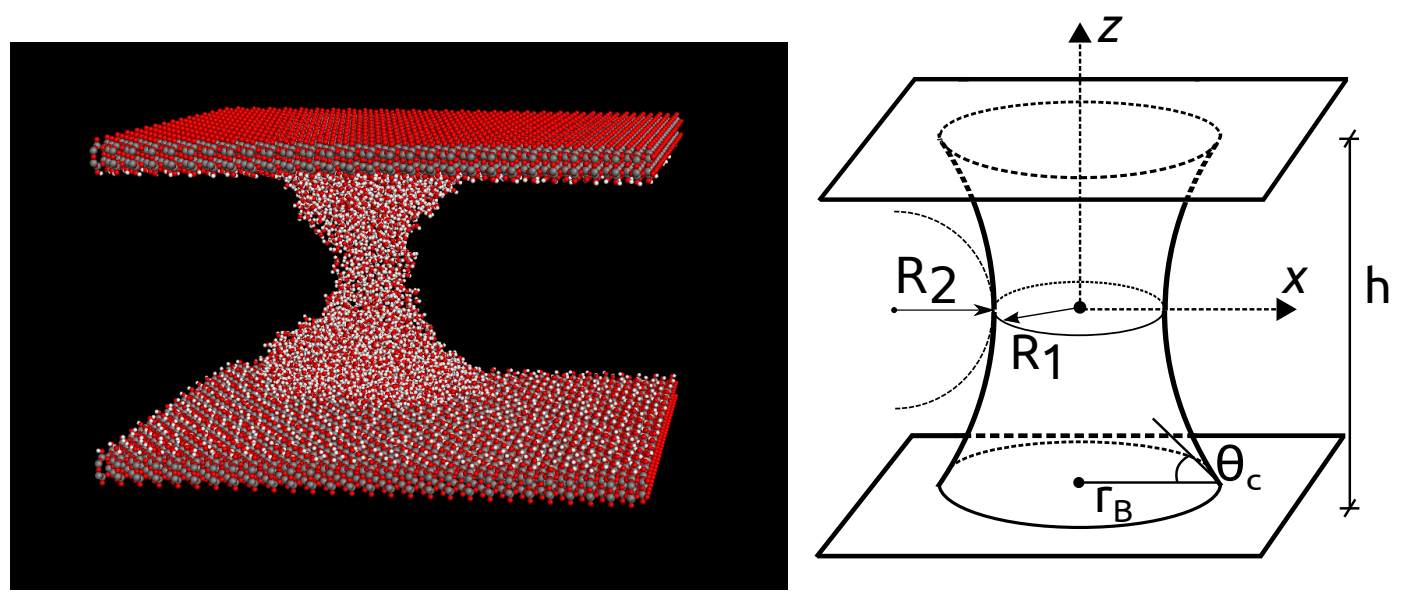

FIG. 1: (Left) Snapshot of a water capillary bridge formed between two hydrophilic surfaces. (Right) Schematic diagram of an AS bridge indicating the relevant parameters used in the present work. $r_{0}=R_{1}$ is the AS bridge radius at $z=0 . R_{1}$ and $R_{2}\left(H=\left(1 / R_{1}+1 / R_{2}\right) / 2\right)$ are the curvature radii of the AS bridge surface. $r_{b}$ is the radius of the AS bridge's base. $\theta_{c}$ is the contact angle. $h$ is the walls separation. 

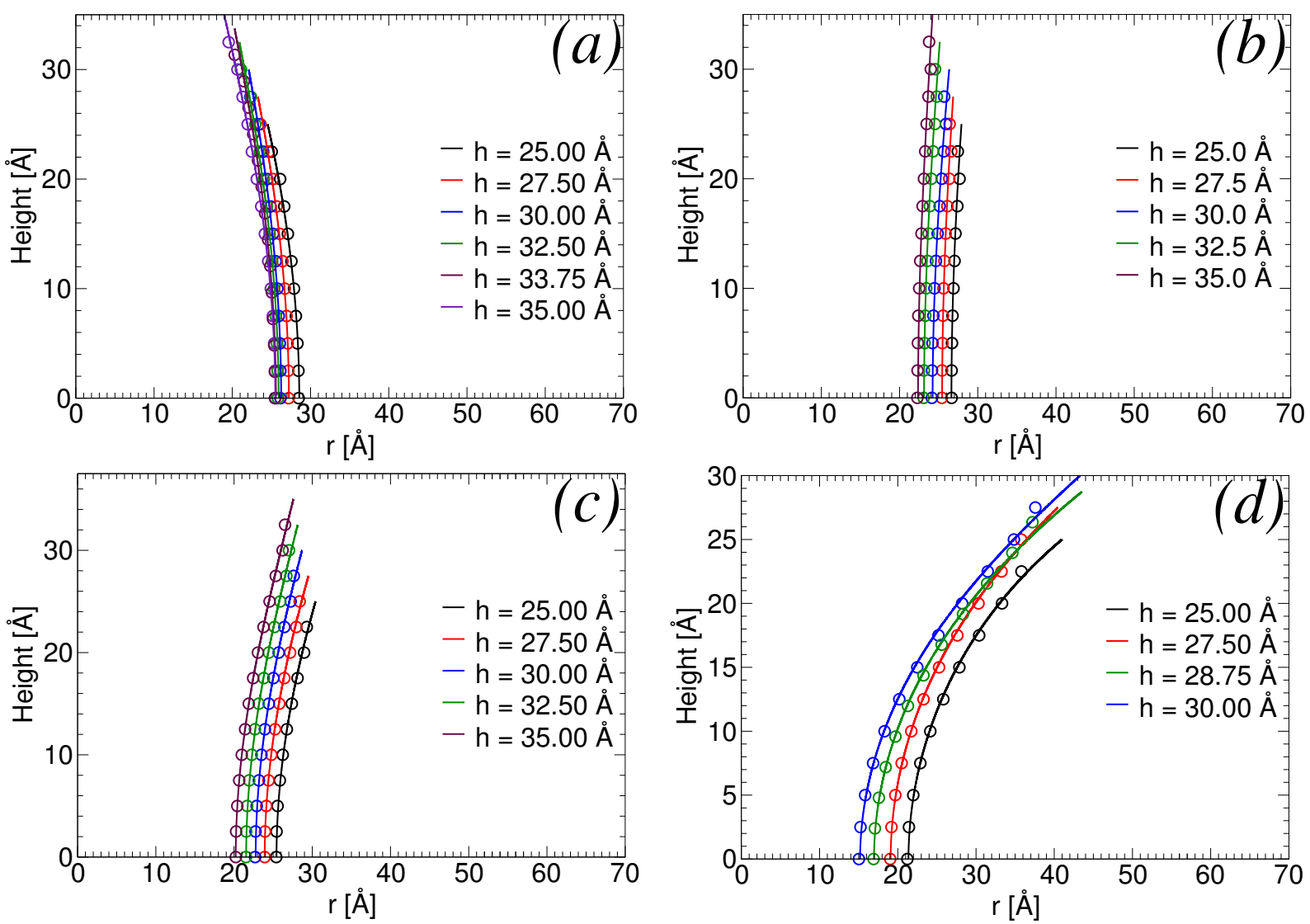

FIG. 2: Average profiles of stable AS bridges, height as a function of radius $r$, calculated from MD simulations (circles), for different separations $h$ between walls. Only the upper half (zí0) of the AS bridge is shown for clarity. The lines are the best fits obtained from CT and using eq 2. (a), (b), (c) and (d) correspond, respectively, to surfaces with polarity $k=0.0,0.4,0.5$ and 0.66 . 

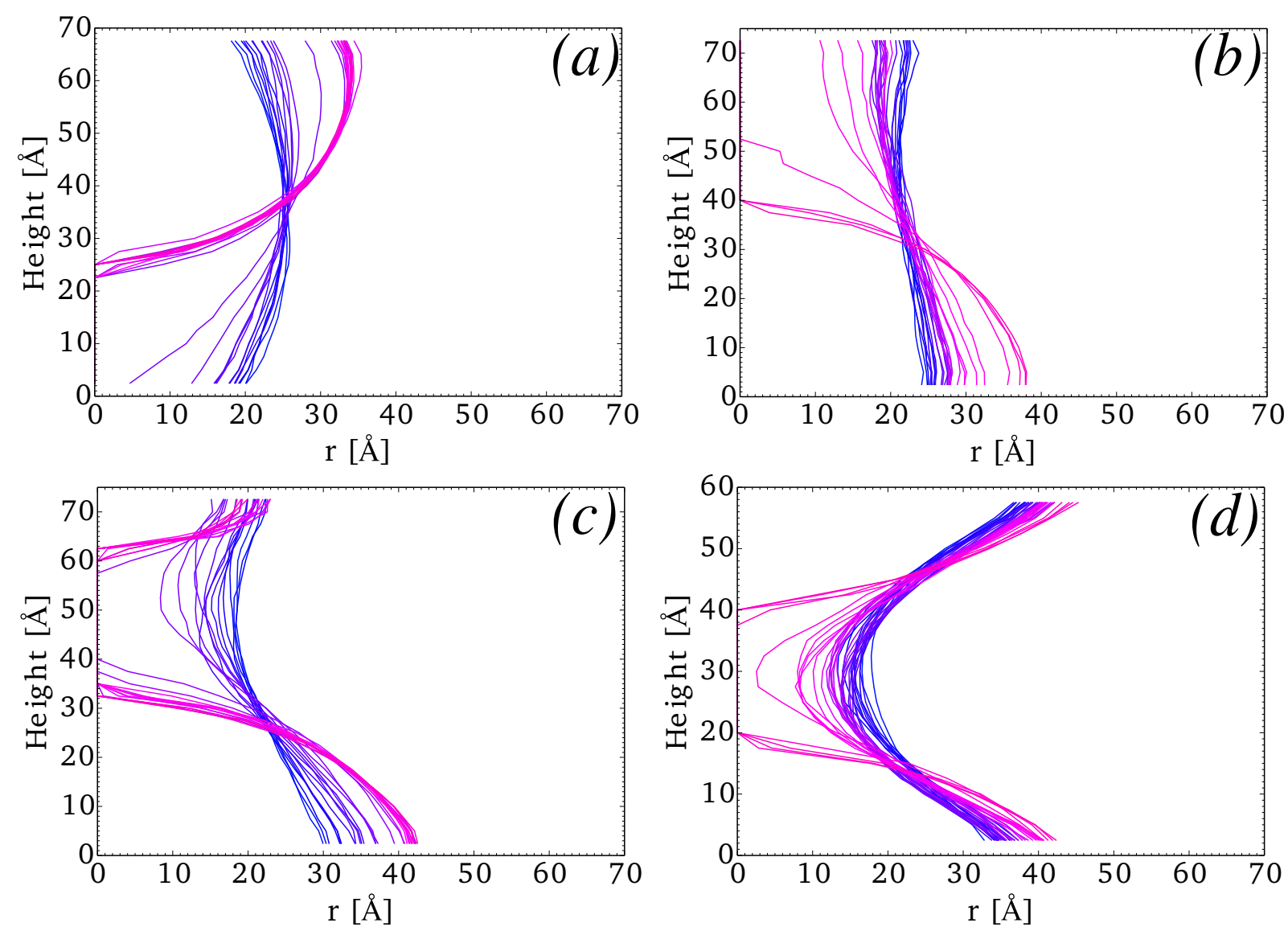

FIG. 3: Profiles of AS bridges during the rupture of AS bridge, at the critical walls separation $h_{C^{\prime}}$. Each profile is obtained over a time window of $0.1 \mathrm{~ns}$, and the gradient color shows the time evolution of AS bridge; time increases from blue to magenta profiles. (a), (b), (c) and (d) correspond, respectively, to surfaces polarity $k=0.0,0.4,0.5$ and 0.66 . 

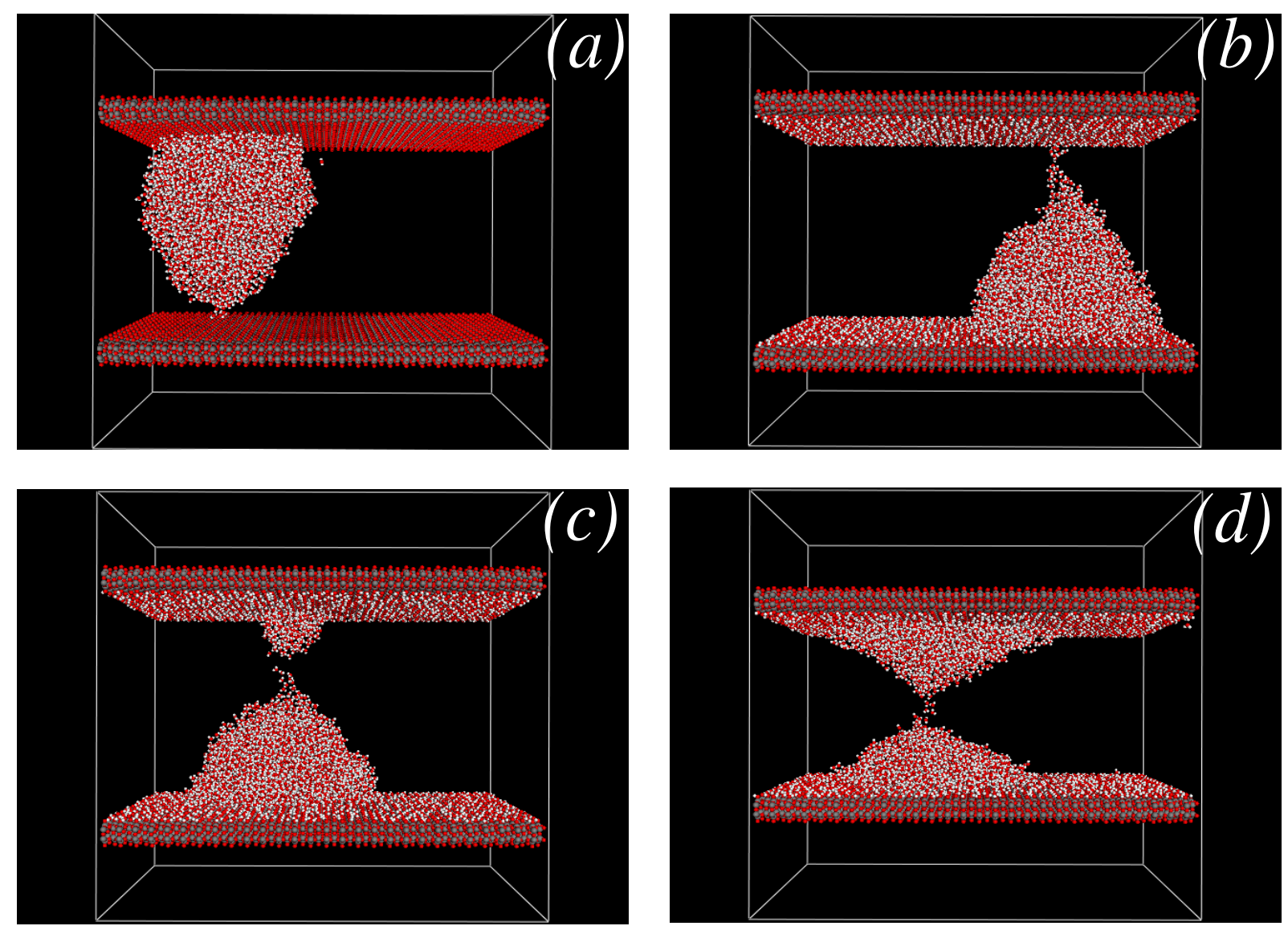

FIG. 4: Snapshots of AS bridges at the critical rupture time $\tau_{r}$. (a), (b), (c) and (d) correspond, respectively, to surfaces with polarity $k=0.0,0.4,0.5$ and 0.66 . (a) shows no hydrogen atom attached to the surface $(k=0.0)$. (d) shows the AS bridge for the case where water contact angle is $28.9^{\circ}$. In this case, the AS bridge splits into two identical as expected theoretically for contact angles lower than $31^{\circ}$. 

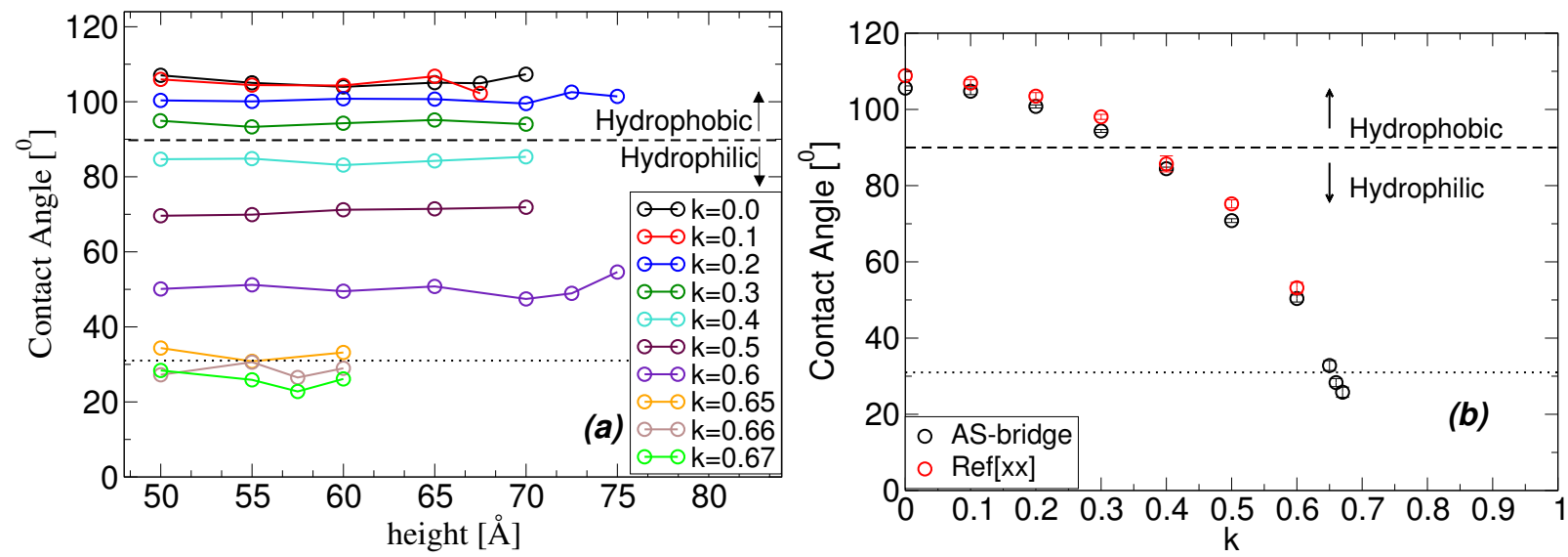

FIG. 5: (a) Water contact angle $\theta_{\mathrm{c}}(h)$ calculated from AS bridges formed between walls separated by a distance $h$ (see SI). Included are results for all surface polarities $k$ studied. (b) Contact angles averaged over $h$ as a function of the surface polarity $k$. For comparison, included are the water contact angles obtained in Ref. [9] for the same surfaces considered here. In (a) and (b), black dashed (dotted) lines indicate $\theta_{c}=90^{\circ}\left(\theta_{c}=31^{\circ}\right)$. 


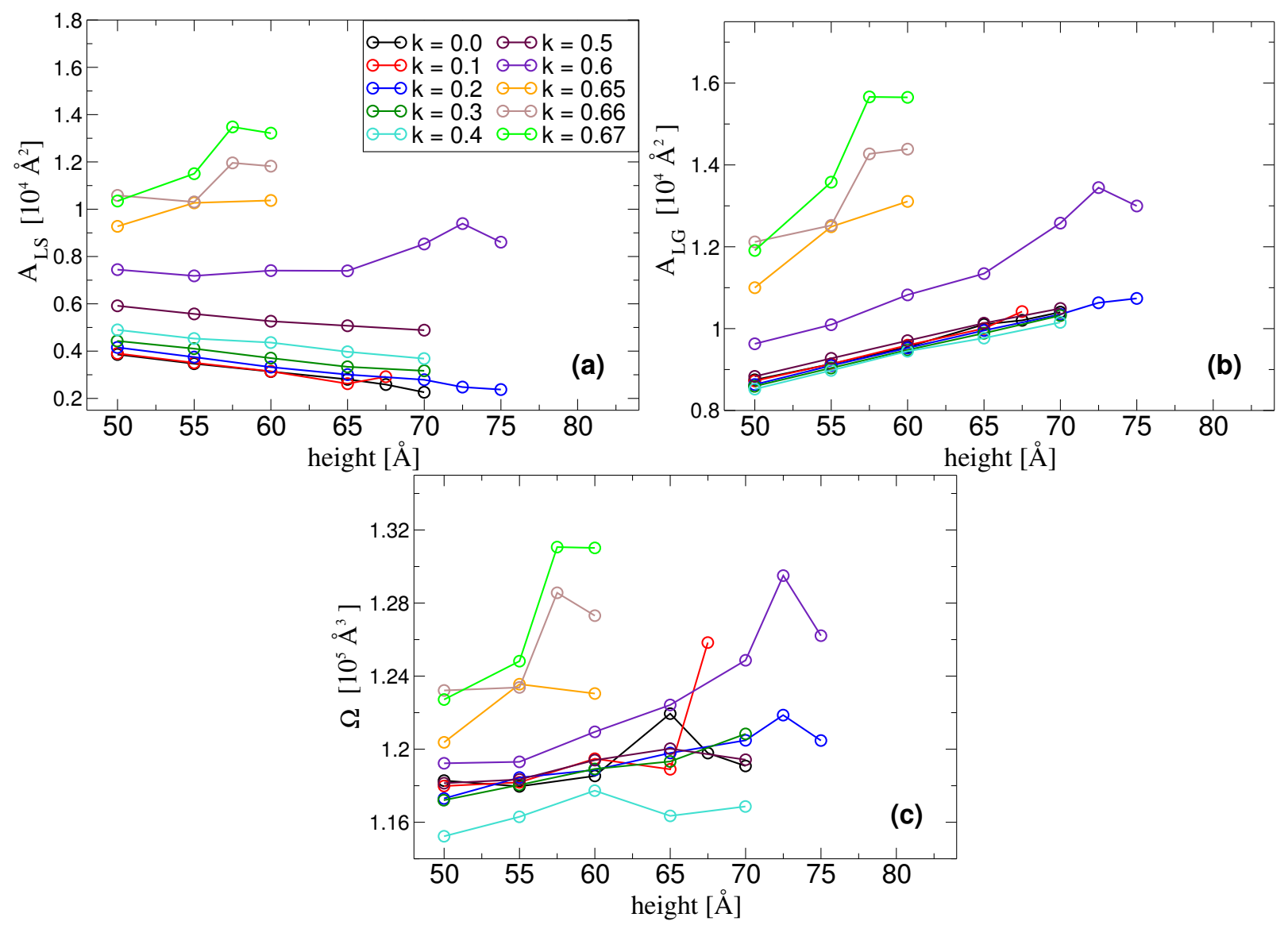

FIG. 6: (a) Liquid-solid $\left(A_{\mathrm{LS}}\right)$ and (b) liquid-gas $\left(A_{\mathrm{LG}}\right)$ interface area of AS bridges formed between walls of surface polarity $k$ as a function the walls separation $h$. (c) Volume $(\Omega)$ of AS bridges considered in (a) and (b). 

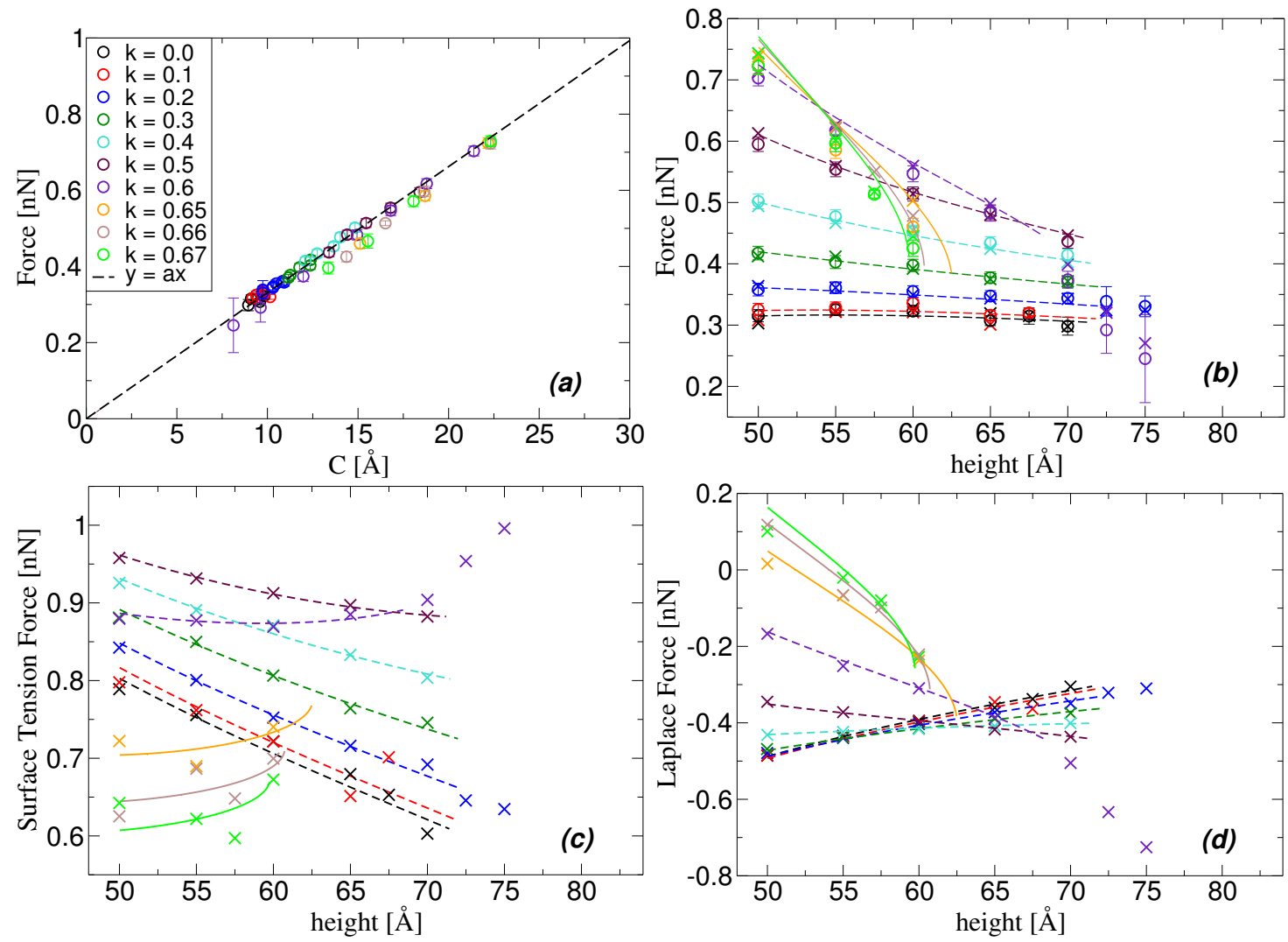

FIG. 7: Forces induced by AS bridges formed between parallel walls as function of (a) the neck parameter $C=r_{0}-H r_{0}^{2}$ (see eq 7) and (b) the walls separations $h$, for all surface polarities studied. (c) and (d) are, respectively, the contributions to the total force due to the liquid-vapor interface and Laplace pressure. The values of $C$, and the corresponding CT prediction calculated with eq $7(\times)$ are based on the fitting parameters resulting, see Figure $2(a)-(d)$ and Figure 1 of the SI, shown on Tables. I-IV. In Figure (a) the surface tension obtained from the fitting is equal to $\gamma=0.053 \pm 0.002 \mathrm{~N} / \mathrm{m}$, and it is not considered the data obtained from the simulation for $k=0.65,0.66$ and 0.67 . This value is used in the calculation of force using eq 7 in Figures $(\mathrm{b}-\mathrm{d})$. In all Figures, dots are the forces on the walls obtained from MD simulation; In Figure (a) the dashed line is the best linear regression intercepting the origin $(y=a x)$. In Figures $(\mathrm{b}-\mathrm{d})$ the dashed lines are the predictions of CT obtained from variational calculus, eq 14, based on minimization of the capilllary bridge free energy. 


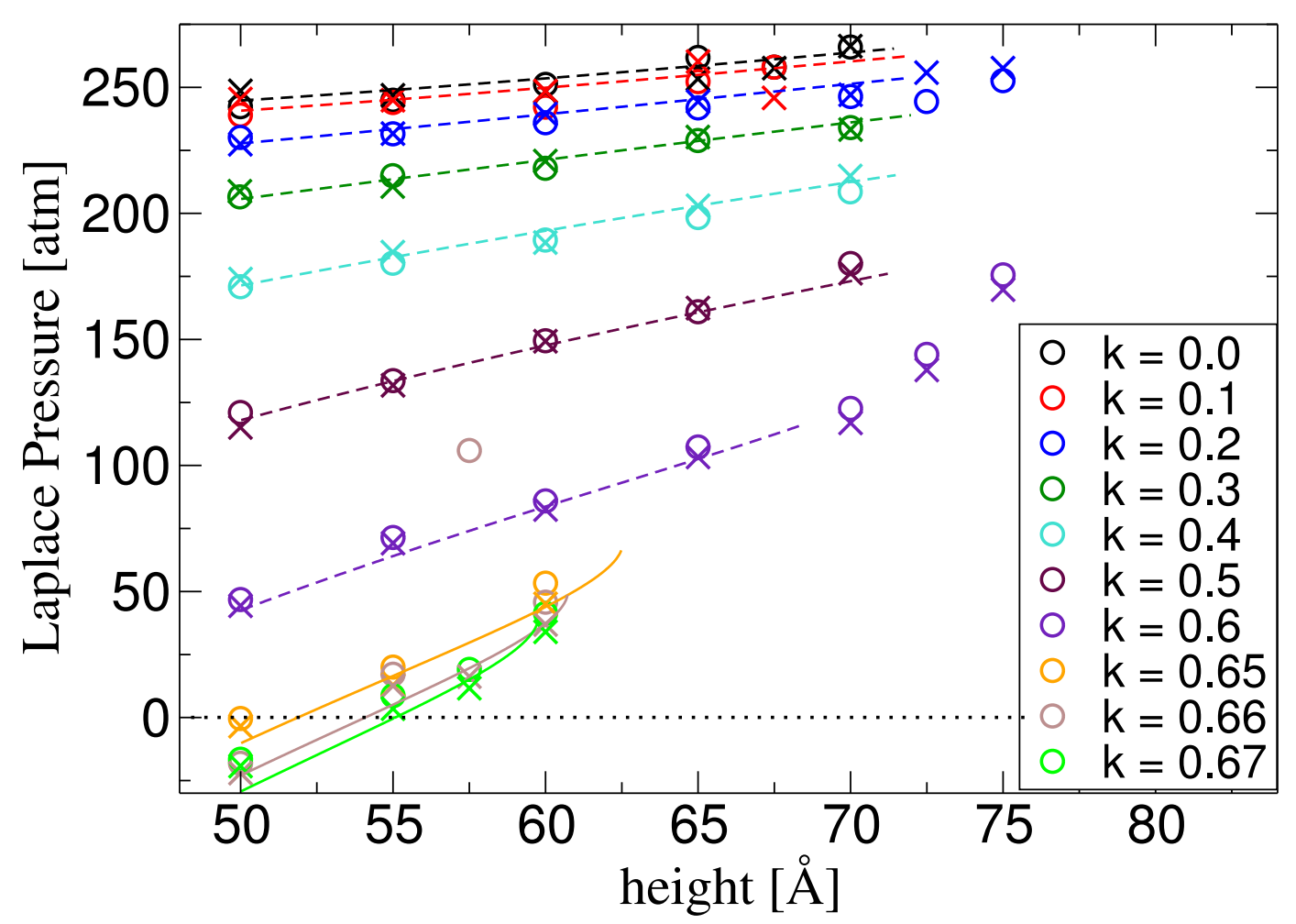

FIG. 8: Laplace pressure inside the AS bridges as function of the surface polarity $\mathrm{k}$ and walls separation h. Dots and crosses are, respectively, the Laplace pressure calculated from eq 9 and eq 1 . The dashed lines are predictions of capillary theory obtained from variational calculus based on minimization of the surface area with the volume and the contact angle constraints, as performed in Ref. [5]. 


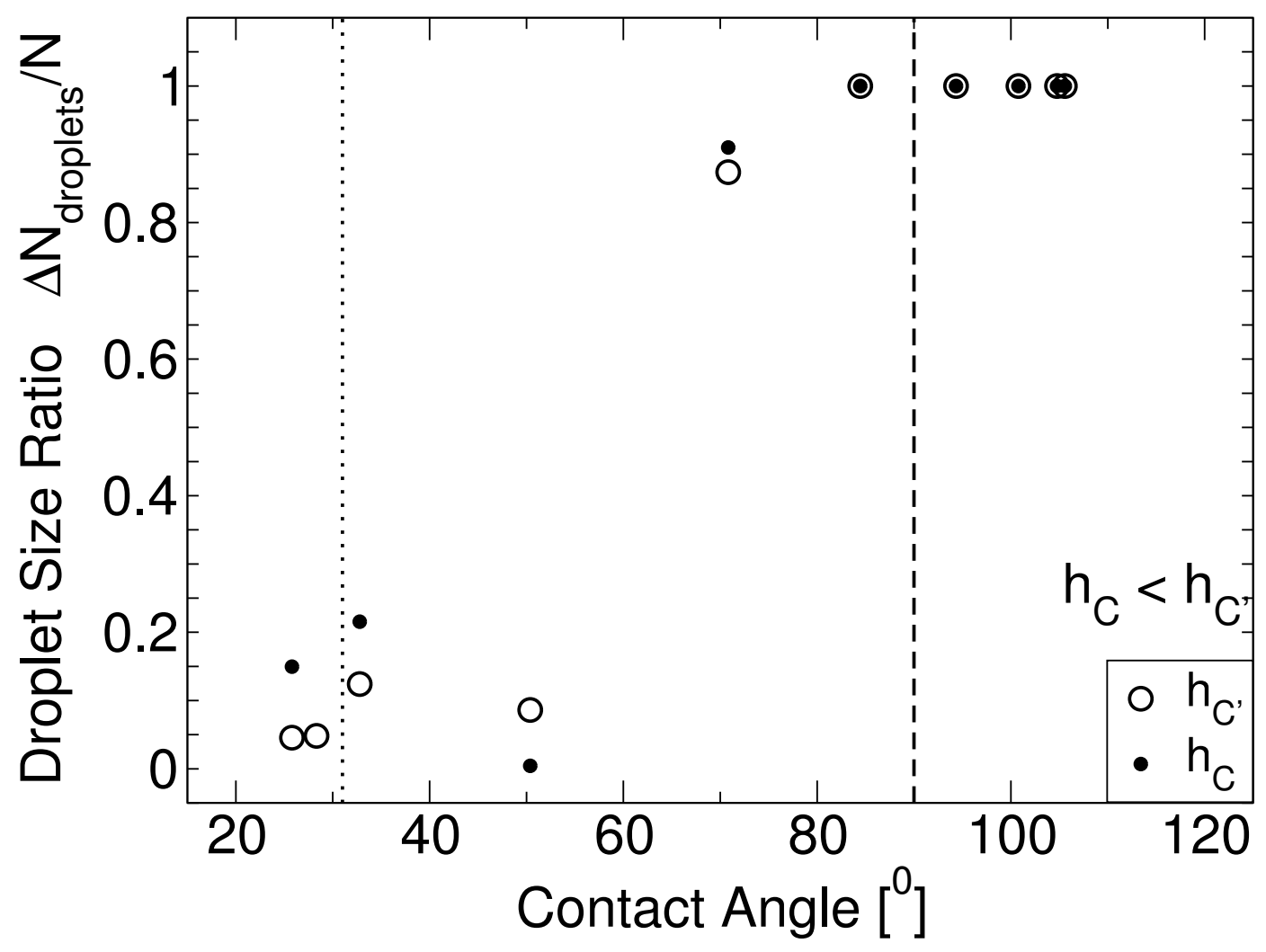

FIG. 9: The ratio of water droplets volume $\Delta N_{\text {droplets }} / N$ formed after the ruputure of AS brtidge, as a function of the contact angle $\theta_{\mathrm{c}}$. For $\Delta N_{\text {droplets }} / N=0\left(\Delta N_{\text {droplets }} / N=1\right)$ the droplets have the different (same) number of water molecules. In the case $k=0.66\left(\theta_{\mathrm{c}}=28.3^{\circ}\right)$ and $h=\left(h_{S}+2.5\right)+1.25=58.75 \AA$, the AS bridge does not break, even for more than $20 \mathrm{~ns}$ simulation. 


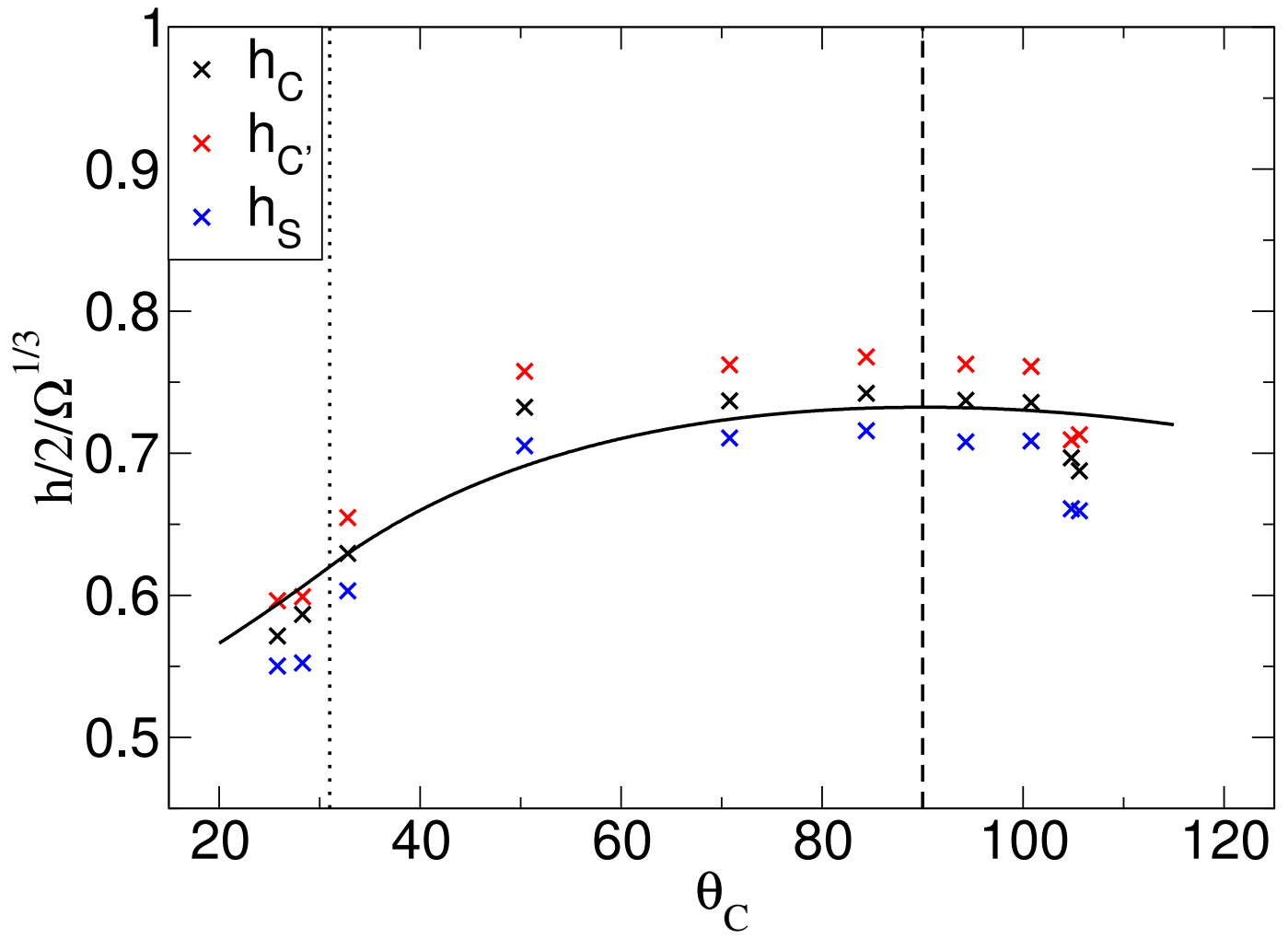

FIG. 10: Half-distance of the AS bridge stable normalized by its volume $h / 2 / \Omega^{1 / 3}$ as a function of contact angle $\theta_{C}$. The $h_{C^{\prime}}$ data shows the unstable heights in which the AS bridge breaks for the first time, when the walls are separated by $\Delta h=5.0 \AA$. The $h_{C}$ represents the second rupture, when the walls are separated by $\Delta h / 2$ or $\Delta h / 4$. In the case $k=0.66\left(\theta_{\mathrm{c}}=28.3^{\circ}\right)$ and $h=\left(h_{S}+2.5\right)+1.25=58.75 \AA$, the AS bridge does not break, even for more than 20 ns simulation. Then, we consider that $h_{\mathrm{C}}=\left(h_{S}+2.5\right)+1.25=58.75 \AA$. The solid line is the prediction of capillary theory obtained from variational calculus based on minimization of the surface area with the volume and the contact angle constraints, as performed in Ref. [5]. The doted line shows the critical contact angle $31^{\circ}$ in which the AS bridre breaks into two symmetrical droplets. The dashed line shows the contact angle $90^{\circ}$, which is the separation between hydrophilic and hydrophobic surfaces. 


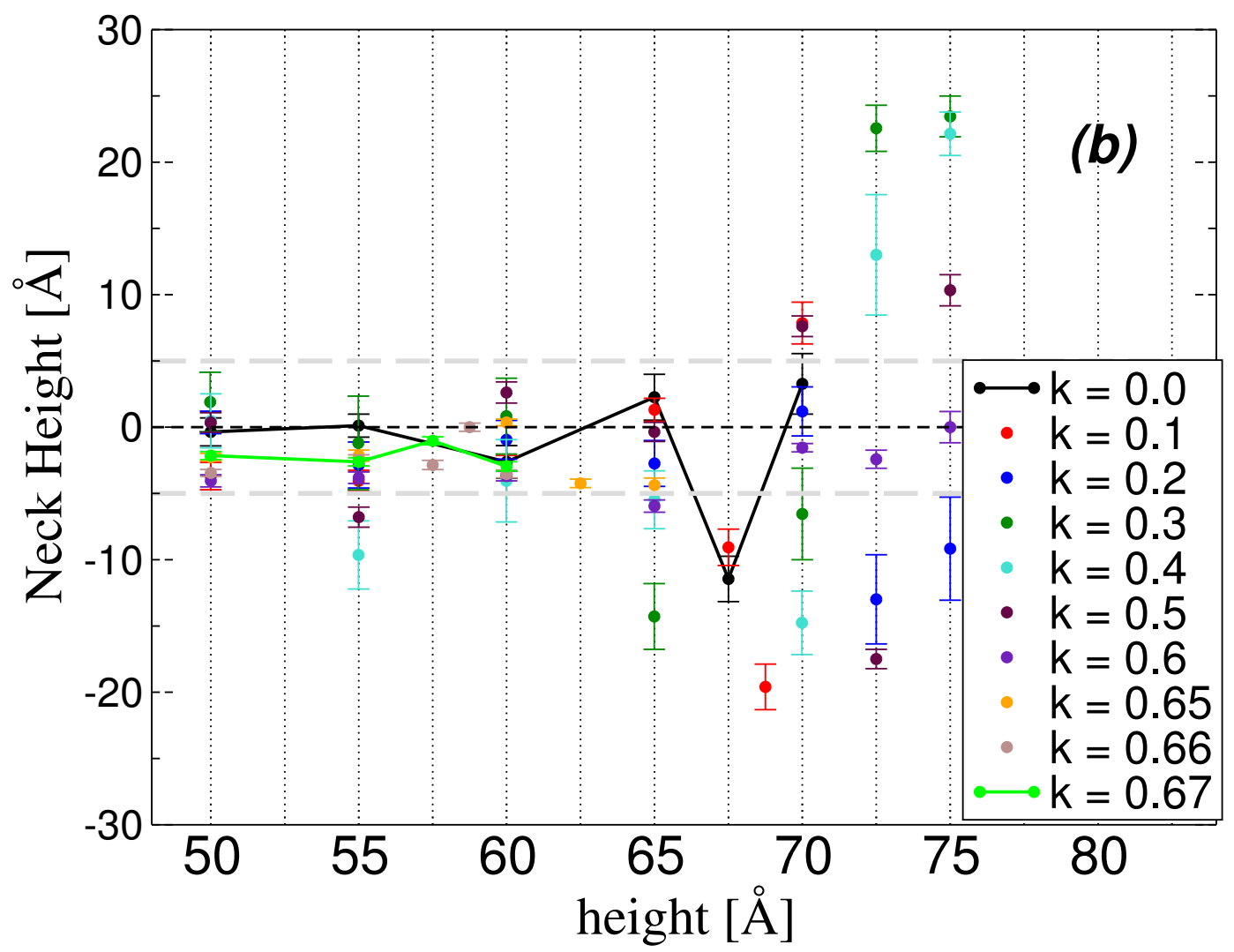

FIG. 11: Distance of neck's height to the box center $(0,0, h / 2)$ for each normalized surface dipole moment $k$, as function of height. At the critical heights $h=h_{C^{\prime}}, h_{C}$ the averages are performed until the rupture time $\tau_{\mathrm{r}}$, see Tables $\mathrm{V}$. The grey dashed lines highlights the region \pm 5 . For $k 0.6$, $z_{0}$ is distributed between \pm 5 . This fact shows the rupture into two droplets with simular volume. For $k<0.6, z_{0}$ is distributed in large regions, which indicates the rupture into one or two different size droplets. 


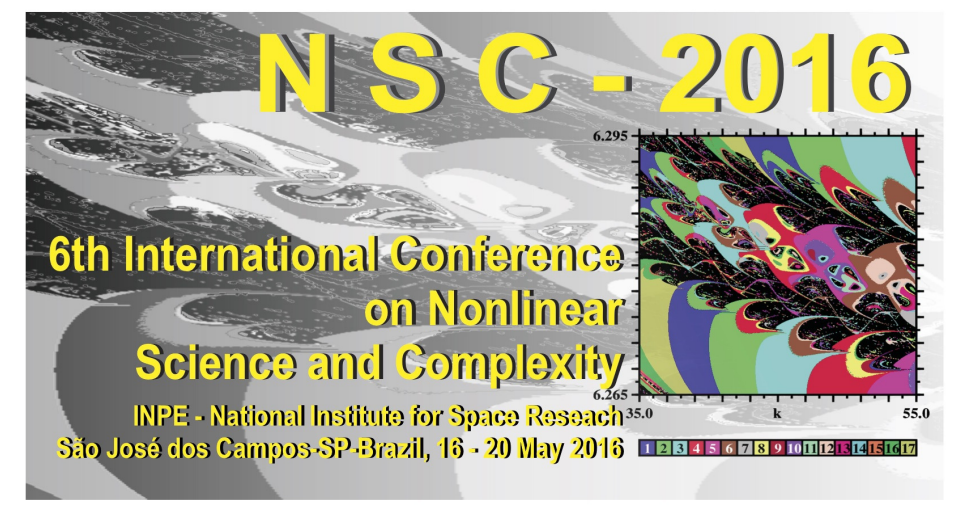

\author{
INPE - National Institute for Space Research \\ São José dos Campos - SP - Brazil - May 16-20, 2016
}

\title{
IRREGULAR DYNAMICS OF THE CENTER OF MASS OF DROPLETS
}

\author{
Alexandre B. Almeida ${ }^{1}$, Nicolas Giovambattista ${ }^{2}$, Sergey V. Buldyrev ${ }^{3}$, Adriano M. Alencar ${ }^{4}$ \\ ${ }^{1}$ Sao Paulo University, Sao Paulo, Brazil, alebaal@if.usp.br \\ ${ }^{2}$ Brooklyn College of the City University of New York, New York City, EUA, ngiovambattista@brooklyn.cuny.edu \\ ${ }^{3}$ Yeshiva University, New York City, EUA, buldyrev@yu.edu \\ ${ }^{4}$ Sao Paulo University, Sao Paulo, Brazil, aalencar@if.usp.br
}

\begin{abstract}
The understanding of droplets is important to different applications, ranging from wetting to diagnosis of airways condition in the lung. In this work, we performed molecular dynamics and Monte Carlo simulations to solve the displacement of center of mass (CM) of droplets, in order to calculate the Hurst exponent in $z$-coordinate and in the $x y$-plane. Depending on the confinement condition, the $\mathrm{CM}$ motion, can be persistent, anti-persistent, Brownian or confined.
\end{abstract}

keywords: Time Series Analysis; Modeling, Numerical Simulation and Optimization; Fluidodynamics, Plasma and Turbulence; Droplet; Liquid Bridge

\section{INTRODUCTION}

Capillary geometries, for example axis symmetric droplets (AS droplets) and axis symmetric bridges, are important to different problems and applications, like the wetting [1] and the diagnosis of airways condition in the lung [2]. Capillary geometries are supposed to not have any fluctuation, as can be found in the movement of pollen grains suspended on the water surface and in the stock market indicators. Though, it is not true at the nanoscale, since the ration between area and volume is bigger than at the macroscale. Molecular dynamics (MD) studies of AS droplet and capillary bridges [3, 4] show that the macroscopic capillary equations, obtained from the minimization of energy, can be applied to nanoscale once considered the fluctuation of the interface. In other study, these capillary geometries were solved by lattice gas model with Monte Carlo (MC) simula- tions for the understanding of a specific sound, called crackle sound, related to the obstruction of lung air ways $[5,6]$.

\section{PURPOSE}

The goal of this work is to understand the fluctuations involved in this capillary geometries. Therefore, we study two simple capillary geometries, droplet and AS droplet, by means of MD and MC. From the configurations generated by the simulations, we build the time series of dynamic of the center of mass (CM) for each geometry. The Hurst analysis is implemented to understand the movement of the $\mathrm{CM}$ at $z$-coordinate and in the $x y$-plane, and the movement is classified as persistent, anti-persistent, Brownian or confined.

\section{METHODS}

\subsection{Atomistic simulation}

The simulations of water droplet and AS droplet are performed using the LAMMPS software package [7]. The water molecules are represented by the SPC/E model. The periodic boundary conditions are applied along the $x, y$, and $z$ coordinates. All simulations are performed for a cubic system of side length $L=138.6 \AA$, at constant volume, number of water molecules $N=2725$, and temperature $T=300 \mathrm{~K}$. Coulomb and Lennard-Jones interactions are cut off at distance $r_{\text {cutoff }}=10 \AA$ and long-range electrostatic interactions are calculated using a particle-particle particle-mesh solver with an accuracy value of $10^{-5}$. For the simulation of AS droplet, we insert a hydrophobic silica wall, with null po- 

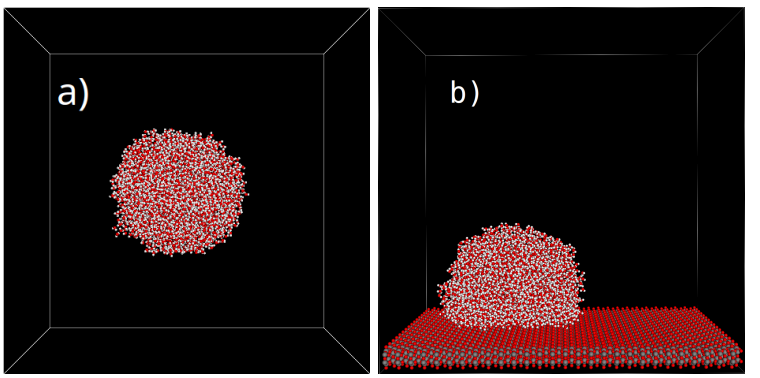

Figure 1 - Snapshots from MD computer simulations of (a) droplet and (b) AS droplet over hydrophobic wall.

larization, that reproduce a contact angle of $109.4^{\circ}$. The hydrophobic silica wall expand across the entire $x y$-plane, and its $\mathrm{O}$ and $\mathrm{Si}$ atoms are not allowed to move. We performed $10 \mathrm{~ns}$ of simulation printing the configuration after every $1000 \mathrm{fs}$. More details about the model can be find at refs. [3, 4].

\subsection{Lattice gas model simulation}
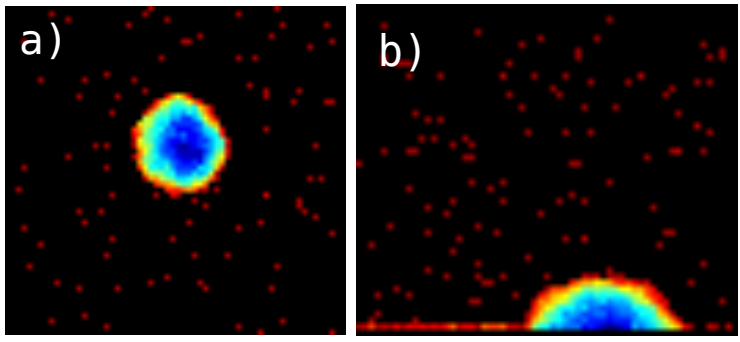

Figure 2 - Snapshots from MC computer simulations of (a) droplet and (b) AS droplet over hydrophilic wall.

Basically, it is a 3D model with lattice size $60 \times 60 \times$ $52\left(a^{3}\right)$, in which $a$ is the lenght unit of the site. Each site of the lattice can be occupied by particles of three types: liquid (l), solid (s), and gas (g). The total amount of liquid particles used to simulate the droplet and AS droplet is 2575 . We simulate the droplet and AS droplets using the MC method with the Metropolis algorithm at temperature $0.93 J / k_{\mathrm{B}}$. For each MC step, the total exchanges is equal to the number of liquid particles. There is no exchange between identical particles, and the exchange between gas and liquid particles are performed randomly according to the Kawasaki dynamics and weighted by the Boltzmann factor. The exchange between liquid and gas particles may happen between any site in the lattice. The solid particles are not exchanged, and they are used to create the wall, in which the AS droplet is attached. According to the interaction between liquid and solid particles, it is generate the contact angle of interest. After $500 \mathrm{MC}$ steps have been concluded, the last configuration is printed at the time $T(\tau)$, in which $\tau$ is the time unit of MC simulation. More details about the model can be find at refs. [5, 6].

\subsection{Center of mass calculation}

From the configurations generated from the MC and MD we calculate the projections of $\mathrm{CM} \overrightarrow{C M}=\frac{1}{N} \sum_{i}^{N} \overrightarrow{r_{i}}$, at the $z$-coordinate and at the $x y$-plane, for AS droplets and droplets, in which $\overrightarrow{r_{i}}$ is the position of the molecule/particle, and $N$ is the total number of molecule/particle. We have to have attention to the periodic boundary conditions of the simulations box. If the simulation is too long, the droplet can be splitted at the border, and it affects the CM calculation. The procedure that fix it is the following. First, we calculate the $\overrightarrow{C M^{\prime}}$ of the droplet or the AS droplet. Then, each molecule/particle is displaced of $-\overrightarrow{C M^{\prime}}$, in order to put the droplet or AS droplet near the origin of the box simulation. During this process, the following condition is applied to coordenates $x, y$ and $z$ of the molecule/particle $i$ :

$$
x_{i}=\left\{\begin{array}{ccc}
x_{i}-C M_{i}{ }^{\prime} & \text { if } & 0<\left(x_{i}-C M_{i}{ }^{\prime}\right)<L \\
x_{i}-C M_{i}{ }^{\prime}+L & \text { if } & \left(x_{i}-C M_{i}{ }^{\prime}\right)<L \\
x_{i}-C M_{i}{ }^{\prime}-L & \text { if } & \left(x_{i}-C M_{i}{ }^{\prime}\right)>L
\end{array}\right.
$$

Then, all molecules/particles are moved again to the original position, now without the periodic boundary condition, by increasing $\overrightarrow{C M^{\prime}}$ to their position. Finally, we calculate again the $\mathrm{CM}$, obtaining now the correct value $\overrightarrow{C M}$. It must be emphasised that this method is only valid if there are a small number of molecule crossing the boundary.

\subsection{Hurst exponent $(H)$ calculation}

The Hurst exponent is calculated from the time series generated from MC and MD simulations of the displacements of CM of AS droplets and droplets in z-coordinate and $x y$ plane. For a time window of size $T_{S}$, it is calculated the average of the square of the absolute distance $B\left(T_{S}\right)$ between two points in this size window $T_{S}$. From the scale relation between $\left\langle B\left(T_{S}\right)^{2}\right\rangle$ and $T_{S}$ we calculate the Hurst exponent as:

$$
\left\langle B\left(T_{S}\right)^{2}\right\rangle \propto T_{S}^{2 H}
$$

in which $H$ is the Hurst exponent [8, 9]. The value of $H$ is obtained from the linear regression of Eq. 2 in a log-log graph. If $H=1 / 2, H<1 / 2, H>1 / 2$ or $H=0$, the movement is Brownian, anti-persistent, persistent or confined, respectively.

\section{RESULTS}

In both MD and MC simulations there are 2575 water molecules and liquid particles, respectively. The amount of points generated from MC and MD simulations to create the time series are 20000 and 10000 , respectively.

First, we study the droplet with MD and MC simulation. For the MC simulation, we observe that the droplet movement are Brownian in both projections $z$-coordinate and $x y$ plane with exactly same slope 1.03. The Hurst exponent, obtained from Eq. 2, is equal to $H=0.51$. For the MD, it is observed that $\left\langle B\left(T_{S}\right)^{2}\right\rangle \approx 0$ independent of $T_{S}$, or in other 


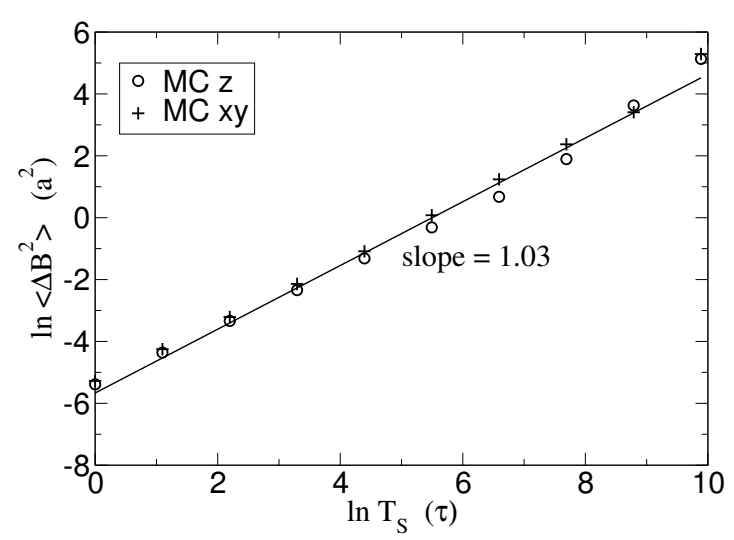

Figure 3 - The mean square of the absolute separation $\Delta B\left(T_{S}\right)$ of the droplet $\mathrm{CM}$ at the $z$-coordinate and $x y$-plane as a function of the time window $T_{S}$, for MC simulations. The line shows the linear regression, and the Hurst exponent obtained from Eq. 2 is $H=0.51$.

words, the droplet do not move in the scale of time observed. These results are seen in Fig 3.

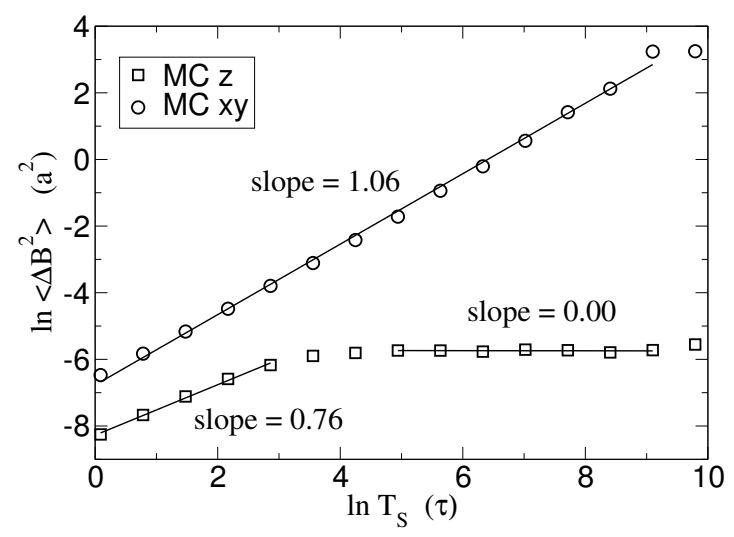

Figure 4 - The mean square of the absolute separation $B\left(T_{S}\right)$ of the AS droplet $\mathrm{CM}$ at the $z$-coordinate and $x y$-plane as a function of the time window $T_{S}$, for MC simulations. The line shows the linear regression. The movement at the $x y$-plane is Brownian, and Hurst exponent obtained from Eq. 2 is $H=0.53$. The movement at the $z$-coordinate has two regimes: anti-persistent, $H=0.38$, and confined, $H=0.00$.

Next, we studied the CM movement of AS droplet and it is observed an interesting behavior. The CM movement of AS droplet changes its regime around $T_{S} \propto e^{4} \tau$, as can be observed in Fig. 4. For the MC simulation, the CM displacement at the $z$-coordinate has two regimes, anti-persistent, $H=0.38$, and confined, $H=0.00$. At the $x y$-plane it is not seen any difference of regime and the movement is Brownian, $H=0.53$.

Then, we compare the behavior of the CM displacement of AS droplet obtained from MD simulations with the MC data discussed previously, see Fig. 4. First we compare the displacement at the $z$-coordinate. Both AS droplet from

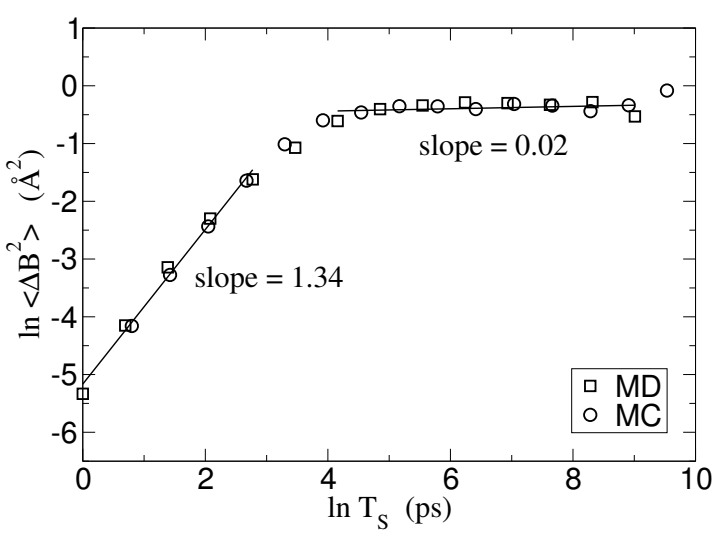

Figure 5 - The mean square of the absolute separation $B\left(T_{S}\right)$ of the AS droplet $\mathrm{CM}$ at the $z$-coordinate as a function of the time window $T_{S}$, for MD and MC simulations. The line shows the linear regression, and the Hurst exponents obtained from Eq. 2 for the persistent and confined regimes are $H=0.67$ and $H=0.01$, respectively. The MC data is obtained from the data shown on Fig. 4, applying Eq. 3.

$\mathrm{MC}$ and MD simulations have the same behavior with two regimes. This fact allow us to convert the units between $\mathrm{MC}$ and MD simulations using the equations below:

$$
\left\{\begin{array}{cc}
\Delta B^{2}\left[\AA^{2}\right]= & \Delta B^{2}\left[a^{2}\right] 1.51\left[\frac{\AA^{2}}{a^{2}}\right]+5.5\left[\AA^{2}\right] \\
T_{S}[\mathrm{ps}]= & T_{S}[\tau] 0.9\left[\frac{\mathrm{ps}}{\tau}\right]+0.8[\mathrm{ps}]
\end{array}\right.
$$

These results are shown on Fig. 5, and we can observe that the regimes are persistent, $H=0.67$, and confined, $H=$ 0.01 . Finally, we compare the displacement at the $x y$-plane applying Eq. 3. We observed an interesting behavior, as can be seen in Fig. 6. Differently from the MC, in the MD simulation the $\mathrm{CM}$ displacement at the $x y$-plane has also two regimes, persistent $H=0.85$ and anti-persistent $H=0.31$.

\section{DISCUSSION}

From Figure 3, we can conclude that the first neighbor interaction and the Kawasaki dynamics are the responsible for the CM displacement. During the Kawasaki dynamic with exchange between liquid and gas particles, the exchange can happen between any two site in the lattice, generating the Brownian behavior. However, the same behavior is not observed for MD simulations. Once the intermolecular interactions are internal forces, they will not cause a CM displacement of the system.

From Figure 4, we can observe the behavior of CM movement of AS droplet for MC simulation. Once there is no restriction at the $x y$-plane, the displacement of CM is Brownian, like the droplet. However, once the droplet is attached to the hydrophilic wall, the movement at the $z$-coordinate has two regimes. It can be anti-persistent, and for long time confined.

From Figures 5 and 6, we compare the results obtained from $\mathrm{MC}$ and MD simulations, by applying Eq. 3. In the MD 


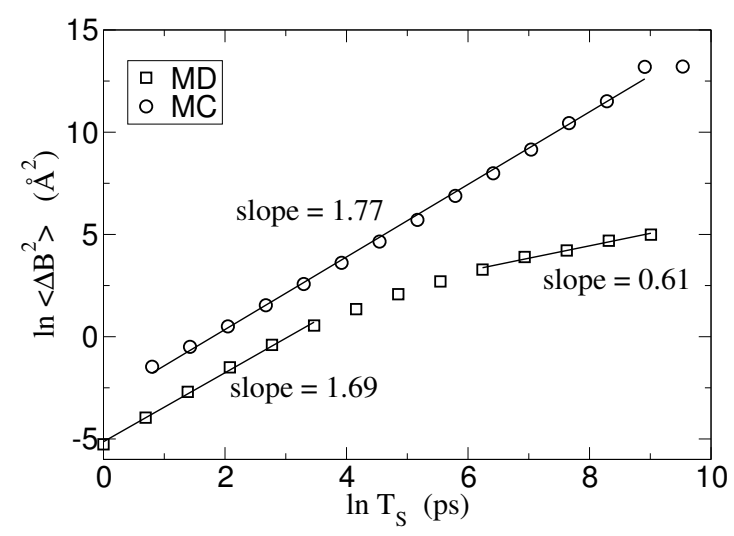

Figure 6 - The mean square of the absolute separation $B\left(T_{S}\right)$ of the AS droplet $\mathrm{CM}$ at the $x y$-plane as a function of the time window $T_{S}$, for MD and MC simulations. The line shows the linear regression. For the MD, the movement can be persistent and anti-persistent, and the and Hurst exponents obtained from Eq. 2 are $H=0.85$ and $H=0.31$, respectively. For the MC, it is not seen any difference of regime and the movement is persistent, and Hurst exponent is $H=0.89$. The MC data is obtained from the data shown on Fig. 4, applying Eq. 3.

simulation, differently from the motion of droplet, the motion of the CM is observed because the silica surface is not allowed to move. The movement at the $z$-coordinate shows the same behavior as observed in MC simulation. However, at the $x y$-plane the MD shows also two regimes: anti-persistent and persistent.

\section{CONCLUSIONS}

Fluctuations are not supposed to be found in problems concerned to capillarity at macroscale. At the nanoscale, the ratio between area and volume is bigger, and fluctuations can be observed at the interface formed. To study these fluctuations, we analysed projections of the CM movement at the $z$-coordinate and $x y$-plane of droplet and AS droplet by MC and MD simulations.

In the droplet study, the MC simulation shown that the $\mathrm{CM}$ movements are Brownian in both projections. In MD simulation, it is not observed movement in both projections. This difference between MC and MD happen due the interaction between water molecules in MD and the particles in the MC. In the first case, the intermolecular interactions are internal force, hence it do not cause any displacement in CM. In the second case, the interactions between first, second and third neighbor, plus the exchange between any particle makes the movement to be characterized as Brownian.

In the AS droplet study, the CM movements have two regimes in both projections. From this observation, we find a couple of equations able to convert units from MC to MD simulations. At $z$-coordinate, the movement can be persistent and confined for both MC and MD, depending on time window size. At $x y$-plane, the MD shown that the movement can be persistent and anti-persistent, and the MC shown that the movement is only persistent.

We concluded that different behavior of the CM can be found in this preliminary study of droplet and AS droplet. A similar study may be applied to understanding more complex problems related to formation and rupture of liquid bridges.

\section{ACKNOWLEDGMENTS}

This work was supported Fundação de Amparo a Pesquisa do Estado de São Paulo (FAPESP), Coordenação de Aperfeiçoamento de Pessoal de Nível Superior (CAPES).

\section{References}

[1] P. de Gennes, F. Brochard-Wyart, and D. Quèré, Capillarity and Wetting Phenomena: Drops, Bubbles, Pearls, Waves, Springer, 2004

[2] R. Notter, Lung Surfactants: Basic Science and Clinical Applications, Marcel Dekker, 2000

[3] N. Giovambattista, P. G. Debenedetti, and P. J. Rossky, "Effect of Surface Polarity on Water Contact Angle and Interfacial Hydration Structure," The Journal of Physical Chemistry B, Vol. 111, No. 32, pp. 95819587, June 2007.

[4] N. Giovambattista, A. B. Almeida, A. M. Alencar, and S. V. Buldyrev, "Validation of Capillarity Theory at the Nanometer-Scale by Atomistic Computer Simulations of Water Droplets and Bridges in Contact with Hydrophobic and Hydrophilic Surfaces" The Journal of Physical Chemistry C, Vol. 120, No. 3, pp. 1597-1608, December 2015.

[5] A. M. Alencar, E. Wolfe, and S. V. Buldyrev, "Monte Carlo simulation of liquid bridge rupture: Application to lung physiology," Physical Review E, Vol. 74, pp. 026311, August 2006.

[6] A. B. Almeida, S. V. Buldyrev, and A. M. Alencar, "Crackling sound generation during the formation of liquid bridges: A lattice gas model," Physica A: Statistical Mechanics and its Applications, Vol. 392, No. 16, pp. 3409-3416, August 2013.

[7] Plimpton, S., "Fast Parallel Algorithms for ShortRange Molecular Dynamics," Journal of Computational Physics, Vol. 117, No. 1, pp. 1-19, March 1995.

[8] A. M. Alencar, D. G. V. da Silva, C. B. Oliveira, A. P. Vieira, H. T. Moriya, G. Lorenzi-Filho "Dynamics of snoring sounds and its connection with obstructive sleep apnea" Physica A: Statistical Mechanics and its Applications, Vol. 392, No. 1, pp. 271-277, January 2013.

[9] P. S. Addison, Fractals and Chaos: An Illustrated Course, CRC Press, 1997 


\section{Apêndice D}

\section{Lista de Abreviaturas}

2D

Duas dimensões

3D Três dimensões

AFM do inglês Atomic Force Microscopy

Cap. Capitulo

CM Centro de massa

DFT do inglês Density Functional Theory

DM Dinâmica Molecular

Eq. Equação

Eqs. Equações

Fig. $\quad$ Figura

Figs. $\quad$ Figuras

gota SA gota com simetria axial

gota SAg gota com simetria axial grande

gota SAp gota com simetria axial pequena

gota ST gota com simetria translacional

GCMC do inglês Grand canonical Monte Carlo

IT Integração termodinâmica

KB Kirkwood-Buff

LAMMPS Large-scale Atomic/Molecular Massively Parallel Simulator 
LJ Lennard Jones

MC Monte Carlo

NDP Nanolitografia Dip-Pen

ODT Octadecanethiol

PPPM do inglês Particle-Particle Particle-Mesh

ponte SA Ponte líquida com simetria axial

ponte ST Ponte líquida com simetria translacional

Ref. Referência

Refs. Referências

Sec. Seção

Secs. Seções

TC Teoria Capilar

UR Umidade Relativa 